DENIS BERTAZZO WATASHI

\title{
ESTUDO PARAMÉTRICO DE ESCAVAÇÕES SUBTERRÂNEAS
}



DENIS BERTAZZO WATASHI

\title{
ESTUDO PARAMÉTRICO DE ESCAVAÇÕES SUBTERRÂNEAS
}

\author{
VERSÃO CORRIGIDA \\ A versão original encontra-se na Escola de Engenharia de São Carlos
}

Dissertação apresentada à Escola de Engenharia de São Carlos da Universidade de São Paulo como parte dos requisitos para a obtenção do título de mestre em Ciências, Programa de PósGraduação em Geotecnia.

Orientador: Prof. Dr. Edmundo Rogério Esquivel

Coorientador: Prof. Dr. Tarcisio Barreto Celestino

São Carlos 

AUTORIZO A REPRODUÇÃO TOTAL OU PARCIAL DESTE TRABALHO, POR QUALQUER MEIO CONVENCIONAL OU ELETRÔNICO, PARA FINS DE ESTUDO E PESQUISA, DESDE QUE CITADA A FONTE.

Ficha catalográfica elaborada pela Biblioteca Prof. Dr. Sérgio Rodrigues Fontes da EESC/USP com os dados inseridos pelo(a) autor(a).

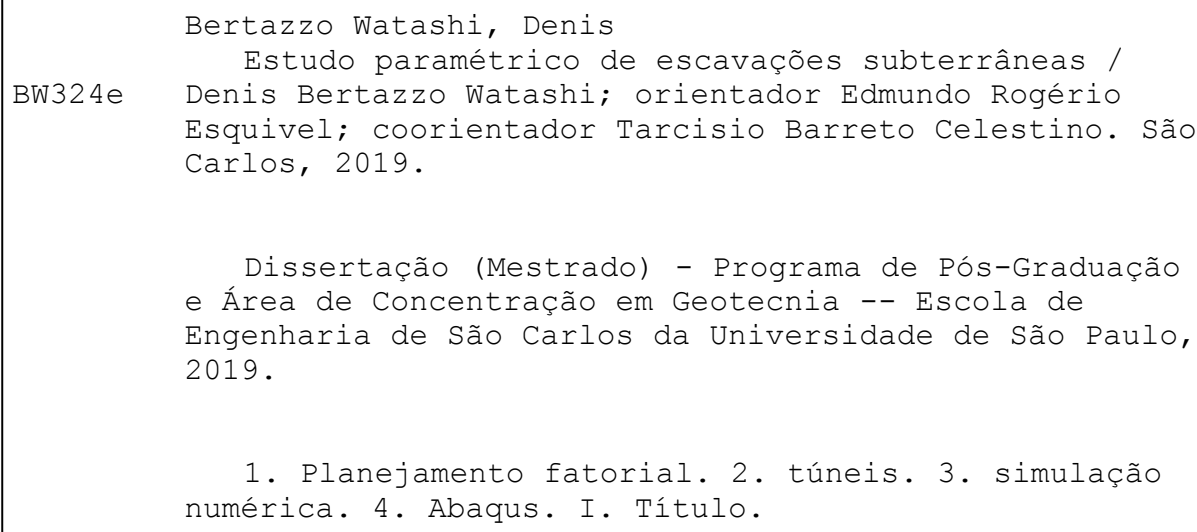

Eduardo Graziosi Silva - CRB - 8/8907 



\section{FOLHA DE JULGAMENTO}

Candidato: Engenheiro DENIS BERTAZZO WATASHI.

Título da dissertação: "Estudo paramétrico de escavações subterrâneas".

Data da defesa: 15/03/2019.

Comissão Julgadora:

Prof. Titular Waldemar Coelho Hachich

(Presidente Designado)

(Escola de Engenharia de São Carlos/EESC)

Prof. Associado Milton Assis Kanji

(Escola Politécnica-EP/USP)

Prof. Dr. Fernando Henrique Martins Portelinha (Universidade Federal de São Carlos/UFSCar)
Resultado:

APROVADO

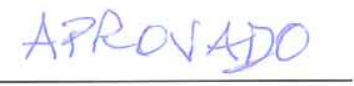

$\triangle P R O V A D C$

Coordenadora do Programa de Pós-Graduação em Geotecnia: Profa. Associada Valéria Guimarães Silvestre Rodrigues

Presidente da Comissão de Pós-Graduação:

Prof. Titular Murilo Araujo Romero 



\section{AGRADECIMENTOS}

Aos meus orientadores, pela amizade e dedicação.

Ao meu orientador Professor Edmundo Rogério Esquivel, pela paciência e conselhos e por acreditar em mim.

Ao meu coorientador Professor Tarcisio Barreto Celestino, pelo fundamental auxílio no desenvolvimento deste trabalho e pelo companheirismo que tivemos durante a monitoria de Mecânica das Rochas ministrada para a graduação.

Ao Professor Waldemar Coelho Hachich por toda a ajuda e motivação durante as fases finais deste trabalho.

Aos membros da banca, Milton Assis Kanji e Fernando Henrique Martins Portelinha pelas contribuições e correções da dissertação e também ao Professor José Antonio Schiavon pelo companheirismo e ajuda que foram fundamentais para a conclusão deste trabalho.

Ao $\mathrm{CNPq}$, pelo apoio financeiro à pesquisa. 

“(...) toda ciência seria supérflua se houvesse coincidência imediata entre a aparência e a essência das coisas (...)" 



\section{RESUMO}

WATASHI, D. B. Estudo paramétrico de escavações subterrâneas. 2019. 148 f. Dissertação (Mestrado em Geotecnia) - Escola de Engenharia de São Carlos, Universidade de São Paulo, São Carlos, 2019.

Um dos grandes problemas da Geotecnia reside na determinação dos parâmetros do solo. Esse fato se deve à natureza da formação do mesmo, que apresenta um elevado grau de incerteza nos valores de seus parâmetros. Portanto, é importante se estabelecer valores para os parâmetros do solo, que produzam valores calculados próximos àqueles medidos em campo. No caso de construção de túneis, este procedimento é fundamental porque a previsão do comportamento do avanço de uma escavação subterrânea geralmente envolve modelos tridimensionais complexos. Tendo sido adotadas algumas simplificações, o objetivo deste estudo foi encontrar modelos analíticos mais simples, que prevejam razoavelmente o comportamento da escavação de um túnel. Com um modelo simples é possível avaliar a influência dos parâmetros no comportamento da escavação. Também é possível realizar retroanálises para que o grau de incerteza desses parâmetros diminua. Neste trabalho são apresentados os principais fundamentos matemáticos pertinentes ao assunto. Também, um procedimento para aplicação de planejamento fatorial de experimentos em modelos numéricos foi desenvolvido. $\mathrm{O}$ objetivo foi fazer com que o procedimento desenvolvido pudesse ser aplicado em problemas de interesse prático da engenharia. O procedimento desenvolvido no presente trabalho foi aplicado em dois casos. No primeiro foi analisado o modelo de um túnel, assumindo um comportamento elástico linear para os materiais. No segundo caso, foi assumido um comportamento elastoplástico para os materiais. Neste segundo caso, o modelo foi calibrado com resultados de modelos centrífugos. O planejamento fatorial de experimentos foi aplicado com sucesso na obtenção da sensibilidade dos parâmetros do solo, em relação aos deslocamentos do teto da escavação. Além disso, esta técnica facilitou a obtenção de modelos simplificados, que permitem fazer a previsão dos deslocamentos do teto da escavação para qualquer combinação dos parâmetros do solo, desde que respeitados os limites de variação arbitrados inicialmente.

Palavras-chave: Planejamento fatorial, túneis, simulação numérica, Abaqus $^{\circledR}$. 



\section{ABSTRACT}

WATASHI, D. B. Parametric study of underground excavations. 2019. 148 f. Master Thesis, School of Engineering of São Carlos, University of São Paulo, São Carlos, 2019.

One of the major problems in Geotechnical Engineering is the determination of soil parameters. This fact is due to the nature of the soil formation, which shows a high degree of uncertainty in the values of its parameters. Therefore, it is important to establish values for the soil parameters, which produce calculated values close to those measured in the field. In the case of tunnel construction, this procedure is fundamental, because predicting the behavior of an underground excavation advance, usually involves complex three-dimensional models. With some simplifications being adopted, the objective of this study was to find simpler analytical models that reasonably predict the behavior of a tunnel excavation. With a simple model, it is possible to evaluate the influence of the parameters on the behavior of the excavation. It is also possible to carry out retro-analyzes, so that the degree of uncertainty of these parameters decreases. In this work, the main mathematical fundamentals concerning the subject are presented. Also, a procedure for applying factorial planning of experiments in numerical models was developed. The objective was to ensure that the developed procedure could be applied to problems of practical engineering interest. The procedure developed herein was applied in two cases. In the first one, a tunnel model was analyzed, assuming a linear elastic behavior for the materials. In the second case, an elastoplastic behavior was assumed for the materials and the model was calibrated with results of centrifugal models. The factorial planning of experiments was successfully applied to obtain the sensitivity of the soil parameters, in respect to the displacements of the tunnel section crown. In addition, this technique facilitated the obtaining of simplified models that make it possible to predict the displacements of the excavation crown for any combination of soil parameters, provided that the variation limits initially observed are respected.

Keywords: Factorial planning, tunnels, numerical simulation, Abaqus ${ }^{\circledR}$. 



\section{LISTA DE ILUSTRAÇÕES}

Figura 1 - Métodos utilizados na escavação sequencial de túneis . . . . . . . . . . . . 34

Figura 2 - Métodos utilizados na escavação sequencial de túneis . . . . . . . . . . . . 34

Figura 3 - Representação das etapas que são executadas no método cut and cover . . . 35

Figura 4 - Representação das etapas que são executadas no método cover and cut . . . 37

Figura 5 - Execução de um túnel com o método tunnel liner em Rio Claro-SP . . . . . 38

Figura 6 - Tipos de parcialização da seção (Parte A) . . . . . . . . . . . . . . . . . 39

Figura 7 - Tipos de parcialização da seção (Parte B) . . . . . . . . . . . . . . 40

Figura 8 - Exemplos de tuneladoras . . . . . . . . . . . . . . 42

Figura 9 - Esquemas de funcionamento das tuneladoras . . . . . . . . . . . . 43

Figura 10 - Tridimensionalidade da frente de escavação . . . . . . . . . . . . . . . 46

Figura 11 - Método da convergência-confinamento . . . . . . . . . . . . . . . . 47

Figura 12 - Sequência das etapas do método da redução de rigidez do núcleo . . . . . . 49

Figura 13 - Método GAP . . . . . . . . . . . . . . . . . . . . . . . 51

Figura 14 - Método da elasticidade hipotética. . . . . . . . . . . . . . . 52

Figura 15 - Método da perda de volume . . . . . . . . . . . . . . . . 53

Figura 16 - Gráfico de efeitos principais, planejamento fatorial $2^{k} \ldots \ldots$. . . . . . 62

Figura 17 - Gráficos de Interação. . . . . . . . . . . . . . . . . . . . . . 63

Figura 18 - Representação geométrica do planejamento $2^{2} \ldots$. . . . . . . . . . . . . . 64

Figura 19 - Muro de contenção analisado (adaptado de Duncan, 2000). . . . . . . . . . 65

Figura 20 - Gráficos resultantes da análise do muro de arrimo. . . . . . . . . . . . . 66

Figura 21 - Etapas da metodologia proposta . . . . . . . . . . . . . . . 72

Figura 22 - Eixo de simetria dos modelos numéricos bidimensionais realizados. . . . . . 73

Figura 23 - Geometria do modelo bidimensional considerado em meio elástico. . . . . . 74

Figura 24 - Geometria do modelo bidimensional considerado em meio elastoplástico. . . 74

Figura 25 - Malha de elementos finitos utilizada nos modelos numéricos. . . . . . . . . 75

Figura 26 - Dimensões do modelo experimental . . . . . . . . . . . . . . . . . 77

Figura 27 - Resultados experimentais x limite inferior para $\varphi^{\prime}=50^{\circ}, \sigma_{s}^{\prime}=210 \mathrm{kPa}$. . 78

Figura 28 - Resultados experimentais x limite inferior para $\varphi^{\prime}=50^{\circ}, C / D=0,5 \ldots 79$

Figura 29 - Comparação de resultados da validação . . . . . . . . . . . . . . . . . . 80

Figura $30-p$ x $D$ para relação $C / D=0,5 \ldots \ldots \ldots \ldots$. . . . . . . 81

Figura $31-p \times$ x para relação $C / D=1,0 \ldots \ldots \ldots \ldots \ldots$

Figura $32-p \times D$ para relação $C / D=1,5 \ldots \ldots \ldots \ldots \ldots$

Figura 33 - Deslocamentos na ruptura $-C / D=0,5 \ldots \ldots \ldots$

Figura 34 - Deslocamentos na ruptura $-C / D=1,0 \ldots \ldots \ldots$

Figura 35 - Deslocamentos na ruptura $-C / D=1,5 \ldots \ldots \ldots$

Figura 36 - Mecanismo de ruptura (adaptado de Atkinson e Potts, 1977). . . . . . . . . 84 
Figura 37 - Análise gráfica dos resultados para o deslocamento lateral. . . . . . . . . 86

Figura 38 - Análise gráfica dos resultados para o deslocamento lateral. . . . . . . . . . 87

Figura 39 - Diagrama de Pareto para $C / D=0,5 \ldots \ldots \ldots \ldots \ldots$

Figura 40 - Variação das respostas - A $C / D=0,5 \ldots \ldots \ldots$. . . . . . . 89

Figura 41 - Variação das respostas - B $C / D=0,5 \ldots \ldots \ldots$. . . . . . . 90

Figura 42 - Representações da resposta da relação Atrito x Coesão para $C / D=0,5$. . 90

Figura 43 - Representações da resposta da relação Atrito x Módulo para $C / D=0,5$. . 91

Figura 44 - Representações da resposta da relação Atrito x Poisson para $C / D=0,5$. . 91

Figura 45 - Deslocamentos para $C / D=0,5 \ldots \ldots \ldots$. . . . . . . . 92

Figura 46 - Diagrama de Pareto para $C / D=1,0 \ldots \ldots \ldots 2 \ldots$

Figura 47 - Variação das respostas - A $C / D=1,0 \ldots \ldots$. . . . . . . . 93

Figura 48 - Variação das respostas - B $C / D=1,0 \ldots \ldots$. . . . . . . . 93

Figura 49 - Representações da resposta da relação Atrito x Coesão para $C / D=1,0$. . 94

Figura 50 - Representações da resposta da relação Atrito x Módulo para $C / D=1,0$. . 94

Figura 51 - Representações da resposta da relação Atrito x Poisson para $C / D=1,0$. . 94

Figura 52 - Deslocamentos para $C / D=1,0 \ldots \ldots \ldots \ldots$

Figura 53 - Diagrama de Pareto para $C / D=1,5 \ldots \ldots \ldots \ldots$

Figura 54 - Variação das respostas - A $C / D=1,5 \ldots \ldots \ldots$. . . . . . . 96

Figura 55 - Variação das respostas - B $C / D=1,5 \ldots \ldots 6$

Figura 56 - Representações da resposta da relação Atrito x Coesão para $C / D=1,5$. . . 97

Figura 57 - Representações da resposta da relação Atrito x Módulo para $C / D=1,5$. . 97

Figura 58 - Representações da resposta da relação Atrito x Poisson para $C / D=1,5$. . 98

Figura 59 - Deslocamentos para $C / D=1,5 \ldots \ldots \ldots$. . . . . . . . 98

Figura 60 - Geometria do cilindro e propriedades do material. . . . . . . . . . . . 113

Figura 61 - Resultados de tensões para o modelo numérico de um tubo de paredes espessas.114

Figura 62 - Contornos do campo de tensão para o cilindro de paredes espessas . . . . . 115

Figura 63 - Geometria do meio infinito considerado. . . . . . . . . . . . . . . . 115

Figura 64 - Malha de elementos CPS8R. . . . . . . . . . . . . . . . . . 116

Figura 65 - Resultados de tensão - meio infinito . . . . . . . . . . . . . . . . 117

Figura 66 - Resultados de tensão para o meio infinito . . . . . . . . . . . . . . . 117

Figura 67 - Solução analítica de Kirsch (adaptado de Assis, 2013). . . . . . . . . . . . . 118

Figura 68 - Box-plot resultante da análise das dimensões do modelo. . . . . . . . . . . . 119

Figura 69 - Solução de Kirsch 2D x resultados numéricos - deslocamentos . . . . . . . 120

Figura 70 - Solução de Kirsch 2D x resultados numéricos - tensões . . . . . . . . . . . 120

Figura 71 - Tensões - Kirsch 2D . . . . . . . . . . . . . . . . . . 121

Figura 72 - Deslocamentos - Kirsch 2D . . . . . . . . . . . . . . . . 121

Figura 73 - Modelo proposto por Salençon (1969) ～. . . . . . . . . . . . . . . . . . . 122

Figura 74 - Solução de Salençon 2D x resultados numéricos - tensões . . . . . . . . . . 124

Figura 75 - Solução de Salençon 2D x resultados numéricos - deslocamentos . . . . . . 124 
Figura 76 - Tensões - Salençon 2D . . . . . . . . . . . . . . . . 125

Figura 77 - Deslocamentos - Salençon 2D . . . . . . . . . . . . . . . 125

Figura 78 - Geometria do problema proposto . . . . . . . . . . . . . . . 126

Figura 79 - Geometria da placa aplicada no modelo numérico. . . . . . . . . . . . . . 126

Figura 80 - Etapas para criar a geometria. . . . . . . . . . . . . . . . . . . 127

Figura 81 - Configuração das propriedades dos materiais. . . . . . . . . . . . . . . 128

Figura 82 - Configuração do Instance. . . . . . . . . . . . . . . . . . . . . . . . 129

Figura 83 - Opções de controle da malha. . . . . . . . . . . . . . . . . . . . . . . . . . 129

Figura 84 - Elementos retangulares. . . . . . . . . . . . . . . . . . . 130

Figura 85 - Elementos triangulares. . . . . . . . . . . . . . . . . . 130

Figura 86 - Escolha e configuração dos elementos. . . . . . . . . . . . . . . . . 131

Figura 87 - Configuração global dos Seeds . . . . . . . . . . . . . . . . . . . . 132

Figura 88 - Configuração local dos Seeds . . . . . . . . . . . . . . . . . . 132

Figura 89 - Representação da direção do gradiente da malha. . . . . . . . . . . . . . . . 133

Figura 90 - Malha gerada para o modelo em questão. . . . . . . . . . . . . . . . . . . 133

Figura 91 - Etapas para definir as condições de contorno. . . . . . . . . . . . . . . . . . 134

Figura 92 - Condições de contorno e carregamento aplicados no modelo. . . . . . . . . 135

Figura 93 - Geometria do problema. . . . . . . . . . . . . . . . 136

Figura 94 - Profundidade do modelo (extrusion) . . . . . . . . . . . . . . . . . 137

Figura 95 - Etapas de partição do modelo - referências. . . . . . . . . . . . . . . . . 138

Figura 96 - Etapas de partição do modelo - ferramentas. . . . . . . . . . . . . . . 138

Figura 97 - Criando as tensões geoestáticas. . . . . . . . . . . . . . . . . . . . . 140

Figura 98 - Configurando as tensões geoestáticas. . . . . . . . . . . . . . . . . . . . . 140

Figura 99 - Configurando o Step. . . . . . . . . . . . . . . . . . . . . . . . . 142

Figura 100-Criando a interação do modelo - Model Change . . . . . . . . . . . . . . 143

Figura 101 -Selecionando a região da escavação. . . . . . . . . . . . . . . . . . . . . 144

Figura $102-$ Tensões geostáticas. . . . . . . . . . . . . . . . . . . . . . . . 144

Figura 103 -Deslocamentos na etapa geostática. . . . . . . . . . . . . . . . . 145

Figura 104-Deslocamentos após a escavação. . . . . . . . . . . . . . . . . 145 



\section{LISTA DE TABELAS}

Tabela 1 - Experimento fatorial de dois fatores caso geral . . . . . . . . . . 58

Tabela 2 - Matriz de planejamento para o experimento fatorial de $2^{4} \ldots \ldots$. . . . . 60

Tabela 3 - Níveis baixo e alto dos fatores considerados . . . . . . . . . . . 66

Tabela 4 - Matriz de planejamento para o Fator de segurança . . . . . . . . . . . 66

Tabela 5 - Tabela de análise da variância (ANOVA) . . . . . . . . . . . . . 68

Tabela 6 - Parâmetros de referência para o meio elástico . . . . . . . . . . . . 73

Tabela 7 - Parâmetros de referência para o solo . . . . . . . . . . . 73

Tabela 8 - Deslocamentos para as diversas combinações de parâmetros elásticos . . . . 85

Tabela 9 - Tabela de análise da variância (ANOVA) para os dados de deslocamento lateral 86

Tabela 10 - Tabela de análise da variância (ANOVA) para os dados de deslocamento do teto 87

Tabela 11 - Deslocamentos para as diversas combinações de parâmetros . . . . . . . . 88

Tabela 12 - Resultados do modelo numérico para um tubo de paredes espessas . . . . . 115

Tabela 13 - Parâmetros de referência para o solo. . . . . . . . . . . . . . . . . . 136 



\section{LISTA DE ABREVIATURAS E SIGLAS}

$\begin{array}{ll}\text { AFTES } & \text { Association Française des Tunnels et de l'Espace Souterrain } \\ \text { ANOVA } & \text { Analysis of variance } \\ \text { CRM } & \text { Curva de Reação do Maciço } \\ \text { EPB } & \text { Earth Pressure Balanced } \\ \text { FS } & \text { Fator de Segurança } \\ \text { MCC } & \text { Método da Convergência-Confinamento } \\ \text { MEF } & \text { Método de elementos Finitos } \\ \text { MEH } & \text { Método da Elasticidade Hipotética } \\ \text { MPF } & \text { Método da Pressão Fictícia } \\ \text { NATM } & \text { New Austrian Tunnelling Method } \\ \text { SPB } & \text { Slurry Pressure Balanced } \\ \text { USP } & \text { Universidade de São Paulo }\end{array}$





\section{LISTA DE SÍMBOLOS}

\begin{tabular}{|c|c|}
\hline$a, r$ & raio da escavação \\
\hline$a, b$ & Dimensões da seção transversal \\
\hline$b$ & Dimensões da base de uma fundação rasa \\
\hline$c$ & Coesão \\
\hline$c^{\prime}$ & Coesão efetiva \\
\hline$c_{c}$ & Coesão codificada \\
\hline$C O V$ & Coeficiente de variação \\
\hline$D$ & matriz constitutiva \\
\hline$D, d$ & Diâmetro \\
\hline$D$ & profundidade de uma fundação rasa \\
\hline$E$ & Módulo de elasticidade ou módulo de young \\
\hline$E_{a}$ & Empuxo ativo \\
\hline$E_{c}$ & Módulo de elasticidade codificado \\
\hline$e$ & Espessura da saia da tuneladora \\
\hline$E_{\text {curtoprazo }}$ & Módulo de rigidez de curto prazo \\
\hline$E_{\text {longoprazo }}$ & Módulo de rigidez de longo prazo \\
\hline$E_{m}$ & Módulo de elasticidade modificado \\
\hline$E_{n}$ & Módulo de elasticidade natural \\
\hline$f$ & Superfície de plastificação, coeficiente de atrito interno \\
\hline$F$ & Função de plastificação \\
\hline$F S$ & Fator de segurança \\
\hline$F S_{D}$ & Fator de segurança ao deslizamento \\
\hline$G$ & Módulo de cisalhamento transversal \\
\hline$G A P$ & Parâmetro que representa o vazio imposto \\
\hline
\end{tabular}




\begin{tabular}{|c|c|}
\hline$G_{p}$ & Espaçamento da tuneladora com o maciço \\
\hline$I$ & Momento de inércia \\
\hline$K$ & Módulo de rigidez volumétrica \\
\hline$K_{0}$ & Coeficiente de empuxo \\
\hline$K_{a}$ & Coeficiente de empuxo ativo \\
\hline$L$ & Comprimento \\
\hline$M$ & Momento em função da posição $x$ \\
\hline$N_{c}$ & Fator de carga devido a coesão efetiva \\
\hline$N_{q}$ & Fator de carga devido ao carregamento distribuído \\
\hline$N_{y}$ & Fator de carga devido ao peso específico \\
\hline$P$ & Carga concentrada \\
\hline$P_{i}$ & Pressão interna \\
\hline$P_{m}$ & Propriedades do material \\
\hline$p_{v}$ & Pressão vertical \\
\hline$p_{x}$ & Pressão horizontal \\
\hline$Q$ & Potencial plástico \\
\hline$q$ & Carregamento distribuído \\
\hline$r$ & Distância da zona elástica ao centro de gravidade, coeficiente de regressão \\
\hline$U$ & Deslocamento devido às deformações e qualidade da construção \\
\hline$U_{3 D}^{*}$ & Deformações elastoplásticas tridimensionais \\
\hline$u_{0}$ & Deslocamento radial \\
\hline$u_{r}^{\infty}$ & $\begin{array}{l}\text { Deslocamento radial a uma distância em que a frente de escavação não tem } \\
\text { mais efeito }\end{array}$ \\
\hline$u_{x}$ & Deslocamento radial a uma distância x da frente de escavação \\
\hline$u_{\theta}$ & Deslocamento circunferencial perpendicular à radial \\
\hline$V$ & Variância \\
\hline
\end{tabular}




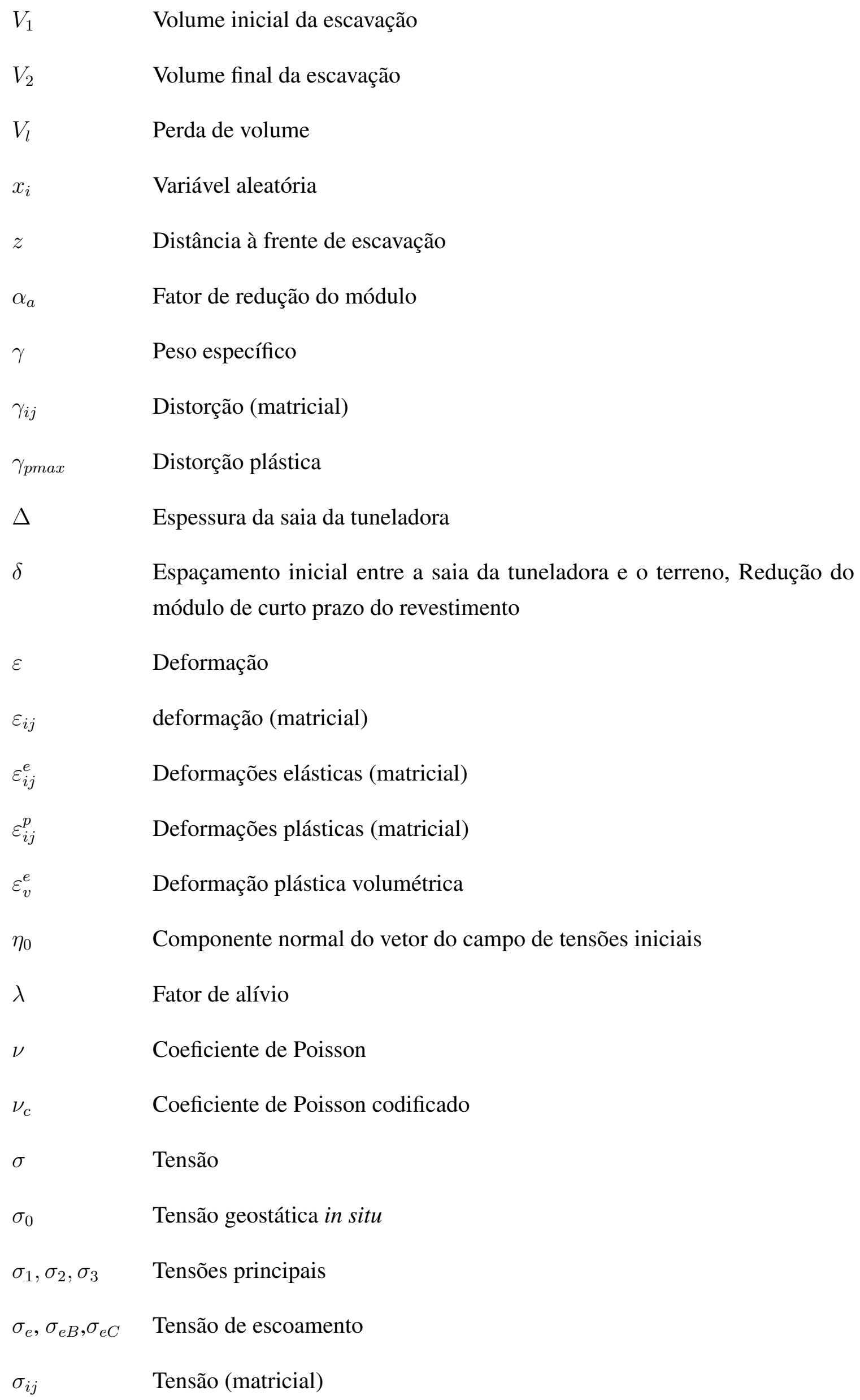




\begin{tabular}{|c|c|}
\hline$\sigma_{n}$ & Tensão efetiva normal à superfície de ruptura \\
\hline$\sigma_{f}$ & Pressão fictícia interna \\
\hline$\sigma_{r}$ & Tensão radial \\
\hline$\sigma_{r e}$ & Tensão reduzida \\
\hline$\sigma_{t}$ & Pressão interna ao túnel \\
\hline$\sigma_{s}$ & Pressão na superfície \\
\hline$\sigma_{\theta}$ & Tensão circunferencial atuante na direção perpendicular à radial \\
\hline$\tau$ & Tensão cisalhante \\
\hline$\tau_{0}$ & Componente de cisalhamento do vetor do campo de tensões iniciais \\
\hline$\tau_{\theta r}$ & Tensão cisalhante atuante sobre a superfície infinitesimal \\
\hline$\varphi$ & Ângulo de atrito interno \\
\hline$\varphi_{c}$ & Ângulo de atrito interno codificado \\
\hline$\psi$ & Ângulo de dilatância \\
\hline$\omega$ & Sobreescavação do terreno ao redor da tuneladora \\
\hline $2 D$ & (subscrito) Parâmetros utilizados em modelos bidimensionais \\
\hline $3 D$ & (subscrito) Parâmetros utilizados em modelos tridimensionais \\
\hline$p$ & (subscrito) Plastificação \\
\hline$r$ & (subscrito) Revestimento \\
\hline$s$ & (subscrito) Solo \\
\hline
\end{tabular}




\section{SUMÁRIO}

CONSIDERAÇÕES INICIAIS . . . . . . . . . . . . . . . . . . . 29

1.1

Introdução

Vala Recoberta - Método Invertido . . . . . . . . . . . . . . . . 36

2.2.1 Análises Numéricas Tridimensionais . . . . . . . . . . . . . . . 45

2.2.2 Análises Numéricas Bidimensionais . . . . . . . . . . . . . . . 45

2.2.2.1 Método da Convergência-Confinamento . . . . . . . . . . . . 46

2.2.2.2 Método da Redução de Rigidez do Núcleo . . . . . . . . . . . . . . . . 48

2.2.2.3 Método do Vazio Imposto ou GAP . . . . . . . . . . . . . . . . . . . 50

2.2.2.4 Método da Elasticidade Hipotética . . . . . . . . . . . . . . . 51

2.2.2.5 Método da Perda de Volume . . . . . . . . . . . . . . . . . . 52

$2.3 \quad$ Limitações dos Modelos Bidimensionais . . . . . . . . . . . . 54

$2.4 \quad$ Planejamento Fatorial de Experimentos . . . . . . . . . . . . 55

2.4.1 Princípios básicos de planejamento e análise de experimentos . . . . 56

2.4.2 Conceitos gerais utilizados em planejamentos fatoriais . . . . . . . . 56

2.4.3 Processo para realizar modelagem numérica aplicando-se os conceitos de planejamento fatorial de experimentos . . . . . . . . . . . . 57

2.4.4 Planejamento Fatorial de Experimentos . . . . . . . . . . . . . . 58

$2.4 .5 \quad$ Planejamento fatorial $2^{k} \ldots \ldots \ldots \ldots \ldots$

2.4.6 Exemplo de aplicação Do Planejamento $2^{2} \ldots \ldots$. . . . . . . 63

2.4.7 Análise de variância dos efeitos de experimentos fatoriais $2^{k} \ldots 67$

2.4.8 Gráfico de probabilidade normal . . . . . . . . . . . . . 68

2.4.9 Conclusões Sobre o Planejamento Fatorial . . . . . . . . . . . . . . 69 
METODOLOGIA . . . . . . . . . . . . . . 71

$3.1 \quad$ Modelos Numéricos . . . . . . . . . . . . . . . . . . 72

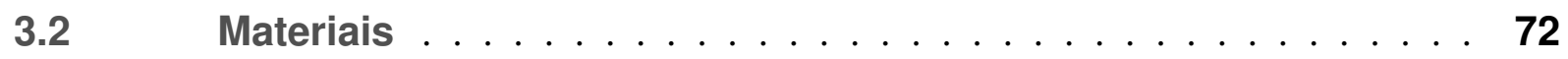

$3.3 \quad$ Geometria . . . . . . . . . . . . . . . . . 73

3.4 Condições de Contorno . . . . . . . . . . . . . . . . 74

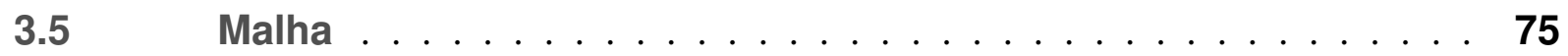

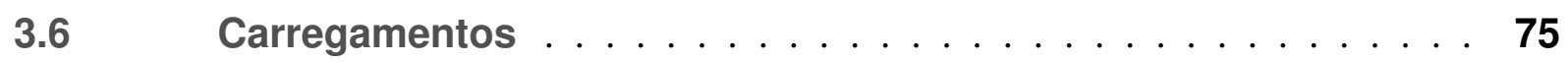

$3.7 \quad$ Estudo de Caso . . . . . . . . . . . . . . . . . . . . 75

3.7.1 Resultados . . . . . . . . . . . . . . . . . . . . . 79

$4 \quad$ RESULTADOS $\ldots \ldots \ldots \ldots \ldots \ldots \ldots$

$4.1 \quad$ Modelo elástico linear . . . . . . . . . . . . . . . . . . . 85

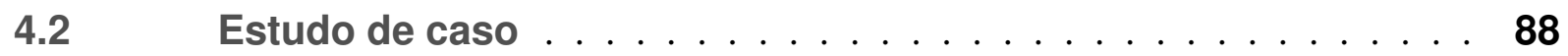

4.2.1 Relação $C / D=0,5 \ldots \ldots \ldots \ldots$. . . . . . . . . . . . 89

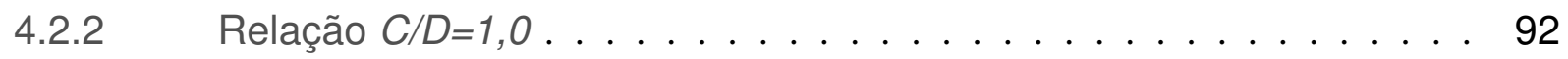

4.2.3 Relação $C / D=1,5 \ldots \ldots \ldots \ldots$

4.2.4 Combinação dos resultados . . . . . . . . . . . . . . 99

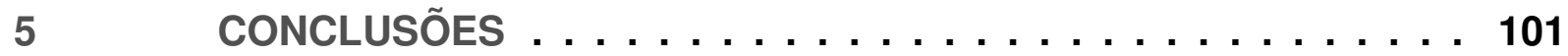

$5.1 \quad$ Sugestões para trabalhos futuros . . . . . . . . . . . 102

REFERÊNCIAS . . . . . . . . . . . . . . 105

APÊNDICES

APÊNDICE A - TRABALHANDO COM O ABAQUS ${ }^{\circledR} \ldots \ldots \ldots$

A.1 Calibração dos modelos . . . . . . . . . . . . . 113

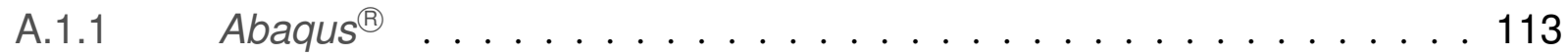

A.1.2 Cilindro de Paredes Espessas . . . . . . . . . . . . . . . . . 113

A.1.3 Meio Infinito com uma Abertura Sujeito a Tensão Uniforme . . . . . 115

A.1.4 Solução Clássica de Kirsch . . . . . . . . . . . . . . . . . . . 117

A.1.5 Solução de Salençon . . . . . . . . . . . . . . . . . . . . . . 121

A.2 Roteiros . . . . . . . . . . . . . . . . . . . 125

A.2.1 Modelo Bidimensional . . . . . . . . . . . . . . . . . . . 125

A.2.2 Modelo Tridimensional . . . . . . . . . . . . . . . . . . . . . . . . 135

A.3 Problemas de convergência . . . . . . . . . . . . . . . . . 145

A.4 Recomendações para a escolha dos elementos . . . . . . . . 147 


\section{CONSIDERAÇÕES INICIAIS}

\subsection{INTRODUÇÃO}

O avanço da escavação de um túnel induz alterações em zonas localizadas próximas à sua frente, produzindo estados de tensão e de deformação com aspectos tipicamente tridimensionais, portanto, uma modelagem mais realista desse avanço exige uma abordagem tridimensional.

Apesar dos mais recentes progressos na computação, tanto na área de software quanto de hardware, os modelos tridimensionais elaborados com o Método dos Elementos Finitos (MEF) ainda demandam altos custos computacionais. Além disso, apresentam alta complexidade, tanto na preparação dos dados como na análise dos resultados. Esses fatos acabam limitando o interesse prático. Por esta razão, os projetistas de túneis ainda empregam em larga escala as modelagens bidimensionais.

A análise da escavação de um túnel, a partir de um modelo bidimensional, requer uma abordagem especial, de modo a simular o mecanismo tridimensional que ocorre na frente de escavação de um túnel.

A modelagem bidimensional conhecida como Método da Convergência-Confinamento (MCC) permite analisar a interação entre o maciço rochoso e o suporte de um túnel. Esse método considera o avanço da frente de escavação e as características reológicas do maciço, permitindo avaliar o comportamento tridimensional através de uma análise bidimensional (PANET et al., 1992). Segundo a Association Française des Tunnels et de l'Espace Souterrain - AFTES (2002) diversos autores têm proposto métodos de análise que adotam o conceito do $\mathrm{MCC}$, tendo sido provavelmente Fenner (1938) o primeiro a relatar este método. Pacher (1964) também utilizou essa mesma abordagem.

A principal falha dessas propostas é desconsiderar as deformações que ocorrem no maciço antes do suporte ser instalado. Assim Lombardi (1973) introduziu o conceito de convergência da frente de escavação. Panet e Guellec (1974) propuseram considerar os efeitos das deformações do maciço utilizando o conceito de alívio das pressões internas à escavação. Essa é a origem do Método da Convergência-Confinamento que recebeu este nome em 1978, em uma reunião da AFTES realizada em Paris.

Outra circunstância que precisa de grande atenção do projetista ao realizar uma análise numérica é a grande variabilidade nas propriedades dos solos naturais, que é uma característica inerente ao processo de formação dos solos. Tal fato pode ser observado na grande dispersão dos parâmetros dos solos determinados em laboratório. Assim, são notadas diferenças de comportamento entre aquele previsto em projeto e aquele observado em obra mesmo utilizando-se modelos matemáticos robustos e sofisticados métodos computacionais. Sendo assim, é de ex- 
trema importância determinar qual parâmetro é o mais significativo para o fenômeno em questão. O conhecimento deste fato possibilita concentrar os esforços das investigações nos parâmetros mais importantes com o objetivo de diminiuir as incertezas associadas a determinação destes parâmetros e assim diminuir essas diferenças de comportamento.

Tais obstáculos podem ser superados a partir de ensaios de laboratório e in situ ou de forma mais abrangente, empregando-se instrumentações durante e após a construção dos túneis. A instrumentação permite avaliar de forma sistemática o desempenho e segurança da obra, bem como a adequação aos resultados previstos pelos modelos empregados fornecendo indicadores do real comportamento da escavação. Entretanto, essas informações por si só não proporcionam conhecimento algum referente aos fatores de incerteza.

A retroanálise é uma ferramenta que permite determinar os parâmetros envolvidos que proporcionam o melhor resultado do processo observado. A grande dificuldade desta técnica está em se obter as equações matemáticas que regem o problema em questão.

O presente trabalho aplica, em modelos numéricos, a técnica conhecida como planejamento fatorial de experimentos, a ser detalhada no item 2.4, pois ela além de permitir avaliar a sensibilidade dos parâmetros também fornece um modelo matemático simplificado que pode ser utilizado em estudos de retroanálise.

Após a calibração dos modelos foram realizados dois estudos de caso, o primeiro considerou um modelo numérico elástico-linear e os resultados foram comparados com a solução de Kirsch e o outro caso tomou como base os modelos reduzidos ensaiados em centrífuga realizados por (POTTS; ZDRAVKOVIC, 2001).

\subsection{JUSTIFICATIVA}

O crescimento populacional implica em um aumento na demanda de infraestrutura em todos os seus âmbitos. Em grandes centros urbanos e nas principais regiões metropolitanas é difícil alinhar essas questões, incorporando novas obras, devido ao espaço físico limitado. Desta forma, a alternativa que oferece melhores condições, em termos financeiros e ambientais, é o emprego de obras subterrâneas.

O projeto e construção de obras subterrâneas requer a contribuição de profissionais multidisciplinares. Principalmente em regiões urbanas, prever o comportamento da escavação durante sua execução é de grande importância, pois movimentações do maciço podem causar eventos indesejáveis. Neste contexto, o engenheiro geotécnico é o especialista responsável pela viabilidade técnica da escavação.

Tal atividade, durante muitos anos, foi norteada basicamente pela vivência e experiência destes profissionais, que se baseavam em métodos empíricos, retroanálises e em outras obras realizadas. Com o passar do tempo e do avanço tecnológico, os métodos empíricos vêm sendo sistematicamente substituídos por análises numéricas que fornecem resultados mais realistas. 
O projetista tem a responsabilidade de garantir a integridade e a segurança da escavação. Para isso ele deve considerar a resistência das estruturas de suporte e as deformações do maciço que podem causar problemas nas estruturas vizinhas ao túnel. Assim, é preciso determinar a intensidade e distribuições das solicitações no suporte, como também os movimentos de curto e longo prazo no maciço escavado. Todas essas questões devem ser analisadas considerando particularidades, tais como, geometria da escavação, condições geológicas e geotécnicas, estado de tensões iniciais, método construtivo, leis constitutivas, etc. Garantir que todas essas características sejam avaliadas em conjunto exige o emprego de métodos numéricos.

A abordagem racional para interpretação e comparação entre resultados de modelos numéricos, elaborados com o MEF, contribui para um melhor entendimento do comportamento dos modelos bidimensionais, implicando em uma maior confiabilidade aos projetos. Por isso, apresentar um modelo matemático mais simples bem como a parcela de contribuição dos parâmetros geomecânicos do maciço na resposta do modelo numérico a partir do planejamento fatorial de experimentos é o que motiva a realização deste trabalho.

\subsection{OBJETIVOS}

\subsubsection{OBJETIVO GERAL}

A pesquisa desenvolvida teve como objetivo principal proporcionar modelos matemáticos simplificados para análise do comportamento das escavações, mais precisamento do deslocamento do teto da escavação, aplicando a técnica de planejamento fatorial de experimentos. As análises numéricas bidimensionais foram realizadas pelo método dos elementos finitos, utilizando-se o software Abaqus $6.14^{\circledR}$. O estudo paramétrico visou avaliar a influência dos parâmetros geomecânicos na resposta dos modelos numéricos frente ao processo de escavação. Tradicionalmente as análises paramétricas são empregadas variando-se um fator de cada vez tal técnica é pouco eficiente, pois não permite avaliar efeitos de interação entre os parâmetros podendo levar à conclusões equivocadas, por isso foi escolhida a técnica de planejamento fatorial de experimentos para conduzir esta pesquisa, pois ao utilizar experimentos estatisticamente planejados o objetivo é ter uma campanha investigativa eficiente e proporcionar uma clareza científica nas conclusões ao tratar estatisticamente o conjunto de dados. O software utilizado para aplicação desta técnica foi o Statistica $13.0^{\circledR}$.

\subsubsection{OBJETIVOS ESPECÍFICOS}

Os objetivos específicos deste trabalho foram:

a) Revisão bibliográfica de métodos de escavações de túneis;

b) revisão bibliográfica dos principais modelos bidimensionais empregados pelos projetistas de túneis que permitem avaliar o deslocamento do teto da escavação; 
c) discussão da viabilidade do emprego do planejamento fatorial de experimentos como alternativa para análise paramétrica de sensibilidade;

d) determinação de modelos matemáticos simplificados para previsão do deslocamento do teto de escavações subterrâneas; 


\section{REVISÃO BIBLIOGRÁFICA}

\subsection{MÉTODOS DE ESCAVAÇÕES DE TÚNEIS}

Esta seção tem o objetivo de apresentar uma breve descrição dos principais métodos empregados na escavação de túneis.

\subsubsection{MÉTODOS SEQUENCIAIS CLÁSSICOS}

Diversos registros da história comprovam a existência de túneis milenares. O mais antigo tem aproximadamente 4000 anos, tendo sido construído sob o leito do rio Eufrates na região da Mesopotâmia. Os primeiros túneis construídos pelo homem empregavam ferramentas rudimentares e técnicas manuais implicando em baixo desempenho. Com o passar dos anos as técnicas foram evoluindo a partir do conhecimento acumulado. Em 1679, pela primeira vez empregou-se o uso de pólvora na construção de um túnel com aproximadamente $157 \mathrm{~m}$ de extensão, localizado no sul da França. Já em 1867, mesmo ano em que Alfred Nobel obteve a patente da dinamite, registrou-se o primeiro desmonte da frente de escavação utilizando-se nitroglicerina durante a construção do túnel de Hoosac em Massachussets (EUA) (ASSIS, 2013).

A Revolução Industrial pode ser considerada como um marco que influenciou a evolução dos métodos de escavação. Este período tem como característica um aumento na demanda por ferrovias para transporte de cargas e pessoas, estando intimamente associado à engenharia de túneis (ASSIS, 2013).

Assim, a partir do século XIX, para suprir tal demanda e aumentar a produtividade na construção de túneis, foram desenvolvidos diferentes métodos de escavação, que empregam o conceito de parcialização da seção. Entre esses métodos, destacam-se:
a) Método Alemão;
b) método Belga;
c) método Austríaco;
d) método Inglês.

A sequência de parcialização de cada método está mostrada nas Figuras 1a, 1b, 2a e 2b respectivamente. 


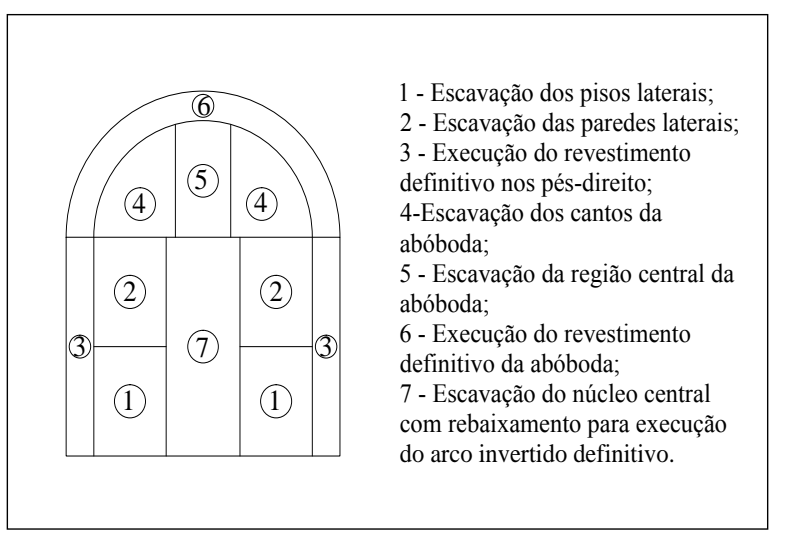

(a) Método Alemão

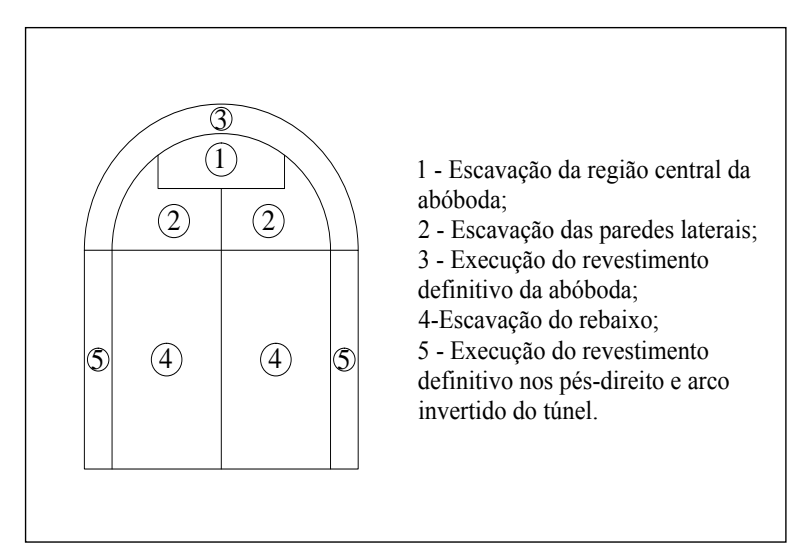

(b) Método Belga

Figura 1 - Métodos utilizados na escavação sequencial de túneis (adaptado de Moraes Júnior, 1999).

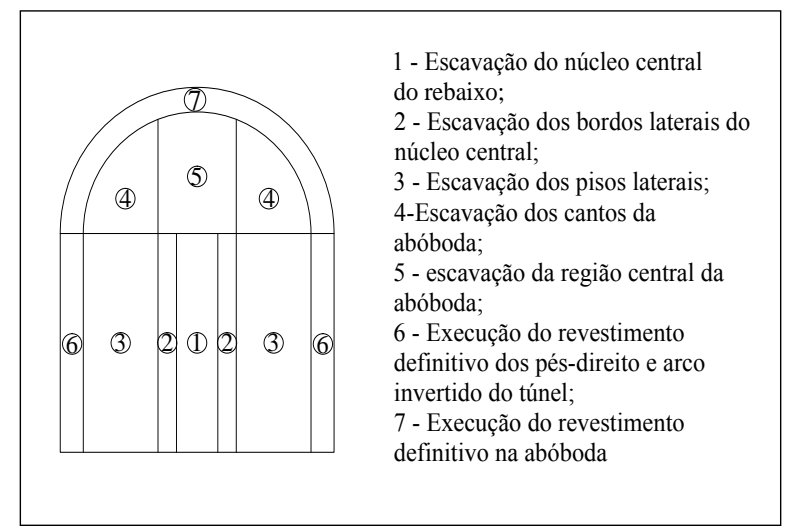

(a) Método Austríaco

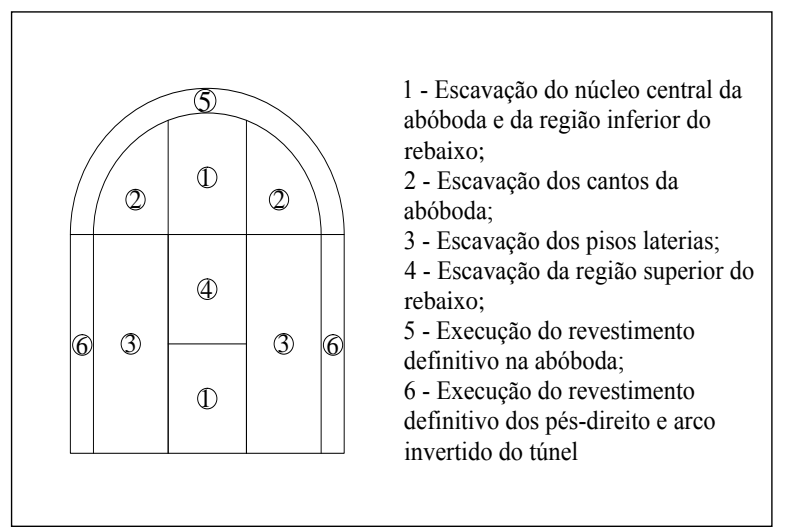

(b) Método Inglês

Figura 2 - Métodos utilizados na escavação sequencial de túneis (adaptado de Moraes Júnior, 1999).

A parcialização da escavação é necessária, pois escavar túneis de grandes dimensões em seção plena é impraticável, tanto construtivamente quanto por razões de segurança. A escolha do método de parcialização a ser empregado depende de diversos fatores, tais como:
a) Viabilidade técnica;
b) geometria do túnel;
c) parâmetros do maciço;
d) condicionantes ambientais;
e) prazos da obra;
f) recursos disponíveis;
g) e nível de segurança desejado. 
Os maiores inconvenientes dos métodos clássicos são o atraso entre a execução do suporte e a escavação e as imperfeições construtivas existentes entre o suporte e o maciço escavado. Ambos podendo implicar em grandes deformações do maciço (TEIXEIRA, 1994).

É importante ressaltar que em todos os métodos apresentados acima, dependendo das condições geológicas do maciço que será escavado pode ser que seja necessário especificar algum tipo de suporte temporário entre as escavações.

\subsubsection{VALA RECOBERTA - MÉTODO DIRETO}

O método de escavação à céu aberto, também conhecido como cut and cover, já foi um dos métodos mais empregados na execução de obras subterrâneas. Este método consiste em executar uma vala de seção retangular, escavando-se toda a região do alinhamento do túnel, executar a estrutura do túnel dentro desta vala e a seguir reaterrar a escavação até o nível desejado (REDAELLI; CERELLO, 1998).

A sequência construtiva deste método, é constituída de quatro etapas básicas representadas na Figura 3:

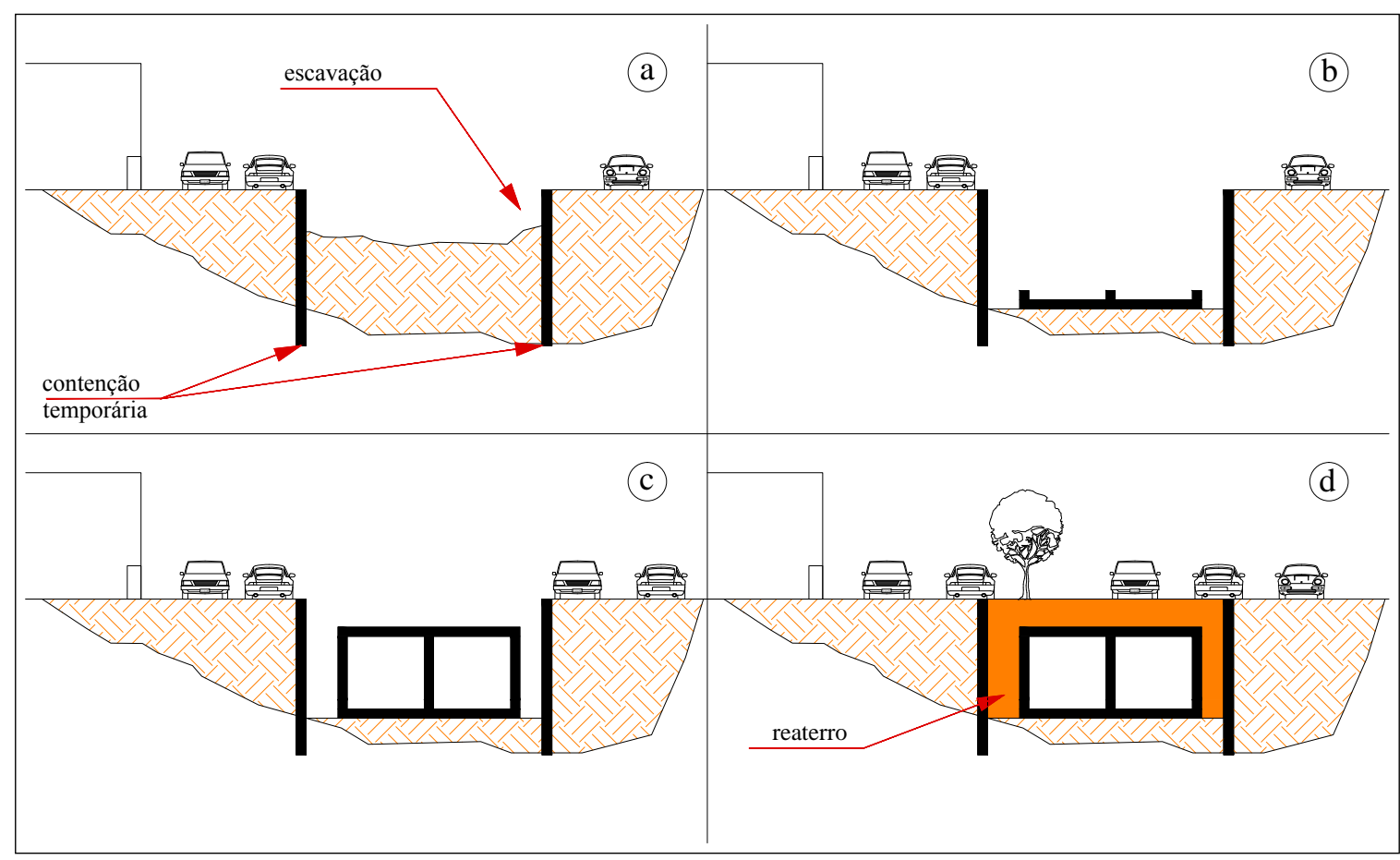

Figura 3 - Representação das etapas que são executadas no método cut and cover (adaptado de Hung et al., 2009).

a) Etapa a: execução das paredes de contenção laterais, que dependem das condições geológicas, nível do lençol freático e da profundidade da escavação.

b) Etapa b: construção da laje de fundo do túnel.

c) Etapa c: construção do restante da estrutura do túnel. 
d) Etapa d: reaterro da vala e recuperação das condições iniciais da superfície.

É fácil notar que este tipo de construção em regiões urbanas densamente ocupadas, apresenta muitos inconvenientes, tais como:

a) Interferências, tais como redes de água, de esgoto, de drenagem, elétricas e lógicas, entre outras. $\mathrm{Na}$ fase de projeto ter um cadastro das interferências atualizado é fundamental para o planejamento da obra e controle do orçamento, caso contrário é possível que ocorram custos adicionais não previstos para custear a realocação;

b) Problemas sociais, os quais podem ocorrer, devido a impactos sonoros, desapropriações, alteração de hábitos devido aos desvios de tráfego e pela implantação do canteiro de obras. Estes são exemplos de situações que refletem na dinâmica social da região onde a escavação está em execução (ASSIS, 2013);

c) Limitação do traçado, que deve necessariamente estar em propriedades do poder público, ou seja, em ruas, avenidas, praças, imóveis desapropriados, etc. (GREIFENEDER, 2003).

Apesar desses inconvenientes, tal método oferece algumas vantagens como o fato de empregar técnicas relativamente fáceis e bem difundidas na construção civil. Além disso, existe a possibilidade de se executar a impermeabilização e os sistemas de drenagem do túnel externamente (ASSIS, 2013).

\subsubsection{VALA RECOBERTA - MÉTODO INVERTIDO}

Este é um método semelhante ao cut and cover e é conhecido como cover and cut. Ele surge como alternativa ao método direto na tentativa de minimizar a grande interferência no sistema viário que esse método produz. O cover and cut consiste em executar estruturas de contenção e em seguida uma laje de cobertura para que a escavação possa ser feita com a proteção desta. Este método foi utilizado na estação Fradique Coutinho da linha 4 do metrô de São Paulo (MEDEIROS, 2006).

A sequência construtiva deste método compreende quatro etapas descritas a seguir e mostradas na Figura 4:

a) Etapa a: execução e instalação das paredes de contenção, diferentemente do método anterior, essas paredes de contenção irão fazer parte integrante da estrutura do túnel.

b) Etapa b: escavação até a cota da cobertura do túnel e posterior construção da cobertura que deverá ser solidarizada com as estruturas de contenção executadas na etapa anterior. Ainda nesta fase é possível executar uma eventual impermeabilização das estruturas do túnel.

c) Etapa c: reaterro da vala e recomposição dos elementos da superfície.

d) Etapa d: execução complementar da escavação do túnel. 


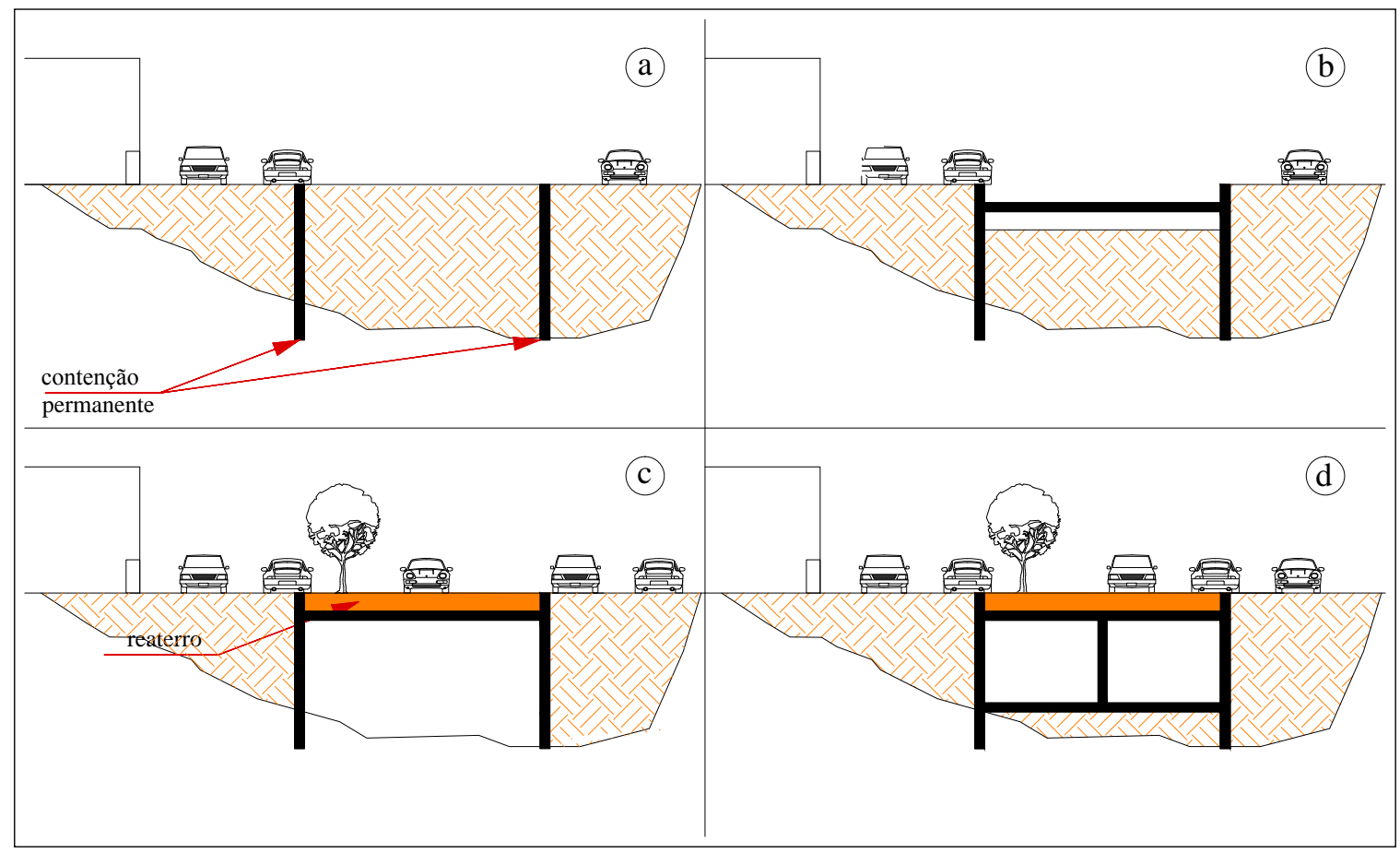

Figura 4 - Representação das etapas que são executadas no método cover and cut (adaptado de Hung et al., 2009).

Comparado ao método anteriormente descrito, o cover and cut apresenta vantagens como a possibilidade de liberar a superfície em um tempo menor e necessitar de menores espaços para a execução da escavação, pois como já dito, as próprias estruturas do túnel também servem como contenções da vala de escavação.

Além das mesmas desvantagens do método cut and cover, o método indireto também pode apresentar outros inconvenientes, tais como: acesso reduzido aos equipamentos e maior probabilidade de deficiência do sistema de impermeabilização, devido ao fato desta ser executada do lado interno do túnel e devido a eventuais falhas na região de ligação da laje de cobertura com as paredes do túnel.

\subsubsection{MÉTODO DE ESCAVAÇÃO - TUNNEL LINER}

O tunnel liner é considerado como um método não destrutivo, devido à particularidade de sua execução consistir em estruturar a escavação com anéis segmentados de aço corrugado. Esta técnica foi muito utilizada nas décadas de 1980 e 1990. Entretanto, com o advento de novas tecnologias, esta técnica só é competitiva para aplicações de trechos curtos e com pequenos diâmetros, como por exemplo obras de drenagem de águas pluviais (NAKAMURA, 2012).

O tunnel liner é um método de abertura de túneis caracterizado pela escavação modular do solo e montagem simultânea do revestimento metálico. Ele é usado para a abertura de túneis circulares com diâmetros entre 1,50 m e 5,0 m (MELLO et al., 1998). 
As maiores vantagens do tunnel liner residem no fato da técnica possuir alta produtividade e a baixa interferência com a superfície uma vez que o acabamento e a escavação são executados praticamente de forma simultânea (ROCHA, 2014).

A Figura 5 mostra um tunnel liner executado em Rio Claro - SP.

Apesar das vantagens apresentadas, alguns cuidados devem ser tomados ao aplicar esta técnica. O primeiro diz respeito a questões laborais, pois os operários estão sujeitos a condições de má ventilação e posições ergonomicamente desfavoráveis, quando se trata de uma escavação de seção pequena. $\mathrm{O}$ segundo refere-se a questões construtivas, pois as juntas dos anéis podem apresentar problemas caso não sejam bem executadas (GARRIDO, 2003).

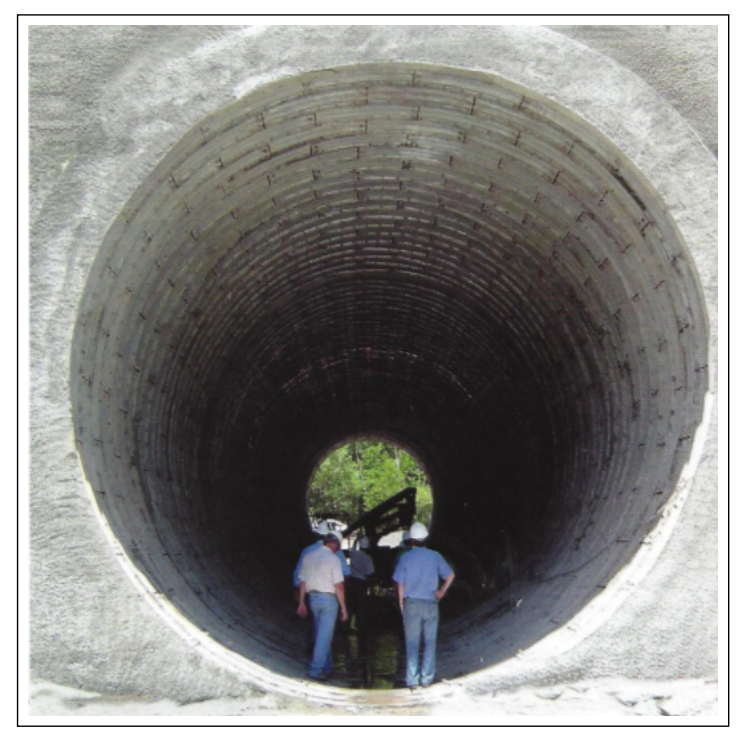

Figura 5 - Execução de um túnel com o método tunnel liner em Rio Claro-SP (Nakamura, 2012).

\subsubsection{NEW AUSTRIAN TUNNELING METHOD - NATM}

O novo método austríaco para a construção de túneis (New Austrian Tunneling Method - NATM) foi desenvolvido em 1945 pelo Professor Dr. Ladislau Von Rabcewicz e patenteado em 1948 (ZIRLIS, 1988). Esse método foi muito aplicado para escavação de túneis de minas de carvão.

A maior vantagem deste método construtivo é possibilitar a escavação de túneis de grandes diâmetros com geometrias diversas e com sequências construtivas variadas.

Com o objetivo de minimizar a influência da escavação nas regiões superficiais do maciço e conferir maior estabilidade à frente, o processo de escavação é executado em etapas parciais. A quantidade de subdivisões depende das condições geológicas da região da escavação. Entretanto, essas características podem ser consideradas como uma vulnerabilidade do método, pois são altamente suscetíveis às falhas humanas. Por isso a instrumentação e o monitoramento constante são partes fundamentais para o sucesso da execução do NATM. 
Alguns exemplos de parcialização da seção e sequenciamento da execução do processo construtivo estão mostrados nas Figuras 6 e 7.

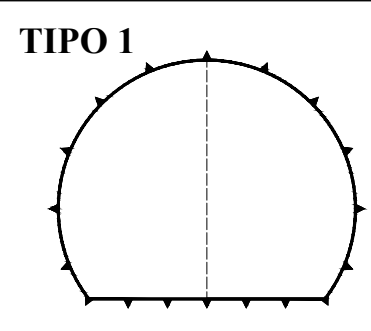

Escavação em seção plena

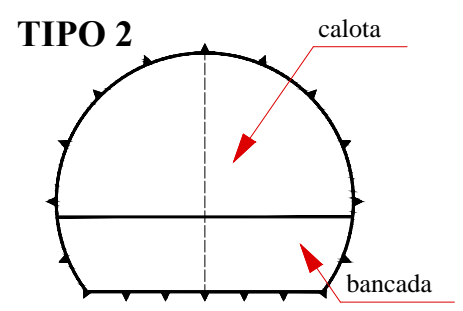

Escavação parcializada

(Calota + bancada)

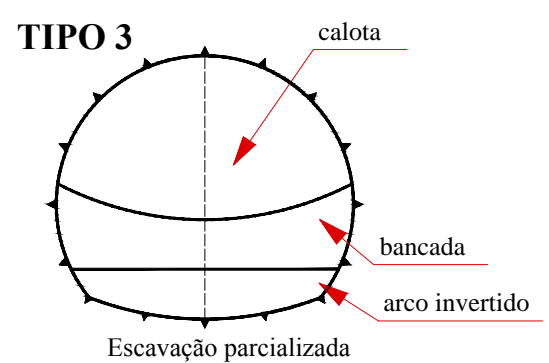

(Calota + bancada+ arco invertido)

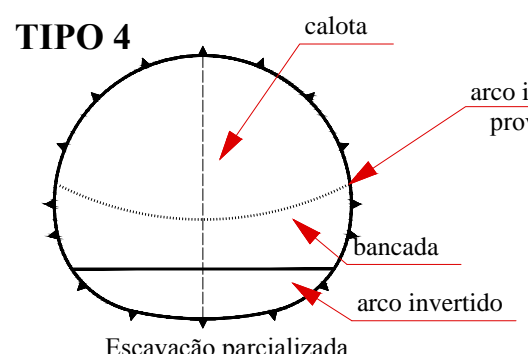

Escavação parcializada

(Calota + bancada+ arco invertido)

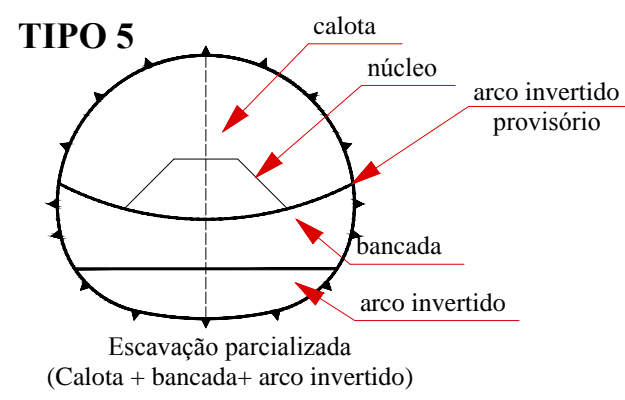

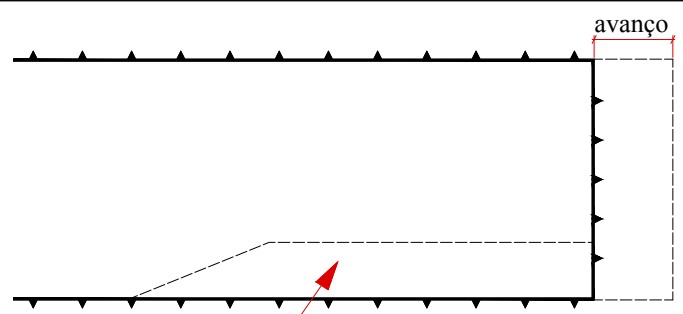

proteção temporária ao arco invertido
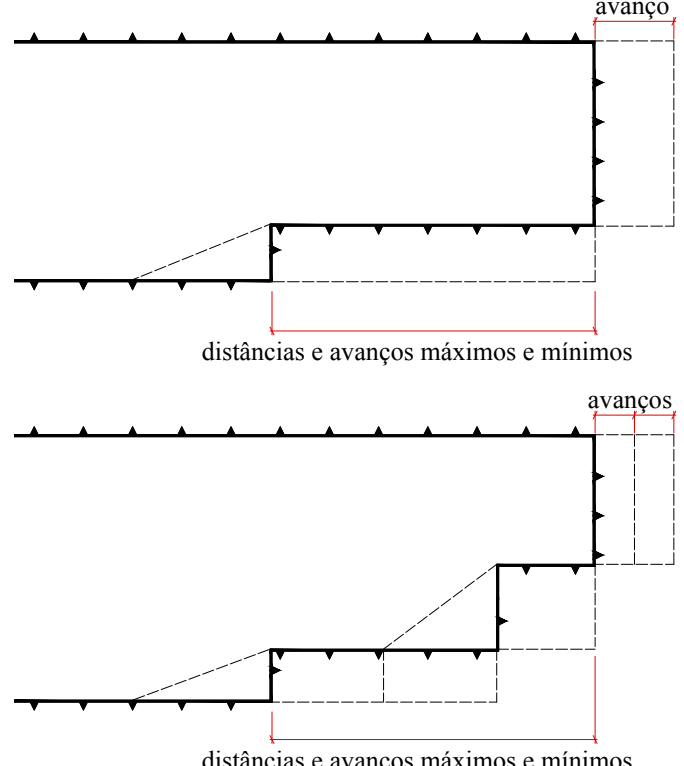

distâncias e avanços máximos e mínimos
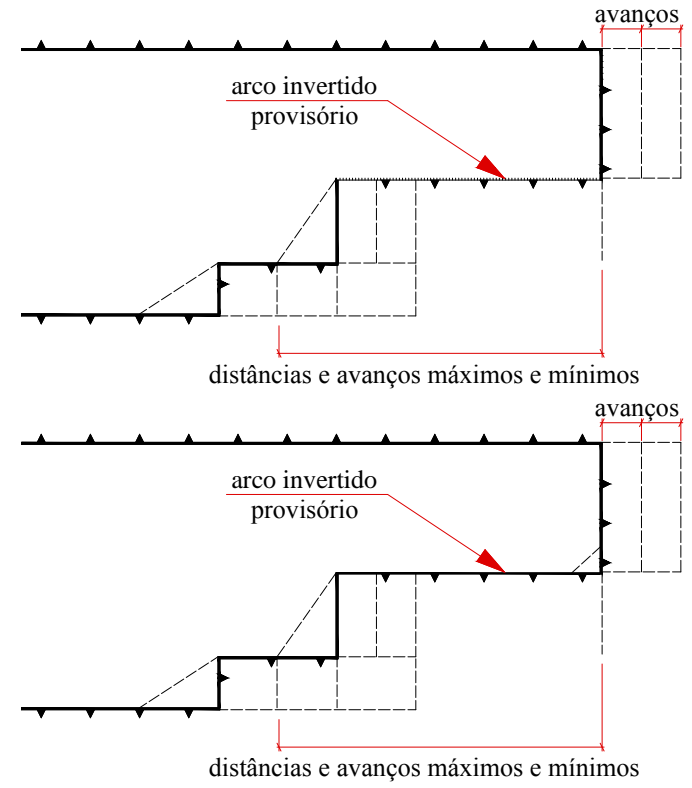

Figura 6 - Tipos de parcialização da seção (Parte A) (adaptado de Corporation, 1997). 


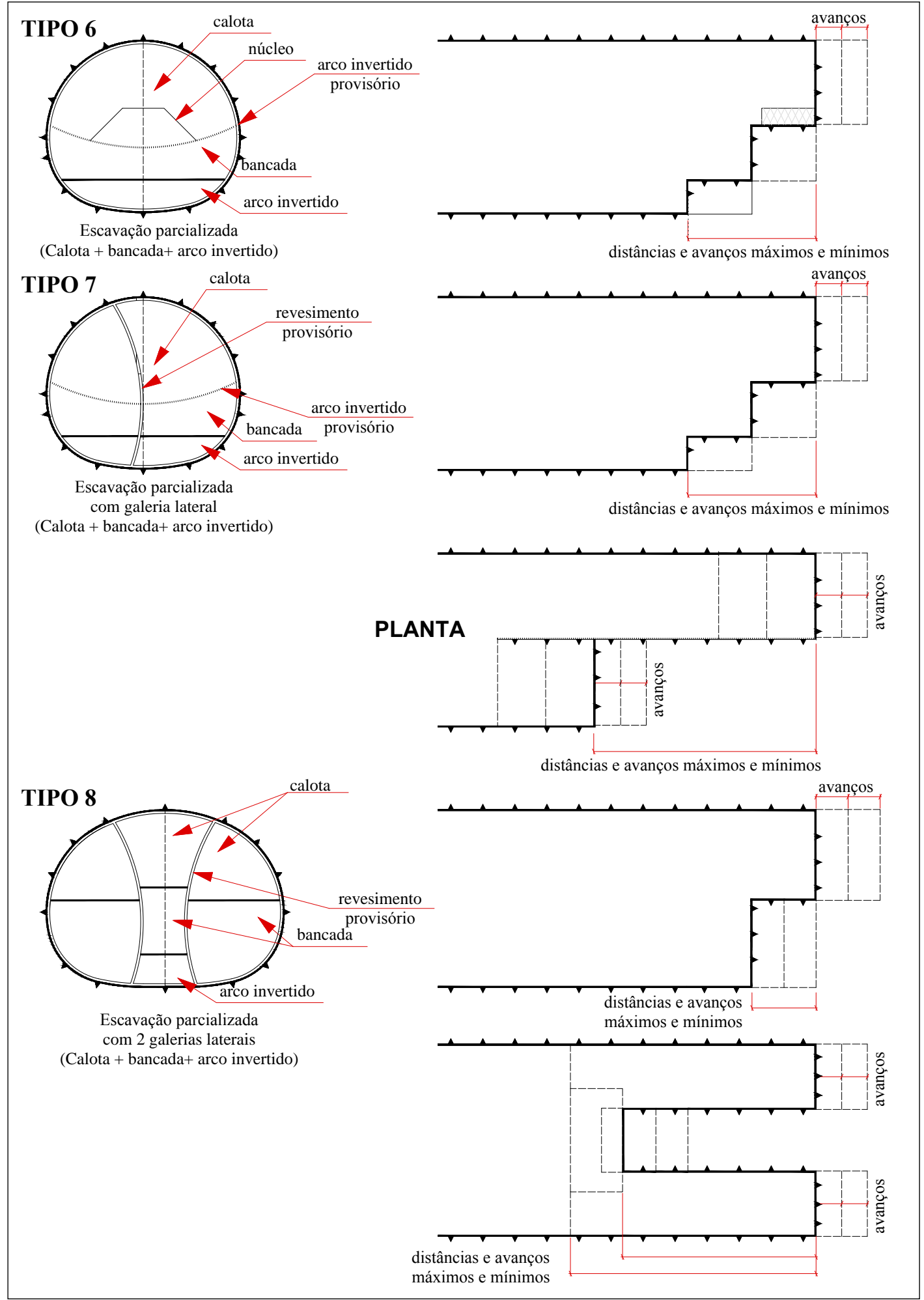

Figura 7 - Tipos de parcialização da seção (Parte B) (adaptado de Corporation, 1997). 
Os dados obtidos com o monitoramento servem para retroalimentar as informações de projeto, redefinindo as diretrizes de como se dará a continuidade da escavação e também para a tomada de decisões na obra (SILVA, 2007).

A essência do NATM está baseada nos seguintes princípios (GOMES, 2006):

a) O maciço circundante também é um elemento portante, devendo ser mobilizado ao máximo para trabalhar de forma otimizada com a estrutura de suporte;

b) A instrumentação deve ser rigorosa para garantir a segurança e as premissas do projeto;

c) O tempo de auto sustentação do maciço deve ser respeitado, ou seja, o suporte da escavação deve ser executado no tempo correto;

d) A prioridade é que o avanço ocorra à seção plena, quando as características do maciço permitirem;

e) Restringir o tempo de ciclo e perturbação do maciço aos menores tempos possíveis;

f) O suporte deve apresentar rigidez compatível com a do maciço, garantindo que os deslocamentos estejam dentro dos limites de segurança;

g) A geometria deve ser adequada, procurando evitar mudanças bruscas e cantos vivos que podem concentrar tensões e induzir a elevados esforços de flexão;

h) Todos os intervenientes envolvidos, tais como contratante, projetista e construtor devem ter uma comunicação eficiente para que as soluções e alternativas de projeto possam ser adotadas e implementadas de forma rápida.

\subsubsection{MÉTODOS DE ESCAVAÇÃO MECANIZADOS}

Os métodos de escavação mecanizados são realizados com o auxílio de um equipamento denominado Tunnel Boring Machine (TBM), no Brasil ele é conhecido como tuneladora. Estes métodos são utilizados em regiões densamente ocupadas e onde as condições de solo são desfavoráveis. Neste tipo de situação a estabilidade do maciço não pode ser comprometida por grandes perturbações nas tensões iniciais do maciço. Os métodos de escavação mecanizados são particularmente eficazes em garantir esta condição.

Neste tipo de método a frente de escavação é suportada pelo mecanismo de corte em conjunto de uma pressão que é aplicada a partir de lama bentonítica ou através do próprio material escavado. As paredes do túnel são inicialmente suportadas pelo escudo da tuneladora e em seguida pelos anéis de concreto ou aço, que são instalados conforme ocorre o avanço da escavação.

Existem dois tipos de tuneladoras específicas para a escavação em solos: Slurry Pressure Balanced-SPB (Figura 8a) e Earth Pressure Balanced-EPB (Figura 8b). 
A escolha entre os dois tipos de tuneladoras depende de vários fatores, entre eles: tipo de solo, do nível freático, da profundidade do túnel e da disponibilidade do equipamento.

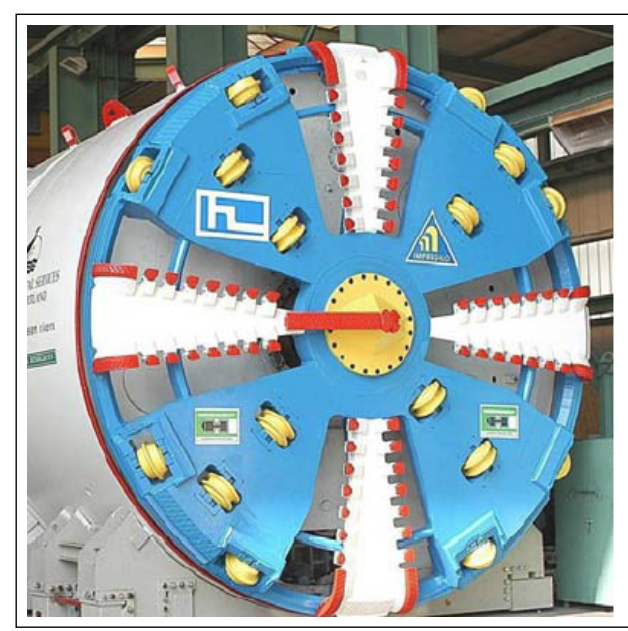

(a) SPB

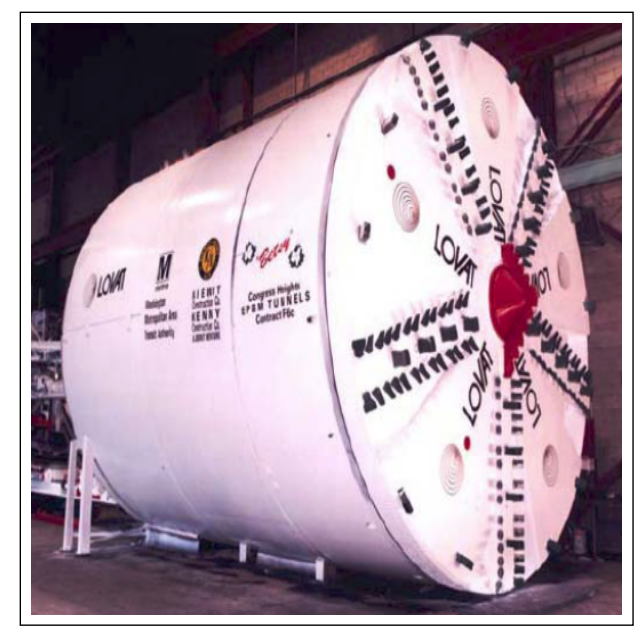

(b) EPB

Figura 8 - Exemplos de tuneladoras (Hung et al., 2009).

As tuneladoras EPB aplicam uma pressão na frente de escavação com o próprio material escavado. Ao avançar a escavação a cabeça de corte encaminha o material escavado para uma câmara de escavação. Dentro da tuneladora um parafuso de Arquimedes é responsável por retirar o material escavado de dentro desta câmara. A diferença entre a taxa de rendimento da escavação e a taxa de produtividade da retirada do solo da câmara que irá produzir a pressão de suporte da frente de escavação (CHAPMAN et al., 2010).

No caso das tuneladoras SPB a pressão aplicada na frente de escavação é proporcionada pelo balanceamento entre a entrada e a saída da lama bentonítica dentro da câmara de escavação. Devido a esta particularidade, o controle da pressão nas tuneladoras SPB é mais preciso do que nas tuneladoras EPB (GUGLIELMETTI et al., 2008).

Uma visão geral da parte interna da tuneladoras pode ser observada nas Figuras 9a e 9b. 


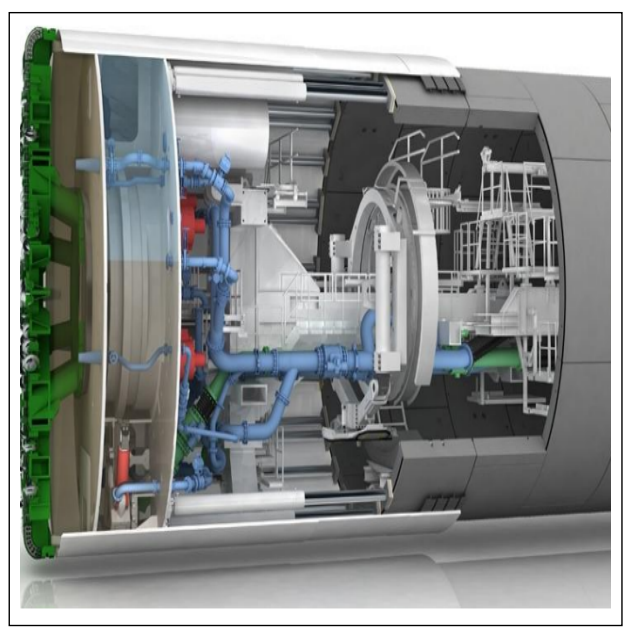

(a) SPB

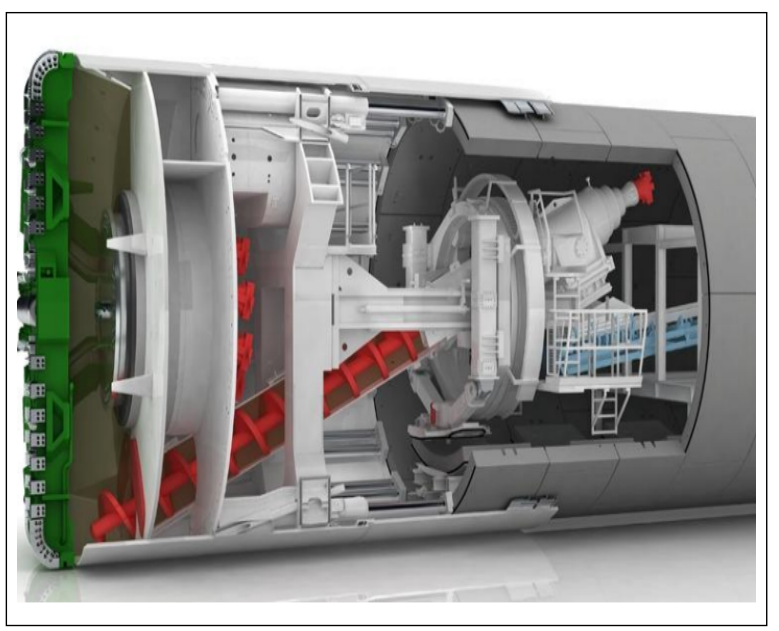

(b) EPB

Figura 9 - Esquemas de funcionamento das tuneladoras (Herrenknecht, 2016).

\subsection{MÉTODOS DE ANÁLISE NUMÉRICA APLICADOS A TÚNEIS}

O estudo de uma escavação subterrânea necessita que muitas variáveis sejam levadas em consideração a fim de se obter um resultado realista. Por conta deste fato a alternativa mais indicada para este tipo de estudo são os métodos de análise numérica. Estes métodos fornecem resultados aproximados ao resolver um conjunto de equações diferencias que governam o comportamento do meio estudado. As metodologias mais empregadas para este fim são: métodos dos elementos finitos, método das diferenças finitas e métodos de elementos de contorno, ou ainda, soluções que combinam estes métodos.

As soluções numéricas permitem considerar geometrias complexas, anisotropia dos materiais, diferentes comportamentos reológicos, descontinuidades do maciço e heterogeneidade, por exemplo.

Além de poder considerar todos estes parâmetros de forma simultânea em um único modelo as simulações numéricas oferecem resultados quanto ao comportamento do maciço durante a escavação, tensões no suporte, movimentos induzidos no terreno, entre outros. Entretanto, para que os modelos numéricos possam proporcionar resultados acurados é necessário considerar, também, o modelo constitutivo adotado e a sequência de escavação que será empregada na obra, pois estes parâmetros influenciam consideravelmente o comportamento do maciço durante a escavação.

Apesar de existirem modelos constitutivos muito elaborados, estes têm um interesse prático limitado, pois são complexos e possuem grande dificuldade na obtenção dos parâmetros de entrada. Desta forma é comum a utilização de modelos mais simples e que forneçam resultados dentro de limites aceitáveis.

A seguir serão apresentadas algumas considerações acerca de modelos numéricos tridimensionais e bidimensionais, com foco nas técnicas disponíveis que permitem a avaliação do 
deslocamento do teto do túnel e que também tentam, de alguma forma, representar um problema marcadamente tridimensional a partir de modelos numéricos bidimensionais.

No caso de túneis sem suporte os estados de deformação obtidos através de análises bidimensionais conduzem a soluções muito próximas daquelas obtidas com simulações numéricas tridimensionais (LEE; ROWE, 1990a; LEE; ROWE, 1990b).

Ao aplicar o Método da Convergência-Confinamento (MCC) em modelos numéricos que simulam a construção de túneis em maciços rochosos que satisfazem o critério de ruptura de Hoek-Brown, Carranza-Torres e Fairhurst (2000) afirmaram que o MCC fornece resultados confiáveis ao se determinar as tensões que o maciço rochoso aplica no suporte do túnel.

Uma análise completa tridimensional da escavação de túneis através do MEF demanda um grande número de fases de escavação tornando tal análise pouco usual na prática de engenharia. Sendo assim, Vermeer et al. (2002a) propuseram uma análise alternativa através de modelos numéricos bidimensionais e concluíram que as bacias de recalques da superfície obtidas com estas simulações apresentavam formatos bem parecidos com os das simulações numéricas tridimensionais. Entretanto para que a análise bidimensional forneça resultados confiáveis ela deve ser calibrada através de modelos tridimensionais mais simples.

Análises numéricas tridimensionais foram realizadas com a intenção de avaliar o comportamento da interação entre o maciço e o suporte, Gomes e Celestino (2009) concluíram que a solução proposta por Schwartz e Einstein (1980) produz erros significativos ao não levar em conta a rigidez do maciço na frente de escavação e o comprimento do lance da escavação.

Ao comparar a resposta do MCC e do método da perda de volume com a resposta de modelos numéricos tridimensionais, Do et al. (2014) concluíram que o MCC fornece resultados mais próximos dos modelos numéricos tridimensionais. Entretanto, modelos numéricos bidimensionais realizados com diferenças finitas não permitem que a interação entre os anéis do revestimento no sentido longitudinal seja levada em consideração. Desta forma, uma análise tridimensional é fundamental para descrever este fenômeno.

Simulações numéricas bidimensionais em estado plano de deformações, conseguem representar com razoável aproximação o comportamento mecânico marcadamente tridimensional da frente de escavação de um túnel, ou seja, produzem resultados de deslocamentos finais bem próximos aos resultados obtidos a partir de modelos numéricos tridimensionais de túneis sem suporte (PAN; HUDSON, 1988).

Por fim outros trabalhos importantes que abordam temas correlatos podem ser encontrados, em: Panet (1976), Swoboda (1979), Hoek e Brown (1980), Panet e Guenot (1982), Rowe et al. (1983), Schikora e Ostermeier (1988), Lee e Rowe (1991), Panet et al. (1992), Swoboda et al. (1994), Powell e Beveridge (1997), Augarde e Burd (2001), Potts e Zdravkovic (2001), Karakus (2007). 


\subsubsection{ANÁLISES NUMÉRICAS TRIDIMENSIONAIS}

Como já citado anteriormente o estudo de uma escavação subterrânea possui uma natureza tridimensional, pois este tipo de modelo permite avaliar, de forma realista, a redistribuição de tensões e deslocamentos no maciço e nas estruturas de suporte durante todo o processo de escavação seja ela mecanizada ou não.

Apesar destes benefícios, empregar um modelo numérico tridimensional pode representar um trabalho bastante complexo tanto na fase de implementação do modelos (dificuldades na elaboração da topologia da malha, tempo necessário para compor a geometria do modelo e grande demanda por requisitos computacionais), tratamento e obtenção dos parâmetros, bem como da análise dos resultados, por isso ainda existe grande interesse prático em modelos numéricos bidimensionais em estado plano de deformação.

\subsubsection{ANÁLISES NUMÉRICAS BIDIMENSIONAIS}

O emprego da análise numérica para avaliação do comportamento dos maciços frente às solicitações induzidas pelo processo de escavação de túneis teve início com o Modelo de Carregamento Completo. Este modelo consiste em considerar um suporte de proteção rígido imaginário e neste suporte é aplicado um carregamento igual ao campo de tensões iniciais. $\mathrm{Na}$ sequência um suporte primário é executado sem carregamento algum atuante, uma vez que ele está protegido pelo suporte de proteção imaginário. Em seguida o suporte imaginário é removido e então toda a carga, devido à remoção, é transferida ao suporte primário (SWOBODA, 1979).

Apesar de ser considerado um modelo que produz resultados a favor da segurança ele tem o ônus de produzir estruturas superdimensionadas, bem como a limitação de não poder ser utilizado em túneis com grandes sobrecargas.

Para suprir essa deficiência, surgiram diversos modelos bidimensionais utilizados em projetos de escavações subterrâneas. Tais processos são artifícios que tentam reproduzir os efeitos tridimensionais do comportamento da frente de escavação. $\mathrm{O}$ efeito de suporte proporcionado pelo maciço à frente de escavação pode ser observado na Figura 10. 


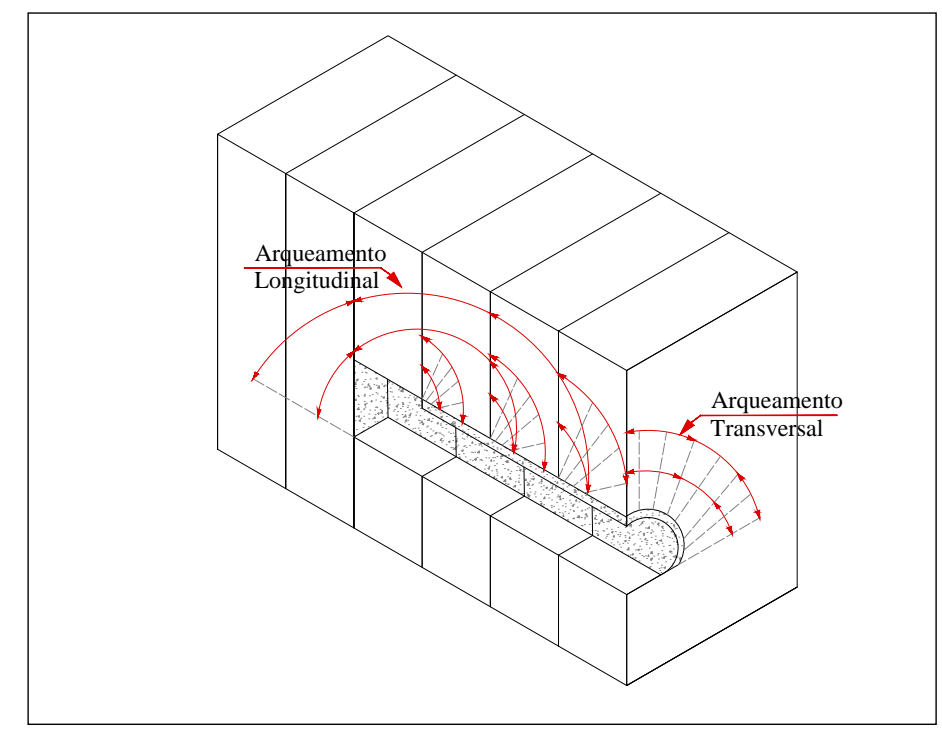

Figura 10 - Tridimensionalidade da frente de escavação (adaptado de Sinha, 2012).

\subsubsection{MÉTODO DA CONVERGÊNCIA-CONFINAMENTO}

No MCC, apresentado por Panet e Guenot (1982), é possível considerar o efeito de suporte que o maciço proporciona à frente de escavação do túnel através de um modelo bidimensional em estado plano. O efeito de suporte à escavação é substituído por uma pressão fictícia radial interna $\left(\sigma_{i}\right)$ aplicada no contorno da escavação. Para simular o avanço da escavação uma redução contínua na pressão radial interna é realizada. Numericamente este fato é representado pela equação:

$$
\sigma_{i}=(1-\lambda) \sigma_{0}
$$

onde: $\sigma_{0}=$ pressão in situ; $\lambda=$ fator de alívio; $\sigma_{i}=$ pressão radial interna.

O fator de alívio é determinado a partir de:

$$
\lambda=\frac{u_{x}(x)}{u_{r}^{\infty}}
$$

onde: $u_{x}(x)=$ componente radial do deslocamento a uma distância $x$ atrás da frente; $u_{r}^{\infty}=$ componente radial do deslocamento em uma seção muito distante atrás da frente de escavação;

Finalmente $u_{r}^{\infty}$ pode ser obtido a partir de:

$$
u_{r}^{\infty}=\frac{1+\nu}{E} \sigma_{0} r
$$

onde: $r=$ raio da escavação; $\nu=$ coeficiente de Poisson; $E=$ módulo de elasticidade.

Tal abordagem permite levar em consideração o alívio de tensão no terreno até a instalação do suporte e a distribuição da carga entre o maciço e o suporte. A Figura 11 mostra as etapas do método. 


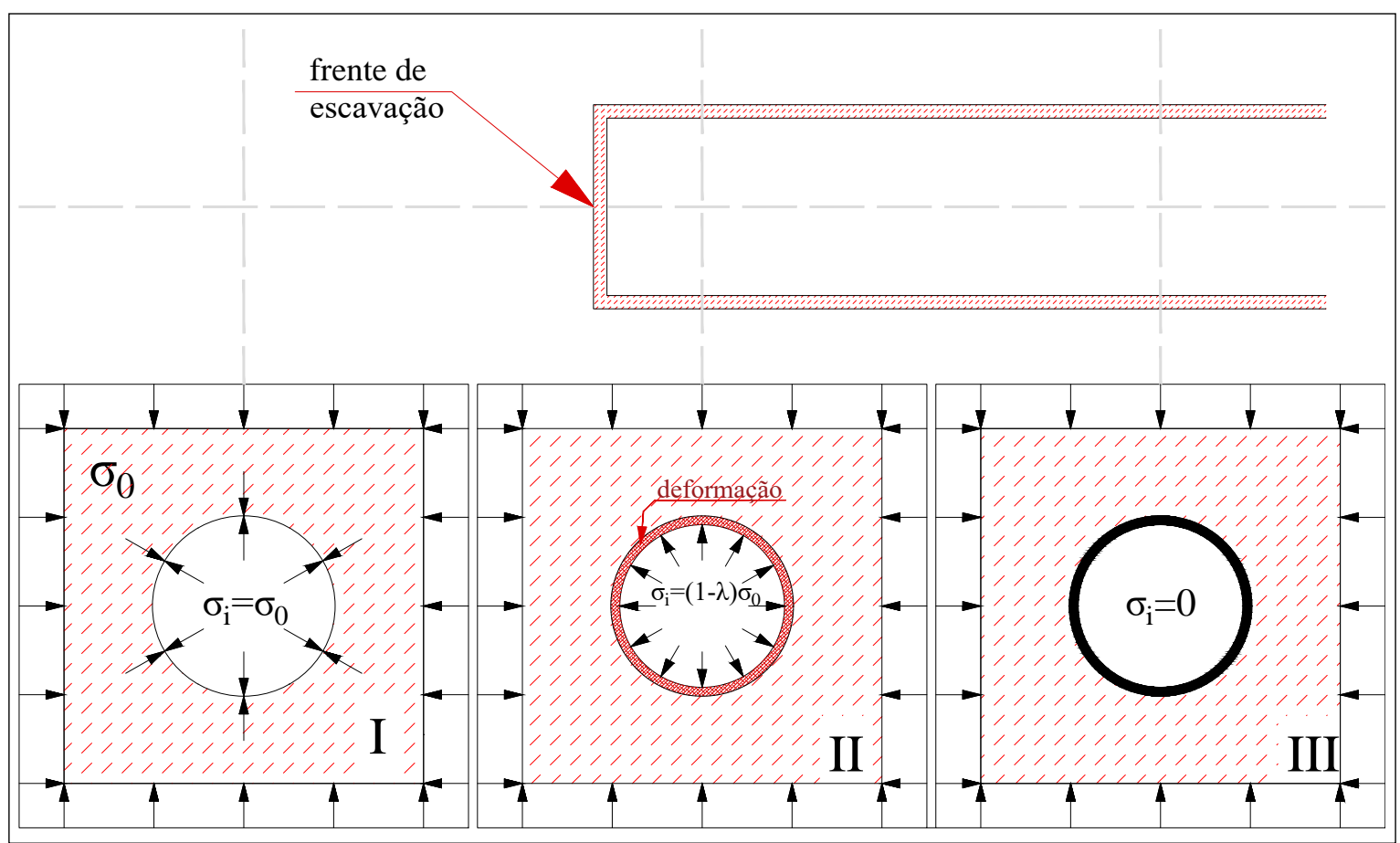

Figura 11 - Método da convergência-confinamento (adaptado de Panet, 1976).

Ao analisar a Figura 11 é possível resumir o método em três etapas básicas:

a) Etapa I - considera-se o maciço escavado com uma cavidade não revestida e com uma pressão radial interna aplicada no contorno da escavação com intensidade numericamente igual à pressão geoestática;

b) Etapa II - Antes da instalação do suporte um fator de alívio $\lambda$ é aplicado à pressão radial interna, conforme a Equação 2.1. Desta forma, ocorre uma deformação radial da escavação em direção ao seu centro;

c) Etapa III - Finalmente quando a deformação apresentar valores iguais aos obtidos através de instrumentação ou aos obtidos com modelos tridimensionais, o suporte é instalado e a pressão radial interna é anulada.

A magnitude do fator de alívio representa condições físicas importantes, pois valores elevados de $\lambda$ correspondem a grandes comprimentos do avanço da escavação ou instalação tardia do suporte, caso em que as deformações do terreno serão grandes e os esforços no suporte pequenos. Por sua vez, valores pouco expressivos de $\lambda$ correspondem a deformações pequenas e esforços elevados.

O fator de redução $\lambda$ é normalmente considerado em torno de 0,5 , porém determinar a magnitude deste fator é uma tarefa difícil e é tema de discussão em diversos trabalhos mostrados adiante, pois ele depende de muitos condicionantes, tais como: comprimento do avanço da escavação, processos construtivos e comportamento do maciço.

Möller (2006) concluiu, através de análises elásticas, que o valor de $\lambda$ aumenta com o 
aumento do comprimento do avanço (que tem importância determinante na variação de $\lambda$ ) e com o aumento da rigidez do terreno. Para módulos de elasticidade entre $20 \mathrm{MPa}$ e $150 \mathrm{MPa}$ e diâmetros de $D=0,5 m$, obtém-se $\lambda$ entre 0,14 e 0,21 , para $D=1,0 m \lambda$ está entre 0,27 e 0,38 e para $D=1,5 m \lambda$ está entre 0,45 e 0,55 . É necessário ter em mente que essas informações são meramente qualitativas uma vez que o estudo não considerou a deformação plástica ao redor do túnel.

Ainda no mesmo trabalho, também foram realizadas análises elastoplásticas, usando o modelo reológico de Mohr-Coulomb. $\mathrm{O}$ autor concluiu que o ângulo de atrito não influencia de forma sensível o fator de alívio $\lambda$, diferente da coesão que apresenta grande importância na determinação deste parâmetro. Tal fato é observado no caso de valores de coesão menores do que $200 \mathrm{kPa}$, valor a partir do qual não existe plastificação do maciço, abaixo deste valor $\lambda$ apresenta uma relação diretamente proporcional com a coesão.

Cecílio (2009) e França (2006) utilizaram o MCC para avaliar escavações realizadas empregando-se a técnica do NATM, enquanto que Dias e Kastner (2013) e Do et al. (2014) utilizaram este método para avaliar escavações realizadas com o auxílio de tuneladoras. Este é um método que fornece resultados razoáveis de acordo com a prática corrente da engenharia. No entanto é importante frisar que este método proporciona resultados confiáveis para deformações, porém os resultados das tensões que atuam nas paredes do túnel podem destoar consideravelmente da realidade (KARAKUS, 2007).

O MCC é um método eficiente para avaliação das deformações tanto no maciço quanto na estrutura de suporte em diferentes etapas do processo de escavação. Com ele também é possível definir a zona de plastificação do túnel e estimar a convergência da escavação. Este método fornece resultados excelentes ao modelar túneis profundos e apesar de não ser o mais indicado para o tratamento de túneis rasos ele ainda pode ser utilizado para estimar as deformações dessas escavações com resultados aceitáveis para estudos de viabilidade e projetos básicos.

\subsubsection{MÉTODO DA REDUÇÃO DE RIGIDEZ DO NÚCLEO}

O método da redução de rigidez do núcleo, introduzido por Swoboda (1979), consiste em uma sequência de simulações bidimensionais para representar uma redução gradual da rigidez do material que será escavado (núcleo da escavação). Este procedimento permite determinar tanto a bacia de recalques da superfície (antes da instalação do revestimento) quanto as deformações laterais da escavação. As diferentes etapas da escavação são simuladas associando para cada etapa um módulo de elasticidade específico para a região a ser escavada. O procedimento é constituído de três etapas básicas (Figura 12):

a) Na primeira etapa, o maciço é considerado intacto com módulo de elasticidade natural $\left(E_{n}\right)$

b) na segunda etapa, antes da escavação o módulo de elasticidade $\left(E_{n}\right)$, da região que 
será escavada, é reduzido para $E_{m}$ através de um fator $\alpha_{a}$ e o maciço apresenta uma deformação radial no sentido do centro da escavação. A equação a seguir mostra a relação numérica desta etapa:

$$
E_{m}=\alpha_{a} E_{n}
$$

onde: $E_{n}=$ módulo de elasticidade natural; $\alpha_{a}=$ fator de redução do módulo e $E_{m}=$ módulo de elasticidade modificado.

c) Por fim instala-se o suporte ao mesmo tempo em que a frente do túnel é escavada. Ainda nesta etapa o módulo de rigidez é reduzido progressivamente até zero fazendo com que o suporte receba o restante da carga devido à deformação do túnel.

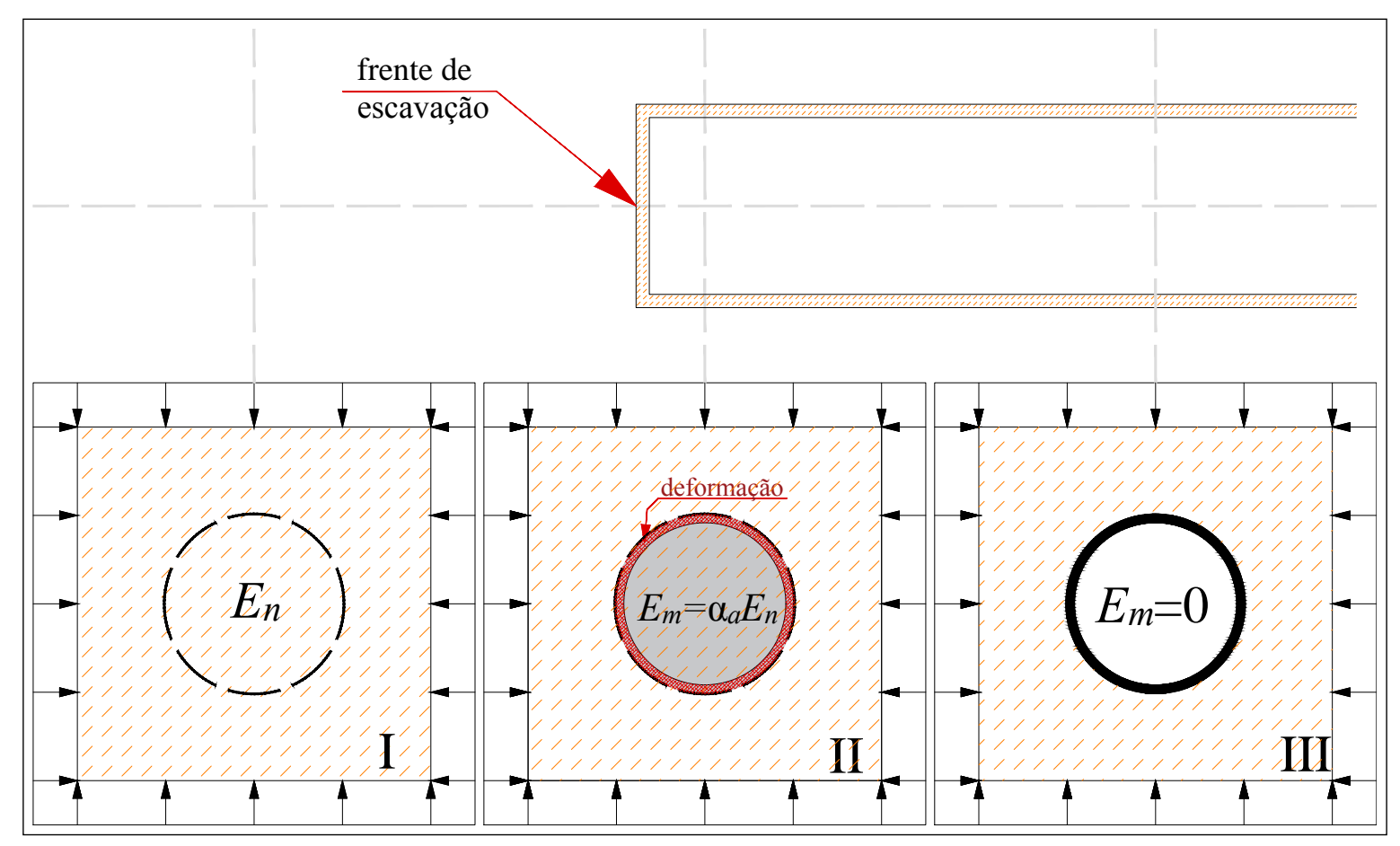

Figura 12 - Sequência das etapas do método da redução de rigidez do núcleo (adaptado de Gomes, 2006).

Ao analisar a Figura 12 pode-se concluir que, quando $\alpha_{a}=1$, não há alteração da rigidez do núcleo da escavação, portanto, não ocorre deformação alguma. Tal situação representa o estágio $I$ da Figura 12, ou seja, a seção considerada encontra-se à frente da escavação. Quando $\alpha_{a}=0$ é o mesmo que $E_{m}=0$, neste caso as deformações radiais são máximas e a seção considerada encontra-se atrás da frente de escavação.

O método da redução de rigidez do núcleo pode apresentar resultados, significativamente, destoantes de valores medidos em campo, isso ocorre principalmente quando são simulados processos construtivos mais complexos e quando forem adotadas leis constitutivas que representam comportamentos não lineares (SCHWEIGER et al., 1997). 
Determinar o fator de redução do módulo de elasticidade representa a principal deficiência do método, já que não existe um modo racional para obtê-lo. Desta forma, o sucesso do método fica muito dependente da experiência do projetista (KOCHEN et al., 1985).

Uma alternativa para reduzir a arbitrariedade na determinação do fator de redução de rigidez é calibrá-lo através de instrumentação. Existe também a possibilidade de realizar a calibração deste fator através de modelagem numérica axissimétrica, pois ela tem condições de fornecer a porcentagem de redução que deverá ser utilizada em cada passo da escavação, isto é, desde que o túnel a ser executado apresente simetria axial (MOLDOVAN; POPA, 2012).

\subsubsection{MÉTODO DO VAZIO IMPOSTO OU GAP}

Inicialmente descrito por Rowe et al. (1983), tem como princípio básico introduzir um vazio na malha $(G A P)$ de elementos finitos. Este artifício numérico tem a intenção de representar a perda de solo esperada decorrente do processo de escavação. Esta perda pode ser entendida como uma medida do volume de material que tenha sido escavado em excesso ao se comparar com o volume teórico nos limites do diâmetro externo do revestimento do túnel. Esse excesso leva em consideração o efeito das deformações elastoplásticas tridimensionais no contorno do túnel $\left(U_{3 D}^{*}\right)$, a qualidade da construção $(\omega)$ e o espaço físico entre a geratriz da tuneladora e a superfície do revestimento $\left(G_{p}\right)$.

Este método foi aperfeiçoado por Lee e Rowe (1991), que aplicaram o parâmetro GAP para considerar a perda de volume em função do processo de escavação do túnel.

O equacionamento do método é apresentado a seguir:

$$
G A P=U+G_{p}
$$

O espaço $G_{p}$ corresponde à espessura do revestimento $(\Delta)$ com o espaço necessário à instalação do revestimento $(\delta)$, conforme a Equação 2.6.

$$
\begin{gathered}
G_{p}=\Delta+\delta \\
U=U_{3 D}^{*}+\omega
\end{gathered}
$$

Karakus (2007) obteve resultados razoáveis através desta técnica, apesar da determinação do parâmetro GAP ser muito sensível aos diferentes tipos de solo, consistindo na principal deficiência desta técnica. A Figura 13 ilustra a geometria do método GAP. 


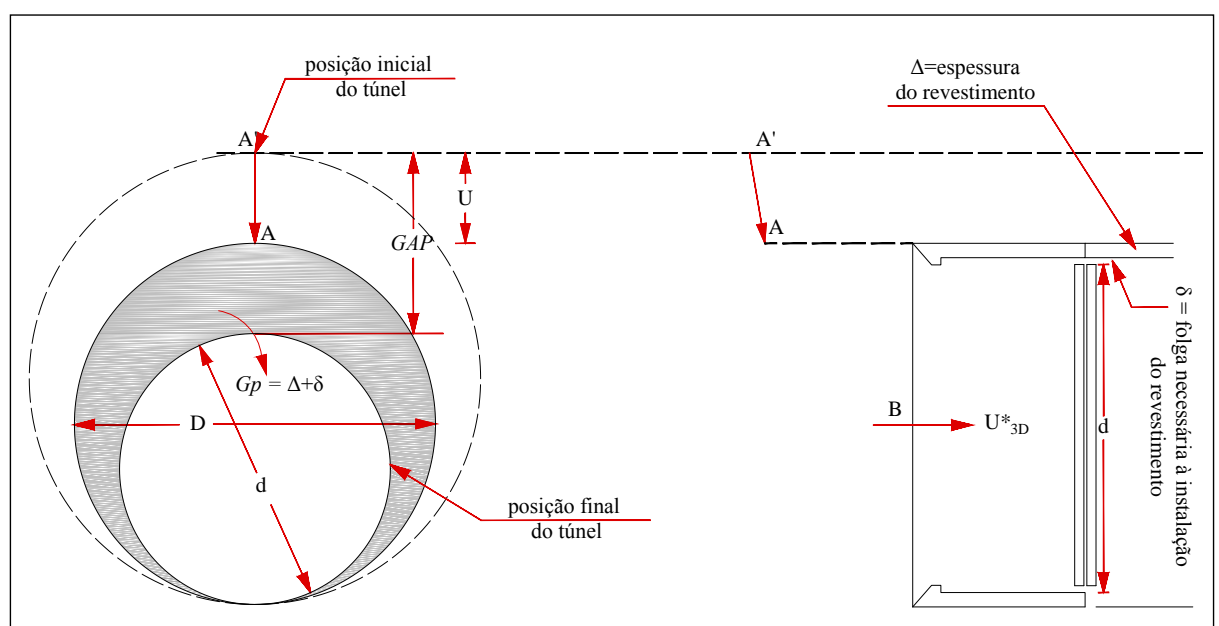

Figura 13 - Método GAP (adaptado de Lee e Rowe, 1991).

Ao realizar modelos numéricos de escavações em argilas utilizando o método do vazio imposto e aplicando o parâmetro GAP a partir de uma relação empírica apresentada por Lo e Rowe (1984) e Ng (1991), Rowe e Lee (1992) obtiveram resultados com bastante concordância com os dados fornecidos a partir da instrumentação das escavações. Concluiram, portanto, que para solos argilosos, desde que bem determinados os parâmetros de coesão não drenada e módulo de elasticidade, a técnica proposta por Lee e Rowe (1991) pode ser utilizada para previsão das deformações superficiais.

Resumidamente, o método descreve a posição final do revestimento do túnel cujo diâmetro é inferior ao da escavação inicial. Ou seja, após a execução do túnel o revestimento será instalado com um determinado vazio em relação ao teto da escavação. Este vazio será fechado pela deformação do maciço (não revestido), e então, quando o maciço entrar em contato com o suporte, será modelada a interação entre eles.

\subsubsection{MÉTODO DA ELASTICIDADE HIPOTÉTICA}

O Método da Elasticidade Hipotética (MEH) pressupõe especificar diferentes valores para o módulo de elasticidade para o revestimento de acordo com a etapa da simulação numérica. O objetivo deste procedimento é considerar a deformação que o maciço sofrerá desde o momento da instalação do suporte até o momento em que este atinja sua resistência máxima.

Tendo em conta que o revestimento de túneis convencionais são executados utilizando-se concreto projetado e que este material apresenta incremento da resistência ao longo do tempo, o MEH torna-se um método particularmente eficiente ao simular a execução deste tipo de escavação, pois as etapas dele podem retratar o referido incremento de resistência do concreto projetado. 
A Figura 14 ilustra as etapas básicas do método.

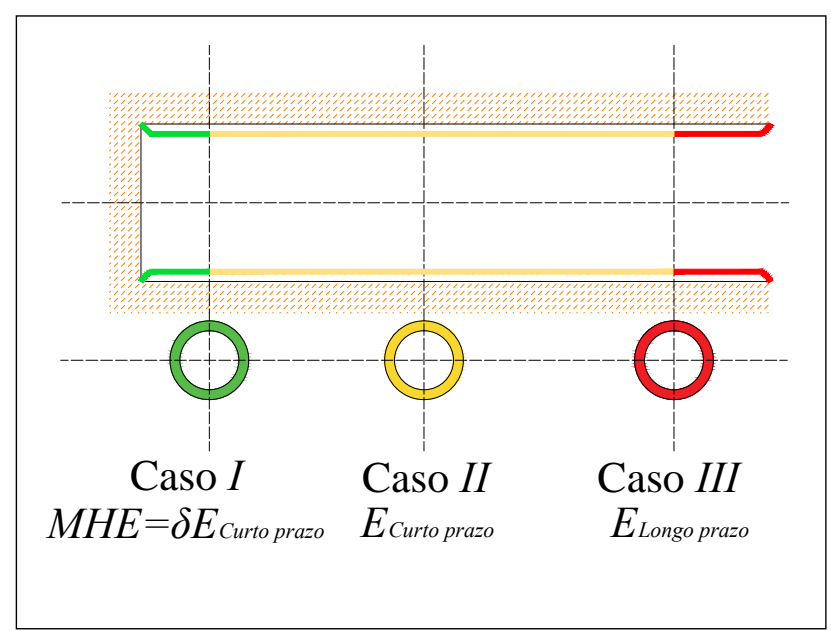

Figura 14 - Método da elasticidade hipotética (adaptado de Karakus, 2007).

Na etapa $I$, a variável $\delta$ representa um fator de redução do módulo de elasticidade de curto prazo do revestimento ou módulo de elasticidade jovem. Esta etapa é definida pela especificação de um módulo de elasticidade reduzido que é aplicado ao revestimento antes mesmo da escavação do túnel. Tal fator é função dos parâmetros geomecânicos do solo, formato do lance de escavação do túnel e do número de estágios para completar a escavação do túnel.

Ao empregar análises numéricas bidimensionais através do MEF, Karakus e Fowell (2003) determinaram valores de $\delta$ entre 0,02 e 0,1 para argilas sobreadensadas de Londres e também indicaram que tal parâmetro pode ser especificado a partir de informações de instrumentação da obra.

Na etapa $I I$, o valor $M E H$ do revestimento é considerado como o módulo de elasticidade de curto prazo sem nenhuma redução e pode variar de 3 a $7 \mathrm{GPa}$.

Finalmente no Caso III o revestimento está totalmente fortalecido, ou seja, apresenta sua máxima resistência, nesta etapa o módulo é nomeado de módulo de elasticidade de longo prazo. A distância entre cada etapa depende principalmente da velocidade de escavação e do processo construtivo empregado (KARAKUS, 2007).

No caso de túneis convencionais os resultados previstos pelo MEH são muito mais próximos dos obtidos com outros métodos. Sendo assim fica claro que escavações sequenciais não devem ser simuladas através de modelos baseados em uma única etapa de escavação (KARAKUS; FOWELL, 2003).

\subsubsection{MÉTODO DA PERDA DE VOLUME}

O método da perda de volume, também conhecido como método da contração, foi introduzido por Bernat (1996) e em seguida aplicado por Addenbrook et al. (1997). Este método aproveita o mesmo princípio do método do vazio imposto ao considerar o volume da perda de 
solo. Entretanto, diferente do método anterior tem a vantagem de ter uma aplicação mais simples e um maior controle ao especificar os parâmetros de entrada.

O controle dos volumes é feito a partir de medidas da deformação radial do perímetro da escavação.

Inicialmente a escavação é simulada através de incrementos sucessivos. Ao final de cada incremento, o volume $V_{1}$ é calculado e então comparado com o volume $V_{2}$ pretendido, de acordo com o seguinte equacionamento:

$$
V_{l}=\frac{V_{1}-V_{2}}{V_{1}} \times 100 \%
$$

onde: $V_{l}=$ perda de volume; $V_{1}=$ volume inicial da cavidade e $V_{2}=$ volume final da cavidade.

Quando o valor objetivo é atingido, instala-se o suporte. Nesta fase ainda ocorre uma perda de volume, porém, muito pequena se comparada a perda de volume inicial. O modelo considera que o contorno da escavação não apresenta restrições de deformações.

O método pode ser aplicado de duas maneiras distintas:

a) Fixar o centro do túnel o que implica em uma deformação uniforme da cavidade (Figura 15a);

b) Não restringir o movimento do centro do túnel, desta forma o movimento das bordas é livre (Figura 15b).

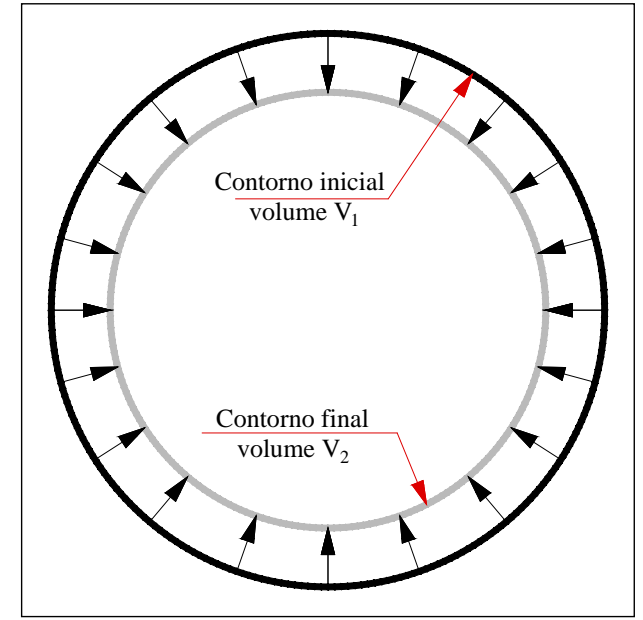

(a) Representação do método da perda de volume - ponto central fixo

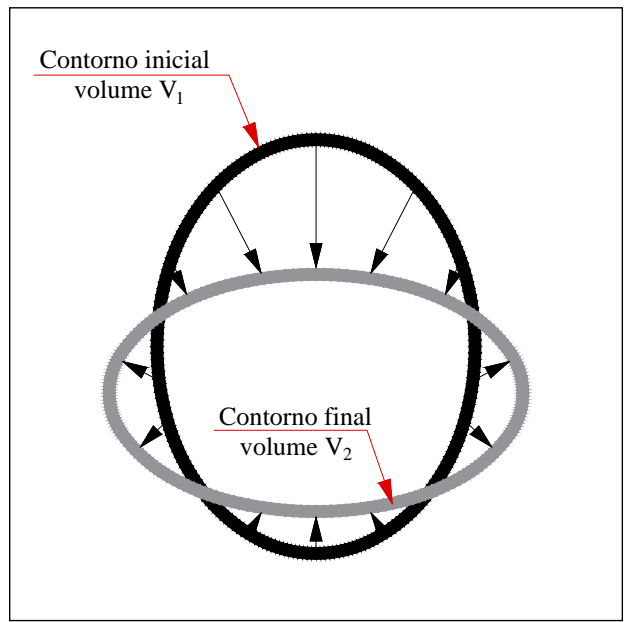

(b) Representação do método da perda de volume - ponto central livre

Figura 15 - Método da perda de volume (adaptado de Do e Dias, 2017).

A segunda situação é mais geral podendo ser aplicada em qualquer caso, já a primeira é restrita ao caso em que o coeficiente de empuxo lateral seja igual a 1.

Comparando as duas formas de aplicação do método, Do e Dias (2017) concluíram que quando se pretende representar a bacia de recalques da superfície e o movimento lateral do solo 
que envolve o túnel o método da perda de volume com o ponto central livre fornece melhores resultados.

Quando se pretende analisar o comportamento global de uma escavação, levando em consideração a interação entre o revestimento e o solo o método da perda de volume é mais indicado do que o MCC na obtenção de dados como deslocamentos radiais da escavação. Entretanto essas informações devem ser validadas através de resultados experimentais, pois, estas conclusões foram feitas considerando apenas modelos numéricos tridimensionais como referência (DO; DIAS, 2017).

Devido à característica de considerar o formato inicial da escavação com formato circular, este método só é possível de ser aplicado quando a escavação for realizada com o emprego de tuneladoras. Apesar de ser limitada a este caso, o método é particularmente eficiente em representar este tipo de escavação, pois nele realmente ocorre a redução do diâmetro final da escavação, condição esta que ocorre devido à diferença existente entre o perímetro da escavação e o diâmetro externo dos anéis da tuneladora.

\subsection{LIMITAÇÕES DOS MODELOS BIDIMENSIONAIS}

Os métodos apresentados neste trabalho representam apenas uma parte de todas as abordagens disponíveis na literatura. Escolher um método para ser utilizado em projeto depende de muitas variáveis dentre as quais pode-se citar o método construtivo empregado, velocidade de escavação, tipo de maciço, software disponível e também preferência do projetista.

O ganho de tempo no processamento das informações fornecido por modelos numéricos bidimensionais representa uma perda na qualidade dos resultados quando comparados com os resultados obtidos através de modelos numéricos tridimensionais. Tal fato é explicado pelas simplificações que devem ser assumidas nestes modelos. Como exemplos das deficiências dessas abordagens podem ser citados alguns trabalhos descritos na literatura:

Vlachopoulos e Diederichs (2013), mostraram que os resultados bidimensionais para formatos de escavações que não fossem circulares produziam resultados de deslocamentos radiais do perímetro da escavação de qualidade reduzida. Com relação as tensões in situ os autores relatam que a maioria dos métodos estudados fornecem bons resultados em meios isotrópicos. Quando considerados revestimentos rígidos, a seção a ser considerada para análise dos deslocamentos radiais deve estar entre 2 a 6 raios de distância da frente de escavação para que as condições de contorno não influenciem esses resultados, distâncias inferiores a duas vezes o raio demandam análises tridimensionais. Os autores ainda recomendam que as condições de contorno adotadas no modelo, quando a escavação precisar levar em consideração o efeito de squeezing, estejam no mínimo à 12 raios do túnel ou, pelo menos, três raios plásticos longe da zona plástica.

Karakus (2007), afirma que o MCC produz resultados mais precisos quando é executada 
uma análise numérica utilizando-se elementos finitos a fim de se obter a bacia de recalques produzida por uma escavação.

Segundo Schweiger et al. (1997), análises numéricas bidimensionais para obtenção de deslocamentos radiais somente são válidas para túneis com poucos estágios de escavação na seção transversal, devendo ser utilizados outros métodos quando da análise de escavações mais complexas.

De acordo com o já citado anteriormente, Karakus (2007), conclui que o MCC mesmo fornecendo resultados razoáveis na determinação de deslocamentos radiais apresenta o grave problema com relação à arbitrariedade na determinação do fator de alívio $\lambda$. Isto se traduz no fato de que ao calibrar o fator de alívio com objetivo de determinar a bacia de recalques produzem, no mesmo modelo, resultados de tensões atuantes insatisfatórios, enquanto que um ajuste do fator de alívio com o objetivo de determinar as tensões atuantes na escavação implica em resultados, no mesmo modelo, de deslocamentos insatisfatórios. Outros autores como Do e Dias (2017) também relatam o mesmo problema.

\subsection{PLANEJAMENTO FATORIAL DE EXPERIMENTOS}

O planejamento fatorial de experimentos teve seu desenvolvimento em meados da década de 1920 a partir dos trabalhos do estatístico inglês Ronald A. Fisher realizados na Rothamsted Experimental Station, Harpender, Reino Unido. Fisher foi quem desenvolveu e usou de forma inovadora a técnica de análise de variância, mais conhecida pela sigla em inglês ANOVA (Analysis of variance), como ferramenta para a análise estatística do projeto experimental. Em seguida diversos outros pesquisadores contribuíram para o desenvolvimento desta técnica, tais como: Box, Bose, Yates, Kempthorne e Cochran (MONTGOMERY et al., 2000).

Um experimento planejado é um teste ou uma série de testes em que se induzem mudanças intencionais nas variáveis de entrada do processo ou fenômeno investigado, de tal forma que seja possível observar, identificar e quantificar os efeitos nas respostas ou nas variáveis de saída. Tradicionalmente as técnicas de planejamento e análise de experimentos são utilizadas basicamente com o objetivo de melhorar as características dos produtos ou processos de fabricação, reduzir o números de testes e ainda otimizar os recursos envolvidos nos processos de fabricação (MONTGOMERY et al., 2000).

Quando é necessário investigar o efeito provocado nas respostas de experimentos por dois ou mais fatores de controle, e cada um destes fatores possuindo dois ou mais níveis de regulagem, Juran et al. (1951) e Montgomery et al. (2000) recomendam a utilização de técnicas de planejamento tais como: planejamento fatorial completo, fatorial fracionado ou experimentos com pontos centrais. Outra metodologia muito explorada na indústria é o método Taguchi, desenvolvida pelo engenheiro japonês G. Taguchi entre as décadas de 1950 e 1960 (TAY; BUTLER, 1999). 
Para realizar este procedimento, inicialmente é necessário especificar os níveis, ou condição de operação dos fatores de controle investigadas. A quantidade de fatores associados à quantidade de níveis determinará quantos experimentos serão necessários (BARROS NETO et al., 2010).

\subsubsection{PRINCÍPIOS BÁSICOS DE PLANEJAMENTO E ANÁLISE DE EXPERIMENTOS}

Nas modelagens numéricas a avaliação e quantificação da influência de determinado parâmetro é realizada através de uma análise de sensibilidade. Existem muitas formas de se realizar tal análise, sendo uma delas o Planejamento Fatorial Completo. Este procedimento é realizado com o objetivo de concentrar as investigações geotécnicas nos parâmetros (fatores) de maior interesse, sendo possível planejar melhor a campanha de investigação e também especificar e justificar a escolha por determinado ensaio. A alternativa ao planejamento fatorial, que é frequentemente usada em estudos geotécnicos, é mudar os fatores um de cada vez ao invés de variá-los simultaneamente, este processo tem o inconveniente de necessitar de mais experimentos ao se comparar com o planejamento fatorial e não há garantia de produzir resultados corretos.

Realizar procedimentos planejados em modelagem numérica podem ser utilizados para responder uma série de questões relacionadas aos níveis e parâmetros que influenciam o comportamento e resposta dos modelos numéricos. Montgomery et al. (2000), Kaye e Frangou (1998) e Steinberg e Hunter (1984) sugerem que a solução de problemas complexos pode ser alcançada mais facilmente quando os experimentos são realizados de forma planejada e os resultados interpretados através de técnicas estatísticas.

Barker e Milivojevich (2016) ressaltam que trabalhar através de técnicas planejadas faz com que os resultados obtidos sejam mais confiáveis.

\subsubsection{CONCEITOS GERAIS UTILIZADOS EM PLANEJAMENTOS FATORIAIS}

No planejamento fatorial alguns termos bastante utilizados devem ser inicialmente definidos (MONTGOMERY et al., 2000):

a) Fatores de controle são os parâmetros que serão investigados. Neles são introduzidos os estímulos e observa-se o efeito produzido na variável de resposta, para que assim sejam determinados os principais fatores do processo;

b) Variáveis de resposta são as variáveis dependentes, as quais são o foco da pesquisa e passam por alterações durante os testes, quando estímulos são produzidos de forma proposital nos fatores;

c) Níveis são às condições de operação dos fatores de controle. Tradicionalmente os níveis são identificados por nível baixo (-1) e nível alto (+1); 
d) Efeitos podem ser entendidos como as alterações sofridas pela variável de resposta quando se altera o nível do fator em questão. Os efeitos são divididos em efeito principal (diferença média observada na resposta ao mudar o nível do fator) e efeito de interação (diferença entre os efeitos principais de um fator nos níveis de outro fator dividida por dois);

e) Interações correspondem a interdependência entre dois ou mais fatores, ou seja, caso o comportamento de um fator não seja o mesmo nos dois níveis de outro fator significa dizer que há interação entre esses fatores;

f) Matriz de experimentos trata-se de um plano formal construído para conduzir os experimentos, ela apresenta de forma clara e organizada todos os fatores de controle que serão investigados e os níveis de operação de cada um.

\subsubsection{PROCESSO PARA REALIZAR MODELAGEM NUMÉRICA APLICANDO-SE OS CONCEITOS DE PLANEJAMENTO FATORIAL DE EXPERIMENTOS}

- 1 - Definição dos objetivos da modelagem nesta primeira etapa é importante determinar qual será a resposta que será investigada, como por exemplo fator de segurança, deslocamentos entre outros;

- 2 - Parâmetros do modelo esta etapa envolve o levantamento de todas as variáveis que podem interferir na resposta do modelo. A lei constitutiva escolhida influenciará de forma determinante esta etapa;

- 3 - níveis dos parâmetros selecionadas nesta etapa deve-se estabelecer em quais níveis de operação que as variáveis independentes irão operar. No caso de se conhecer o desvio padrão de cada parâmetro investigado, ele poderá indicar os níveis extremos de operação de cada um deles;

- 4 - elaboração da matriz experimental esta quarta etapa corresponde à construção da matriz experimental que servirá para balizar e organizar valores dos parâmetros de entrada dos modelos que serão implementados. Para a construção dela devem ser considerados o número de fatores de controle e o número de níveis;

- 5 - Análise dos dados nesta etapa podem ser utilizados softwares estatísticos tais como: MINITAB, EXCEL, STATISTICA e R, pois estes auxiliam na utilização das técnicas de planejamento e análise de experimentos. Os conceitos estatísticos são aplicados nos resultados dos modelos numéricos, com o objetivo de descrever o comportamento das variáveis de controle, a relação entre elas e para estimar os efeitos produzidos nas respostas observadas (REY, 1993); 


\subsubsection{PLANEJAMENTO FATORIAL DE EXPERIMENTOS}

Ao se planejar os modelos numéricos com a técnica fatorial, considera-se que todos os tratamentos da matriz experimental sejam realizados. $O$ planejamento fatorial é indicado quando há a necessidade de se definir os fatores (parâmetros de entrada) mais importantes e assim estudar os efeitos sobre a variável escolhida.

Para ilustrar o procedimento desta técnica considere-se um experimento com dois fatores (A e B) em que cada um destes fatores será testado com $a$ níveis para o fator A e $b$ níveis para o fator $\mathrm{B}$, pode-se concluir que neste processo existem $a b$ combinações. A matriz de planejamento para o experimento fatorial descrito pode ser observada na Tabela 1. Essa organização também refere-se ao caso geral do experimento fatorial de dois fatores, para uma resposta $\left(y_{i j k}\right)$ observada quando o fator A está no $i$-ésimo nível $(i=1,2, \cdots, a)$. Em modelagem numérica não há necessidade de aletorização dos modelos, já que a resposta será sempre a mesma para um mesmo nível de operação dos parâmetros.

Tabela 1 - Experimento fatorial de dois fatores caso geral

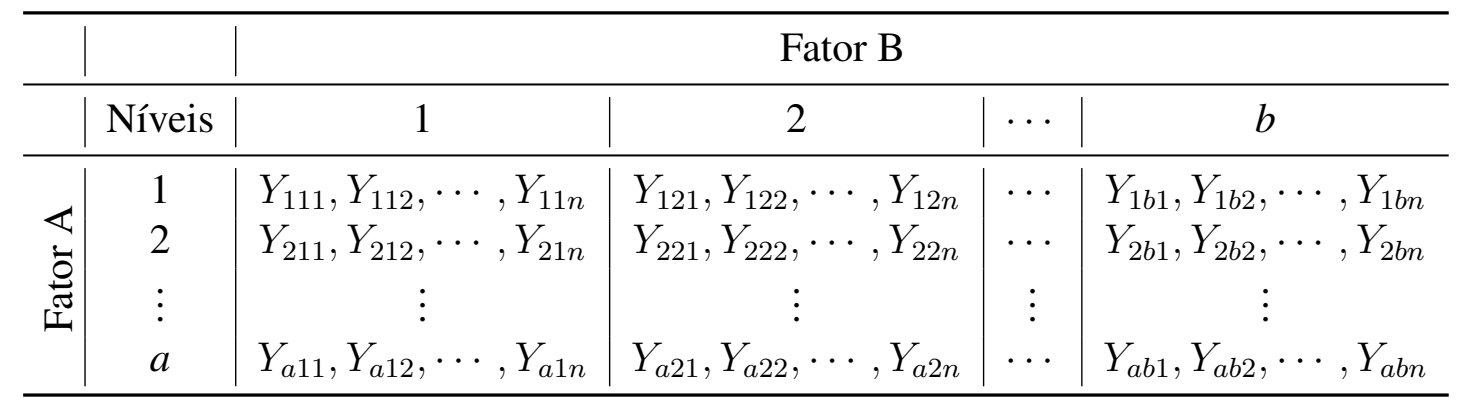

Segundo DeVor et al. (2007) com o experimento organizado conforme apresentado é possível verificar se:

- a resposta é alterada significativamente quando altera-se o nível do fator A;

- a resposta é alterada significativamente quando altera-se o nível do fator B;

- a interação entre os fatores (linha $x$ coluna) altera significativamente a resposta.

Os autores também definem que o modelo estatístico do planejamento fatorial é representado pela equação a seguir:

$$
y_{i j k}=\mu+\tau_{i}+\beta_{i}+(\tau \beta)_{i j}+\varepsilon_{i j k}
$$

onde: $\mu$ é a média dos resultados; $\tau_{i}$ é o efeito principal do fator $\mathrm{A} ; \beta_{i}$ é o efeito principal do fator $\mathrm{B} ;(\tau \beta)_{i j}$ é o efeito de interação dos fatores $\mathrm{A}$ e $\mathrm{B} \varepsilon_{i j k}$ é o erro experimental. 
Duas abordagens são possíveis de serem utilizadas para determinar os coeficientes da Equação 2.9. A primeira corresponde à um método generalizado apresentado a seguir em um exemplo de aplicação e a outra é a Análise de Variância (ANOVA), explicada na sequência, e que também pode ser utilizada para verificar os efeitos dos parâmetros na resposta da função estudada, ambos os métodos estão descritos com mais detalhes em (MONTGOMERY et al., 2000) e (DEVOR et al., 2007).

\subsubsection{PLANEJAMENTO FATORIAL $2^{k}$}

Um experimento fatorial com $k$ fatores, cada um deles operando em dois níveis, é denominado experimento fatorial $2^{k}$. Para este tipo de planejamento a quantidade de testes que devem ser realizados, considerando um planejamento completo é obtida conforme a seguinte equação:

$$
n=2^{k}
$$

onde: $n=$ quantidade de testes e $k=$ quantidade de parâmetros.

O planejamento em dois níveis é o mais simples possível e por isso os resultados podem não representar de maneira completa uma grande região no espaço das variáveis, mas mesmo assim este procedimento é vantajoso, pois permite avaliar a tendência e comportamento dos resultados proporcionando subsídios para a realização de investigações posteriores, ajudando a otimizar determinado procedimento (NEVES et al., 2002).

Para ilustrar o procedimento dessa técnica considere um experimento com quatro fatores e cada um desses parâmetros sendo testados em dois níveis $(-1,+1)$. A tabela a seguir apresenta o resultado do planejamento do experimento hipotético citado: 
Tabela 2 - Matriz de planejamento para o experimento fatorial de $2^{4}$

\begin{tabular}{c|ccccc}
\hline Combinação & Fator 1 & Fator 2 & Fator 3 & Fator 4 & Resposta \\
\hline $\mathbf{0 1}$ & - & - & - & - & $y_{1}$ \\
$\mathbf{0 2}$ & + & - & - & - & $y_{2}$ \\
$\mathbf{0 3}$ & - & + & - & - & $y_{3}$ \\
$\mathbf{0 4}$ & + & + & - & - & $y_{4}$ \\
$\mathbf{0 5}$ & - & - & + & - & $y_{5}$ \\
$\mathbf{0 6}$ & + & - & + & - & $y_{6}$ \\
$\mathbf{0 7}$ & - & + & + & - & $y_{7}$ \\
$\mathbf{0 8}$ & + & + & + & - & $y_{8}$ \\
$\mathbf{0 9}$ & - & - & - & + & $y_{9}$ \\
$\mathbf{1 0}$ & + & - & - & + & $y_{1} 0$ \\
$\mathbf{1 1}$ & - & + & - & + & $y_{1} 1$ \\
$\mathbf{1 2}$ & + & + & - & + & $y_{1} 2$ \\
$\mathbf{1 3}$ & - & - & + & + & $y_{1} 3$ \\
$\mathbf{1 4}$ & + & - & + & + & $y_{1} 4$ \\
$\mathbf{1 5}$ & - & + & + & + & $y_{1} 5$ \\
$\mathbf{1 6}$ & + & + & + & + & $y_{1} 6$ \\
\hline
\end{tabular}

A codificação dos níveis dos fatores estudados é importante devido aos seguintes fatos:

a) Apesar de não ser o caso desta pesquisa, é possível que as variáveis independentes sejam qualitativas. Desta forma, é necessário realizar a codificação para que seja possível estimar o modelo de regressão;

b) O processo matemático envolvido no procedimento necessita de inversão de matrizes para a determinação dos efeitos, quando utilizada ANOVA, dos parâmetros dos modelos. Neste processo podem ocorrer erros consideráveis de arredondamento, provocando discrepâncias nas estimativas dos parâmetros. A codificação ao facilitar o processo de inversão de matriz reduz significativamente estes erros;

c) A codificação também remove as unidades de medida dos fatores de controle e a distância ao longo dos eixos o que torna os gráficos com um aspecto melhor para serem interpretados;

d) A codificação pode eliminar problemas de multicolinearidade ${ }^{1}$ que podem induzir em erros nos coeficientes dos modelos estatísticos. A multicolinearidade diz respeito à existência de uma relação linear exata ou aproximadamente exata entre variáveis independentes. A existência da multicolinearidade implica em grandes erros ao se determinar os parâmetros da regressão linear ou impossibilidade de estimação caso a multicolinearidade seja perfeita.

1 Quando o coeficiente de regressão é alto, mas nenhum dos coeficientes de regressão é significativo, isso pode indicar multicolinearidade. 
Segundo Montgomery et al. (2000) o modelo estatístico do experimento fatorial $2^{4}$ é dado pela seguinte equação:

$$
\begin{aligned}
& y_{i j k w}=\mu+\alpha_{i}+\beta_{j}+\gamma_{k}+\tau_{w}+\left(\alpha \beta_{i j}\right)+\left(\alpha \gamma_{i k}\right)+\left(\alpha \tau_{i w}\right)+ \\
& \left(\beta \gamma_{j k}\right)+\left(\beta \tau_{j w}\right)+\left(\gamma \tau_{k w}\right)+\left(\alpha \beta \gamma_{i j k}\right)+\left(\alpha \beta \tau_{i j w}\right)+ \\
& \left(\alpha \gamma \tau_{i k w}\right)+\left(\beta \gamma \tau_{j k w}\right)+\left(\alpha \beta \gamma \tau_{i j k w}\right)+\varepsilon_{i j k w}
\end{aligned}
$$

onde: $\mu=$ média dos resultados; $\alpha_{i}=$ efeito principal do fator $x_{1} ; \beta_{j}=$ efeito principal do fator $x_{2}$; $\gamma_{k}=$ efeito principal do fator $x_{3} ; \tau_{w}=$ efeito principal do fator $x_{4} ; \alpha \beta_{i j}=$ efeito de interação entre os fatores $x_{1}$ e $x_{2} ; \alpha \gamma_{i k}=$ efeito de interação entre os fatores $x_{1}$ e $x_{3} ; \alpha \tau_{i w}=$ efeito de interação entre os fatores $x_{1}$ e $x_{4} ; \beta \gamma_{j k}=$ efeito de interação entre os fatores $x_{2}$ e $x_{3} ; \beta \tau_{j w}=$ efeito de interação entre os fatores $x_{2}$ e $x_{4} ; \gamma \tau_{k w}=$ efeito de interação entre os fatores $x_{3}$ e $x_{4} ; \alpha \beta \gamma_{i j k}=$ efeito de interação entre os fatores $x_{1}, x_{2}$ e $x_{3} ; \alpha \beta \tau_{i j w}=$ efeito de interação entre os fatores $x_{1}$, $x_{2}$ e $x_{4} ; \alpha \gamma \tau_{i k w}=$ efeito de interação entre os fatores $x_{1}, x_{3}$ e $x_{4} ; \beta \gamma \tau_{j k w}=$ efeito de interação entre os fatores $x_{2}, x_{3}$ e $x_{4} ; \beta \gamma \tau_{j k w}=$ efeito de interação entre os fatores $x_{1}, x_{2}, x_{3}$ e $x_{4}$ e $\varepsilon_{i j k w}=$ erro experimental.

No caso de modelagem numérica não faz sentido obter erros experimentais, uma vez que a repetição dos experimentos levará ao mesmo resultado, ou seja, os graus de liberdade na análise de variância são nulos bem como o termo $\varepsilon_{i j k w}$. Assim a Equação 2.11 geralmente é truncada nos termos de segunda ordem e os termos de ordem superior são somados para compor os “erros" $\left(\varepsilon_{i j k w}\right)$. Tal procedimento é válido, pois estes termos tendem a diminuir sua significância conforme se aumenta a ordem.

A seguir é apresentado o método generalizado que pode ser utilizado para a determinação dos efeitos principais e de interação dos fatores. Esse método é descrito por DeVor et al. (2007); Box e Bisgaard (1987) e Montgomery et al. (2000).

Os efeitos principais correspondem à mudança da resposta média quando o nível de um fator é alterado. O procedimento consiste em multiplicar os resultados pelos valores $\pm 1 \mathrm{de}$ cada fator, associados a coluna da matriz experimental correspondente ao efeito principal que se deseja estimar. Em seguida, os valores obtidos devem ser somados e divididos pela metade do número de ensaios realizados, conforme é ilustrado a seguir:

$$
E_{i}=\frac{\sum y_{i} \times x_{i}}{\frac{N}{2}}
$$

onde $E_{i}$ é o efeito estimado; $N$ é o número total de modelos, $\sum y_{i} \times x_{i}$ é a soma dos resultados do experimento multiplicados pelo nível do fator analisado.

Para determinar o efeito de interação, antes devem ser construídas as colunas de interações na matriz de planejamento que são obtidas através da multiplicação das colunas dos efeitos principais. Por exemplo para se obter o efeito de interação $E_{34}$, multiplica-se as colunas dos 
fatores 3 e 4 . Em seguida, os valores \pm 1 associados à coluna 34 da matriz experimental são utilizados para estimar o efeito de interação, conforme apresentado na Equação 2.12.

Embora seja simples calcular estes efeitos, muitas vezes é difícil determinar qual realmente é o fator de controle que produz uma diferença significativa nas respostas devendo-se então lançar mão de métodos gráficos. Para representar e interpretar graficamente os efeitos principais e de interação é necessário definir duas propriedades, conforme a seguir (DEVOR et al., 2007):

- o sinal $( \pm)$ indica a direção do efeito, isto é, se a resposta aumenta ou diminui com a variação do nível de (-1) para (+1);

- a magnitude indica a intensidade do efeito

A representação gráfica do efeito principal $\left(E_{i}\right)$ pode ser observada na Figura 16. Esse gráfico ilustra a variação média das respostas em função da mudança do nível $(-1,+1)$ de um fator, mantendo os outros fatores constantes.

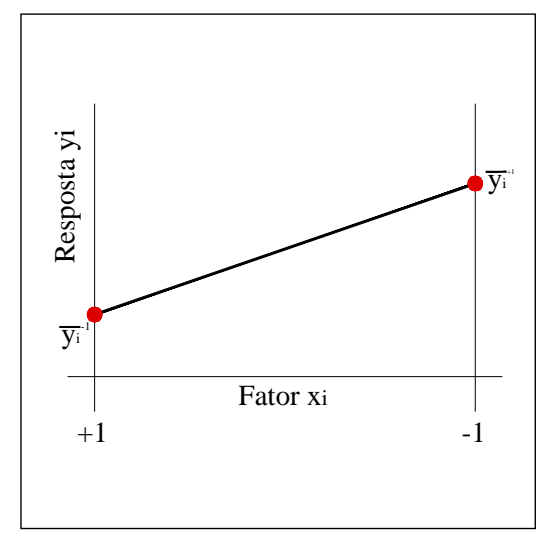

Figura 16 - Gráfico de efeitos principais, planejamento fatorial $2^{k}$.

Os gráficos dos efeitos de interação descrevem a variação média de um fator em função dos níveis de outros fatores. Por exemplo, a Figura 17a ilustra que o efeito provocado pela mudança de nível do fator $x_{1}$ na resposta depende do fator $x_{2}$, ou seja, existe interação entre os fatores $x_{1}$ e $x_{2}$, já a Figura $17 \mathrm{~b}$ mostra que o efeito provocado pela mudança do nível do fator $x_{1}$ na resposta é independente do nível do fator $x_{2}$, portanto não existe interação entre esses fatores. 


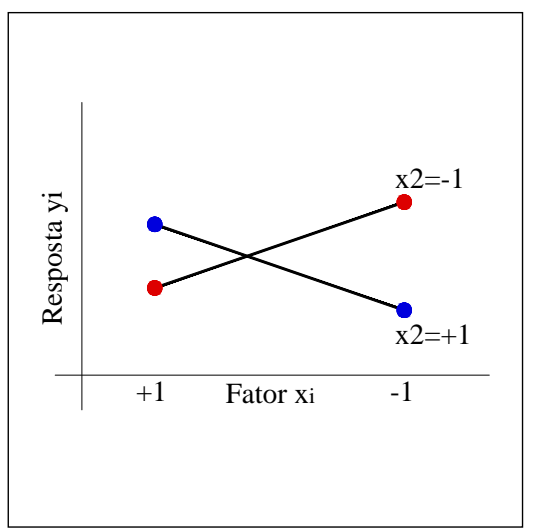

(a) Presença de interação

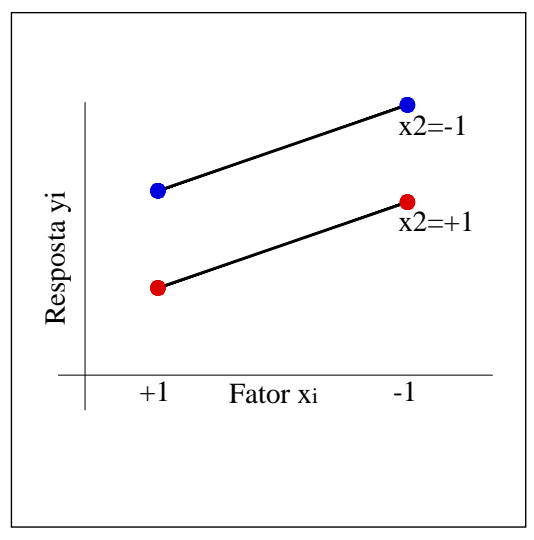

(b) Falta de interação

Figura 17 - Gráficos de Interação.

Outro gráfico que pode ser utilizado na análise dos resultados dos modelos é o de probabilidade normal. Esses gráficos são utilizados em situações em que não é possível repetir um experimento fatorial $2^{k}$, e é importante obter uma estimativa independente do erro experimental para julgar a importância dos efeitos principais e de interação (DEVOR et al., 2007). No caso de modelos numéricos, como já dito, não faz sentido a repetição, pois não vai existir variação no resultado ao se repetir o modelo sob condições preestabelecidas. Desta forma, o gráfico de probabilidade normal irá demonstrar se o modelo estatístico é capaz de fazer previsões satisfatórias.

O princípio do gráfico de probabilidade normal é baseado no fato de que tantos os efeitos principais quanto os efeitos de interação que são desprezíveis se distribuem de acordo com uma distribuição normal centrada no zero e com variância $\sigma^{2}$, isto significa dizer que esses efeitos possuem a tendência de se concentrar ao longo de uma reta. No entanto, se os pontos marcados no gráfico apresentarem grandes desvios, existem motivos para acreditar que os dados obtidos não estão distribuídos de maneira normal, portanto, são efeitos significativos que devem ser analisados com mais detalhes (LEVINE et al., 1998).

\subsubsection{EXEMPLO DE APLICAÇÃO DO PLANEJAMENTO $2^{2}$}

O planejamento $2^{2}$ considera dois fatores $A$ e $B$, cada um com dois níveis. Este planejamento é mostrado na Figura 18. Como ele é composto apenas de 4 experimentos é possível representá-lo geometricamente como um quadrado, sendo que os vértices deste quadrado representam cada experimento. 


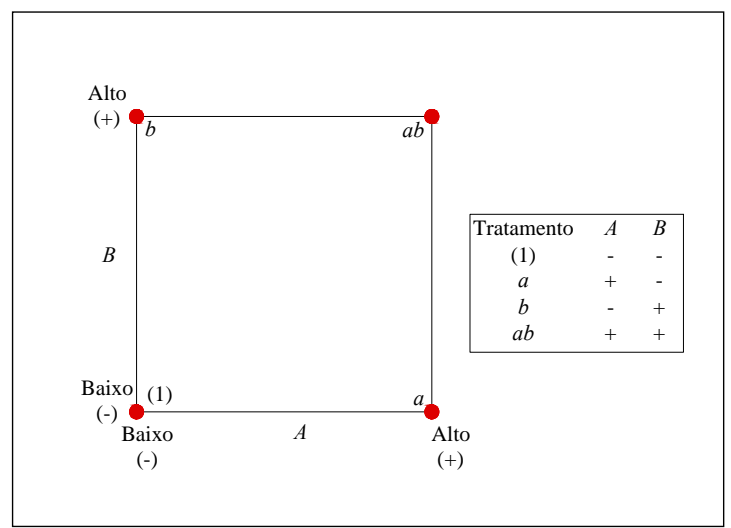

Figura 18 - Representação geométrica do planejamento $2^{2}$ (adaptado de Montgomery et al., 2000).

Em geral as combinações dos experimentos são representadas através de uma notação especial em que cada tratamento é marcado por uma letra minúscula. No caso de uma letra estar presente significa que o fator correspondente é tratado no nível alto e, se estiver ausente, o fator é tratado em seu nível baixo. Por exemplo a combinação de ambos os fatores em nível baixo é representada por (1), enquanto que a combinação de ambos os fatores em nível alto é representada por $a b$.

No planejamento $2^{2}$ os efeitos de interesse são os efeitos principais $A$ e $B$ e o efeito de interação $A B$. Estes efeitos podem ser obtidos conforme as equações a seguir:

$$
\begin{aligned}
& A=\frac{1}{2 n}[a+a b-b-(1)] \\
& B=\frac{1}{2 n}[b+a b-a-(1)] \\
& A B=\frac{1}{2 n}[a b+(1)-a-b]
\end{aligned}
$$

A Equação 2.13 é obtida fazendo a média das observações no lado direito do quadrado mostrado na Figura 18, estando $A$ no nível alto, e subtraindo desse valor a média das observações no lado esquerdo do quadrado, onde $A$ está no nível baixo.

Analogamente, o efeito principal de $B$ é obtido fazendo o mesmo procedimento anterior, porém com a parte superior e inferior do quadrado da Figura 18.

Por fim, a interação $A B$ é estimada ao realizar a diferença entre as médias das diagonais da Figura 18.

Para aplicar estes conceitos o seguinte problema é proposto: 
Uma estrutura de contenção, como mostrada na Figura 19, foi projetada e é necessário determinar qual dos fatores - peso específico do muro $(A)$ e peso específico do solo $(B)$ - é o mais influente na resposta do fator de segurança contra o deslizamento $\left(F S_{D}\right)$.

Os parâmetros dos materiais foram estimados com valores correntes utilizados em obras de engenharia. O processo foi baseado nas equações apresentadas a seguir, sendo que todas elas foram executadas com o auxílio de planilhas do Excel ${ }^{\circledR}$.

Por definição o fator de segurança contra o deslizamento do muro é dado por:

$$
F S_{D}=\frac{\sum F_{V} \operatorname{tg} \delta}{E_{a}}
$$

onde: $F_{V}=$ somatório das forças verticais; $\delta=$ ângulo de atrito entre o solo e a base do muro e $E_{a}=$ componente horizontal do empuxo ativo.

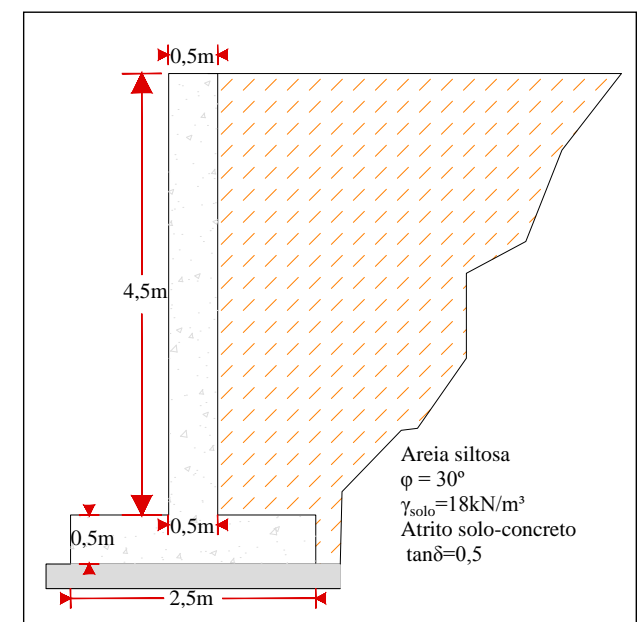

Figura 19 - Muro de contenção analisado (adaptado de Duncan, 2000).

A Figura 19 mostra um muro de arrimo em que não há ações de sobrecarga, o terrapleno é horizontal. Assim, de acordo com a teoria de Rankine a Equação 2.16 assume a forma expressa na Equação 2.17.

$$
F S_{D}=\frac{\left(3,5 \gamma_{c o n c}+4,5 \gamma_{\text {solo }}\right) \operatorname{tg} \delta}{12,5 \gamma_{\text {solo }} \operatorname{tg}^{2}\left(45-\frac{\phi}{2}\right)}
$$

onde: $\gamma_{c o n c}=$ peso específico do concreto $\left(25 \mathrm{kN} / \mathrm{m}^{3}\right) ; \gamma_{\text {solo }}=$ peso específico do solo $\left(18 \mathrm{kN} / \mathrm{m}^{3}\right)$ e $\phi=$ ângulo de atrito do solo atrás do muro.

Neste exemplo $\phi$ e $\delta$ vão ter valores constantes e $\gamma_{\text {conc }}$ (fator $A$ ) e $\gamma_{\text {solo }}$ (fator $B$ ) vão ter seus níveis ${ }^{2}$ baixo e alto definidos como mostrado na Tabela 3.

2 Quando o valor do desvio padrão for conhecido os níveis são geralmente definidos como a média menos o desvio padrão e a média mais o desvio padrão. 
Tabela 3 - Níveis baixo e alto dos fatores considerados

\begin{tabular}{c|cc}
\hline Combinação & $\gamma_{\text {conc }}$ & $\gamma_{\text {solo }}$ \\
\hline$(1)$ & 22 & 15 \\
$a$ & 28 & 15 \\
$b$ & 22 & 21 \\
$a b$ & 28 & 21 \\
\hline
\end{tabular}

Os resultados para o $F S_{D}$ aplicando-se os valores acima estabelecidos estão resumidos na Tabela 4 a seguir:

Tabela 4 - Matriz de planejamento para o Fator de segurança (codificados)

\begin{tabular}{c|ccc}
\hline Combinação & $\boldsymbol{A}\left(\gamma_{\text {conc }}\right)$ & $\boldsymbol{B}\left(\gamma_{\text {solo }}\right)$ & $F S_{D}$ \\
\hline$(1)$ & - & - & 1,16 \\
$a$ & + & - & 1,32 \\
$b$ & - & + & 0,98 \\
$a b$ & + & + & 1,10 \\
\hline
\end{tabular}

Aplicando-se as Equações 2.13, 2.14 e 2.15, obtém-se os resultados mostrados no diagrama de Pareto da Figura 20a, ele indica que o fator $B$ (peso específico do solo) é o mais significativo, pois uma mudança do nível mais baixo para o nível mais alto faz com que o $F S_{D}$ diminua de 0,2 , já o parâmetro $A$ (peso específico do concreto) ao passar do nível mais baixo para o mais alto o fator de segurança aumenta 0,14. Analisando-se a Figura 20b pode-se concluir há interação entre os fatores, pois as retas possuem coeficientes angulares distintos e que o fator de segurança é altamente sensível à variações de ambos os fatores uma vez que as retas apresentam elevada inclinação.

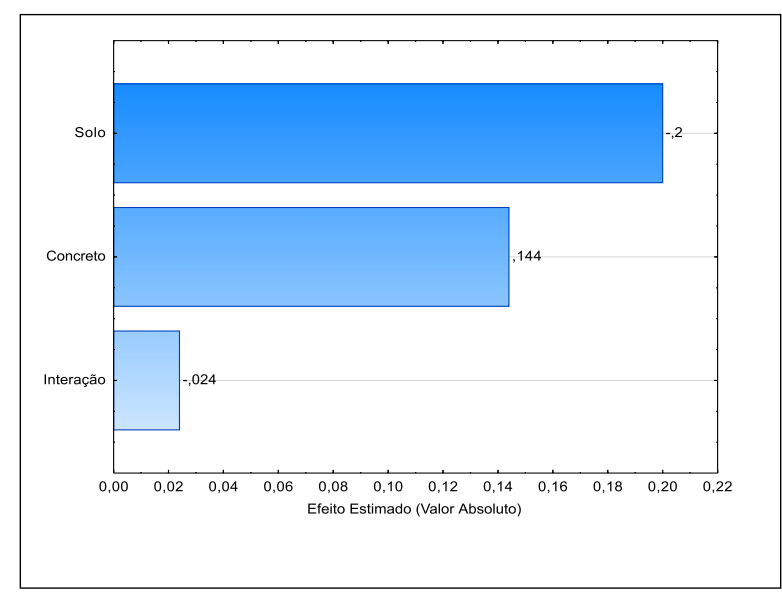

(a) Diagrama de Pareto

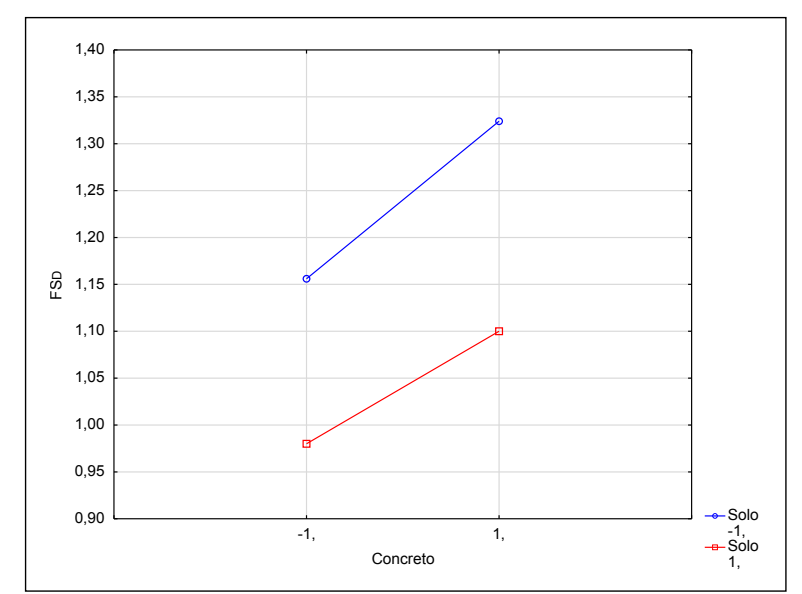

(b) Gráfico de interação

Figura 20 - Gráficos resultantes da análise do muro de arrimo. 


\subsubsection{ANÁLISE DE VARIÂNCIA DOS EFEITOS DE EXPERIMENTOS FATORIAIS $2^{k}$}

A ANOVA pode ser entendida como uma técnica estatística usada para comparação de mais de níveis de uma ou mais variáveis de teste. $\mathrm{O}$ objetivo dela é analisar a variação média dos resultados dos modelos e assim demonstrar quais são realmente os parâmetros que produzem efeitos, sejam eles principais ou de interações, significativos na resposta do fenômeno investigado.

DeVor et al. (2007) e Montgomery et al. (2000) propõem uma sequência de passos que podem ser utilizadas para conduzir o teste de hipótese de experimentos (principal etapa da ANOVA), são eles:

- Formulação das hipóteses - A primeira hipótese é conhecida como hipótese nula $\left(H_{0}\right)$. Essa hipótese considera que não existe diferença significativa entre as variáveis, ou seja, as médias amostrais não possuem diferença significativa e, portanto, podem ser consideradas de uma mesma população. A hipótese alternativa $\left(H_{1}\right)$ só será verdadeira caso a hipótese nula seja considerada falsa;

- Obter o valor crítico da estatística de teste: durante o desenvolvimento das hipóteses dos testes é necessário que seja calculada uma estatística específica, com base no resultado da amostra. Este processo pode ser auxiliado por softwares estatísticos. Muitas distribuições estatísticas, como $t$-Student, Z-Standard, F-Fisher, etc. podem ser usadas para se determinar a probabilidade de uma hipótese nula ser considerada verdadeira (MONTGOMERY et al., 2000).

Para proceder com a ANOVA é necessário a obtenção dos seguintes parâmetros estatísticos (média e soma dos quadrados dos desvios):

$$
\bar{y}=\frac{\sum_{i=1}^{N} y_{i}}{N}
$$

Soma dos quadrados totais:

$$
S Q_{T}=\sum_{i=1}^{N}\left(y_{i}-\bar{y}\right)^{2}
$$

Soma dos quadrados dos erros:

$$
S Q_{E}=\sum_{i=1}^{N}\left(y_{i}-y_{r i}\right)^{2}
$$

Soma dos quadrados dos resíduos:

$$
S Q_{R}=\sum_{i=1}^{N}\left(y_{r i}-\bar{y}\right)^{2}
$$




$$
S Q_{T}=S Q_{R}+S Q_{E}
$$

onde: $N$ é o número total de observações, $y_{i}$ é a resposta do modelo e $y_{r i}$ a previsão do modelo para o valor $y_{i}$. Como já citado anteriormente, no caso de modelos numéricos $y_{r i}=0$

De posse destes parâmetros é possível construir a Tabela 5. Nesta tabela, $M S_{R}$ e $M S_{E}$ são os quadrados médios (variâncias) e $p$ é o número de parâmetros estimados do modelo.

Tabela 5 - Tabela de análise da variância (ANOVA)

\begin{tabular}{c|cccc}
\hline Fonte devariação & Soma de Quadrados & g.l. & Quadrados médios & Estatística F \\
\hline \multirow{2}{*}{ Modelo } & $S Q_{R}$ & $(p-1)$ & $M S_{R}=\frac{S Q_{R}}{p-1}$ & $F=\frac{M S_{R}}{M S_{E}}$ \\
Erro & $S Q_{E}$ & $(N-p)$ & $M S_{R}=\frac{S Q_{E}}{N-p}$ & \\
Total & $S Q_{T}$ & $(N-1)$ & & \\
\hline
\end{tabular}

A estatística $F$ é utilizada para concluir sobre a rejeição ou não da hipótese nula. Ela é comparada com um valor tabelado $F_{\alpha},{ }_{(p-1)},{ }_{(N-p)}$, correspondente à distribuição padrão de Fisher. Para tal é necessário fixar um nível de significância $\alpha$ para um teste com $(p-1)$ graus de liberdade da soma $S Q_{R}$ e $(N-p)$ graus de liberdade da soma $S Q_{E}$. Caso a estatística obtida seja maior que a tabelada, rejeita-se a hipótese nula e o procedimento de aproximação está estatisticamente validado. Contudo, é possível que apesar apesar de uma regressão estar estatisticamente válida do ponto de vista do teste F, o modelo obtido não seja útil para se realizar previsões. Desta forma Box e Bisgaard (1987) sugerem que para que modelo seja não apenas estatisticamente significativo, mas também útil para previsões, o valor da métrica $F$ deve ser maior do que pelo menos quatro vezes o valor de $F_{\alpha},{ }_{(p-1)},{ }_{(N-p)}$ obtido nas tabelas de Fisher.

\subsubsection{GRÁFICO DE PROBABILIDADE NORMAL}

Para que os tratamentos estatísticos proporcionem estimativas confiáveis é necessário que a distribuição assumida ou arbitrada para o conjunto de dados tratados seja igual a distribuição real destes dados. Uma forma eficiente de verificar se tal premissa é válida é construir um gráfico de probabilidade (MONTGOMERY et al., 2000).

A premissa básica de um gráfico de probabilidade é comparar duas distribuições de probabilidade: a função de distribuição da amostra com uma função de distribuição teórica ou arbitrada. No caso de se escolher a distribuição normal como a função teórica o gráfico será chamado de gráfico de distribuição normal. Este gráfico está baseado na hipótese de que se a distribuição na qual ele foi construído estiver correta, seus pontos estarão próximos de uma linha reta, caso contrário os pontos apresentarão um padrão substancialmente diferente de um padrão linear. 
Um gráfico de probabilidade normal é construído obedecendo-se a seguinte relação matemática:

$$
y=\sigma x+\mu
$$

onde: $\sigma$ é o desvio padrão e $\mu$ é a média.

Desta forma, um gráfico que apresenta pontos próximos da reta definida pela equação 2.23 sugere que a suposição de um distribuição populacional normal é admissível.

\subsubsection{CONCLUSÕES SOBRE O PLANEJAMENTO FATORIAL}

A rigor todos os experimentos são planejados. Contudo, alguns são planejados de forma equivocada o que acaba produzindo resultados ineficientes (MONTGOMERY et al., 2000). O planejamento fatorial de experimentos por ser um processo sistemático proporciona uma clareza científica para o processo de pesquisa nas mais diversas áreas, pois trata estatisticamente o conjunto de dados. A partir de uma adequada aplicação deste método pode-se direcionar a pesquisa, indicar o tamanho da amostra que deve ser selecionada e também facilitam o desenvolvimento e crítica dos modelos estudados. Como vantagens e desvantagens deste método podem ser citados:

a) Vantagens:

- Avaliar o efeito de um grande número de variáveis;

- Não necessita de muitos cenários para serem avaliados;

- Permite avaliar a interação entre os parâmetros;

- Permite análise com variáveis qualitativas;

- Representação do processo estudado através de expressões matemáticas;

- Permite realizar estudos de otimização.

b) Desvantagens:

- Quando avaliados mais de 3 fatores a visualização dos resultados é complexa;

- Análises com mais de dois níveis necessitam de muitos testes. 



\section{METODOLOGIA}

A metodologia proposta consiste de quatro etapas:

a) Desenvolvimento da revisão bibliográfica, abordando os seguintes tópicos:

- Principais métodos de escavação de túneis;

- Modelos bidimensionais mais utilizados na análise de escavações para determinação de deslocamentos radiais nas paredes dos túneis;

- Apresentar e aplicar o planejamento fatorial de experimentos.

b) Validação dos modelos numéricos de interesse por comparação com modelos analíticos e com modelos físicos em centrífuga;

c) Emprego de análise numérica para a previsão de deslocamentos no topo da escavação;

d) Ajuste de um modelo matemático simplificado para a previsão do deslocamento no topo da escavação aplicando o planejamento fatorial de experimentos e análise de variância; 


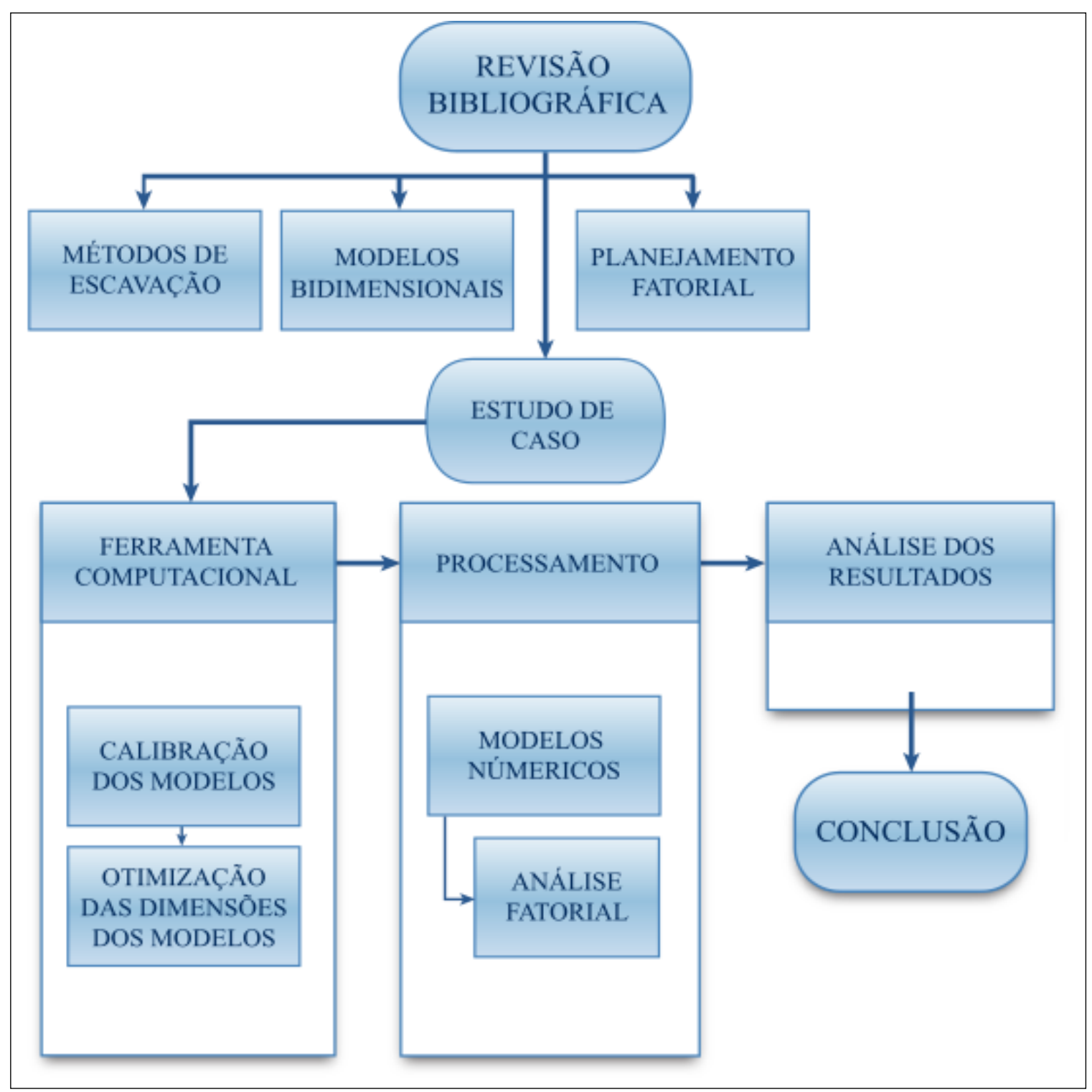

Figura 21 - Etapas da metodologia proposta

\subsection{MODELOS NUMÉRICOS}

Todos os modelos numéricos bidimensionais foram considerados em estado plano de deformações e foram realizados conforme descrito a seguir:

\subsection{MATERIAIS}

O primeiro estudo, realizado em meio elástico linear para comparação com a solução de Kirsch (1898), considerou os parâmetros e intervalos de variação apresentados na 6:

Para o segundo estudo o comportamento reológico adotado para o solo é o de MohrCoulomb. Os modelos foram elaborados utilizando os parâmetros geotécnicos presentes no trabalho desenvolvido por Atkinson e Potts (1977) e também por Delgado (2009) e estão apresentados na Tabela 7. 
Tabela 6 - Parâmetros de referência para o meio elástico

\begin{tabular}{l|cccc}
\hline Parâmetro & Símbolo & Limite Inferior & Limite Superior & Unidade \\
\hline Peso específico & $\gamma_{s}$ & 15,0 & 20,0 & $k N / m^{3}$ \\
Módulo de Elasticidade & $E_{s}$ & 40,0 & 60,0 & $\mathrm{MPa}$ \\
Relação C/D & $C / D$ & 0,50 & 3,0 & - \\
Coeficiente de empuxo & $K_{0}$ & 0,50 & 1,0 & - \\
\hline
\end{tabular}

Tabela 7 - Parâmetros de referência para o solo (adaptado de Atkinson e Potts, 1977; Delgado, 2009)

\begin{tabular}{l|ccc}
\hline Parâmetro & Símbolo & Valor & Unidade \\
\hline Peso específico & $\gamma_{s}$ & 16,1 & $\mathrm{kN} / \mathrm{m}^{3}$ \\
Módulo de Elasticidade & $E_{s}$ & 30 & $\mathrm{MPa}$ \\
Coeficiente de Poisson & $\nu_{s}$ & 0,30 & - \\
Ângulo de Atrito & $\phi_{s}$ & $45^{1}$ & $\mathrm{Graus}$ \\
Dilatância & $\psi_{s}$ & 45 & $\mathrm{Graus}$ \\
Coesão & $c^{\prime}$ & $1^{2}$ & $\mathrm{kPa}$ \\
Coeficiente de empuxo & $K_{0}$ & 1 & - \\
\hline
\end{tabular}

\subsection{GEOMETRIA}

A geometria destes modelos leva em consideração o plano de simetria conforme apresentado na Figura 22.

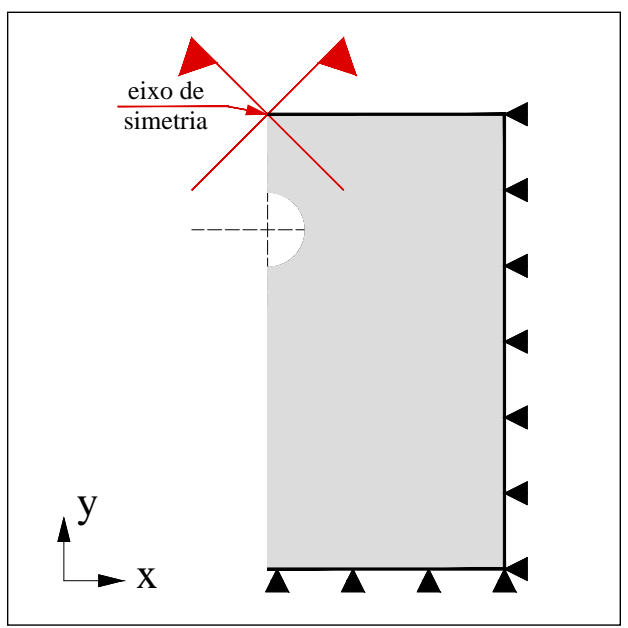

Figura 22 - Eixo de simetria dos modelos numéricos bidimensionais realizados.

Os modelos considerados em meio elástico foram implementados com a geometria mostrada na Figura 23:

1 O autor menciona em (ATKINSON; POTTS, 1977) que este é um valor conservador para o material granular em questão.

2 Apesar do material não estar saturado este é um valor muito pequeno podendo ser considerado como praticamente nulo. 


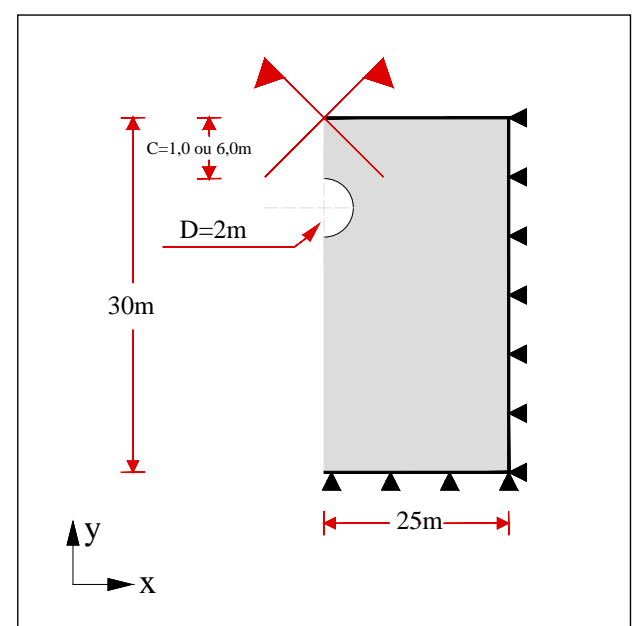

Figura 23 - Geometria do modelo bidimensional considerado em meio elástico.

Cada modelo numérico bidimensional do estudo de caso, foi implementado con condições praticamente idênticas às do modelo anterior, com diferença apenas nas dimensões do conforme apresentado na Figura 24. Tais dimensões foram determinadas com base nas calibrações e nas informações presentes no trabalho de Atkinson e Potts (1977).

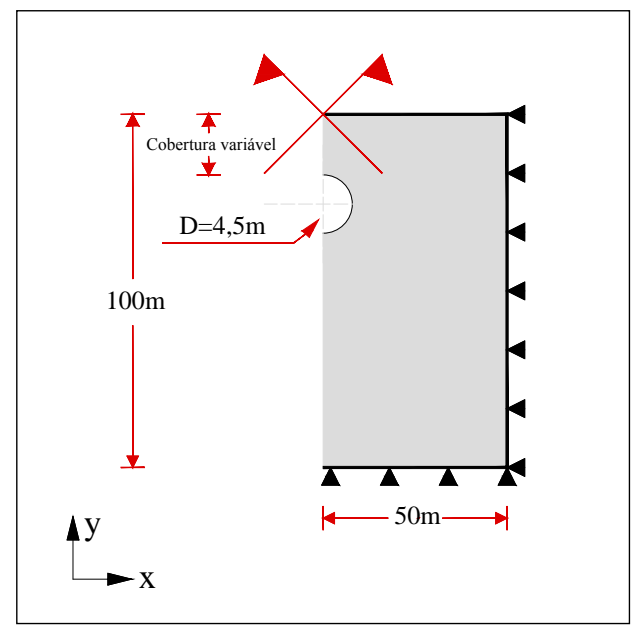

Figura 24 - Geometria do modelo bidimensional considerado em meio elastoplástico.

\subsection{CONDIÇÕES DE CONTORNO}

Supondo que os modelos sejam suficientemente extensos, foram adotadas as seguintes condições de contorno, de acordo com o sistema de referência ${ }^{1}$ indicado nas Figuras 23 e 24:

a) Topo - sem restrição alguma;

b) eixo de simetria - XSYMM(U1=UR2=UR3=0);

c) base do modelo $\mathrm{U} 2=0$;

1 O Abaqus 6.14 ${ }^{\circledR}$ adota uma convenção em que U significa deslocamento e UR significa rotação. Os eixos são representados por números da seguinte forma: $x=1, y=2$ e $z=3$. Por exemplo: U1 refere-se ao deslocamento no sentido do eixo $x$ e UR3 refere-se a rotação em torno do eixo $z$. 
d) lateral direita do modelo $\mathrm{U} 1=0$.

\subsection{MALHA}

Em todos os modelos utilizou-se o elemento CPE4R - quadrilátero bilinear de quatro nós para estado plano de deformação.

Na região próxima a escavação há uma densidade maior de elementos para se adequarem melhor a geometria circular. Já no restante do modelo foram utilizados elementos maiores e de tamanho variável, por não se tratar de uma região de interesse. Esse procedimento faz com que a topologia da malha fique otimizada tornando a análise numérica mais ágil. A malha utilizada está mostrada na Figura 25.

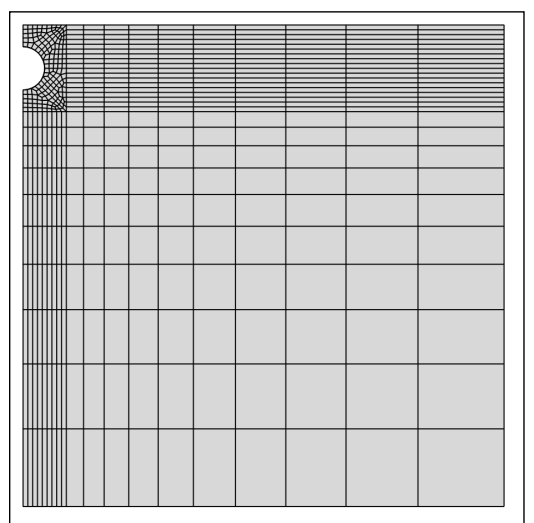

(a) Modelo completo.

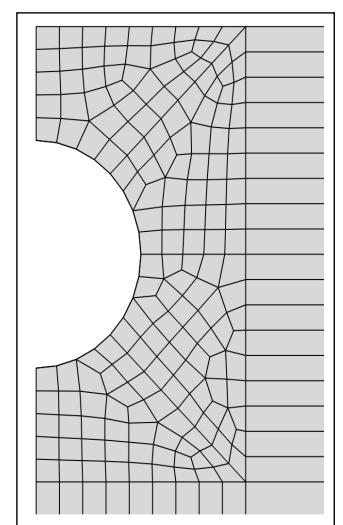

(b) detalhe da região da escavação

Figura 25 - Malha de elementos finitos utilizada nos modelos numéricos.

\subsection{CARREGAMENTOS}

Inicialmente, os modelos foram carregados com as tensões geostáticas. Essas tensões iniciais foram determinadas pelo software com o recurso Predefined Fields.

A pressão fictícia interna somente foi aplicada nos modelos que consideram o comportamento reológico de Mohr-Coulomb.

Todo o processo de escavação foi realizado com o recurso de desativação de parte da geometria, disponível no Abaqus $6.14^{\circledR}$.

\subsection{ESTUDO DE CASO}

As obras geotécnicas são complexas de serem avaliadas devido às grandes dimensões envolvidas e por conta do comportamento não linear dos solos e rochas que depende fundamentalmente da tensão geostática e do histórico de tensões. Assim, investigar essas obras através de modelos em escala reduzida é uma alternativa economicamente atraente além de proporcionar 
a possibilidade de criar um ambiente controlado e instrumentado. Entretanto, com a redução da escala é necessário criar um artifício para que o modelo reduzido tenha um comportamento semelhante com o problema real.

É nesse contexto que surge o conceito de modelagem centrífuga, que tem como princípio rotacionar o modelo físico reduzido e, com isso, através da força centrípeta, criar um campo gravitacional capaz de produzir tensões geostáticas semelhantes às encontradas in situ. As primeiras centrífugas foram construídas nos Estados Unidos para auxiliar nos estudos de problemas relacionados à mineração (BUCKY, 1931).

A modelagem experimental realizada em centrífuga proporciona informações úteis para a compreensão de mecanismos de deformação e ruptura e, também, é um elemento fundamental para validar resultados obtidos através de modelos numéricos. Este tipo de abordagem experimental passou a ser popular em pesquisas envolvendo escavações subterrâneas a partir de 1970 e deu subsídios para o desenvolvimento de métodos empíricos (e.g. Peck (1969)).

Outro benefício proporcionado pela modelagem experimental em centrífuga foi o desenvolvimento das abordagens teóricas para análise de projetos de túneis, pois ela proporcionou uma melhor compreensão dos fenômenos envolvidos durante uma escavação.

A abordagem teórica, desenvolvida em paralelo à experimental, dividiu-se nos métodos de análise limite e nos métodos de equilíbrio limite.

A análise limite considera as relações entre tensões e deformações dos solos e permite que sejam obtidas soluções exatas para a carga de colapso. Essas soluções baseiam-se nos teoremas de limite superior e inferior, que admitem para o material um comportamento rígido-plástico, ou elastoplástico perfeito com fluxo associado.

A solução de limite superior, fornece uma capacidade resistente do maciço acima ou igual ao valor real. Desta forma, um limite superior é um mecanismo de ruptura cinematicamente admissível para o qual o trabalho das forças exteriores aplicadas seja superior ou igual ao trabalho total dissipado dentro do sistema.

Já as soluções de limite inferior fornecem resultados mais conservadores, pois neste tipo de abordagem é necessário estabelecer um campo de tensões que satisfaça as equações de equilíbrio, as condições de contorno e o critério de ruptura escolhido.

Atkinson e Potts (1977) realizaram uma modelagem experimental na centrífuga da Universidade de Cambridge. O trabalho em questão teve como objetivo avaliar a estabilidade de túneis rasos não revestidos escavados em solos granulares. $\mathrm{O}$ material utilizado nos experimentos é uma areia seca denominada Leigthton Buzzard.

As dimensões do protótipo utilizado pelos autores na modelagem experimental em centrífuga estão mostradas na Figura 26. 


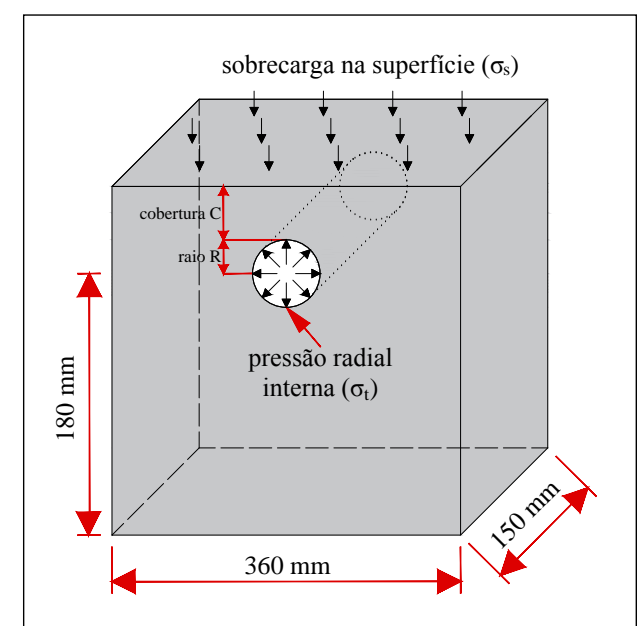

Figura 26 - Dimensões do protótipo utilizado na modelagem em centrífuga (adaptado de Atkinson e Potts, 1977).

A modelagem experimental em centrífuga foi conduzida com uma aceleração constante de $75 \mathrm{~g}$. O modelo físico dispunha de um túnel com $60 \mathrm{~mm}$ de diâmetro, que nesta aceleração corresponde a um túnel com 4,5 m de diâmetro na gravidade terrestre.

As características do ensaio correspondem a uma condição de escavação não revestida, sendo assim ele pode ser representado numericamente através de um modelo bidimensional em estado plano de deformações.

Considerando túneis não revestidos em condições drenadas Atkinson e Potts verificaram a ruptura local é mais comum para estes casos e possuí geometria como apresentada na Figura 36. Estes autores consideraram este mecanismo de ruptura e então determinaram uma solução de limite superior para um solo granular com fluxo de escoamento associado, ou seja angulo de dilatância numericamente igual ao ângulo de atrito, conforme a equação a seguir:

$$
\frac{\sigma_{t}}{\gamma D}=\frac{1}{4 \cos \varphi^{\prime}}\left[\frac{1}{\tan \varphi^{\prime}}+\varphi^{\prime}-\frac{\pi}{2}\right]
$$

A Equação 3.1 será válida sempre que a cunha apresentada na Figura 36 não atingir a superfície, condição garantida sempre que:

$$
\frac{C}{D}=\frac{1}{2}\left(\frac{1}{\operatorname{sen} \varphi^{\prime}}-1\right)
$$

Neste mesmo trabalho, Atkinson e Potts deduziram soluções de limite inferior para a pressão de suporte mínima $\sigma_{t}$ para o material citado. A solução geral considerando $\gamma \neq 0$ e $\sigma_{s} \neq 0$ é expressa através da Equação 3.3.

$$
\sigma_{t}=\frac{D}{2\left(K_{p}-2\right)}\left[\left(\frac{D}{D+2 C}\right)^{K_{p}-2}\left(\left(\frac{\sigma_{s}}{D / 2+C}+\frac{2 \gamma}{K_{p}}\right)\left(K_{p}-2\right)+\gamma\right)-\gamma\right]
$$


A Equação 3.3 pode ser substituída pela Equação 3.4 quando $\gamma=0$ ou pela Equação 3.5 quando $\sigma_{s}=0$.

$$
\begin{gathered}
\sigma_{t}=\sigma_{s}\left(1+\frac{2 C}{D}\right)^{1-K_{p}} \\
\frac{\sigma_{t}}{\gamma D}=\frac{1}{2\left(K_{p}-2\right)}\left[\left(\frac{D}{D+2 C}\right)^{K_{p}-2}\left(3-\frac{4}{K_{p}}\right)-1\right]
\end{gathered}
$$

No caso em que não há sobrecarga superficial $\left(\sigma_{s}\right)$, Atkinson e Potts propuseram um equação alternativa à Equação 3.5:

$$
\frac{\sigma_{t}}{\gamma D}=\frac{K_{p}}{K_{p}^{2}-1}
$$

onde: $K_{p}=$ coeficiente de empuxo passivo de Rankine; $C=$ cobertura do túnel; $D=$ diâmetro do túnel; $\sigma_{t}=$ pressão radial interna ao túnel; $\sigma_{s}=$ sobrecarga na superfície e $\gamma=$ peso específico do solo.

Pelo fato do termo que corresponde à cobertura do túnel estar no denominador da equação 3.5 fica claro que esta equação representa o comportamento de túneis rasos (mecanismo de ruptura global) enquanto que a Equação 3.4 é mais adequada para túneis profundos (mecanismo de rupturalocal).

Os gráficos das Figuras 27 e 28 evidenciam que as previsões de Atkinson e Potts (1977) estão de acordo com os resultados experimentais obtidos através da modelagem em centrífuga.

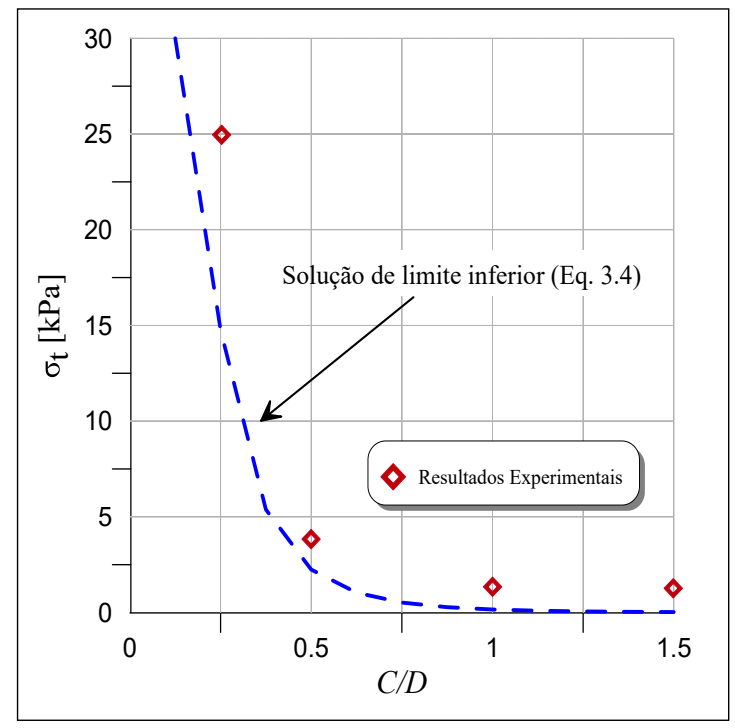

Figura 27 - Comparação dos resultados experimentais com a solução de limite inferior proposta por Atkinson e Potts (1977) - $\varphi^{\prime}=50^{\circ}, \sigma_{s}^{\prime}=210 \mathrm{kPa}$. 


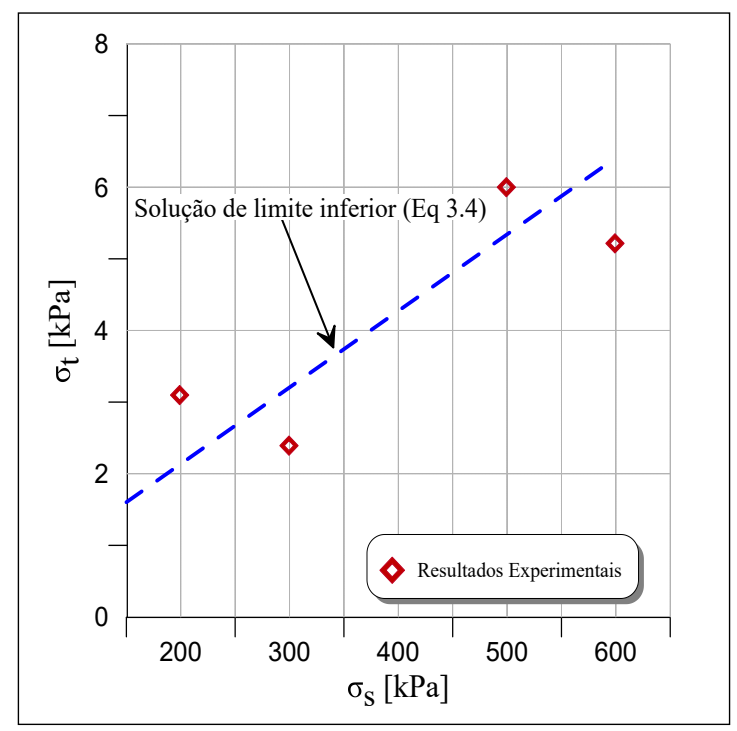

Figura 28 - Comparação dos resultados experimentais com a solução de limite inferior proposta por Atkinson e Potts (1977) $-\varphi^{\prime}=50^{\circ}, C / D=0,5$.

Os autores ainda afirmam que as soluções propostas podem ser aplicadas em areias saturadas, desde que a distribuição de pressões no maciço circundante ao túnel seja conhecida e esteja em regime estacionário. Desta forma, a pressão de colapso corresponderia a soma entre as pressões obtidas pelas soluções propostas com a pressão neutra.

Apesar das soluções propostas por Atkinson e Potts (1977) não levarem em conta a contribuição da coesão a Equação 3.6 fornece um resultado a favor da segurança, conforme descrito em Atkinson et al. (1974).

\subsubsection{RESULTADOS}

A Figura 29 mostra os resultados obtidos ao realizar três modelos com a relação entre cobertura e diâmetro iguais a: $C / D=0,5 ; C / D=1,0$ e $C / D=1,5$, na iminência da ruptura, com pressão interna determinada conforme procedimento descrito a seguir.. Na mesma imagem ainda estão mostrados os resultados obtidos por Atkinson e Potts (1977) e Delgado (2009). 


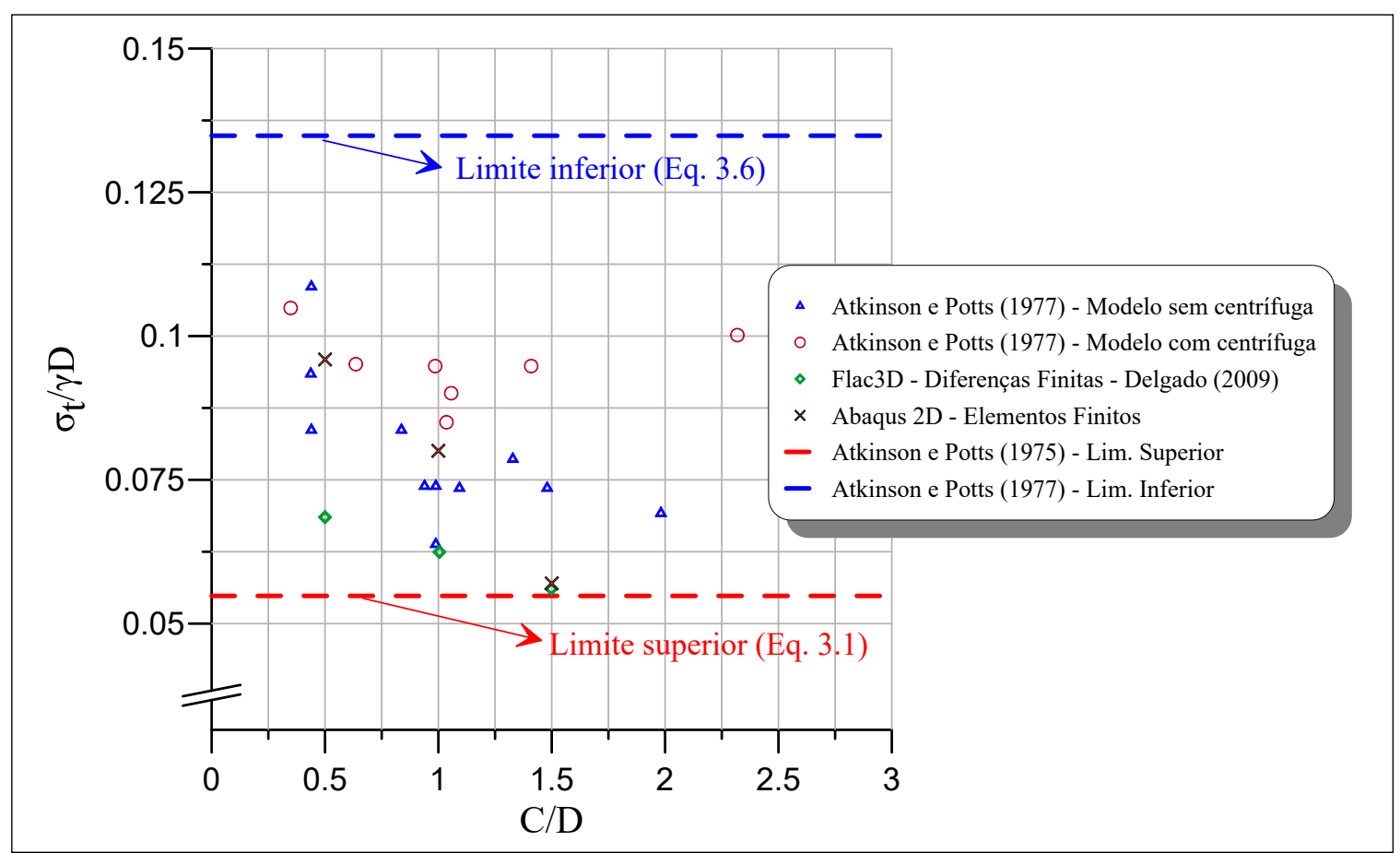

Figura 29 - Comparação entre os resultados obtidos a partir dos modelos realizados e os resultados apresentados por Atkinson e Potts.

A pressão de suporte mínima foi obtida conforme metodologia descrita por Vermeer et al. (2002b) que consiste em diminuir a pressão de suporte aplicada no túnel sistematicamente até que se observe um deslocamento abrupto do topo do túnel, em alguns casos é discutível o que deve ser considerado um aumento expressivo do deslocamento entre sucessivas diminuições de pressão. Assim, quando não foi possível identificar esta condição, a pressão de suporte mínima foi considerada a menor pressão em que o modelo ainda apresentasse convergência. Os resultados deste procedimento estão mostrados nas Figuras 30, 31 e 32. 


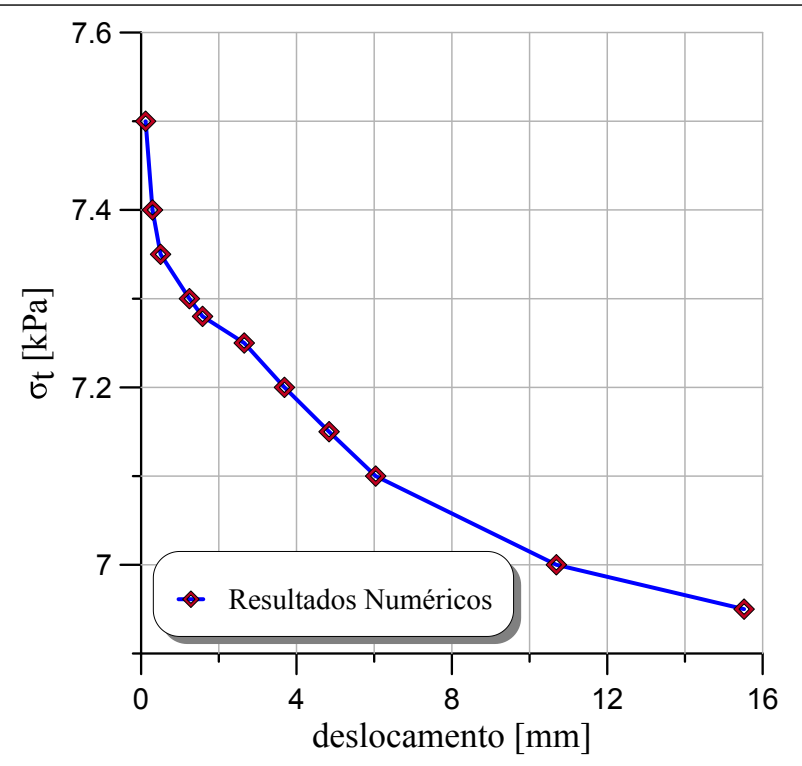

Figura 30 - Variação da pressão x deslocamento para relação $C / D=0,5$.

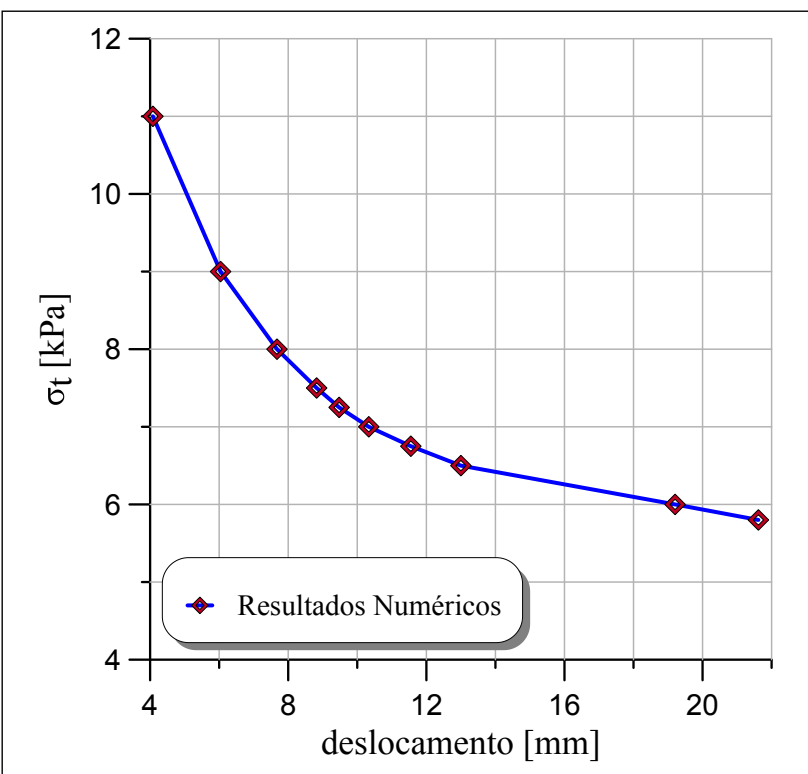

Figura 31 - Variação da pressão x deslocamento para relação $C / D=1,0$. 


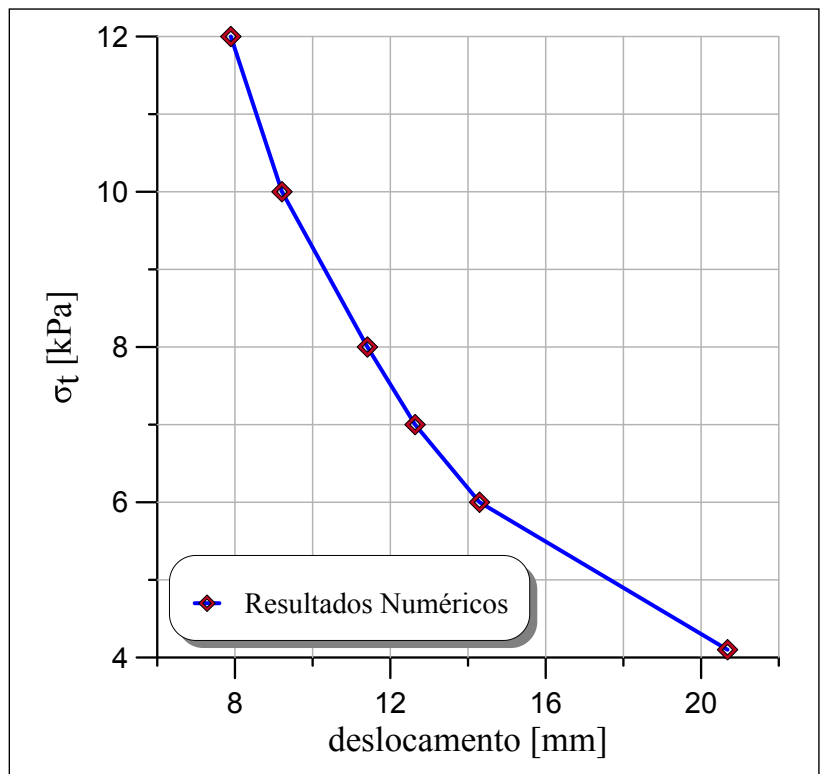

Figura 32 - Variação da pressão x deslocamento para relação $C / D=1,5$.

É possível observar um bom enquadramento entre os resultados experimentais e os realizados numericamente, conforme mostrado na Figura 29. Ainda que os resultados experimentais apresentem uma grande dispersão, estes sempre estão dentro dos limites das soluções de limite inferior e superior. É possível observar que o mecanismo de ruptura mostrado nas Figuras 33, 34 e 35, obtido através dos modelos numéricos ao restringir os deslocamentos na metade inferior (invert) da escavação também estão de acordo com o mecanismo de ruptura proposto por Atkinson e Potts (1977) (Figura 36). 


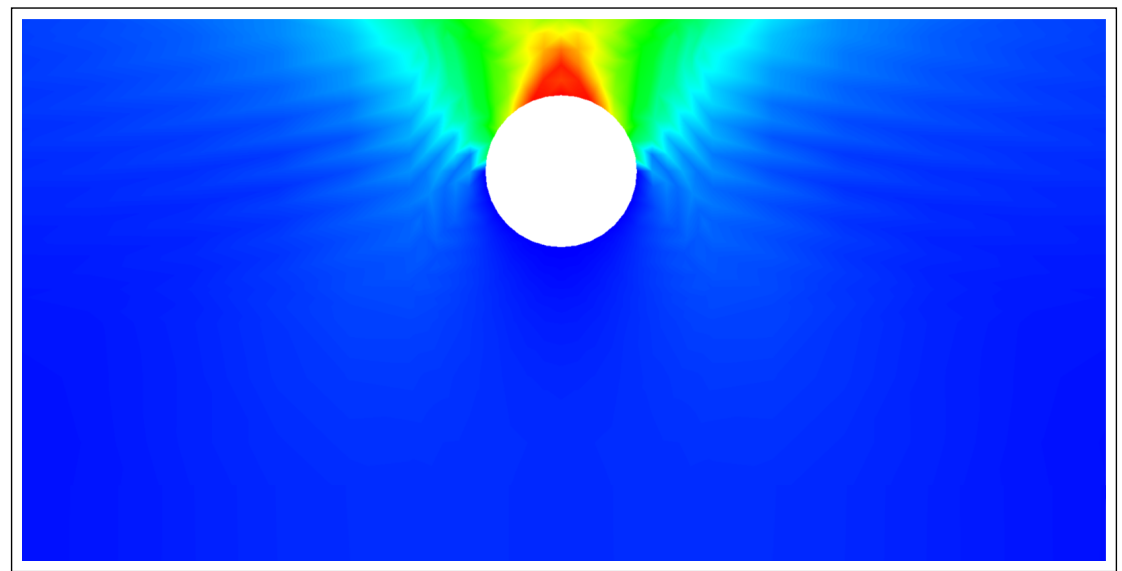

Figura 33 - Deslocamentos na ruptura - $C / D=0,5$.

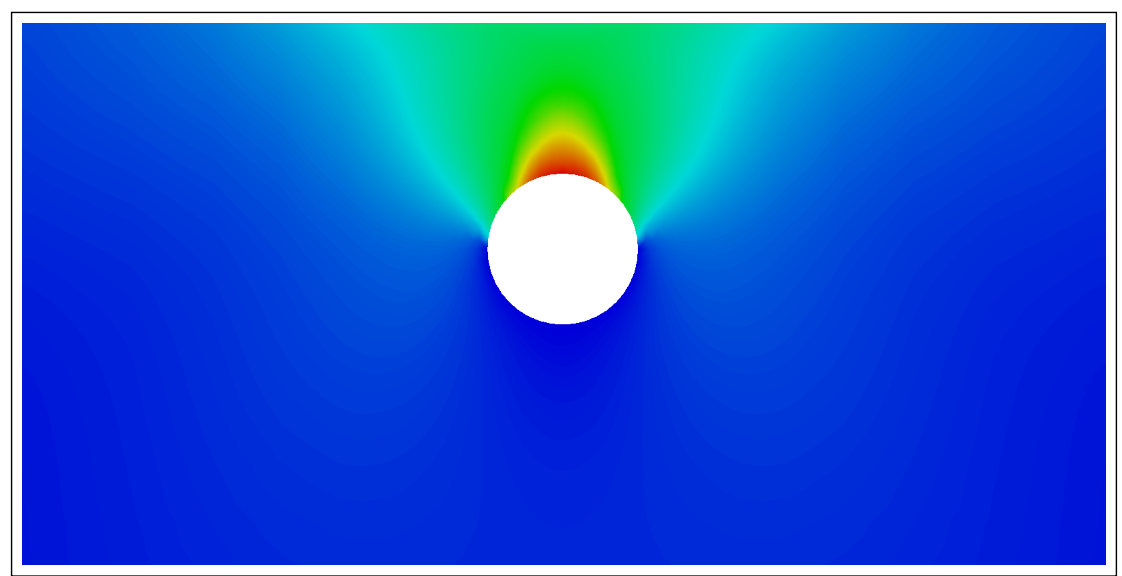

Figura 34 - Deslocamentos na ruptura $-C / D=1,0$.

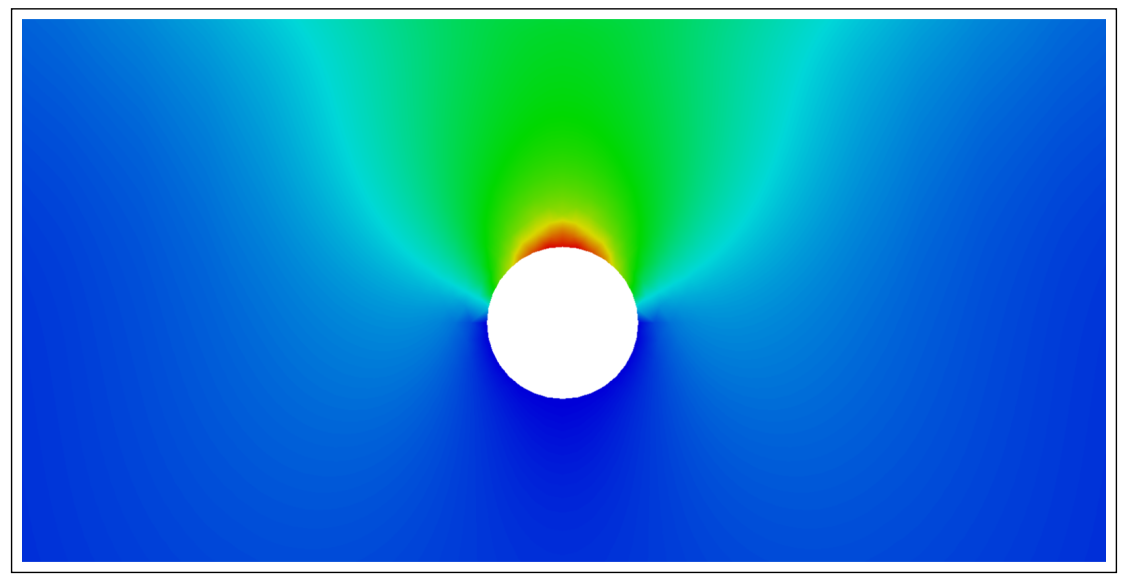

Figura 35 - Deslocamentos na ruptura - $C / D=1,5$. 


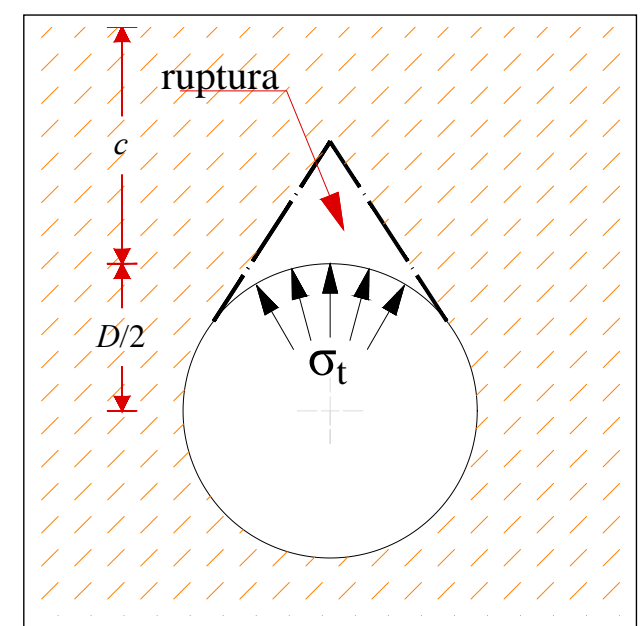

Figura 36 - Mecanismo de ruptura (adaptado de Atkinson e Potts, 1977). 


\section{RESULTADOS}

Neste capítulo serão apresentados os resultados das análises utilizando o planejamento fatorial para o estudo de caso e para o modelo elástico linear.

\subsection{MODELO ELÁSTICO LINEAR}

A tabela a seguir apresenta os deslocamentos obtidos no topo e na lateral da escavação para as diversas combinações entre os parâmetros elásticos.

Tabela 8 - Deslocamentos obtidos a partir das combinações do planejamento fatorial para os parâmetros elásticos envolvidos no modelo.

\begin{tabular}{c|c|c|c|c|c}
\hline \multicolumn{4}{c}{ Parâmetros } & \multicolumn{3}{c}{ Deslocamentos [mm] } \\
\hline$E$ & $\gamma$ & $C / D$ & $K_{0}$ & Lateral & Teto \\
\hline- & - & - & - & 1,11 & 0,12 \\
+ & - & - & - & 0,74 & 0,08 \\
- & + & - & - & 0,15 & 0,16 \\
+ & + & - & - & 0,99 & 0,11 \\
- & - & + & - & 1,18 & 3,22 \\
+ & - & + & - & 0,79 & 2,15 \\
- & + & + & - & 1,57 & 4,26 \\
+ & + & + & - & 1,05 & 2,86 \\
- & - & - & + & 1,44 & 0,23 \\
+ & - & - & + & 0,96 & 0,15 \\
- & + & - & + & 1,92 & 0,30 \\
+ & + & - & + & 1,28 & 0,20 \\
- & - & + & + & 3,46 & 2,48 \\
+ & - & + & + & 1,66 & 2,31 \\
- & + & + & + & 3,31 & 4,62 \\
+ & + & + & + & 3,08 & 2,21 \\
\hline
\end{tabular}

As tabelas ANOVA, diagramas de Pareto e gráficos de probabilidade normal são apresentados a seguir tanto para o caso dos deslocamentos laterais quanto para os deslocamentos do teto da escavação: 
Tabela 9 - Tabela de análise da variância (ANOVA) para os dados de deslocamento lateral

\begin{tabular}{l|c|c|c|c|c}
\hline $\begin{array}{c}\text { Fonte de } \\
\text { Variação }\end{array}$ & $\begin{array}{c}\text { Soma de } \\
\text { Quadrados (SS) }\end{array}$ & $\begin{array}{c}\text { Graus de } \\
\text { Liberdade }\end{array}$ & $\begin{array}{c}\text { Quadrados } \\
\text { Médios (MS) }\end{array}$ & Estatística F & p-valor \\
\hline$(1) E$ & 0,813 & 1 & 0,81 & 6,06 & 0,06 \\
$(2) \gamma$ & 0,252 & 1 & 0,25 & 1,88 & 0,23 \\
$(3) C / D$ & 3,529 & 1 & 3,53 & 26,33 & 0,00 \\
$(4) K_{0}$ & 5,683 & 1 & 5,68 & 42,40 & 0,00 \\
1 by 2 & 0,388 & 1 & 0,39 & 2,89 & 0,15 \\
1 by 3 & 0,332 & 1 & 0,33 & 2,48 & 0,18 \\
1 by 4 & 0,459 & 1 & 0,46 & 3,43 & 0,12 \\
2 by 3 & 0,212 & 1 & 0,21 & 1,58 & 0,26 \\
2 by 4 & 0,283 & 1 & 0,28 & 2,12 & 0,21 \\
3 by 4 & 1,165 & 1 & 1,16 & 8,69 & 0,03 \\
\cline { 1 - 3 } Erro & $\mathbf{0 , 6 7 0}$ & $\mathbf{5}$ & $\mathbf{0 , 1 3}$ & & \\
\hline Total SS & $\mathbf{1 3 , 7 8 6}$ & $\mathbf{1 5}$ & & & \\
\hline
\end{tabular}

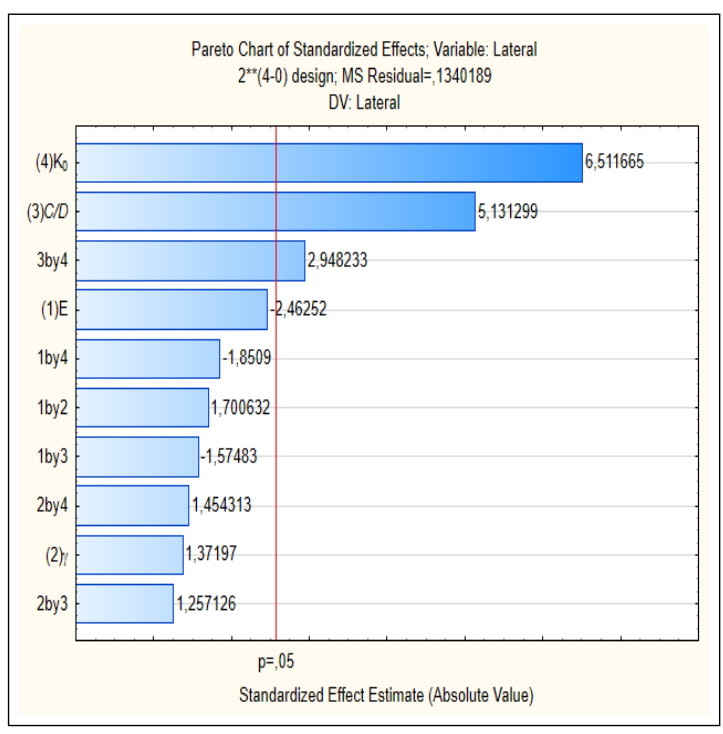

(a) Diagrama de Pareto

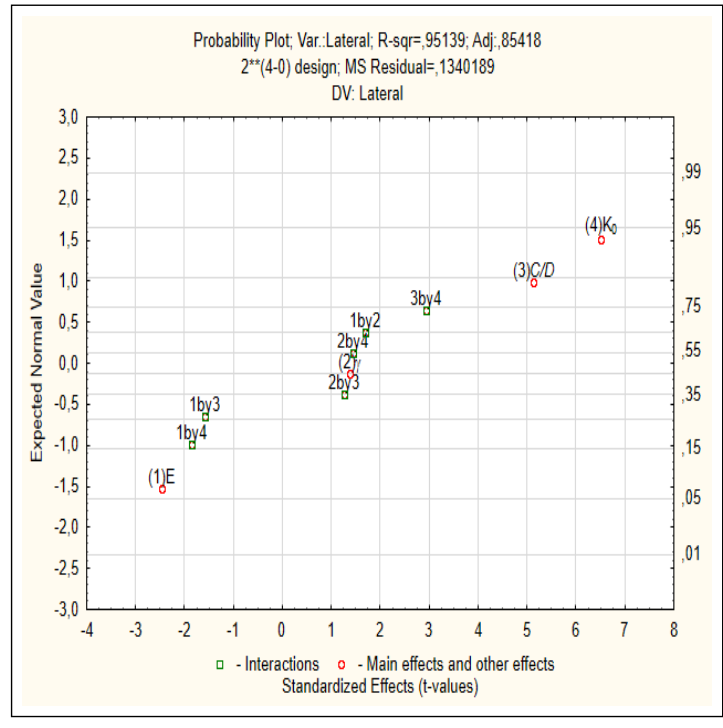

(b) Gráfico de probabilidade normal

Figura 37 - Análise gráfica dos resultados para o deslocamento lateral.

A partir das imagens mostradas na Figura 37 é possível notar que os parâmetros mais influentes no modelo elástico linear para os deslocamentos laterais são o $K_{0}$, a relação $C / D$ e a interação entre esses dois parâmetros, já os outros termos não apresentam efeito significativo para o nível de confiança considerado. Podemos concluir também que os dados possuem uma distribuição normal, já que os pontos apresentados em 37b estão distribuídos em torno de uma reta.

O modelo estatístico capaz de realizar a previsão dos deslocamentos laterais da escavação, dentro dos limites de variação adotados para os parâmetros elásticos é apresentado a seguir: 


$$
\begin{aligned}
& u_{\text {lateral }}=1,5411-0,4507 \cdot E+0,2511 \cdot \gamma+0,9392 \cdot C / D+1,1919 \cdot K_{0}+ \\
& 0,3113 \cdot E \cdot \gamma-0,2883 \cdot E \cdot C / D-0,3388 \cdot E \cdot K_{0}+ \\
& 0,2301 \cdot \gamma \cdot C / D+0,2662 \cdot \gamma \cdot K_{0}+0,5396 \cdot C / D \cdot K_{0}
\end{aligned}
$$

Tabela 10 - Tabela de análise da variância (ANOVA) para os dados de deslocamento do teto

\begin{tabular}{l|c|c|c|c|c}
\hline $\begin{array}{c}\text { Fonte de } \\
\text { Variação }\end{array}$ & $\begin{array}{c}\text { Soma de } \\
\text { Quadrados (SS) }\end{array}$ & $\begin{array}{c}\text { Graus de } \\
\text { Liberdade }\end{array}$ & $\begin{array}{c}\text { Quadrados } \\
\text { Médios (MS) }\end{array}$ & Estatística F & p-valor \\
\hline$(1) E$ & 1,77262 & 1 & 1,77262 & 10,3536 & 0,023526 \\
$(2) \gamma$ & 0,99035 & 1 & 0,99035 & 5,7845 & 0,061234 \\
$(3) C / D$ & 32,37965 & 1 & 32,37965 & 189,1252 & 0,000036 \\
$(4) K_{0}$ & 0,01434 & 1 & 0,01434 & 0,0838 & 0,783848 \\
1 by 2 & 0,42129 & 1 & 0,42129 & 2,4607 & 0,177516 \\
1 by 3 & 1,43148 & 1 & 1,43148 & 8,3611 & 0,034125 \\
1 by 4 & 0,00233 & 1 & 0,00233 & 0,0136 & 0,911761 \\
2 by 3 & 0,80778 & 1 & 0,80778 & 4,7182 & 0,081922 \\
2 by 4 & 0,00698 & 1 & 0,00698 & 0,0408 & 0,847972 \\
3 by 4 & 0,10296 & 1 & 0,10296 & 0,6014 & 0,473110 \\
\cline { 1 - 4 } Erro & $\mathbf{0 , 8 5 6 0 4}$ & $\mathbf{5}$ & $\mathbf{0 , 1 7 1 2 1}$ & & \\
\hline Total SS & $\mathbf{3 8 , 7 8 5 8 2}$ & $\mathbf{1 5}$ & & & \\
\hline
\end{tabular}

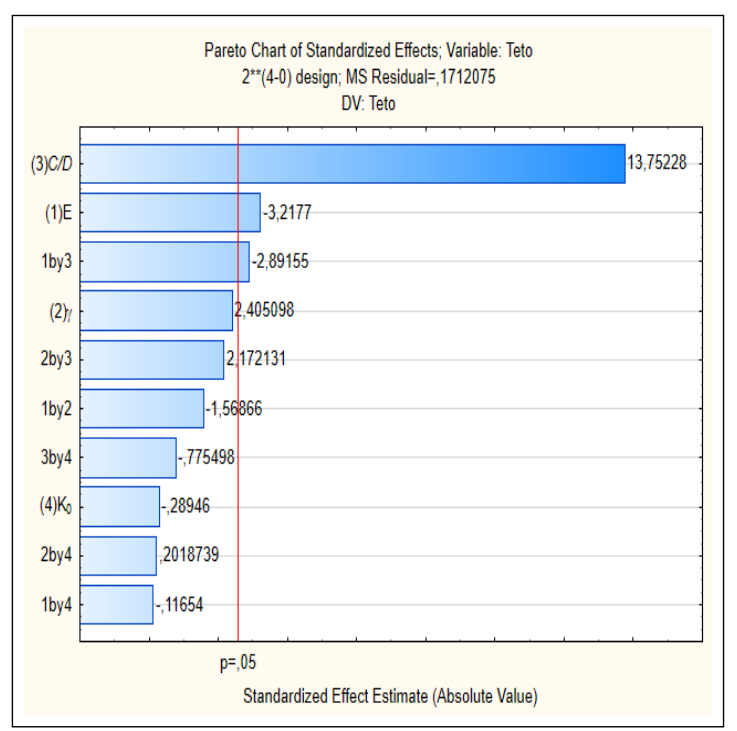

(a) Diagrama de Pareto

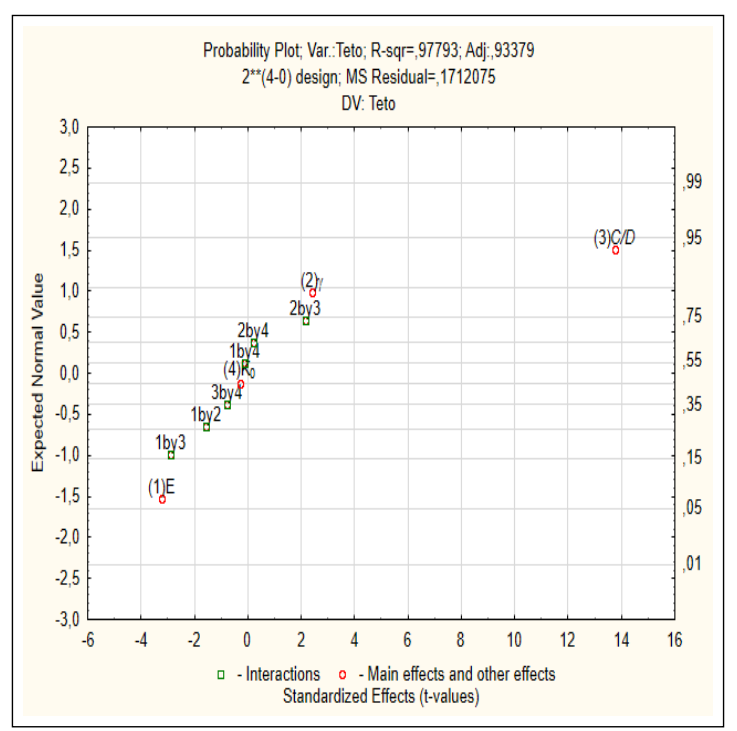

(b) Gráfico de probabilidade normal

Figura 38 - Análise gráfica dos resultados para o deslocamento lateral.

A partir das imagens mostradas na Figura 38 é possível notar que o parâmetro mais influente no modelo elástico linear para os deslocamentos do teto é a relação $C / D$, o módulo de elasticidade e a interação entre esses dois últimos, também apresentam influência significativa 
com relação ao nível de confiança considerado, porém muito inferior se ao evidenciado pela relação $C / D$. A distribuição normal destes dados é confirmada, pois quase todos os pontos estão distribuídos em uma reta. Entretanto, a relação $C / D$ está muito distante da reta. Isto ocorre devido ao fato da relação $C / D$ ser muito influente neste modelo. Neste caso pode ser necessário que tal parâmetro deva ser ajustado com outro tipo de distribuição para que os modelos de previsão possam fornecer dados confiáveis. Este resultado também indica que é necessário investigar escavações rasa e profundas de maneira distinta mesmo em regime elástico.

O modelo estatístico apresentado em 4.2 também pode ser utilizado para a previsão dos deslocamentos do teto da escavação, dentro dos limites de variação adotados para os parâmetros elásticos.

$$
\begin{aligned}
& u_{\text {lateral }}=1,5913-0,6657 \cdot E+0,4976 \cdot \gamma+2,8451 \cdot C / D-0,0599 \cdot K_{0} \\
& -0,3245 \cdot E \cdot \gamma-0,5982 \cdot E \cdot C / D-0,0241 \cdot E \cdot K_{0}+ \\
& 0,4493 \cdot \gamma \cdot C / D+0,0418 \cdot \gamma \cdot K_{0}-0,1604 \cdot C / D \cdot K_{0}
\end{aligned}
$$

\subsection{ESTUDO DE CASO}

A tabela a seguir apresenta os deslocamentos obtidos no topo da escavação para as diversas combinações entre os parâmetros geotécnicos.

Tabela 11 - Deslocamentos obtidos a partir das combinações do planejamento fatorial para as diversas relações $C / D$ e com pressão interna de $7 \mathrm{kPa}$

\begin{tabular}{c|ccc}
\hline Combinação & $\boldsymbol{C} / \boldsymbol{D}=\mathbf{0 , 5}-[\mathbf{m m}]$ & $\boldsymbol{C} \boldsymbol{D}=\mathbf{1 , 0}-[\mathbf{m m}]$ & $\boldsymbol{C} / \boldsymbol{D}=\mathbf{1 , 5}-[\mathbf{m m}]$ \\
\hline $\mathbf{0 1}$ & 10,689 & 10,333 & 12,638 \\
$\mathbf{0 2}$ & 9,717 & 9,393 & 11,496 \\
$\mathbf{0 3}$ & 11,078 & 10,157 & 12,455 \\
$\mathbf{0 4}$ & 10,071 & 9,234 & 11,328 \\
$\mathbf{0 5}$ & 6,016 & 10,015 & 12,511 \\
$\mathbf{0 6}$ & 5,469 & 9,103 & 11,381 \\
$\mathbf{0 7}$ & 6,530 & 9,817 & 12,348 \\
$\mathbf{0 8}$ & 5,936 & 8,925 & 11,231 \\
$\mathbf{0 9}$ & 2,656 & 4,702 & 7,625 \\
$\mathbf{1 0}$ & 2,415 & 4,274 & 6,936 \\
$\mathbf{1 1}$ & 2,342 & 4,981 & 7,855 \\
$\mathbf{1 2}$ & 2,129 & 4,528 & 7,143 \\
$\mathbf{1 3}$ & 2,676 & 4,643 & 7,592 \\
$\mathbf{1 4}$ & 2,433 & 4,220 & 6,905 \\
$\mathbf{1 5}$ & 2,361 & 4,923 & 7,822 \\
$\mathbf{1 6}$ & 2,146 & 4,476 & 7,113 \\
\hline
\end{tabular}




\subsubsection{RELAÇÃO $C / D=0,5$}

Conforme metodologia apresentada no capítulo 2.4, os resultados obtidos por meio do planejamento fatorial estão mostrados nas Figuras 39 até 44.

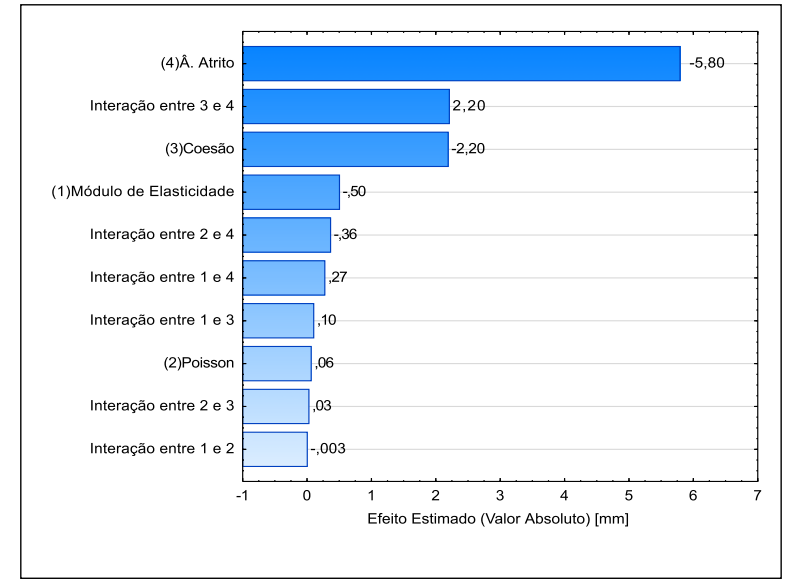

Figura 39 - Diagrama de Pareto para $C / D=0,5$.

Analisando o diagrama de Pareto da Figura 39 e desconsiderando os fatores de interação é possível verificar que apenas o coeficiente de Poisson não apresenta influência dentro do limite de significância de 5\% quando avaliada a resposta dos deslocamentos do modelo numérico. Para a relação $C / D=0,5$ o diagrama de Pareto evidencia que o módulo de elasticidade apresenta uma significância pouco expressiva quase não sendo fundamental para a resposta do modelo em questão. $\mathrm{O}$ ângulo de atrito e a coesão foram os parâmetros que apresentaram significância negativa mais expressiva com destaque para o ângulo de atrito, fato já esperado para solos granulares. Isso significa que é necessário realizar ensaios em quantidade suficiente para determinar com boa acurácia os valores de ângulo de atrito e coesão do solo, garantindo que as previsões obtidas nos modelos sejam representativas dos deslocamentos medidos através de instrumentação na obra.

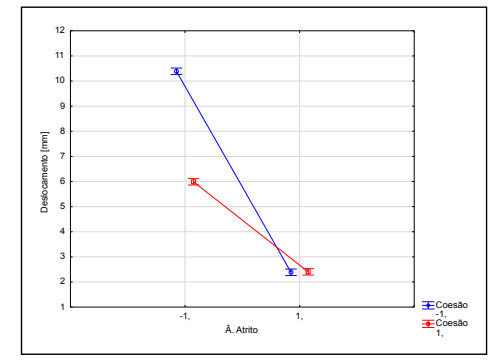

(a) Atrito x Coesão

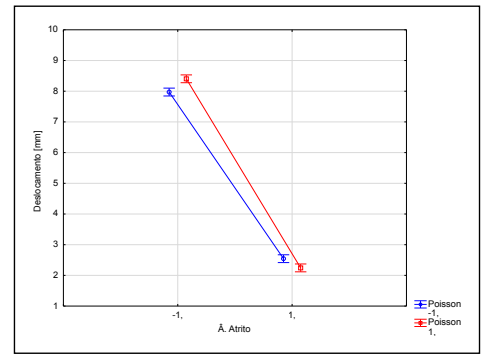

(b) Atrito x Poisson

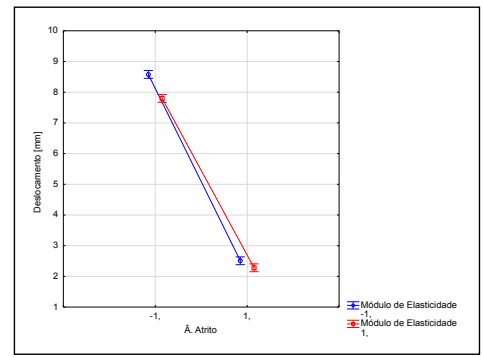

(c) Atrito x Módulo

Figura 40 - Variação das respostas de acordo com o nível dos parâmetros - A para $C / D=0,5$ 


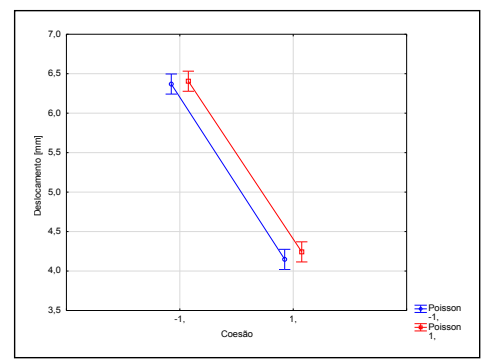

(a) Coesão x Poisson

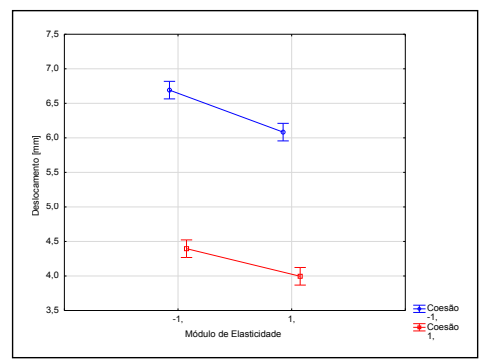

(b) Módulo x Coesão

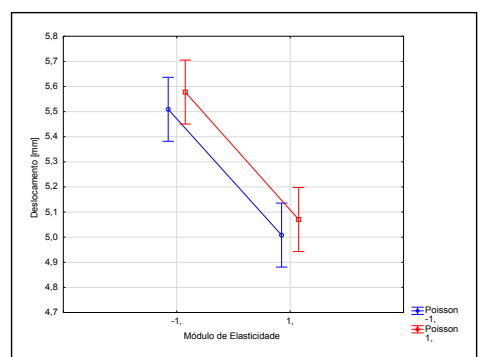

(c) Poisson x Módulo

Figura 41 - Variação das respostas de acordo com o nível dos parâmetros - B para $C / D=0,5$

A interação entre os parâmetros pode ser avaliada através das Figuras 40 e 41 . A partir delas é possível concluir que, no intervalo considerado, a interação entre o ângulo de atrito e a coesão e entre o ângulo de atrito e o módulo de elasticidade são bem expressivas com destaque para a primeira. Fato mostrado nas Figuras 40a e 40c (retas concorrentes). Já quando as retas são paralelas significa que não há interação entre os parâmetros (Figuras 40b, 41a, 41b e 41c).

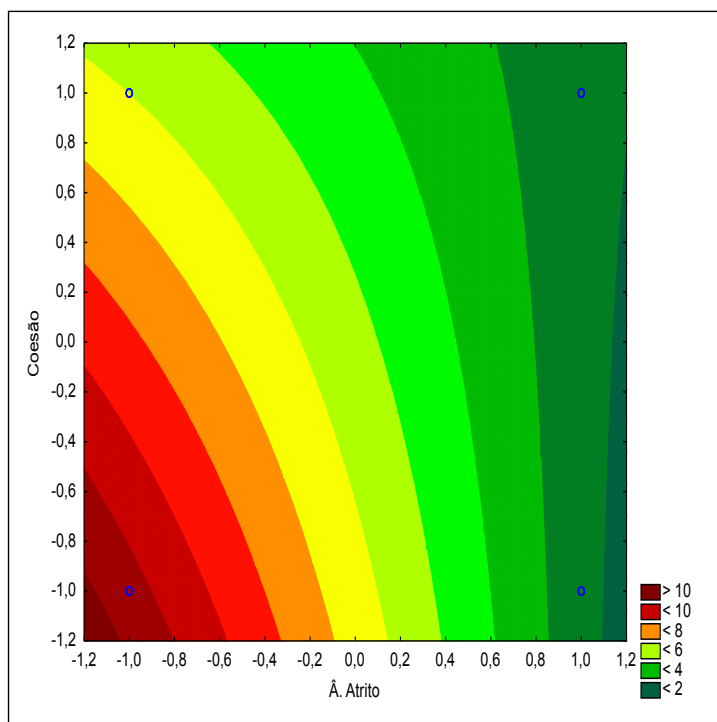

(a) Curvas de nível

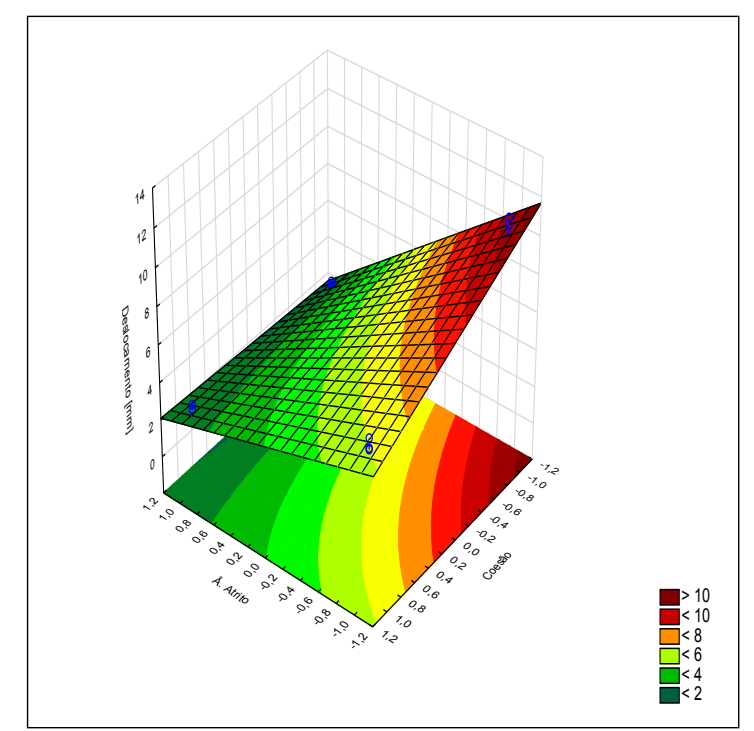

(b) Superfície

Figura 42 - Representações da resposta da relação Atrito x Coesão para $C / D=0,5$.

A Figura 42 reforça graficamente a relação entre o ângulo de atrito e a coesão ao mostrar isolinhas com aspecto curvo. Através da superfície mostrada na Figura 42 fica claro que ao manter o Ângulo de atrito constante a resposta do modelo numérico para os deslocamentos irá se alterar com a mudança no nível da coesão. 


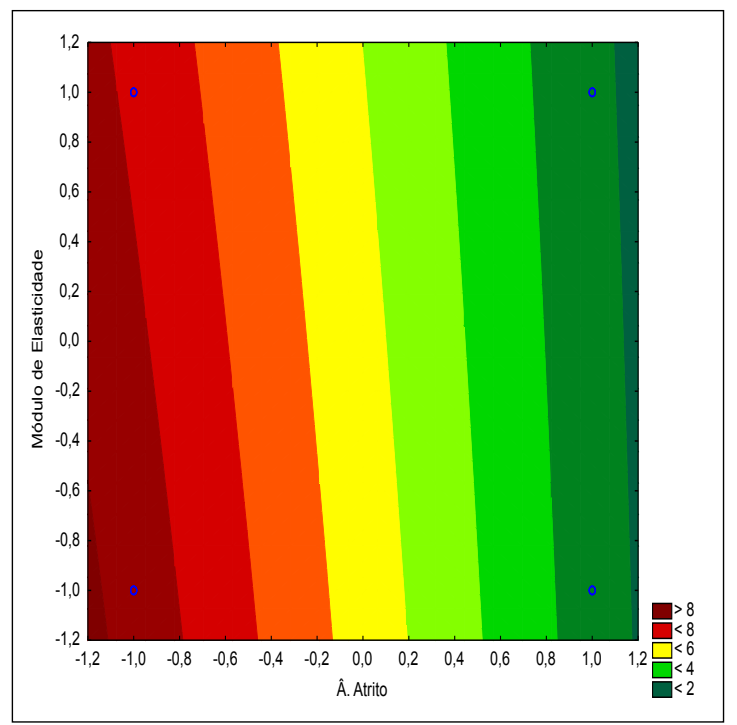

(a) Curva de nível

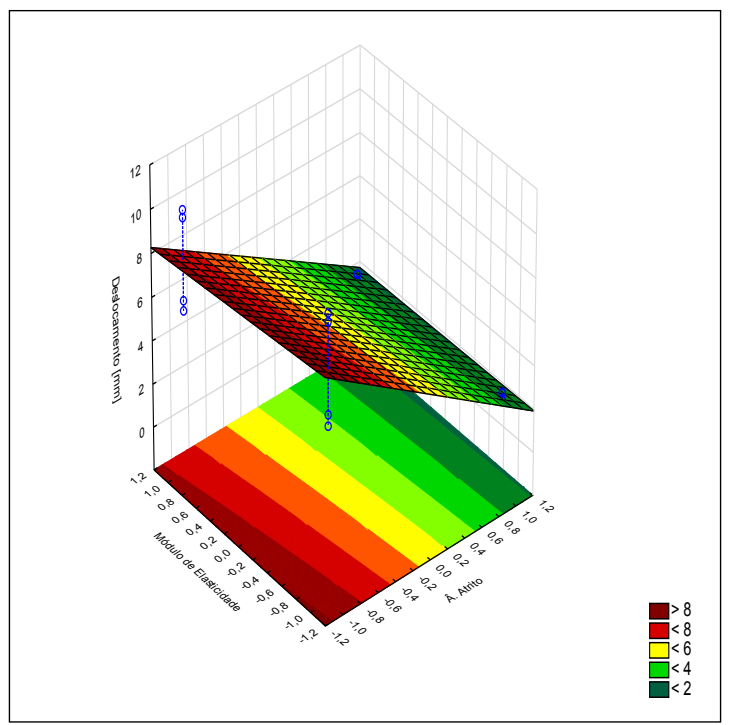

(b) Superfície

Figura 43 - Representações da resposta da relação Atrito x Módulo para $C / D=0,5$.

Já as Figuras 43 e 44 mostram a baixa ou nenhuma interação entre os parâmetros envolvidos ao mostrar isolinhas praticamente verticais, ou seja, ao manter o ângulo de atrito constante em determinado nível a resposta do modelo numérico não irá sofrer alteração significativa com a mudança nos níveis do módulo de elasticidade ou do coeficiente de Poisson.

Quando dois parâmetros apresentam uma interação expressiva significa dizer que não é possível interpretar e avaliar o efeito destes parâmetros de forma isolada.

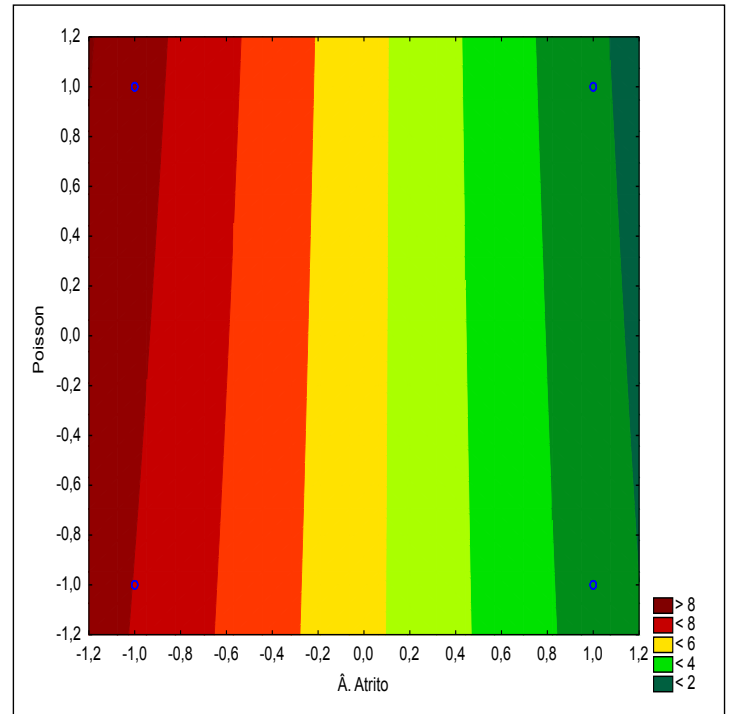

(a) Curva de nível

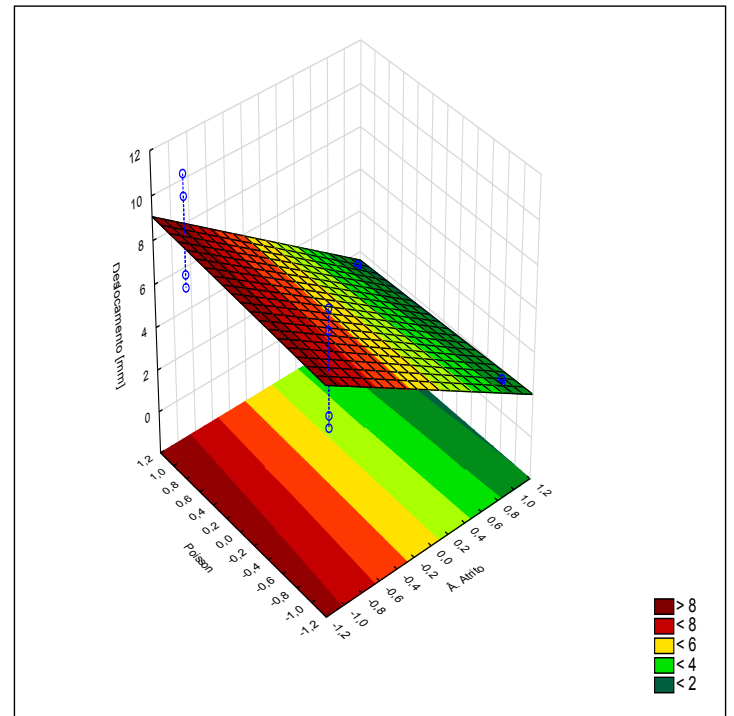

(b) Superfície

Figura 44 - Representações da resposta da relação Atrito x Poisson para $C / D=0,5$

A seguir apresenta-se o modelo estatístico que estima o deslocamento do teto do túnel 
em função das variáveis consideradas e com validade no intervalo definido com variação de $10 \%$.

$$
\begin{aligned}
& u=5,29-0,51 E_{c}+0,06 \nu_{c}-2,19 c_{c}-5,79 \phi_{c}+E_{c}\left(-0,003 \nu_{c}+0,11 c_{c}+0,27 \phi_{c}\right) \\
& +\nu\left(0,029 c_{c}-0,36 \phi_{c}\right)+2,2 c_{c} \phi_{c}
\end{aligned}
$$

onde: $E_{c}=$ módulo de elasticidade codificado ${ }^{1} ; \nu_{c}=$ coeficiente de Poisson codificado $; c_{c}=$ coesão codificada e $\phi_{c}=$ ângulo de atrito codificado.

A Figura 45 mostra os deslocamentos, na iminência da ruptura, obtidos a partir do modelo numérico realizado no Abaqus 6.14 utilizando os valores médios dos parâmetros geomecânicos, uma pressão interna de $6,95 k P a$ e relação $C / D=0,5$.

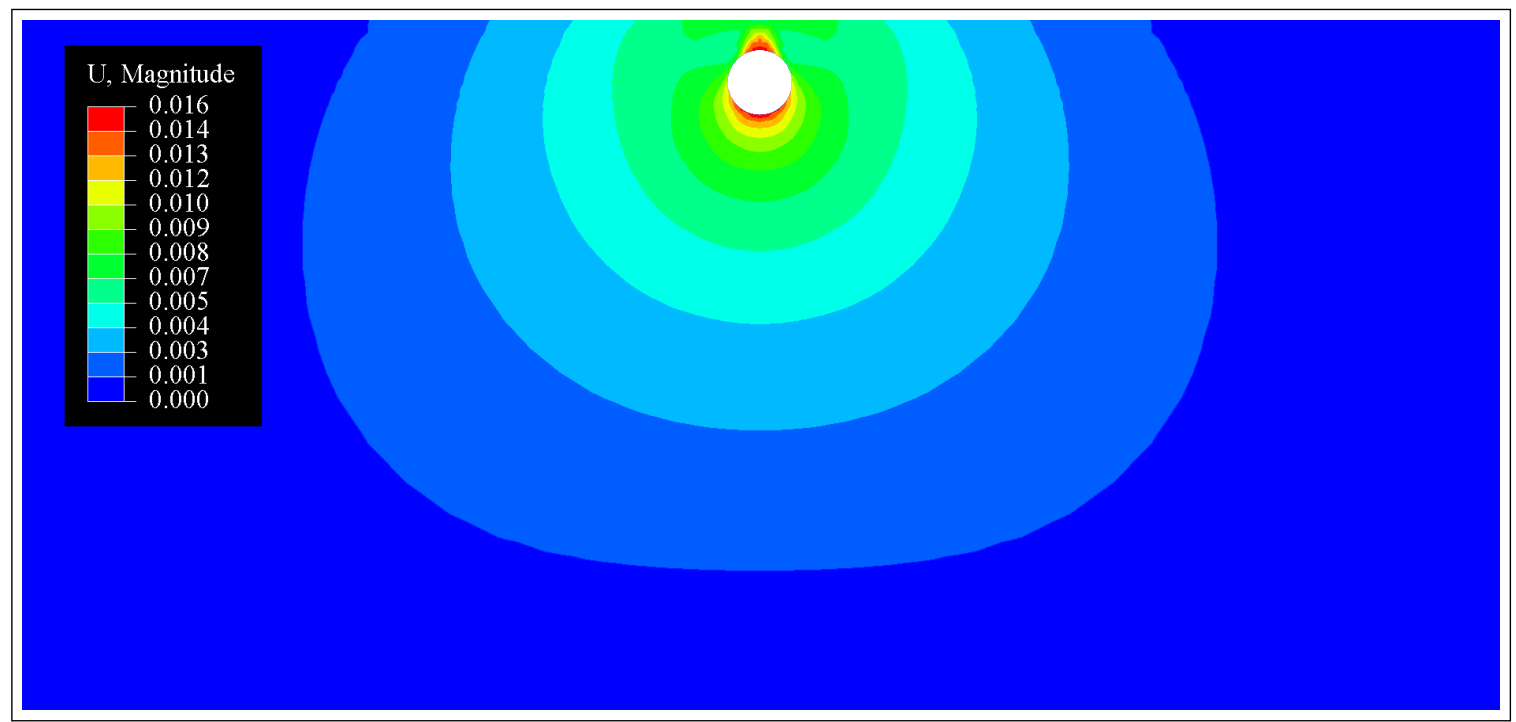

Figura 45 - Deslocamentos para o modelo numérico com relação $C / D=0,5$

\subsubsection{RELAÇÃO $C / D=1,0$}

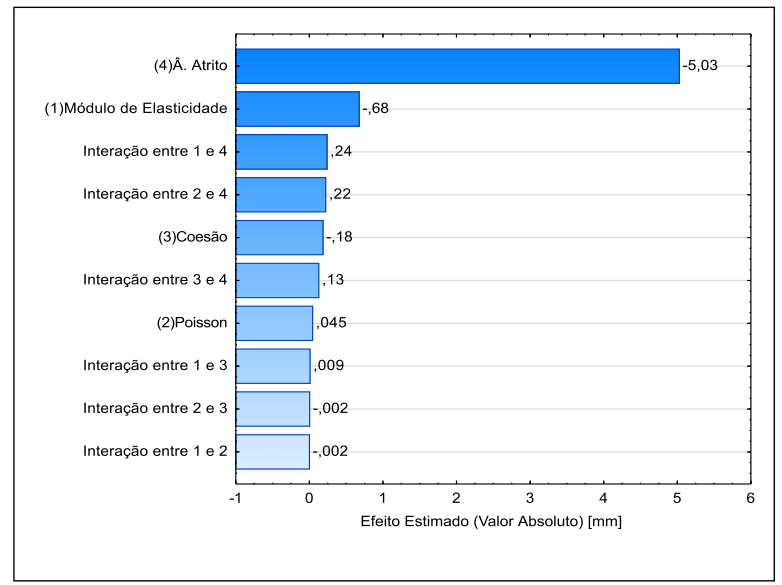

Figura 46 - Diagrama de Pareto para $C / D=1,0$.

1 variáveis codificadas assumem qualquer valor entre - 1 e 1 e, neste caso, -1 representa o valor médio e 1 o valor médio acrescido de $10 \%$. 
Analisando o diagrama de Pareto mostrado na Figura 46 é possível identificar que o ângulo de atrito e o módulo de elasticidade são os parâmetros mais influentes na resposta do modelo numérico ao considerar os deslocamentos do topo do túnel como variável de resposta . É interessante notar que a importância da coesão foi bem menos significativa do que no caso anterior. Ficando com influência menos expressiva do que as interações entre o ângulo de atrito e o coeficiente de Poisson.

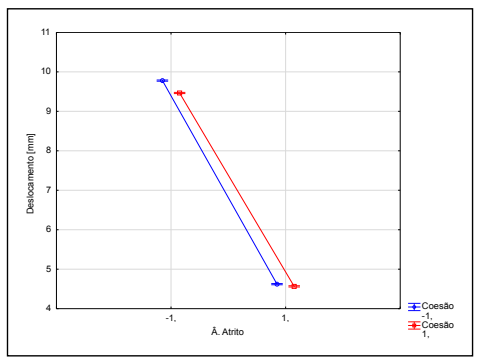

(a) Atrito x Coesão

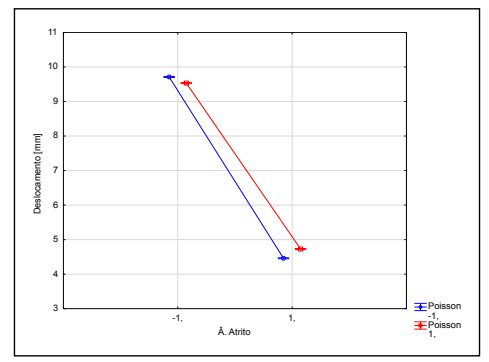

(b) Atrito x Poisson

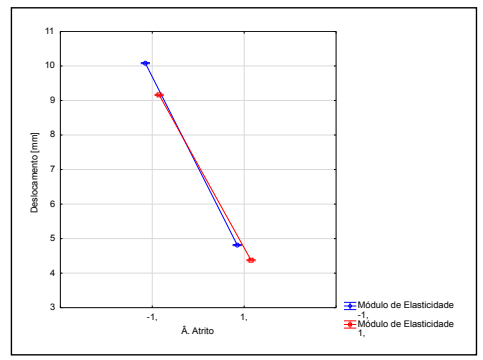

(c) Atrito x Módulo

Figura 47 - Variação das respostas de acordo com o nível dos parâmetros - A para $C / D=1,0$

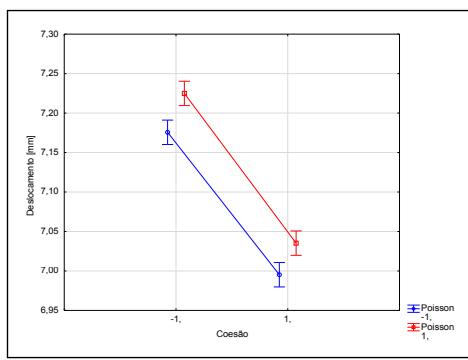

(a) Coesão x Poisson

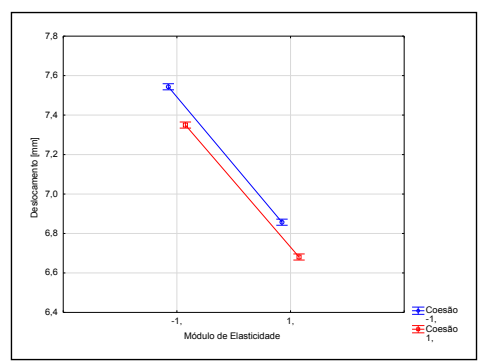

(b) Módulo x Coesão

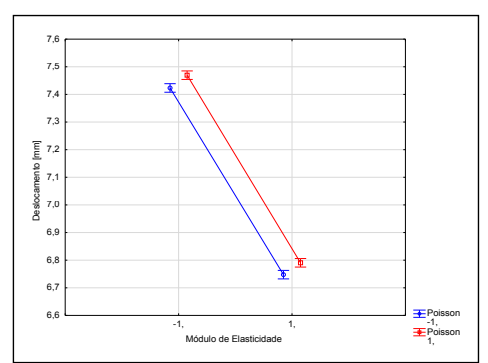

(c) Poisson x Módulo

Figura 48 - Variação das respostas de acordo com o nível dos parâmetros - B para $C / D=1,0$

A interação entre os parâmetros mostrada nas Figuras 47 e 48, revela que há pouca interação entre os parâmetros avaliados. O módulo de elasticidade e o ângulo de atrito apresentam uma interação pouco expressiva evidenciada na Figura 47c e corroborada pelos resultados mostrados no diagrama de Pareto (Figura 46).

Já as Figuras 49, 50, e 51 mostram que caso o ângulo de atrito for mantido constante os deslocamentos não sofrerão mudanças expressivas com a alteração dos outros parâmetros estudados (módulo de elasticidade, coesão e coeficiente de Poisson). 


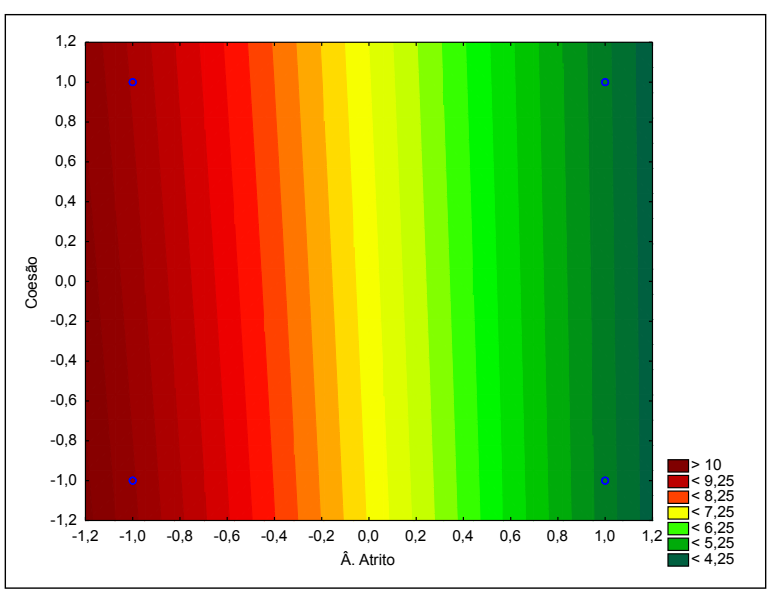

(a) Curva de nível

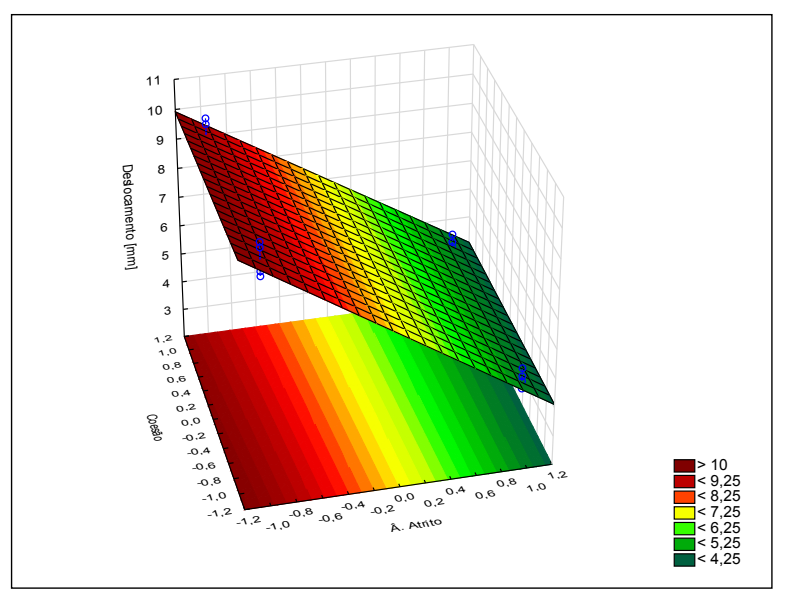

(b) Superfície

Figura 49 - Representações da resposta da relação Atrito x Coesão para $C / D=1,0$.

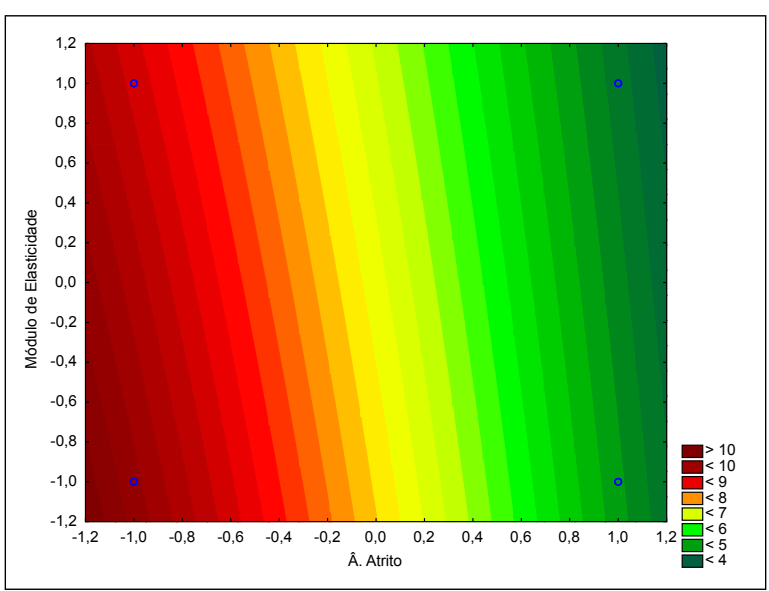

(a) Curva de nível

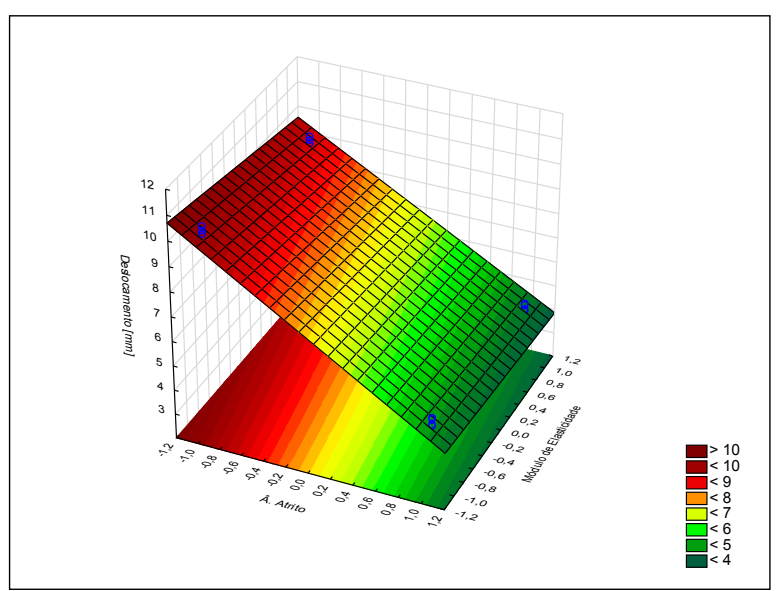

(b) Superfície

Figura 50 - Representações da resposta da relação Atrito x Módulo para $C / D=1,0$.

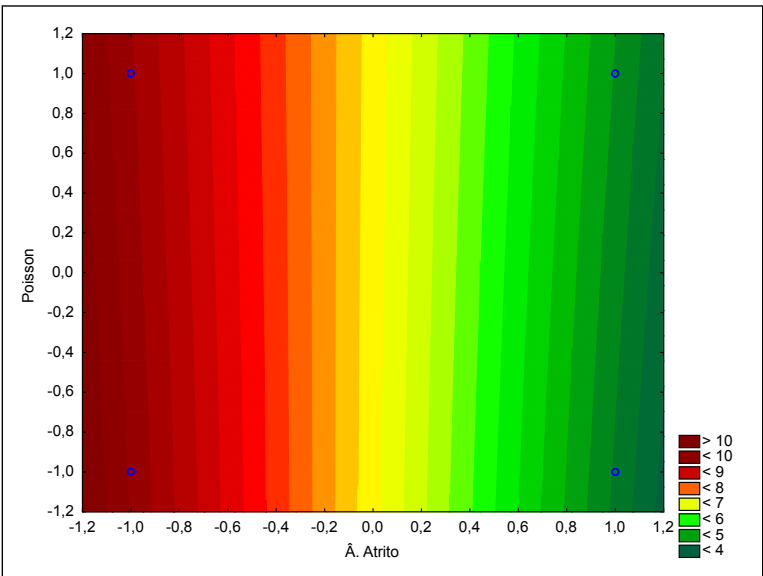

(a) Curva de nível

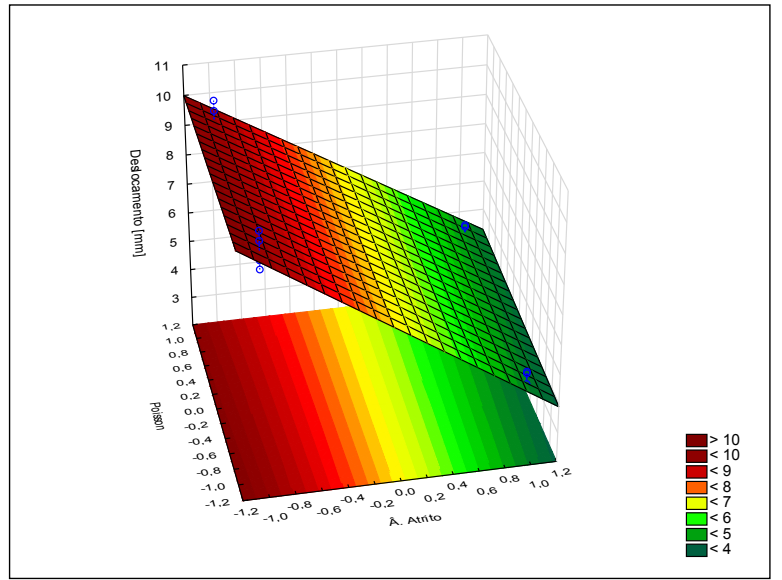

(b) Superfície

Figura 51 - Representações da resposta da relação Atrito x Poisson para $C / D=1,0$. 


$$
\begin{aligned}
& u=7,11-0,68 E_{c}+0,04 \nu_{c}-0,18 c_{c}-5,03 \phi_{c}+ \\
& E_{c}\left(-0,002 \nu_{c}+0,009 c_{c}+0,24 \phi_{c}\right) \\
& +\nu\left(-0,005 c_{c}+0,22 \phi_{c}\right)+0,13 c_{c} \phi_{c}
\end{aligned}
$$

A Equação 4.4 expressa o modelo de previsão, obtido através de regressão linear.

A Figura 52 mostra os deslocamentos, na iminência da ruptura, obtidos a partir do modelo numérico realizado no Abaqus 6.14 ao se utilizar os valores médios dos parâmetros geomecânicos, uma pressão interna de $5,8 k P a$ e relação $C / D=1,0$.

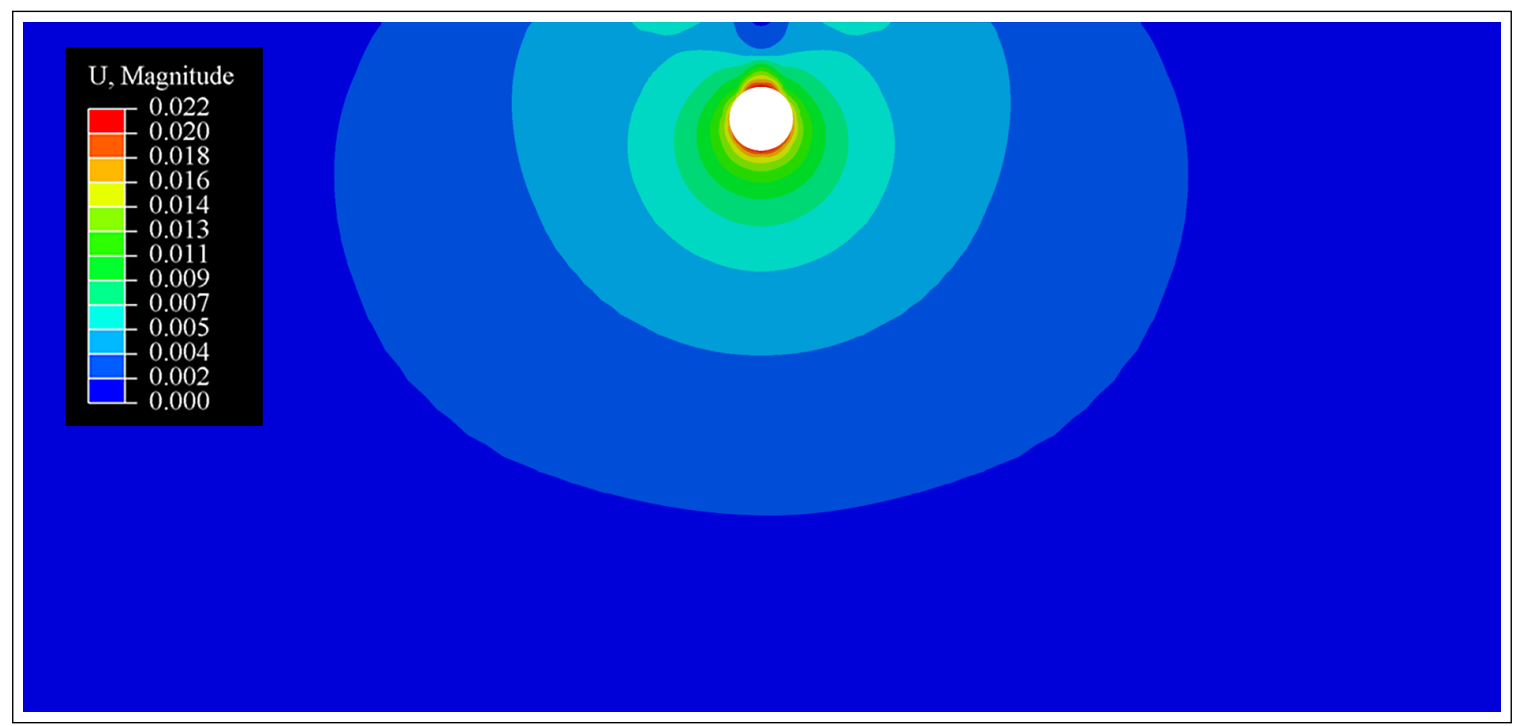

Figura 52 - Deslocamentos para o modelo numérico com relação $C / D=1,0$

\subsubsection{RELAÇÃO $C / D=1,5$}

O diagrama de Pareto mostrado na Figura 53 reforça o fato de que ao aumentar a profundidade da escavação o módulo de elasticidade passa a apresentar uma parcela de contribuição mais expressiva na resposta do modelo numérico do que a coesão. Também é possível notar que para a relação $C / D=1,5$ a coesão deixa de apresentar uma contribuição significativa na resposta do modelo numérico. 


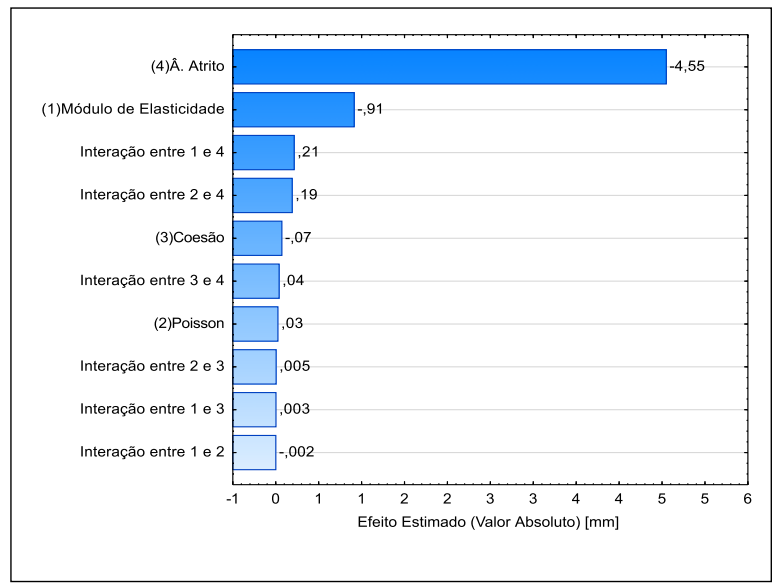

Figura 53 - Diagrama de Pareto para $C / D=1,5$.

As Figuras 54 e 55 mostram que a interação entre os parâmetros estudados tem uma relação parecida com o caso anterior, ou seja, somente a interação entre o ângulo de atrito e o módulo de elasticidade e entre o ângulo de atrito e o coeficiente de Poisson que apresentaram influência, pouco expressiva, na resposta do modelo numérico.

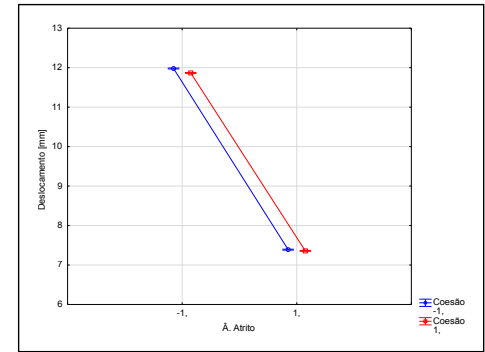

(a) Atrito x Coesão

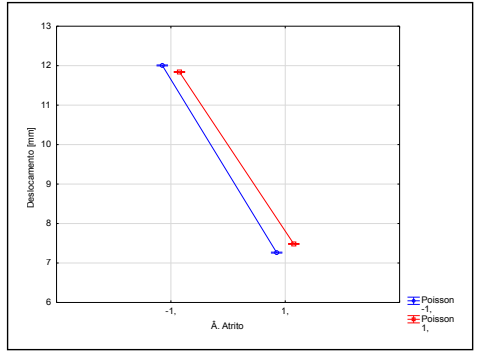

(b) Atrito x Poisson

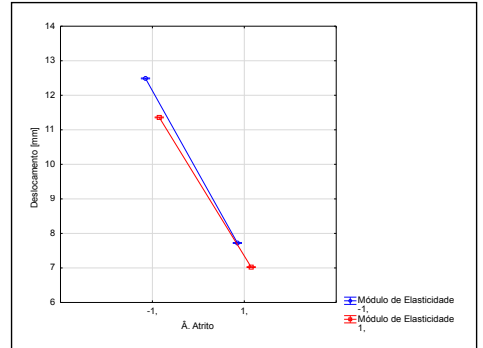

(c) Atrito x Módulo

Figura 54 - Variação das respostas de acordo com o nível dos parâmetros - A para $C / D=1,5$

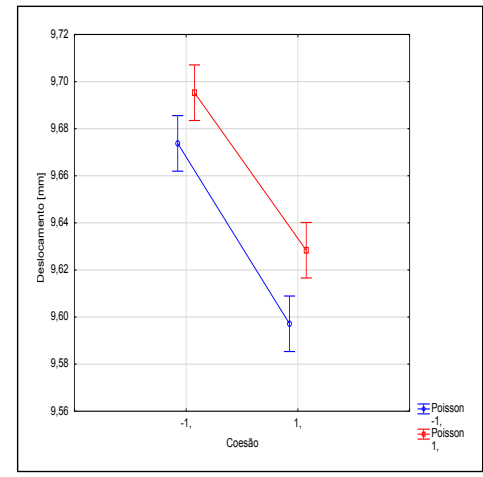

(a) Coesão x Poisson

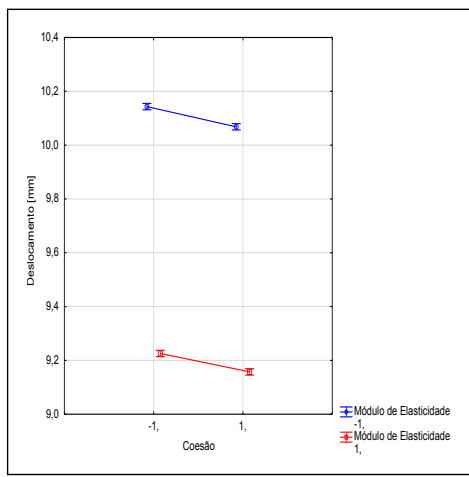

(b) Módulo x Coesão

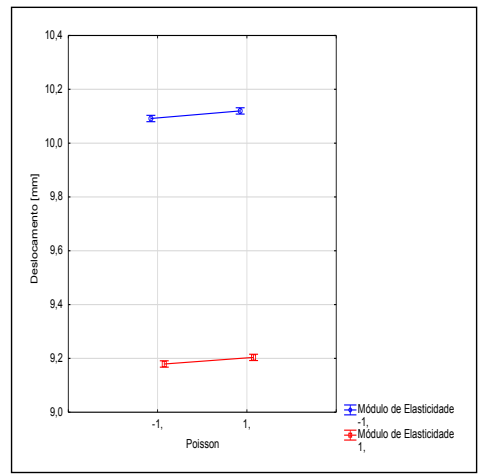

(c) Poisson x Módulo

Figura 55 - Variação das respostas de acordo com o nível dos parâmetros - B para $C / D=1,5$ 


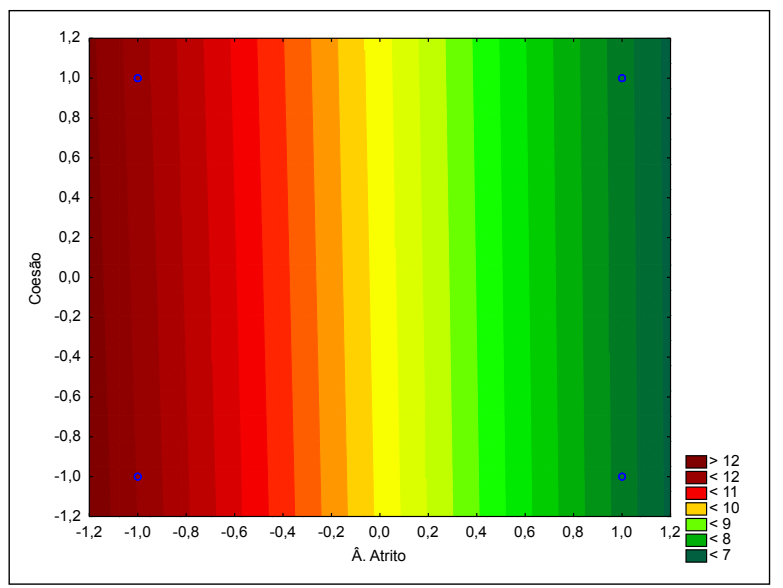

(a) Curva de nível

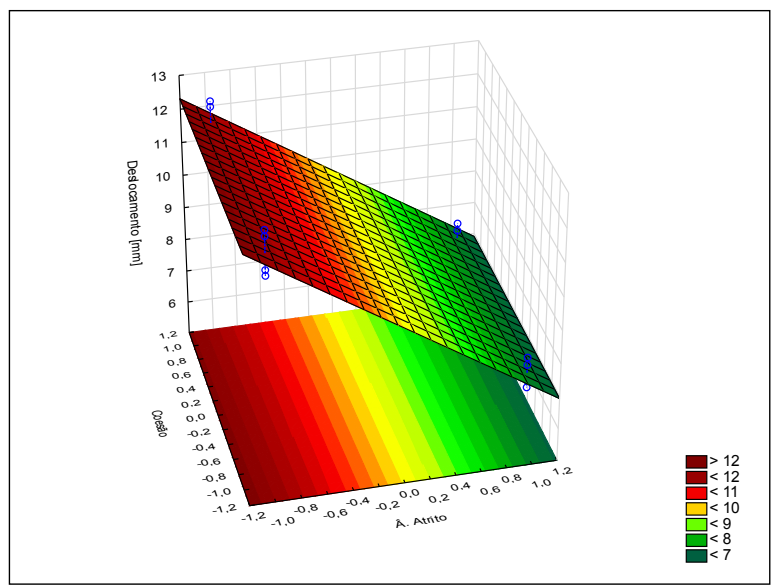

(b) Superfície

Figura 56 - Representações da resposta da relação Atrito x Coesão para $C / D=1,5$.

As superfícies mostradas nas Figuras 56, 57 e 58 mostram que para um nível constante do ângulo de atrito as variações da coesão, módulo de elasticidade ou coeficiente de Poisson não afetam de forma expressiva a resposta dos modelos numéricos.

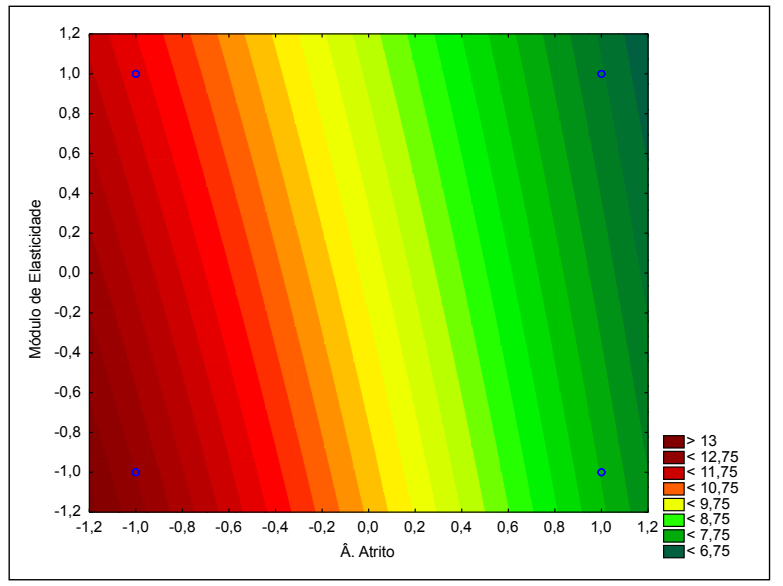

(a) Curva de nível

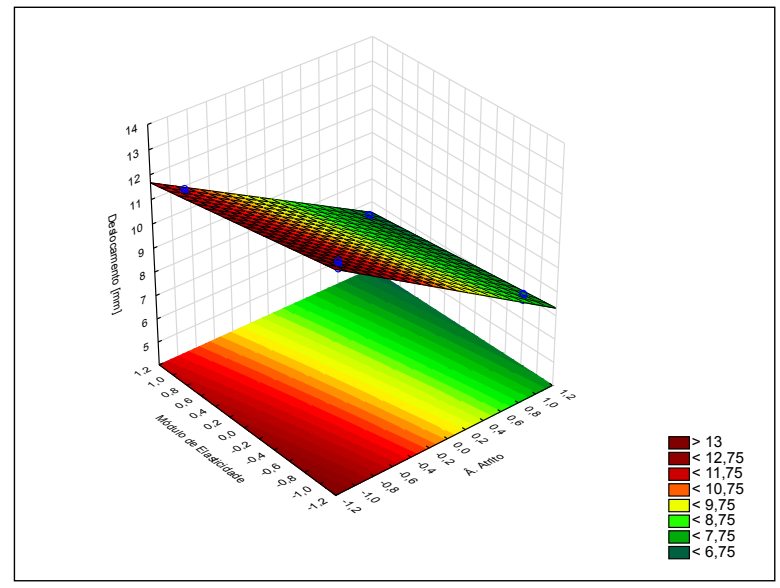

(b) Superfície

Figura 57 - Representações da resposta da relação Atrito x Módulo para $C / D=1,5$. 


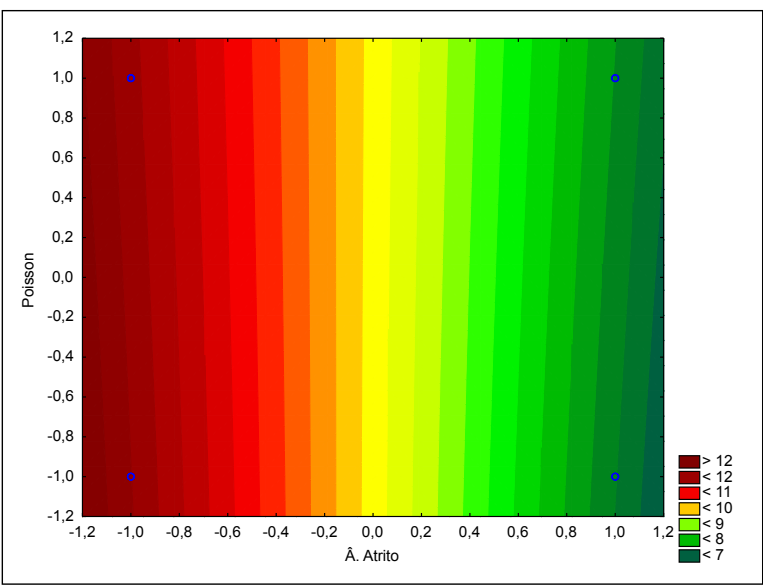

(a) Curva de nível

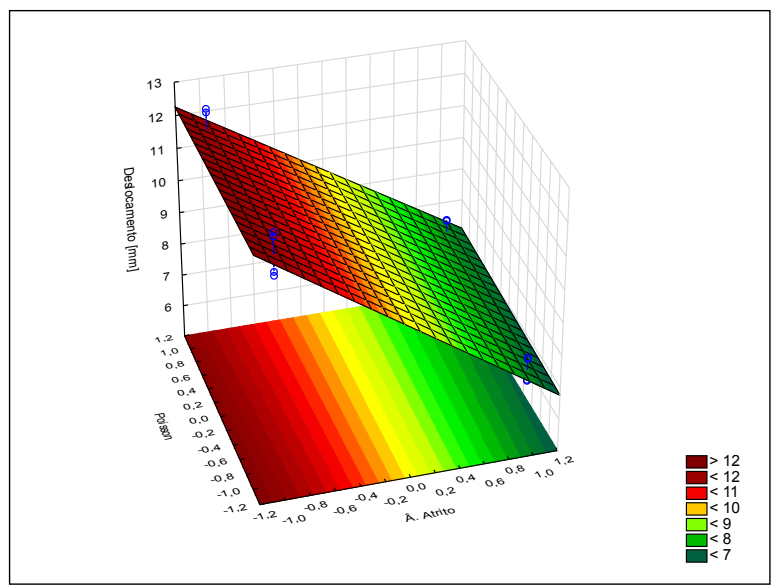

(b) Superfície

Figura 58 - Representações da resposta da relação Atrito x Poisson para $C / D=1,5$.

$$
\begin{aligned}
& u=9,65-0,91 E_{c}+0,03 \nu_{c}-0,072 c_{c}-4,55 \phi_{c} \\
& +E_{c}\left(-0,002 \nu_{c}+0,003 c_{c}+0,21 \phi_{c}\right) \\
& +\nu\left(+0,005 c_{c}+0,19 \phi_{c}\right)+0,04 c_{c} \phi_{c}
\end{aligned}
$$

Os efeitos principais e os efeitos das interações de segunda ordem estão mostrados na Equação 4.5 que representa o modelo estatístico de previsão dos deslocamentos do topo do túnel.

A Figura 59 mostra os resultados dos deslocamentos, na iminência da ruptura, obtidos a partir do modelo numérico realizado no Abaqus 6.14 utilizando os valores médios dos parâmetros geomecânicos, uma pressão interna de $4,2 k P a$ e relação $C / D=1,5$.

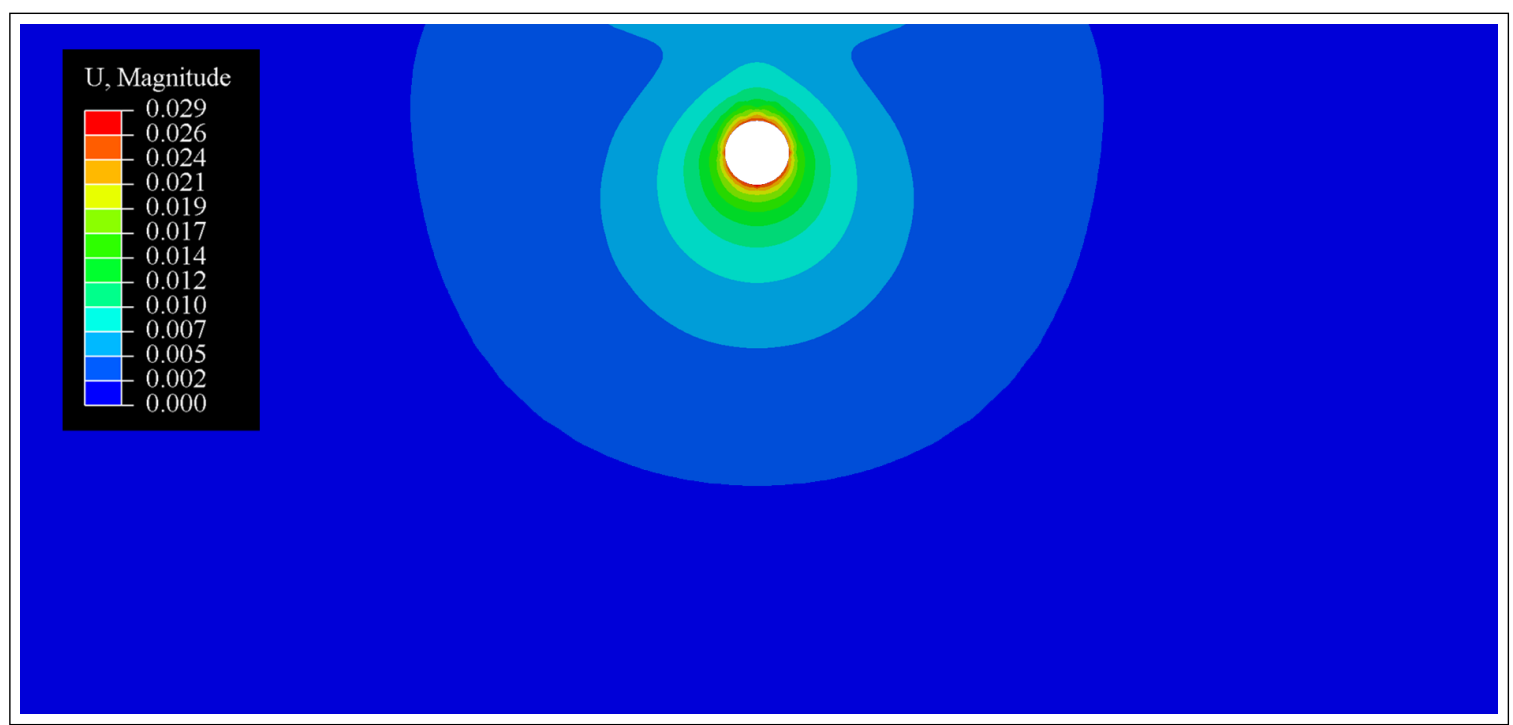

Figura 59 - Deslocamentos para o modelo numérico com relação $C / D=1,5$ 


\subsubsection{COMBINAÇÃO DOS RESULTADOS}

Avaliando-se os resultados apresentados, verificou-se que o coeficiente de Poisson não apresenta influencia significativa para estes modelos. Sendo assim, ele foi substituído na análise pela relação $C / D$. Desta forma, foi possível obter um modelo simplificado que pode fazer a previsão dos deslocamentos do teto do túnel conforme apresentado a seguir:

$$
\begin{aligned}
& u=7,45-0,71 \cdot E_{c}+4,37 \cdot C / D_{c}-1,15 \cdot c_{c}-5,084 \cdot \phi_{c} \\
& +E_{c} \cdot\left(-0,206 \cdot C / D_{c}+0,547 \cdot c_{c}+0,241 \cdot \phi_{c}\right) \\
& +C / D_{c} \cdot\left(1,072 \cdot c_{c}+0,343 \cdot \phi_{c}\right)+1,142 \cdot c_{c} \cdot \phi_{c}
\end{aligned}
$$

O modelo estatístico representado pela Equação 4.6 foi obtido aplicando-se o mesmo tratamento estatístico desenvolvido até o momento nos dados da Tabela 11. Os níveis considerados para o parâmetro $C / D$ foram 0,5 e 1,5 . 



\section{CONCLUSÕES}

O presente trabalho avalia a sensibilidade aos parâmetros geomecânicos de escavações subterrâneas pouco profundas, considerando um maciço contínuo, homogêneo, isotrópico e elastoplástico e dos parâmetros elásticos e geométricos de modelos elásticos lineares, através do planejamento fatorial de experimentos. As informações para aplicação dos métodos foram obtidas através de análises numéricas bidimensionais realizadas com o auxílio do programa Abaqus $6.14^{\circledR}$ que é baseado no método de elementos finitos. Os modelos numéricos consideram um estado plano de deformações, característica válida para escavações não revestidas. Os modelos numéricos realizados no Abaqus $6.14^{\circledR}$ foram otimizados após o trabalho de calibração ao reproduzir problemas com solução analítica conhecida.

O objetivo principal que era determinar modelos simplificados para a previsão do deslocamento do teto da escavação foi plenamente satisfeito, ao aplicar a análise de variância nos dados obtiveram-se os coeficientes de regressão necessários para a composição dos modelos preditivos. Somente o caso do modelo elástico linear apresentou uma discrepância nos dados para o parâmetro $C / D$ ele foi o único que não se adequou à distribuição normal, fato que pode implicar em um modelo preditivo pouco eficiente. Isso pode ter ocorrido por se tratar de escavações rasas em que a distribuição do campo de tensões não é uniforme. Também foi possível determinar o nível de influência de cada parâmetro considerado nos modelos. Destaca-se que o estudo do software Abaqus $6.14^{\circledR}$ para otimizar as dimensões dos modelos numéricos também foi satisfatoriamente cumprido. Conclui-se que as leis constitutivas e o método numérico precisam ser escolhidos e usados cuidadosamente para que possam representar com fidelidade o problema estudado. É necessária uma compreensão profunda das limitações dos softwares empregados, pois o uso inadequado deles pode induzir a resultados destoantes da realidade e que se forem utilizados para tomadas de decisões podem representar perigos potenciais.

Nota-se do levantamento bibliográfico que diversos trabalhos têm como o objetivo quantificar a influência de parâmetros geomecânicos na resposta do fator de segurança de determinado fenômeno. Na geotecnia o estudo paramétrico é muito comum, mas carece de um método sistemático. Para contornar este problema foi empregada a técnica de planejamento fatorial de experimentos. O emprego do planejamento fatorial de experimentos costuma ser mais comum em problemas de engenharia química, de alimentos e de produção, mas isso não impediu que fossem encontrados resultados satisfatórios em problemas geotécnicos.

As análises paramétricas realizadas a partir do planejamento fatorial de experimentos possibilitaram a determinação dos parâmetros geomecânicos que apresentam maior influência na resposta de modelos numéricos de túneis. No modelo elástico linear o parâmetro que apresentou maior influência no deslocamento do teto foi a relação $C / D$ e para os deslocamentos laterais os parâmetros mais influentes foram o $K_{0}$, a relação $C / D$ e a interação entre esses dois parâmetros 
respectivamente. Já para o estudo de caso o ângulo de atrito e a coesão foram os parâmetros que tiveram mais destaque, sendo que ao aumentar a profundidade da escavação a coesão passou a ter menos influência do que o módulo de elasticidade. Com este estudo foi possível verificar que os parâmetros mecânicos apresentaram uma influência na resposta dos modelos numéricos diretamente proporcional à profundidade da escavação. Por isso que análises numéricas elásticas e lineares fornecem bons resultados ao representar escavações profundas.

A partir do planejamento fatorial e da ANOVA pode-se ainda determinar equações analíticas para cada relação $C / D$ estudada, estas equações fornecem uma previsão dos deslocamentos a partir dos parâmetros geomecânicos codificados. No estudo de caso após concluir que o coeficiente de poisson não apresentava influência significativa, este foi retirado da análise e assim fora determinada uma nova equação considerando a relação $C / D$ como parâmetro do modelo preditivo de deslocamentos do teto da escavação.

A partir deste equacionamento é possível realizar estudos de viabilidade ao variar os parâmetros em questão de forma mais ágil, ou seja, sem a necessidade de realizar novos modelos numéricos. Desde que sejam considerados os limites máximos e mínimos representados pelos níveis de operação arbitrados para as variáveis escolhidas.

A grande maioria das técnicas aplicadas na geotecnia estão baseadas em análises determinísticas, principalmente quando se determina o fator de segurança de determinado problema. Por isso, estudos como os desenvolvidos nesta pesquisa ganham cada vez mais destaque ao passo que conceitos de estatística e probabilidade vem sendo sistematicamente incorporados no meio geotécnico.

A identificação dos parâmetros de projeto mais significativos, permite que o engenheiro realize um estudo otimizado do comportamento das escavações subterrâneas. Como os parâmetros geomecânicos apresentam uma grande variabilidade, devido principalmente ao processo de formação do solo, fato que influenciam diretamente a previsão determinística, determinar essa sensibilidade permite compreender melhor os fenômenos envolvidos nas escavações subterrâneas e podem ajudar na determinação da probabilidade de falha dos projetos geotécnicos.

Com relação à aplicação do planejamento fatorial, muito ainda pode ser feito. Esta é uma técnica extremamente robusta e relativamente fácil de ser aplicada. A maior dificuldade desta técnica é a interpretação dos dados que aumentam a complexidade conforme aumentam o número de variáveis a serem estudadas.

\subsection{SUGESTÕES PARA TRABALHOS FUTUROS}

Como sugestão para pesquisas futuras, para complementar e aprofundar os estudos iniciados com o presente trabalho, tornando-os cada vez mais úteis para a engenharia, sugere-se:

a) Realizar um estudo similar considerando maciços heterogêneos; 
b) utilizar outros modelos reológicos, como Hardening Soil, Cam Clay ou Hoek-Brown;

c) alterar o tipo de variável e assim quantificar a influência de carregamento superficial, pressão interna ou presença de água;

d) utilizar o planejamento fatorial para quantificar a influência dos parâmetros geomecânicos no FS da frente de escavação.

e) utilizar o planejamento fatorial de experimentos e as superfícies de resposta para otimizar soluções de projeto como os de aterros, já que as superfícies de resposta podem apresentar pontos máximos ou mínimos;

f) validar o estudo apresentado com dados reais de obras já executadas.

g) realizar uma previsão de deslocamentos longitudinais de escavações subterrâneas através de modelos estatísticos obtidos ao se aplicar o planejamento fatorial e comparar estes resultados com os obtidos através de modelos numéricos tridimensionais ou dados de instrumentação. 



\section{REFERÊNCIAS}

ADDENBROOK, T. I.; POTTS, D.; PUZRIN, A. M. The influence of pre-failure soil stiffness on the numerical analysis of tunnel construction. Geotechnique, p. $693-712,1997$.

AFTES. Recommendations on the convergence confinement method. Tunnels et Ouvrages Souterrains 174. [S.1.], 2002. 414 - 424 p.

ASSIS, A. P. Mecânica das rochas: Obras subterrâneas - apostila. 2013.

ATKINSON, J.; CAIRNCROSS, A.; JAMES, R. Model tests on shallow tunnels in sand and clay: 7f, 9r. tunnels and tunnelling, july, 1974, p28-32. In: PERGAMON. International Journal of Rock Mechanics and Mining Sciences \& Geomechanics Abstracts. [S.1.], 1974. v. 11, n. 10, p. 204.

ATKINSON, J.; POTTS, D. Stability of a shallow circular tunnel in cohesionless soil. Geotechnique, Thomas Telford Ltd, v. 27, n. 2, p. 203-215, 1977.

AUGARDE, C. E.; BURD, H. J. Three-dimensional finite element analysis of lined tunnels. International Journal for Numerical and Analytical Methods in Geomechanics, v.25, p. $243-262,2001$.

BARKER, T. B.; MILIVOJEVICH, A. Quality by experimental design. [S.1.]: CRC Press, 2016.

BARROS NETO, B.; SCARMINIO, I. S.; BRUNS, R. E. Como Fazer Experimentos. Aplicações na Ciência e na Indústria. [S.1.]: Bookman, 2010. ISBN 9788577806522.

BERNAT, S. Modélisation des déformations induites par le creusement d un tunnel Application au métro de Lyon Vaise. Tese (Doutorado) - Ecole Centrale Lyon, 1996.

BOX, G. E.; BISGAARD, S. The scientific context of quality improvement. [S.1.]: Center for Quality and Productivity Improvement, University of Wisconsin-Madison, 1987.

BUCKY, P. B. Use of models for the study of mining problems. [S.1.]: American Institute of Mining and Metallurgical Engineers, Incorporated, 1931.

CARRANZA-TORRES, C.; FAIRHURST, C. Application of the convergence-confinement method of tunnel design to rock masses that satisfy the hoek-brown failure criterion. Tunneling and Underground Space Technology, v. 15, n. 2, p. 187 - 213, 2000.

CECÍLIO, M. O. Estudo do comportamento de um túnel em solo residual de gnaisse por meio de ensaios triaxiais com controle de trajetória de tensões. 204 p. Dissertação (Mestrado) — Escola Politécnica da Universidade de São Paulo, Sã Paulo, 2009.

CHAPMAN, D.; METJE, N.; STÄRK, A. Introduction to Tunnel Construction. [S.1.]: Taylor \& Francis, 2010. (Applied geotechnics). ISBN 9780203895153.

CORPORATION, D. G. S. Company Brochure. Herndon, 1997.

DELGADO, A. M. E. F. Estabilização da frente de túneis com inclusões lineares. Tese

(Doutorado) - Universidade do Porto Faculdade de engenharia, set. 2009. 
DEVOR, R. E.; CHANG, T.-h.; SUTHERLAND, J. W. Statistical quality design and control: contemporary concepts and methods. [S.1.]: Prentice Hall, 2007.

DIAS, D.; KASTNER, R. Movements caused by the excavation of tunnels using face pressurized shields - analysis of monitoring and numerical modelling results. Engineering Geology, v. 152, p. $17-25,2013$.

DO, N. A.; DIAS, D. A comparison of $2 \mathrm{~d}$ and $3 \mathrm{~d}$ numerical simulations of tunnelling in soft soils. Environmental Earth Sciences, v. 76, n. 3, p. 102, 2017.

DO, N. A.; DIAS, D.; ORESTE, P.; DJERAN-MAIGRE, I. 2d tunnel numerical investigation: The influence of the simplified excavation method on tunnel behavior. Geotech. Geol. Eng., v. 32, p. $43-58,2014$.

DUNCAN, J. M. Factors of safety and reliability in geotechnical engineering. Journal of geotechnical and geoenvironmental engineering, American Society of Civil Engineers, v. 126, n. 4, p. 307-316, 2000.

FENNER, R. Untersuchungen zur erkenntis des gebirgsdruckes. Glükauf, v. 74, 1938.

FRANÇA, P. T. Estudo do comportamento de túneis: análise numérica tridimensional com modelos elasto-plásticos. Dissertação (Mestrado), 2006.

GARRIDO, J. O pipe-jacking abre uma janela para o futuro. Revista Engenharia, n. 560, p. 42 - 72, 2003. Disponível em: <http://www.geocompany.com.br/ftp/janela.pdf>. Acesso em: $27 / 11 / 2017$.

GOMES, R. A.; CELESTINO, T. B. Influence of physical and geometrical parameters on three-dimensional load transfer mechanism at tunnel face. Can. Geotech. J., v. 46, p. 855 - 868, 2009.

GOMES, R. A. M. P. Análise tridimensional de túneis considerando o comportamento dependente do tempo na interação maciço-suporte. Tese (Doutorado) — Universidade de São Paulo, 2006.

GREIFENEDER, E. Comparison of cut-and-cover tunneling method vs. new austrian tunneling method (NATM) for urban tunnels with shallow overburden. Dissertação (Mestrado) - Technische Universitat Wien, Viena, Áustria, 2003.

GUGLIELMETTI, V.; GRASSO, P.; MAHTAB, A.; XU, S. Mechanized tunnelling in urban areas: design methodology and construction control. [S.1.]: CRC Press, 2008.

HERRENKNECHT, T. S. Pioneering underground technologies. In: Herrenknecht Tunnelling Systems, 2016. Disponível em: <https://www.herrenknecht.com/en/home.html>. Acesso em: 31 mai. 2018.

HOEK, E.; BROWN, E. T. Underground excavations in rock. Institution of Mining and Metallurgy, London, p. 527, 1980.

HUNG, C. J.; MONSEES, J.; MUNFAH, N.; WISNIEWSKI, J. Technical Manual for Design and Construction of Road Tunnels - Civil Elements. One Penn Plaza, New York, NY 10119, 2009. $702 \mathrm{p}$. 
JURAN, J.; JR, F. G.; JR, R. B. Quality control Handbook. 3 ed.. ed. [S.1.]: McGraw-Hill, 1951.

KARAKUS, M. Appraising the methods accounting for $3 \mathrm{~d}$ tunneling effects in $2 \mathrm{~d}$ plane strain fem analysis. Tunneling and Underground Space Technology, v. 20, p. 47 - 56, 2007.

KARAKUS, M.; FOWELL, R. Effects of different tunnel face advance excavation on the settelement by fem. Tunnelling and underground space technology, v. 18, n. 5, p. $513-523$, 2003.

KAYE, J. A. M.; FRANGOU, A. A strategic methodology to the use of advanced statistical quality improvement techniques. The TQM magazine, MCB UP Ltd, v. 10, n. 3, p. 169-176, 1998.

KIRSCH, G. Die theorie der elastizität und die bedürfnisse der festigkeitslehre. Zeitschrift des Vereines deutscher Ingenieure, p. 797-807, 1898.

KOCHEN, R.; JR., A. N.; HEINZ., H.; ROTTMANN, E. Simulação de escavações subterrâneas por elementos finitos. Simpósio sobre escavações subterrâneas por elementos finitos, p. 195-217, 1985.

LEE, K. M.; ROWE, R. K. Finite element modelling of the three-dimensional ground deformations due to tunnelling in soft cohesive soils: Part 1 - method of analysis. Computer and Geotechnics 10, p. 87-109, 1990.

LEE, K. M.; ROWE, R. K. Finite element modelling of the three-dimensional ground deformations due to tunnelling in soft cohesive soils: Part 2 - results. Computer and Geotechnics 10, p. 111 - 138, 1990.

LEE, K. M.; ROWE, R. K. An analysis of three-dimensional ground moviments: the thunder bay tunnel. Canadian Geotechinical Journal,, v. 28, p. 25 - 41, 1991.

LEVINE, D.; BERENSON, M.; STEPHAN, D. Estatística: teoria e aplicações. [S.1.]: Livros Técnicos e Científicos, 1998.

LO, K.; ROWE, R. Predicting settlement due to tunnelling in clays. tunnelling in soil and rock. American Society of Civil Engineers, Geotechnical III Conference, Atlanta, p. 48 76, 1984.

LOMBARDI, G. Dimensionning of tunnel linings with regard to constructional procedure. Tunnels and Tunneling, 1973.

MEDEIROS, H. Engenharia subterrânea. Téchne, n. 107, fev. 2006. Disponível em: $<$ http://techne17.pini.com.br/engenharia-civil/107/artigo287064-1.aspx>. Acesso em: 27/11/2017.

MELlO, V.; BOSCOV, P.; CAMPANHA, C. Túneis em Terrenos Pouco Consistentes. São Paulo, 1998.

MOLDOVAN, A. R.; POPA, A. Finite element modelling for tunneling excavation. Acta Technica Napocensis: Civil Engineering and Architecture, v. 55, n. 1, p. 99 - 113, 2012.

MÖLLER, S. Tunnel induced settlements and structural forces in linings. Tese (Doutorado) — Stuttgart University, 2006. 
MONTGOMERY, D. C.; RUNGER, G. C.; CALADO, V. Estatística Aplicada E Probabilidade Para Engenheiros . [S.1.]: Grupo Gen-LTC, 2000.

MORAES JÚNIOR, A. Simulação numérica tridimensional de túneis escavados pelo NATM. 123 p. Dissertação (Mestrado) — Departamento de Engenharia Civil e Ambiental, Universidade de Brasília, Brasília, DF, 1999.

NAKAMURA, J. Execução de tunnel liner. Infraestrutura Urbana, n. 18, set. 2012. Disponível em: <http://infraestruturaurbana17.pini.com.br/solucoes-tecnicas/18/artigo265044-1.aspx>. Acesso em: 27/11/2017.

NEVES, C. d. F. C.; SCHVARTZMAN, M. M. d. A. M.; JORDÃO, E. Variables search technique applied to gas separation. Química Nova, SciELO Brasil, v. 25, n. 2, p. 327-329, 2002.

NG, R. A procedure for prediction of settlement due to tunnels in clays. Pan American Conference on Soil Mechanics and Foundation Engineering, Vina del mar, Chile, v. 3, p. 1413 - 1430, 1991.

PACHER, F. Deformations messungen in versuchsstollen als mittel zur erfoschung des gebirgs verhaltens bemessung des ausbaues. Felsmechanik und Ingenieursgeologie, Supplementum IV, 1964.

PAN, X. D.; HUDSON, J. A. Plane strain analysis in modelling three-dimensional tunnel excavations. Int. J. Rock Mech. Min. Sci. and Geomech., v. 25, n. 5, p. 331 - 337, 1988.

PANET, M. Analyse la stanilité d'un tunnel creusé dans massif rocheux en tenat compte du comportement aprés la rupture. Rock Mechanics 8, p. 209 - 223, 1976.

PANET, M.; DOBEREINER, L.; SAMAMA, L. O método da convergência-confinamento aplicado aos maciços rochosos brandos. Geotecnia - Revista da Sociedade Portuguesa de Geotecnia, n. 66, p. 17 - 40, Novembro 1992.

PANET, M.; GUELLEC, P. Contribution á l'étude du souténement derriére le front de taille. Proc. 3rd Cong. Int. Soc. Rock Mechanics, Denver, v. 2, n. B, 1974.

PANET, M.; GUENOT, A. Analysis of convergence behind face of tunnel. Tunnelling, London, p. $197-203,1982$.

PECK, R. B. Deep excavations and tunneling in soft ground. Proc. 7th Int. Con. SMFE, State of the Art, p. 225-290, 1969.

POTTS, D. M.; ZDRAVKOVIC, L. Finite element Analysis in Geotechnical Engineering: Application. London: Thomas Telford, 2001. v. 2.

POWELL, D. B.; BEVERIDGE, J. P. Heathrow-express-design and performance of platform tunnels a terminal 4. Tunnelling '97 IMM, p. 565 - 593, 1997.

REDAELLI, L.; CERELLO, L. Escavações. Geologia de Engenharia. São Paulo: Associação Brasileira de Geologia de Engenharia e Ambiental. ABGE. Cap, v. 19, p. 311-330, 1998.

REY, L. Planejar e redigir trabalhos científicos. [S.1.]: Edgard Blucher, 1993.

ROCHA, M. d. O. Estudo da estabilidade da frente de escavação de túneis rasos em solo.

Universidade Federal de Minas Gerais. Minas Gerais, Brasil, 2014. 
ROWE, R.; LO, K.; KACK, K. A method of estimating surface settlement above shallow tunnels constructed in soft ground. Canadian Geotechnical Journal, v. 20, p. 11 - 22, 1983.

ROWE, R. K.; LEE, K. M. Subsidence owing to tunneling. ii. evaluation of prediction techique. Canadian Geotechical Journal, v. 29, n. 6, p. 941 - 954, 1992.

ROWE, R. K.; LO, K. Y.; KACK, K. J. A method of estimating surface settlement above shallow tunnels constructed in soft ground. Canadian Geotechinical Journal, v. 20, p. 11 - 22, 1983.

SALENÇON, J. Contraction quasi-statique d'une cavite a symetrie spherique ou cylindrique dans un milieu elastoplastique. In: Annales des ponts et chaussées. [S.1.: s.n.], 1969. v. 4, p. 231-236.

SCHIKORA, K.; OSTERMEIER, B. Two-dimensional calculation model in tunneling. verification by measurement results and by spatial calculation. Proceedings of the 6th International Conference on Numerical Methods in Geomechanics, Innsbruck, p. 1499 $-1503,1988$.

SCHWARTZ, C. W.; EINSTEIN, H. H. Improved design tunnel supports: Vol1 - simplified analysis for ground-structure interation in tunneling. In: Report No. UMTA-MA-06-0100-80-4, p. $427,1980$.

SCHWEIGER, H. F.; SCHULLER, H.; PÖTTLER, R. Some remarks on 2d models for numerical simulation of underground constructions with complex cross sections. In: The ninth international Conference on Computer Methods and Advances in Geomechanics. Wuhan, China: [s.n.], 1997.

SILVA, C. A. R. d. Perfil geológico-geotécnico do subsolo ao longo do traçado do metrô de Goiânia. Dissertação (Mestrado) — Universidade de Brasília, 2007.

SINHA, R. S. Underground structures: design and instrumentation. [S.l.]: Elsevier, 2012.

STEINBERG, D. M.; HUNTER, W. G. Experimental design: review and comment.

Technometrics, Taylor \& Francis, v. 26, n. 2, p. 71-97, 1984.

SWOBODA, G. Finite element analysis of the new australian tunneling method (natm). In: Proceedings of the 3rd International Conference on Numerical Methods in Geomechanics, p. $581-586,1979$.

SWOBODA, G.; MARENCE, M.; MADER, I. Finite element modelling of tunnel excavation. International Journal of Engineering Modelling,, v. 6, p. 51 - 63, 1994.

TAY, K.-M.; BUTLER, C. Methodologies for experimental design: A survey, comparison, and future predictions. Quality Engineering, Taylor \& Francis, v. 11, n. 3, p. 343-356, 1999.

TEIXEIRA, A. Estudo do comportamento do túnel do metrô do Distrito Federal escavado em solos porosos colapisíveis. Dissertação (Mestrado) - Universidade de Brasília, Brasília, DF, 1994.

VERMEER, P. A.; BONNIER, P. G.; MÖLLER, S. On a smart use of 3d-fem in tunneling. In: 8th International Symposium on Numerical Models in Geomechanics, Roma, Italy, 2002.

VERMEER, P. A.; RUSE, N.; MARCHER, T. Tunnel heading stability in drained ground. Felsbau, v. 20, n. 6, p. 8-18, 2002. 
VLACHOPOULOS, N.; DIEDERICHS, M. S. Appropriate uses and practical limitations of $2 \mathrm{~d}$ numerical analysis of tunnels and tunnel support response. Geotechnical and Geological Engineering, 2013. ISSN 0960-3182.

ZIRLIS, A. Soil nailing-chumbamento de solos: alguns aspectos desta recente técnica de contenção. Palestra na escola politécnica da Universidade Federal da Bahia. ESTE Engenharia Serviços Técnicos Especiais, 1988. 
Apêndices 



\section{APÊNDICE A - TRABALHANDO COM O ABAQUS ${ }^{\circledR}$}

\section{A.1 CALIBRAÇÃO DOS MODELOS}

\section{A.1.1 $A B A Q U S^{\circledR}$}

O Abaqus $6.14^{\circledR}$ é um software de simulação numérica, baseado no MEF, fabricado pela empresa Dassault Systèmes. Ele apresenta uma extensa biblioteca de elementos que possibilitam modelar praticamente qualquer geometria. Apresenta também uma grande lista de modelos constitutivos que permitem simular o comportamento reológico dos mais diversos materiais. Este software é uma ferramenta robusta que auxilia no estudo de inúmeros problemas de engenharia tais como: problemas estruturais, de mecânica dos fluídos, termodinâmicos, etc.

Os seguintes modelos foram realizados para reproduzir problemas com soluções analíticas conhecidas. A intenção desta etapa é validar os resultados numéricos e também otimizar as propriedades dos modelos como dimensões, tipos de elementos, densidade e topologia da malha.

\section{A.1.2 CILINDRO DE PAREDES ESPESSAS}

Para este caso considerou-se um cilindro de paredes espessas como mostrado na Figura 60. As dimensões e propriedades do material são típicas de tubos utilizados em projetos de engenharia mecânica. Este é um caso que pode ser resolvido de forma axissimétrica.

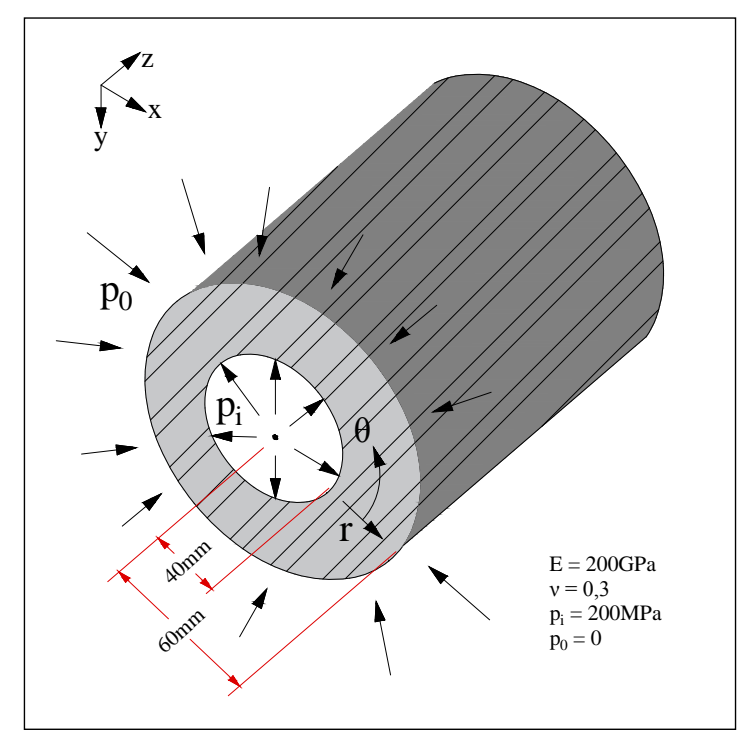

Figura 60 - Geometria do cilindro e propriedades do material.

A solução analítica para as tensões e deslocamentos radiais foi proposta por Gabriel 
Lamé em 1833 e é dada pelas seguintes equações:

$$
\begin{gathered}
\sigma_{\theta}=p_{i} \frac{b^{2}}{a^{2}-b^{2}}\left(1+\frac{a^{2}}{r^{2}}\right)-p_{0} \frac{a^{2}}{a^{2}-b^{2}}\left(1+\frac{b^{2}}{r^{2}}\right) \\
\sigma_{r}=p_{i} \frac{b^{2}}{a^{2}-b^{2}}\left(1-\frac{a^{2}}{r^{2}}\right)-p_{0} \frac{a^{2}}{a^{2}-b^{2}}\left(1-\frac{b^{2}}{r^{2}}\right) \\
u_{r}=\frac{1-\nu}{E} \frac{\left(b^{2} p_{i}-a^{2} p_{0}\right)}{a^{2}-b^{2}}+\frac{1+\nu}{E} \frac{\left(p_{i}-p_{0}\right) a^{2} b^{2}}{\left(a^{2}-b^{2}\right) r^{2}}
\end{gathered}
$$

onde: $\sigma_{r}=$ tensão radial na direção do centro do cilindro; $\sigma_{\theta}=$ tensão circunferencial atuante na direção perpendicular à radial; $u_{r}=$ deslocamento radial atuante na direção do centro do cilindro; $a=$ raio interno; $b=$ raio externo; $r=$ distância do centro do cilindro ao ponto desejado; $p_{i}=$ pressão interna; $p_{0}=$ pressão externa; $E=$ módulo de elasticidade e $\nu=$ coeficiente de Poisson.

Assim, utilizando-se coordenadas cilíndricas as seguintes condições serão satisfeitas:

a) Deslocamento circunferencial nulo $\left(u_{\theta}\right)=0$;

b) Tensões e deformações não variam $\operatorname{com} \theta$;

c) As tensões e os deslocamentos radiais não variam com a coordenada $z$;

d) Estado plano de deformação, ou seja, tensões e deformações axiais estão desacopladas das tensões e deformações no plano produzidas pela pressão interna ou externa.

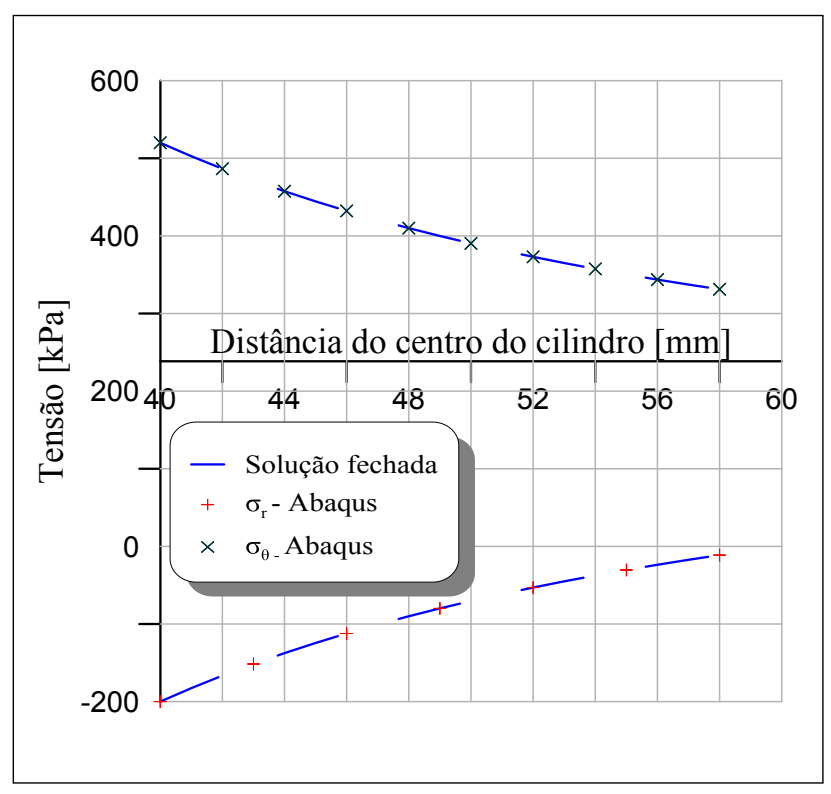

Figura 61 - Resultados de tensões para o modelo numérico de um tubo de paredes espessas. 


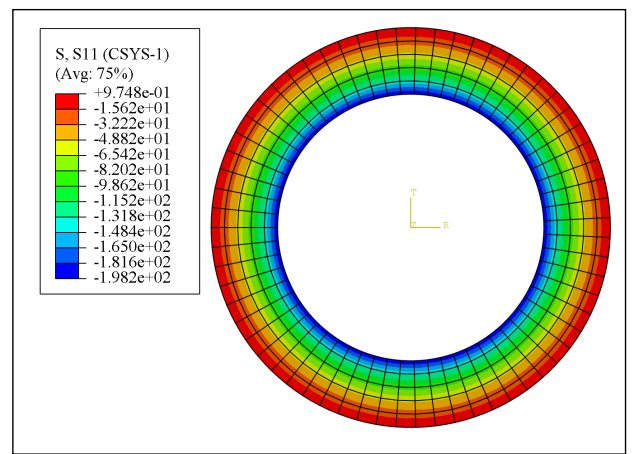

(a) tensões radiais

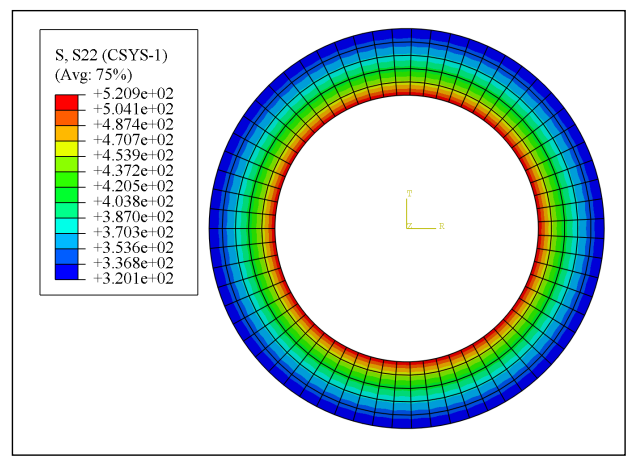

(b) tensões circunferenciais

Figura 62 - Contornos de tensão para o cilindro de paredes espessas.

Utilizando-se o elemento CPS4, com tamanho aproximado de $1 \mathrm{~mm}$ o modelo numérico apresentou 315 elementos e 1071 nós, os resultados estão mostrados nas Figuras 61 e 62 . O resumo dos resultados do modelo numérico em questão está mostrado na Tabela 12.

Tabela 12 - Resultados do modelo numérico para um tubo de paredes espessas

\begin{tabular}{c|ccc}
\hline & Erro Mín.[\%] & Erro Máx.[\%] & Erro Médio[\%] \\
\hline$\sigma_{\theta}$ & 0,04 & 0,26 & 0,17 \\
$\sigma_{r}$ & 0,15 & 6,38 & 1,33 \\
\hline
\end{tabular}

\section{A.1.3 MEIO INFINITO COM UMA ABERTURA SUJEITO A TENSÃO UNIFORME}

Neste caso foi considerado um meio infinito, com uma cavidade sem pressão interna e sujeito a um campo de tensões uniforme aplicado somente na direção $x$ (Figura 63).

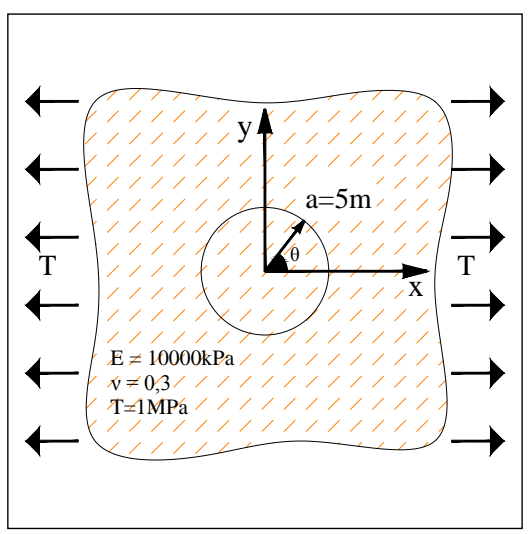

Figura 63 - Geometria do meio infinito considerado.

Para este caso a variação da tensão no perímetro da cavidade em função de $\theta$ é dada de acordo com a Equação A.4.

$$
\sigma_{\theta}(a, \theta)=T \times(1-2 \cos (2 \theta))
$$


onde: $\sigma_{\theta}=$ tensão circunferencial no perímetro da cavidade; $T=$ tensão atuante no meio infinito; $\theta=$ ângulo no sentido anti-horário com origem no eixo $x$ e $a=$ raio da cavidade.

O modelo numérico foi realizado utilizando o elemento CPS8R, com tamanho aproximado de $0,5 \mathrm{~m}$, a topologia da malha foi elaborada com o controle estruturado e para diminuir as distorções dos elementos a geometria foi particionada em quatro a partir das diagonais (Figura 64).

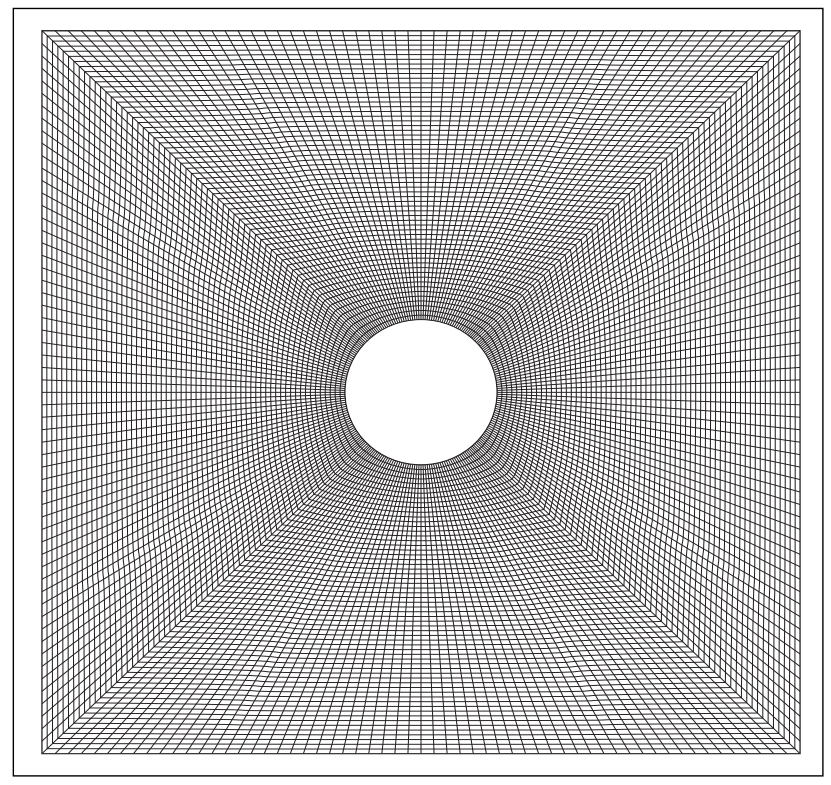

Figura 64 - Malha de elementos CPS8R.

Os resultados obtidos forneceram erros médios da ordem de 16,61\% com mínimo de 0,67\% e máximo de 49,26\% a comparação entre os resultados numéricos e os analíticos está mostrada na Figura 65. 


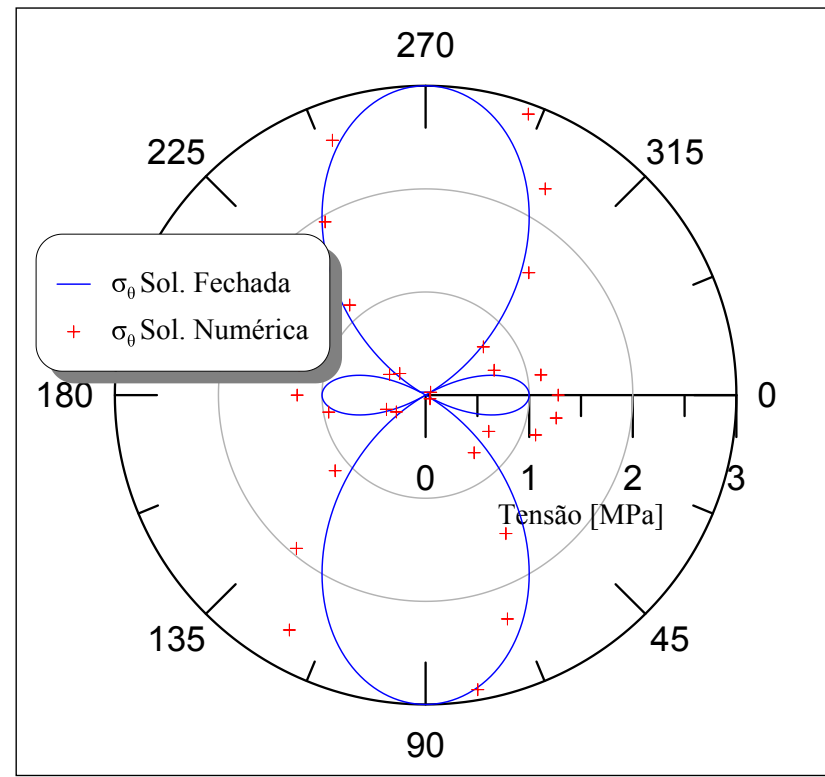

Figura 65 - Comparação entre os resultados de tensões obtidos através do modelo numérico e dos obtidos com a Equação A.4.

Os resultados dos contornos do campo de tensão estão mostrados nas Figuras 66a e 66b.

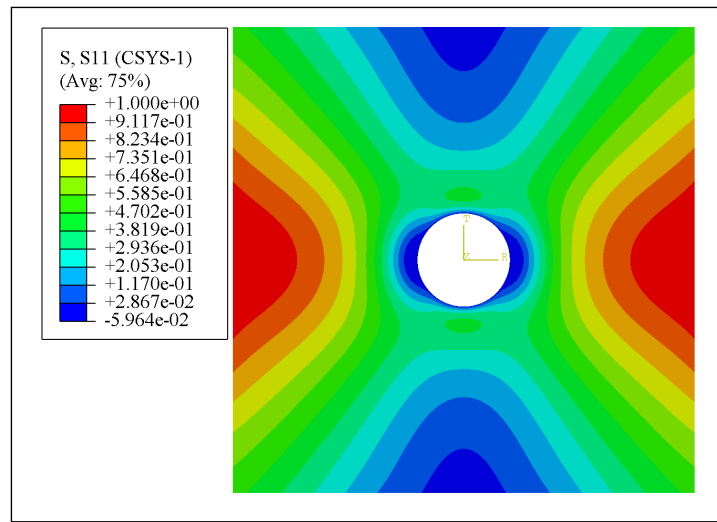

(a) tensões radiais

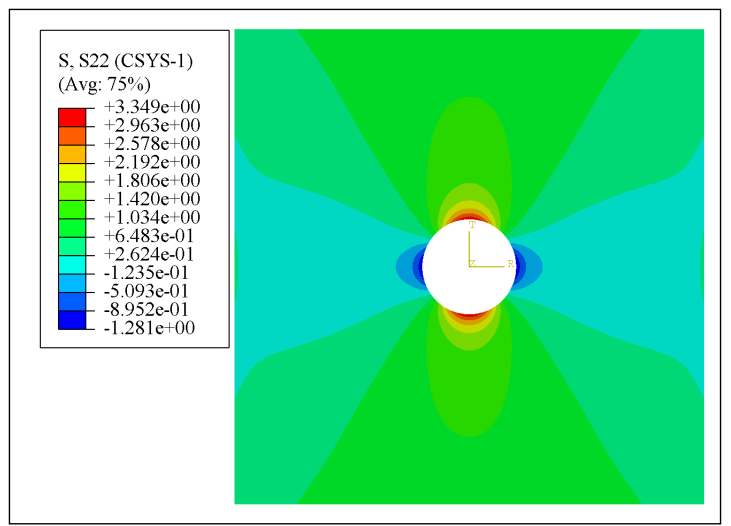

(b) tensões circunferenciais

Figura 66 - Contornos do campo de tensão para o modelo de um meio infinito com uma cavidade.

\section{A.1.4 SOLUÇÃO CLÁSSICA DE KIRSCH}

A solução proposta por Kirsch (1898), foi baseada na solução de tensões ao redor de uma placa sob estado plano de tensões e com um furo no centro. A Figura 67 mostra o modelo considerado por Kirsch. 


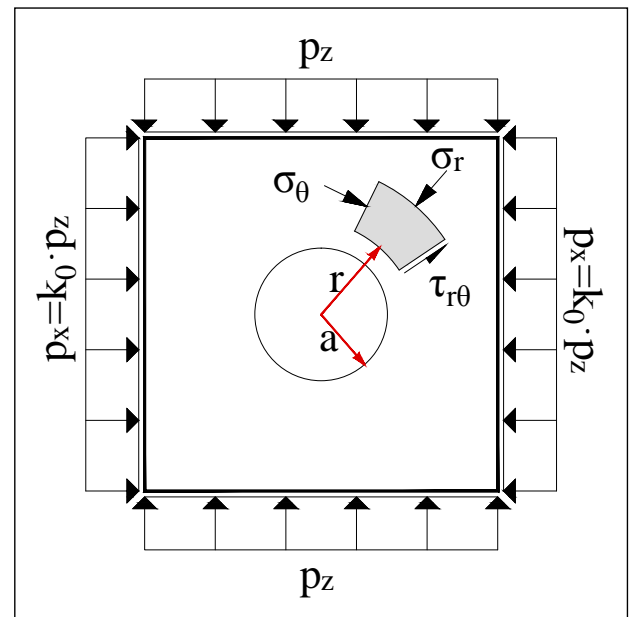

Figura 67 - Solução analítica de Kirsch (adaptado de Assis, 2013).

Utilizando coordenadas polares as equações para as tensões e deslocamentos assumem as formas apresentadas a seguir:

$$
\begin{gathered}
\sigma_{r}=\left(\frac{p_{x}+p_{z}}{2}\right) \times\left(1-\frac{a^{2}}{r^{2}}\right)+\left(\frac{p_{x}-p_{z}}{2}\right) \times\left(1-\frac{4 a^{2}}{r^{2}}+\frac{3 a^{4}}{r^{4}}\right) \times \cos (2 \theta) \\
\sigma_{\theta}=\left(\frac{p_{x}+p_{z}}{2}\right) \times\left(1+\frac{a^{2}}{r^{2}}\right)-\left(\frac{p_{x}-p_{z}}{2}\right) \times\left(1+\frac{3 a^{4}}{r^{4}}\right) \times \cos (2 \theta) \\
\tau_{r \theta}=-\left(\frac{p_{x}-p_{z}}{2}\right) \times\left(1+\frac{2 a^{2}}{r^{2}}-\frac{3 a^{4}}{r^{4}}\right) \times \operatorname{sen}(2 \theta) \\
u_{r}=-\left(\frac{p_{x}+p_{z}}{4 G}\right) \times \frac{a^{2}}{r}-\left(\frac{p_{x}-p_{z}}{4 G}\right) \times \frac{a^{2}}{r} \times\left[4(1-\nu)-\frac{a^{2}}{r^{2}}\right] \times \cos (2 \theta) \\
u_{\theta}=\left(\frac{p_{x}-p_{z}}{4 G}\right) \times \frac{a^{2}}{r} \times\left[2(1-\nu)+\frac{a^{2}}{r^{2}}\right] \times \operatorname{sen}(2 \theta)
\end{gathered}
$$

onde: $\sigma_{r}=$ tensão radial na direção do centro da escavação; $\sigma_{\theta}=$ tensão circunferencial atuante na direção perpendicular à radial; $\tau_{r \theta}=$ tensão cisalhante atuante sobre a superfície infinitesimal; $u_{r}=$ deslocamento radial atuante na direção do centro da escavação; $u_{\theta}=$ deslocamento circunferencial perpendicular à radial; $p_{x}=$ pressão horizontal que pode ser considerada tensão horizontal $\left(\sigma_{h}\right)$; $p_{v}=$ pressão vertical que pode ser considerada tensão vertical $\left(\sigma_{v}\right) ; a=$ raio da escavação; $r=$ distância do centro da escavação até o ponto de interesse; $G=$ módulo cisalhante do maciço e $\nu=$ coeficiente de Poisson.

Neste caso foram realizados dois estudos: o primeiro diz respeito a variação das dimensões do modelo mantendo-se o diâmetro da escavação constante, o segundo serviu para validar os resultados numéricos ao compará-los com os obtidos através da solução fechada. 
No primeiro estudo foram realizados seis modelos. As dimensões de cada um variaram de 2, 4, 8, 10, 20 e 40 diâmetros. O procedimento adotado pode ser resumido da seguinte forma:

a) Fixar o diâmetro da escavação;

b) implementar um primeiro modelo com dimensões de 2 diâmetros;

c) rodar o modelo;

d) comparar os resultados de deslocmentos radiais obtidos com o modelo numérico com os obtidos através da solução de Kirsch;

e) elaborar um box-plot com o resultado da comparação feita na etapa anterior (erros relativos)

f) efetuar as mesmas etapas anteriores para modelos com dimensões de 4D, 8D, 10D, $20 \mathrm{D}$ e $40 \mathrm{D}^{1}$;

g) todos os box-plot foram dispostos lado a lado para poder compor uma comparação visual dos resultados entre os diversos modelos numéricos implementados.

O resultado da aplicação do procedimento descrito está mostrado na Figura 68.

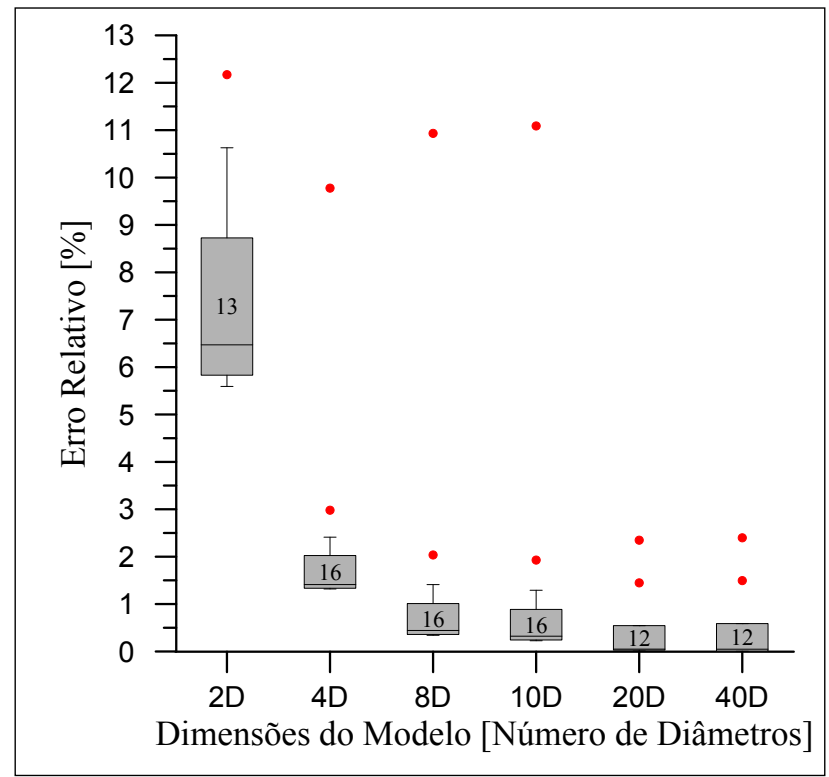

Figura 68 - Box-plot resultante da análise das dimensões do modelo.

Somente no modelo com extensão de 2 diâmetros foi utilizado o elemento linear. Todos os outros foram executados com elementos quadráticos.

Pode-se notar que a partir de 10 diâmetros os erros mantiveram-se praticamente constantes, estes resultados corroboram com o que está amplamente divulgado na literatura.

1 nesta tomou-se o cuidado de fixar em 2 diâmetros, a partir da borda da escavação, a região em que os dados de deslocamentos eram obtidos. Desta forma, garante-se que a comparação dos resultados entre os diversos modelos não seja influenciada por uma quantidade de dados amostrais muito diferentes entre si ou por alguma outra variável não prevista 
A partir desses resultados todos os modelos numéricos subsequentes foram elaborados de acordo com essas diretrizes, ou seja, as condições de contorno foram mantidas a uma distância mínima de dez diâmetros do centro da escavação.

Os resultados do segundo estudo, estão mostrados nas Figuras 69 e 70.

A partir da Figura 69 pode-se notar que os erros para os deslocamentos são praticamente nulos no contorno da cavidade. Entretanto à medida que se aproxima do ponto de aplicação da tensão os erros relativos ficam maiores, mas ainda não são significativos.

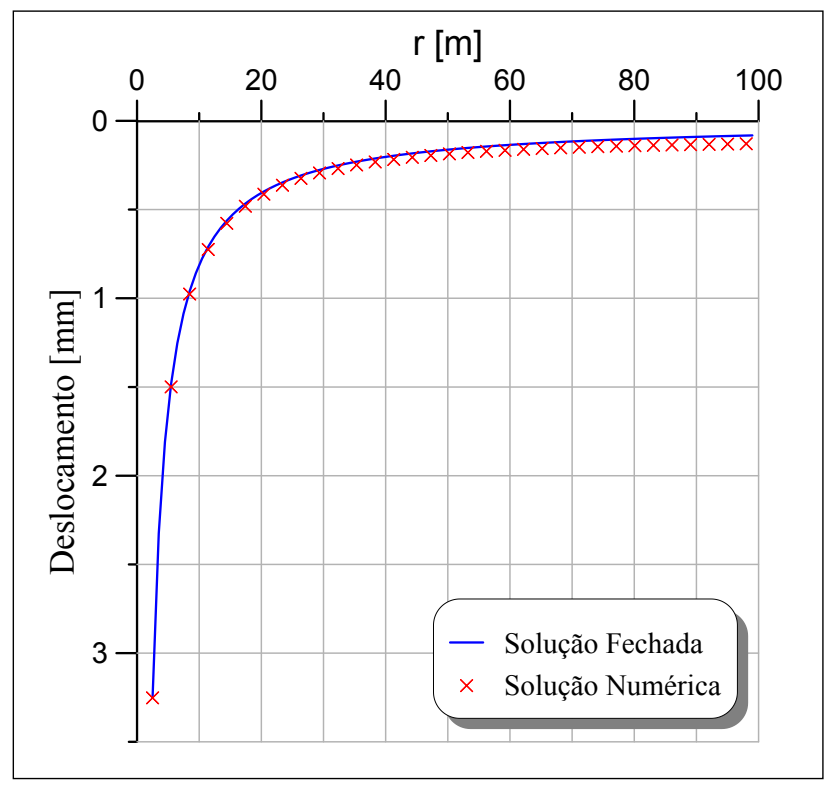

Figura 69 - Gráfico comparativo entre os resultados dos deslocamentos obtidos através dos modelos numéricos e os obtidos através da solução de Kirsch considerando $p_{1}=p_{2}$.

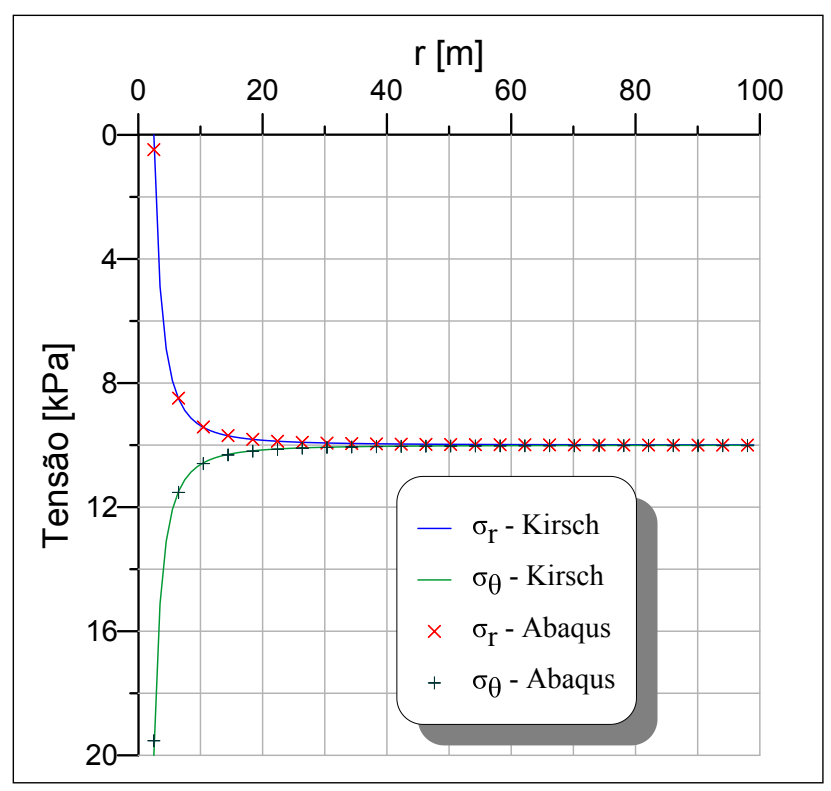

Figura 70 - Gráfico comparativo entre os resultados de tensões obtidas a partir dos modelos numéricos e os obtidos através da solução de Kirsch considerando $p_{1}=p_{2}$. 
As Figuras 71a, 71b e 72 mostram os contornos dos campos de tensão, circunferencial e radial e os deslocamentos respectivamente.

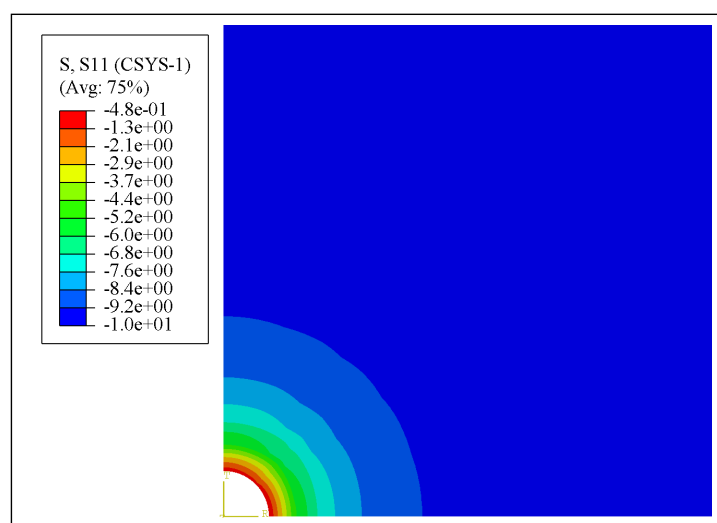

(a) Tensões circunferenciais

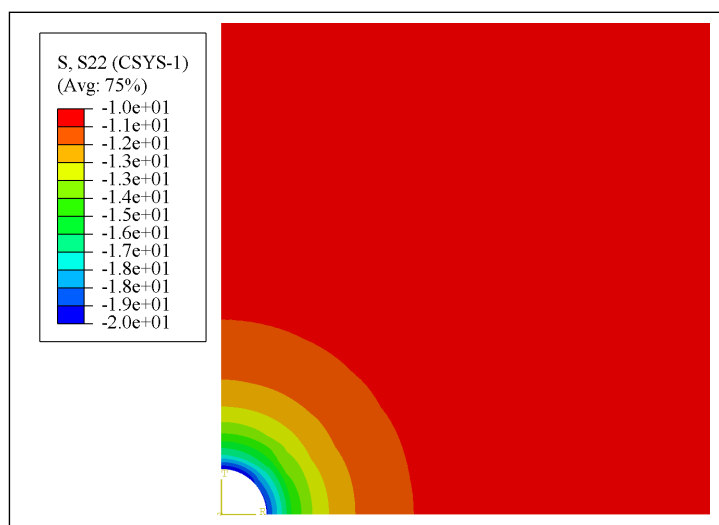

(b) Tensões radiais

Figura 71 - Contornos do campo de tensão pós-processados pelo Abaqus $6.14^{\circledR}$ para a solução de Kirsch.

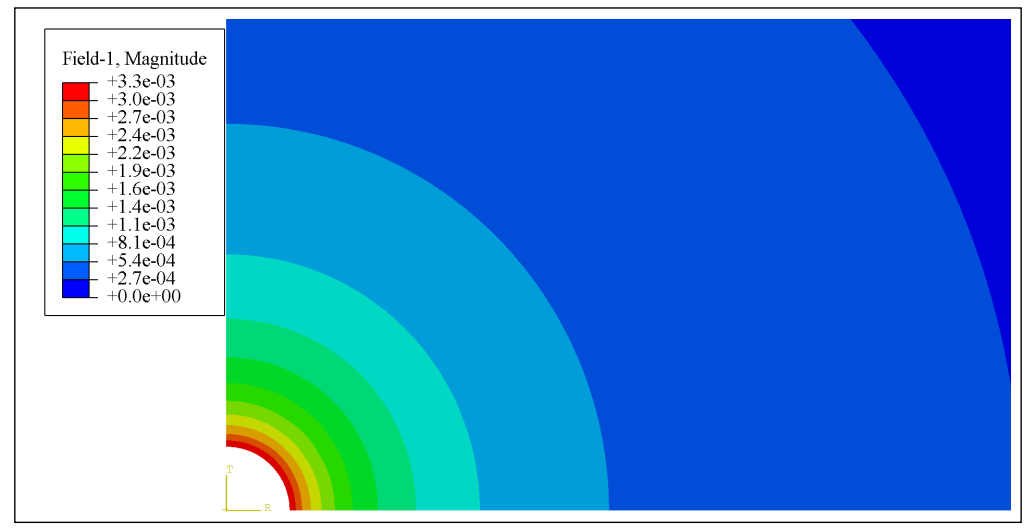

Figura 72 - Deslocamentos para a solução de Kirsch.

\section{A.1.5 SOLUÇÃO DE SALENÇON}

A solução fechada proposta por Salençon (1969) fornece os resultados de tensão e deslocamentos em uma cavidade cilíndrica executada em um meio elastoplástico submetido a um campo de tensões constante e uniforme. Assume-se para o material utilizado, um comportamento elástico linear e perfeitamente plástico, com a superfície de ruptura definida pelo critério de ruptura de Mohr-Coulomb. A geometria do modelo está mostrada na Figura 73. 


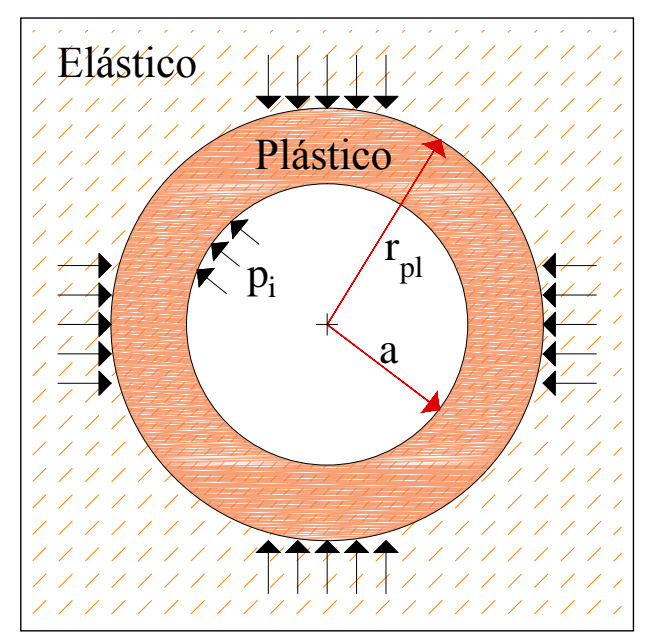

Figura 73 - Modelo proposto por Salençon (1969).

O raio da região de plastificação $r_{p l}$ é dado analiticamente por um modelo teórico baseado na solução de Salençon (1969) e pode ser avaliado utilizando-se a Equação A.10.

$$
r_{p l}=a\left(\frac{2}{K_{p}+1} \times \frac{\sigma_{0}+\frac{q}{K_{p}-1}}{p_{i}+\frac{q}{K_{p}-1}}\right)^{\left(\frac{1}{K_{p}-1}\right)}
$$

com:

$$
K_{p}=\frac{1+\operatorname{sen} \phi}{1-\operatorname{sen} \phi}
$$

e

$$
q=2 \times c \times \operatorname{tg}\left(45+\frac{\phi}{2}\right)
$$

onde: $a=$ raio da escavação; $\sigma_{0}=$ tensão inicial in situ; $p_{i}=$ pressão interna; $\phi=$ ângulo de atrito in situ e $c=$ coesão.

A tensão radial na interface entre a região elástica e a região plástica dada pela Equação A.13.

$$
\sigma_{r e}=\frac{1}{K_{p}+1} \times\left(2 \sigma_{0}-q\right)
$$

Para a região elástica as tensões e os deslocamentos radiais são expressos pelas equações a seguir:

$$
\begin{gathered}
\sigma_{r}=\sigma_{0}-\left(\sigma_{0}-\sigma_{r e}\right) \times\left(\frac{r_{p l}}{r}\right)^{2} \\
\sigma_{\theta}=\sigma_{0}+\left(\sigma_{0}-\sigma_{r e}\right) \times\left(\frac{r_{p l}}{r}\right)^{2}
\end{gathered}
$$




$$
u_{r}=\frac{r_{p l}^{2}}{2 G} \times\left(\sigma_{0}-\frac{2 \sigma_{0}-q}{K_{p}+1}\right) \times \frac{1}{r}
$$

Para a região plástica o deslocamento radial e as tensões são expressas, pelas equações abaixo:

$$
\begin{gathered}
\sigma_{r}=-\frac{q}{K_{p}-1}+\left(p_{i}+\frac{q}{K_{p}-1}\right) \times\left(\frac{r}{a}\right)^{\left(K_{p}-1\right)} \\
\sigma_{\theta}=-\frac{q}{K_{p}-1}+K_{p} \times\left(p_{i}+\frac{q}{K_{p}-1}\right) \times\left(\frac{r}{a}\right)^{\left(K_{p}-1\right)} \\
\frac{2 G \times u_{r}}{r}=(2 \nu-1)\left(\sigma_{0}+\frac{q}{K_{p}-1}\right)+ \\
\frac{(1-\nu)\left(K_{p}^{2}-1\right)}{K_{p}+K_{p s}}\left(p_{i}+\frac{q}{K_{p}-1}\right)\left(\frac{r_{p l}}{a}\right)^{\left(K_{p}-1\right)}\left(\frac{r_{p l}}{r}\right)^{K_{p s}+1}+l \\
\left(\frac{(1-\nu)\left(K_{p} K_{p s}+1\right)}{K_{p}+K_{p s}}-\nu\right)\left(p_{i}+\frac{q}{K_{p}-1}\right)\left(\frac{r}{a}\right)^{\left(K_{p}-1\right)}
\end{gathered}
$$

com:

$$
K_{p s}=\frac{1+\operatorname{sen} \psi}{1-\operatorname{sen} \psi}
$$

onde: $\psi=$ ângulo de dilatância; $\nu=$ coeficiente de Poisson e $G=$ módulo de rigidez.

O modelo numérico foi realizado com os seguintes parâmetros: $\sigma_{0}=250 \mathrm{kPa}, p_{i}=0$, $a=5 m, \nu=0.3, E=10.000 \mathrm{kPa}, c=100 \mathrm{kPa}, \phi=30^{\circ}$ e $\psi=30^{\circ}$. A comparação entre os resultados obtidos através do modelo numérico e os obtidos a partir da solução fechada estão mostrados nas Figuras 74, 75, 76a, 76b e 77. 


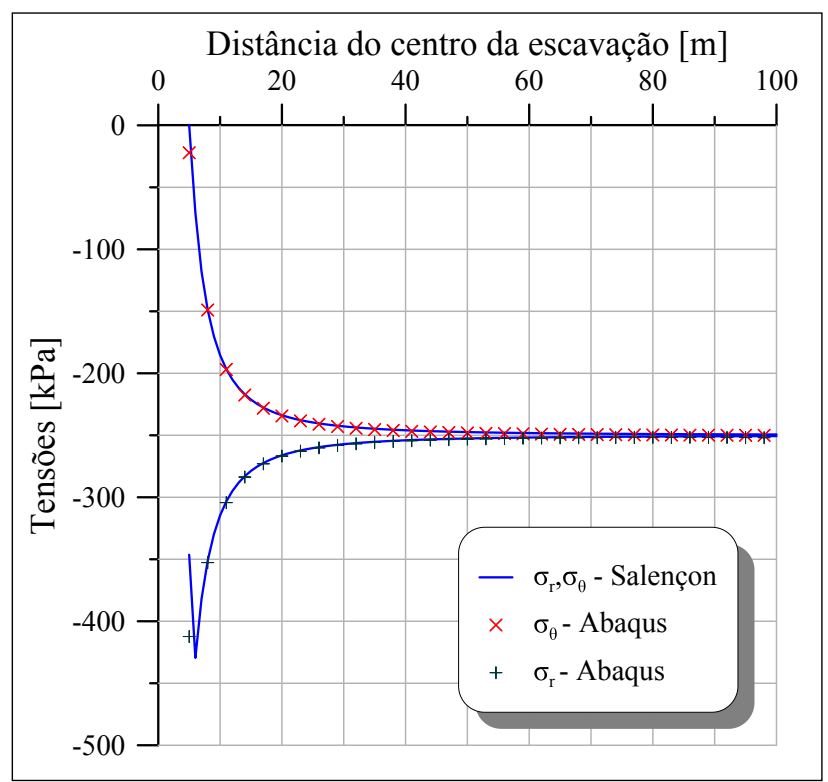

Figura 74 - Gráfico comparativo entre os resultados das tensões obtidos através dos modelos numéricos e os obtidos a partir da solução de Salençon (1969).

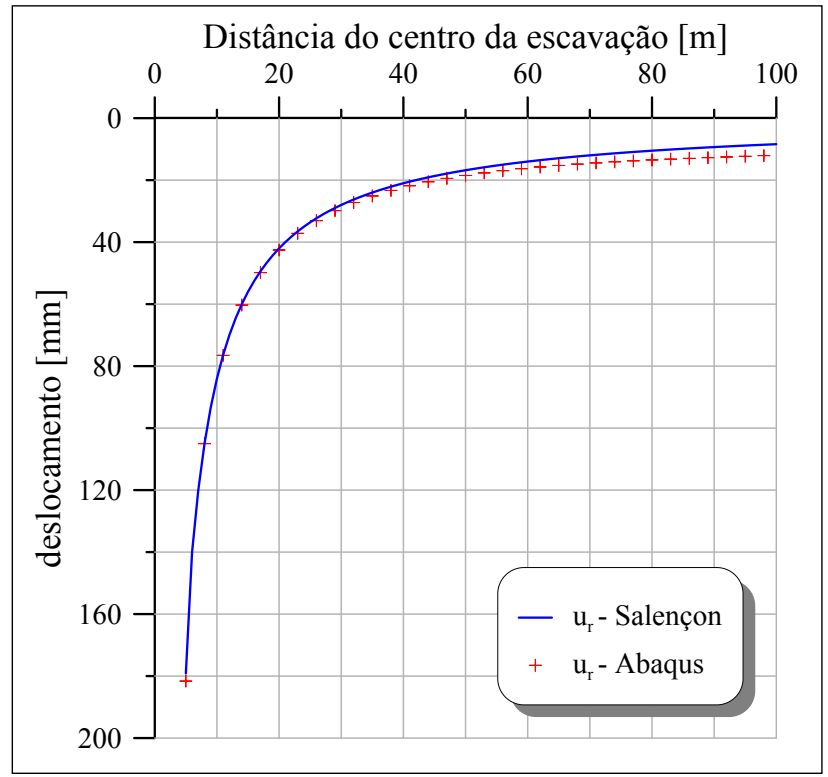

Figura 75 - Gráfico comparativo entre os resultados dos deslocamentos obtidos através dos modelos numéricos e os obtidos a partir da solução de Salençon (1969). 


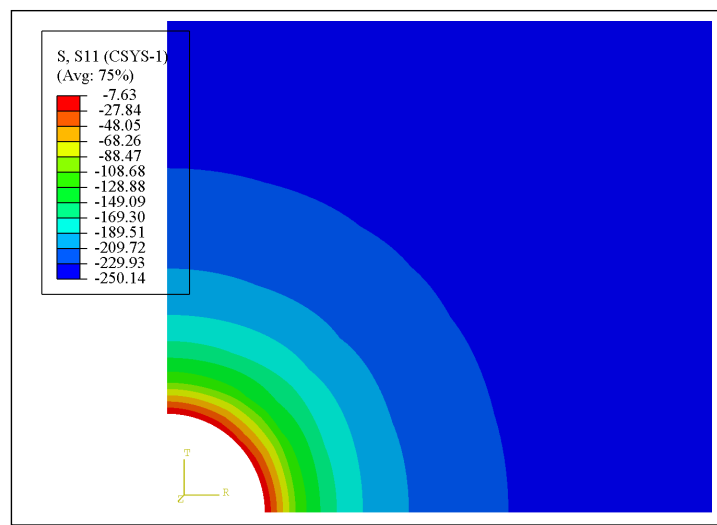

(a) Tensões radiais

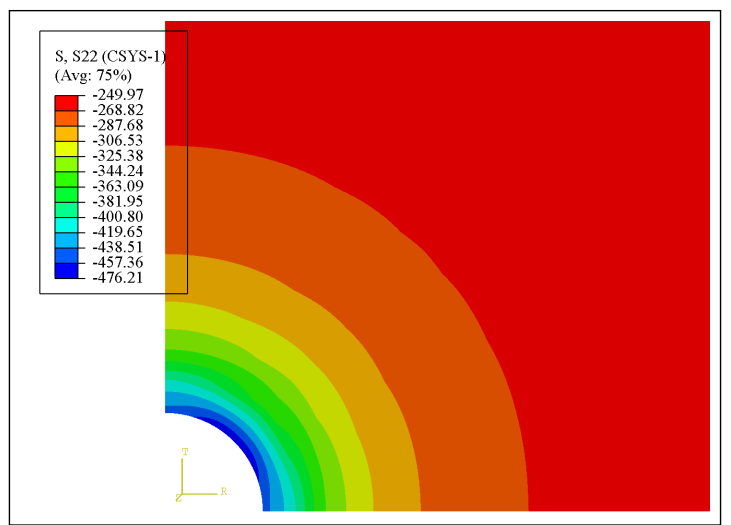

(b) Tensões circunferenciais

Figura 76 - Contornos do campo de tensão pós-processados pelo Abaqus $6.14^{\circledR}$ para a solução de Salençon (1969).

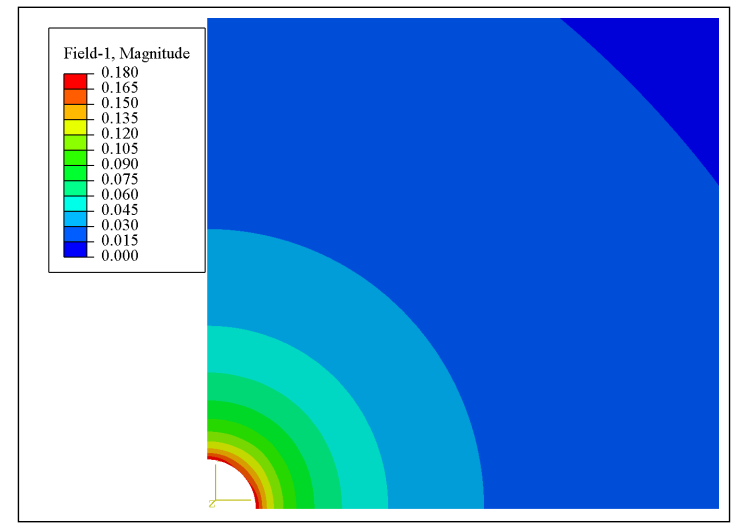

Figura 77 - Deslocamentos pós-processados pelo Abaqus $6.14^{\circledR}$ para a solução de Salençon (1969). 


\section{A.2 ROTEIROS}

\section{A.2.1 MODELO BIDIMENSIONAL}

Este primeiro exemplo tem a intenção de mostrar os conceitos utilizados nos modelos numéricos bidimensionais, tais como:

a) Utilização de planos de simetria;

b) Seleção de elementos;

c) Aplicação de carregamentos de pressão;

d) Refinamento de malha;

e) Tipo de controle de malha.

Para isto será analisada uma placa retangular com um furo no centro, submetido a um estado plano de tensão. A placa será engastada em uma extremidade e na outra extremidade será aplicado um carregamento distribuído, como mostra a Figura 78:

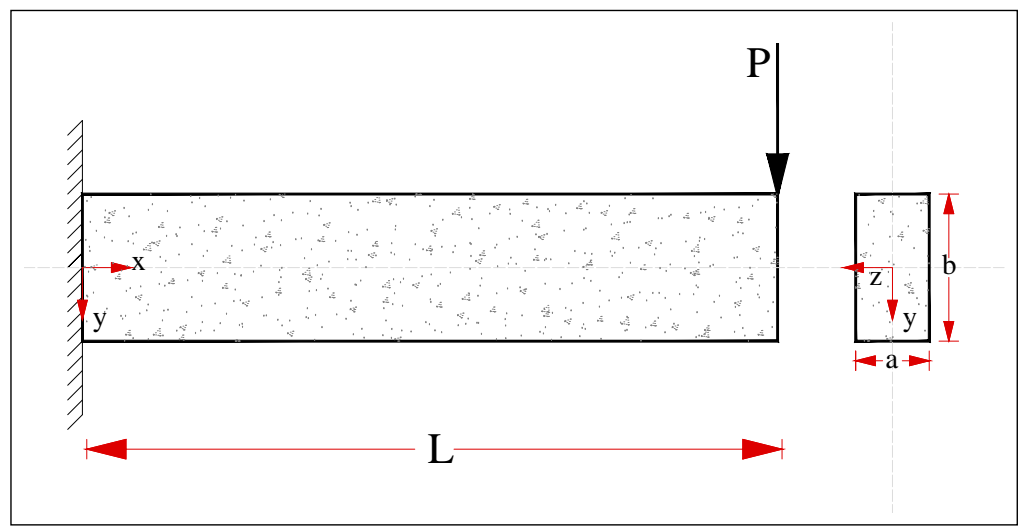

Figura 78 - Geometria do problema proposto

Para aproveitar a simetria da placa será utilizada apenas um quarto dela, este procedimento é importante, pois diminui a quantidade de elementos do modelo reduzindo a quantidade de equações que devem ser resolvidas. Isso implica em um tempo de processamento menor.

Ao utilizar os planos de simetria o que deve ser observado são as novas condições de contorno, desta forma o modelo ficará como mostrado na Figura 79:

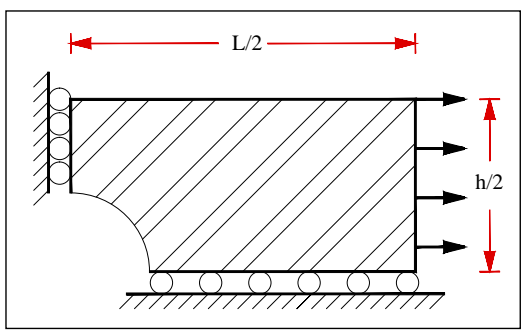

Figura 79 - Geometria da placa aplicada no modelo numérico. 


\section{Geometria}

A primeira etapa do modelo é criar a geometria. Na aba Model clicar duas vezes em Parts, como na Figura 80a.

Na sequência nomear o elemento e selecionar as opções: 2 D Planar $\rightarrow$ Deformable $\rightarrow$ Shell $\rightarrow$ Approximate Size colocar 20, como mostra a Figura 80b clique em continue....

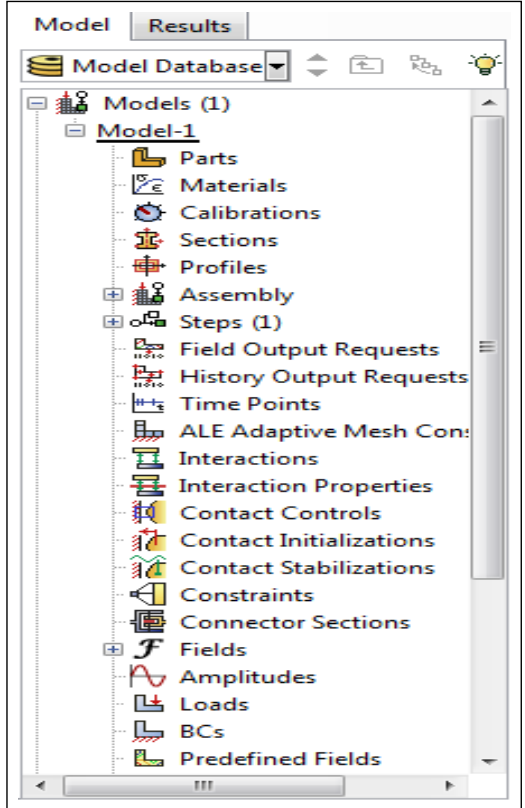

(a) Menu principal

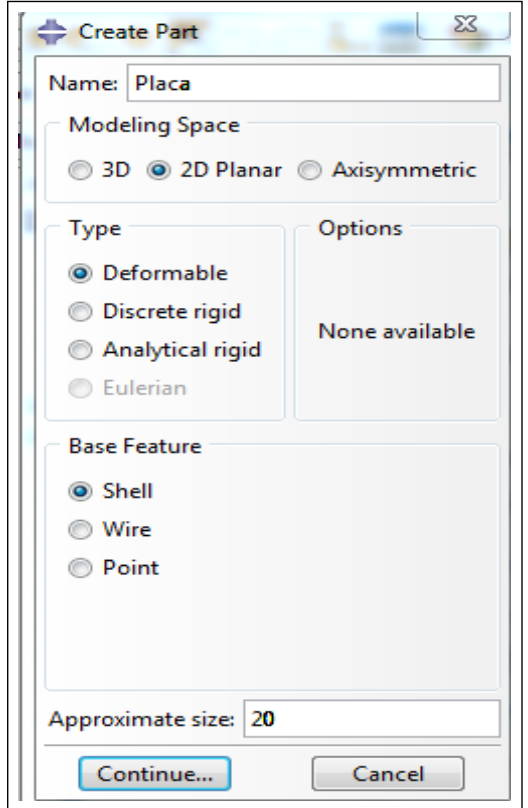

(b) Configuração da geometria

Figura 80 - Etapas para criar a geometria.

O ambiente para edição da geometria será ativado, selecionar a ferramenta Create lines connected. Utilizar as seguintes coordenadas: $(1.0,0.0)-(5.0,0.0)-(5,0,2,0)-(0,0.2,0)$ finalizando o comando em $(0.0,1.0)$. O próximo passo é criar um arco com a ferramenta create arc: center and two points inserindo as coordenadas: $(0.0,0.0)-(0.0,1.0)$ e $(1.0,0.0)$, clicar em Done.

\section{Material}

Em Model clicar duas vezes em Materials na caixa que se abrirá proceder da seguinte maneira: Selecionar: Mechanical $\rightarrow$ Elasticity $\rightarrow$ Elastic como na Figura 81 e entrar com os dados de módulo de elasticidade 200GPa e coeficiente de Poisson 0.3. 


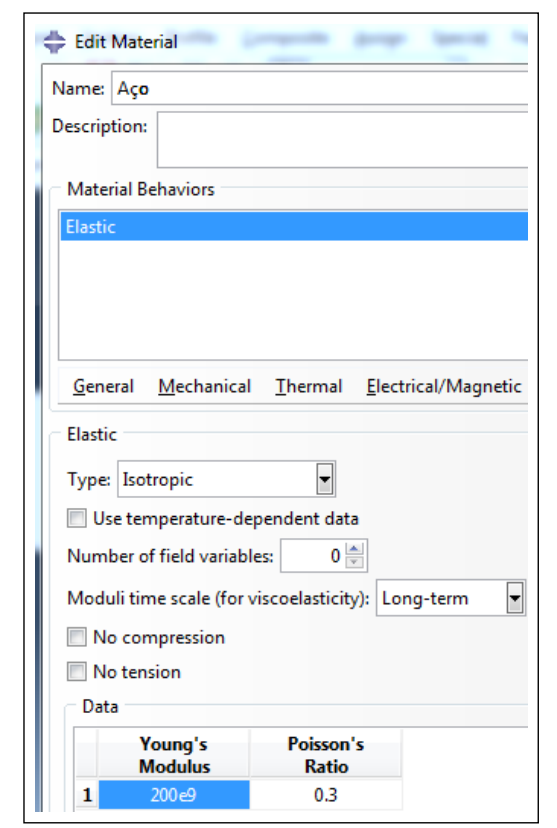

Figura 81 - Configuração das propriedades dos materiais.

\section{Propriedades da Seção}

Em Model clicar duas vezes em Sections. Somente alterar o nome da seção e clicar em Continue... na próxima caixa de diálogo marcar a opção Plane stress/strain thickeness e insirir o valor 0.01 , finalizando o comando ao clicar em $O K$.

Com a seção criada, agora basta atribuir essas propriedades à geometria.

Para isto selecionar a opção Assign Section, clicar na placa e depois em Done. No canto inferior direito da tela, na janela que irá aparecer clicar em $O K$, a placa irá mudar de cor indicando que o as propriedades do material foram atribuídas ao modelo.

\section{Montagem do modelo}

Novamente em Model expandir a opção Assembly e clicar duas vezes em Instance, esta opção ${ }^{2}$ auxilia a construção de modelos mais complexos a partir das geometrias previamente criadas. Na janela que irá surgir selecionar as opções conforme a Figura 82 e clicar em $O K$.

$\overline{2}$ Por exemplo é possível criar apenas um elemento de barra e com ele compor uma treliça. 


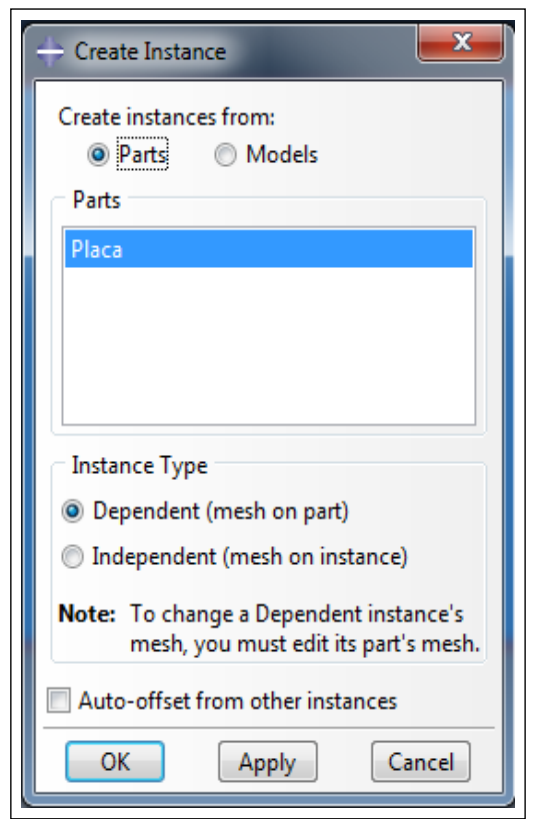

Figura 82 - Configuração do Instance.

\section{Malha}

Para criar a malha, no menu Model, expandir o elemento Parts e depois o elemento Placa clicar duas vezes na última opção Mesh.

A placa irá mudar de cor para uma coloração rosa ${ }^{3}$. A técnica para gerar a topologia da malha bem como o formato dos elementos pode ser alterada em Mesh Controls disponível na barra superior do modelo como mostra a Figura 83.

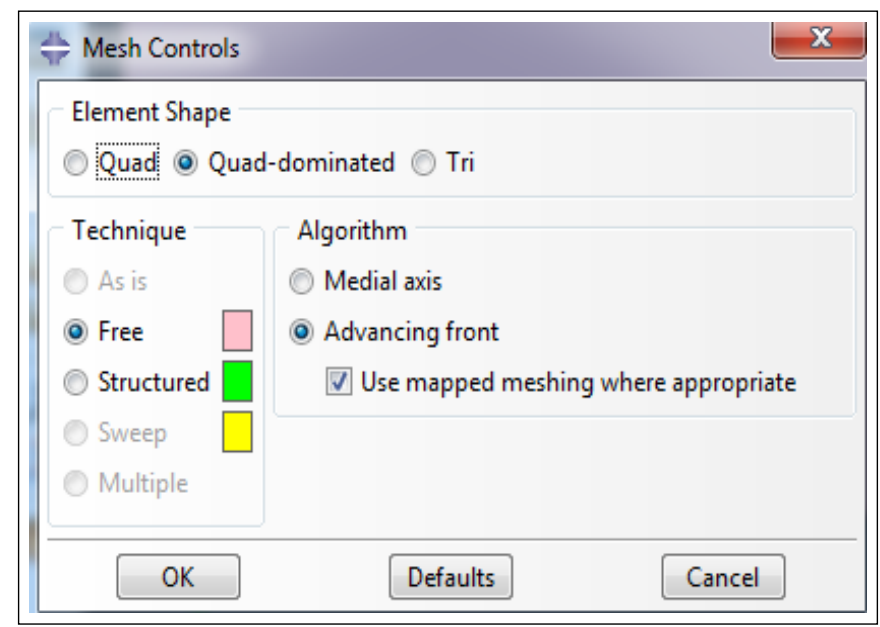

Figura 83 - Opções de controle da malha.

O resultado da topologia da malha, alterando-se a técnica e o tipo de elemento pode ser observado nas Figuras 84a, 84b, 85a, e 85b.

3 Neste ambiente a cor da peça indica o tipo de técnica utilizada para gerar a topologia da malha de elementos finitos. 


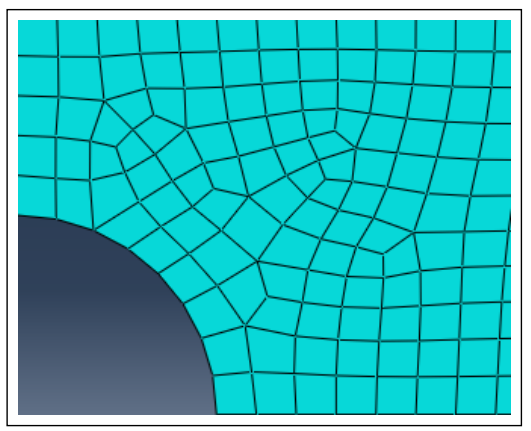

(a) Free Technique

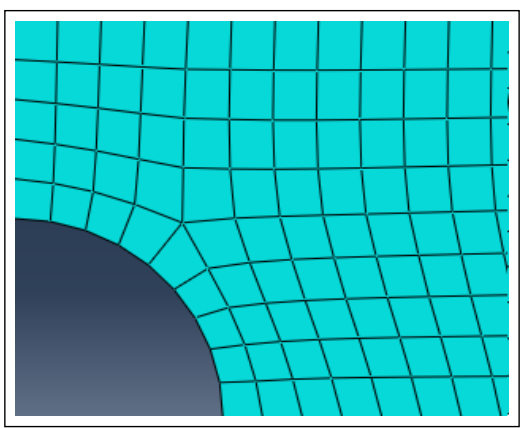

(b) Structured Technique

Figura 84 - Elementos retangulares.

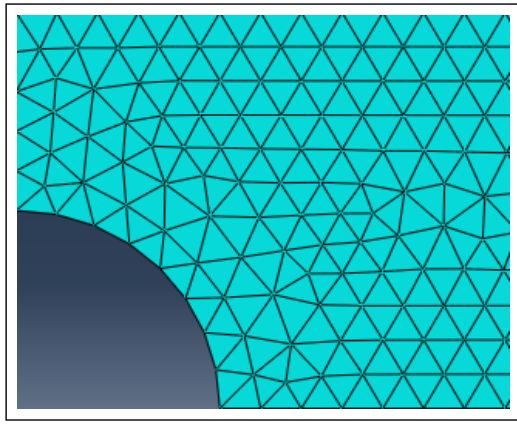

(a) Free Technique

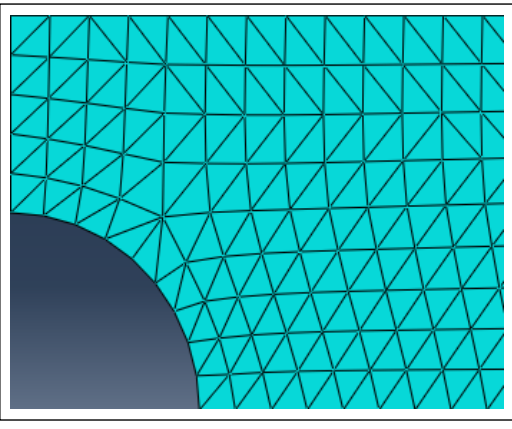

(b) Structured Technique

Figura 85 - Elementos triangulares.

O Abaqus $6.14^{\circledR}$ dispõe três tipos diferentes de técnica para definir a topologia da malha, são elas:

a) Structured - Aplica padrões pré-estabelecidos a topologias de modelos particulares, quando se trabalha com modelos complexos é necessário particionar a geometria em modelos menores e em regiões mais simples para que a malha não fique muito distorcida;

b) Sweep - Essa é uma técnica interessante quando se trabalha com geometrias circulares, pois ela gira a malha ao redor de um eixo, mas tem o mesmo problema da malha estruturada sendo limitada a geometrias simples;

c) Free - este é o tipo de técnica mais flexível, podendo ser utilizada em quase qualquer geometria por não usar nenhum tipo de padrão pré-estabelecido.

Ao clicar novamente em Mesh, na barra superior. Escolhera a opção element type nela é possível mudar as seguintes opções:

a) Tipo de integração das funções de interpolação;

b) Ordem da geometria, significa dizer se o elemento será linear ou quadrático (nó intermediário); 
c) Escolher a família de elementos ${ }^{4}$.

Esta janela pode ser vista na Figura 86.

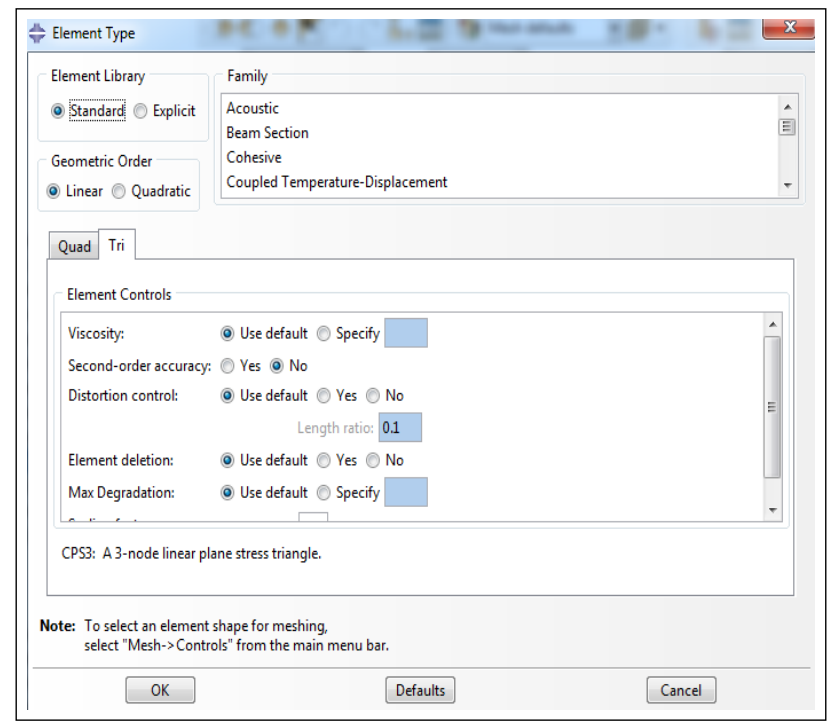

Figura 86 - Escolha e configuração dos elementos.

Para este modelo desmarcar a opção de integração reduzida, selecionar elementos quadráticos e triangulares, e o tipo de controle livre.

O próximo passo para conseguir gerar a malha é determinar os Seeds, responsáveis por definir o tamanho dos elementos. O Abaqus $6.14^{\circledR}$ permite definir um tamanho aproximado de forma global para todo o elemento. Também é possível, em cada borda do modelo, atribuir diferentes tamanhos, de forma gradual ou constante. Essa opção deve ser usada com cautela para não gerar malhas muito distorcidas ou incompatíveis com o tipo de elemento e controle escolhidos.

A opção Seed Part, mostrada na Figura 87, é a opção que permite distribuir os elementos com um tamanho aproximado por toda a geometria de forma constante. Este procedimento é utilizado em geometrias mais simples que não necessitam de um tratamento especial para o refinamento da malha.

4 Opção muito relevante dependendo do modelo que será elaborado. Por exemplo, caso necessite simular percolação de água em uma barragem de terra será é necessário escolher um elemento de uma família específica. 


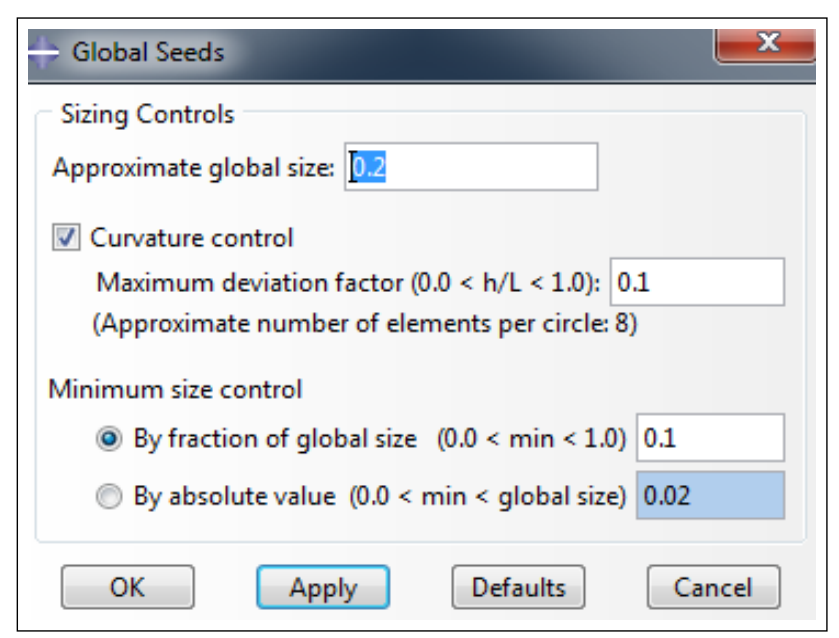

Figura 87 - Configuração global dos Seeds.

Já em Seed Edges, mostrado na Figura 88 é possível gerar elementos com dimensões variando de forma gradual.

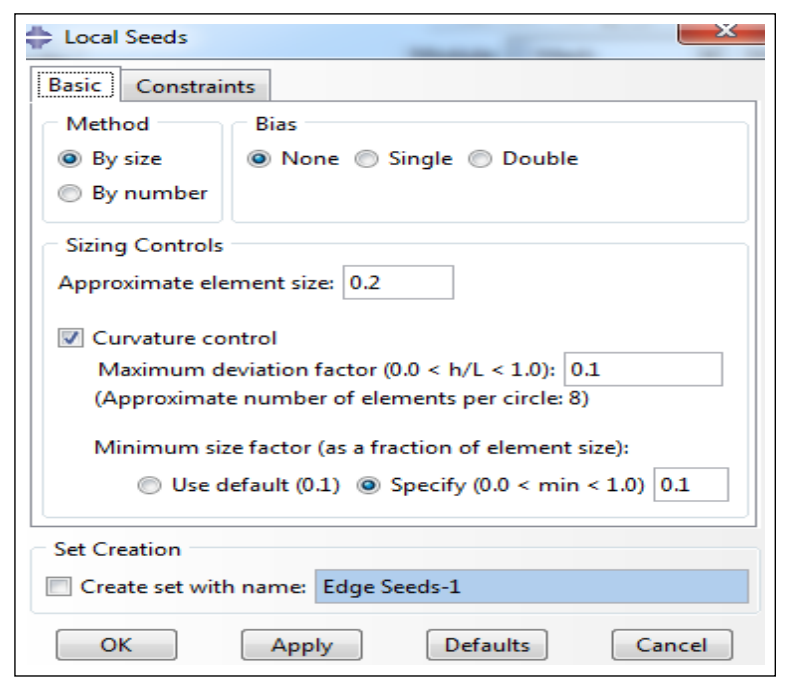

Figura 88 - Configuração local dos Seeds.

É possível fixar uma quantidade de elementos distribuídos de forma gradual na borda selecionada. Ou fixar a dimensão dos elementos. Em Bias o usuário tem a opção de determinar a direção do gradiente de distribuição dos elementos.

Um exemplo do resultado das malhas alterando-se direção do gradiente e deixando fixo a quantidade de elementos pode ser observada nas Figuras 89a e 89b. 


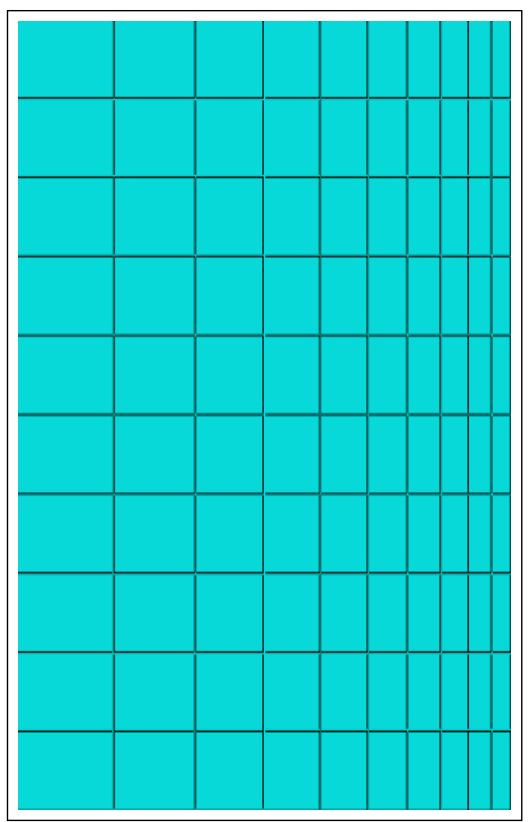

(a) Gradiente único

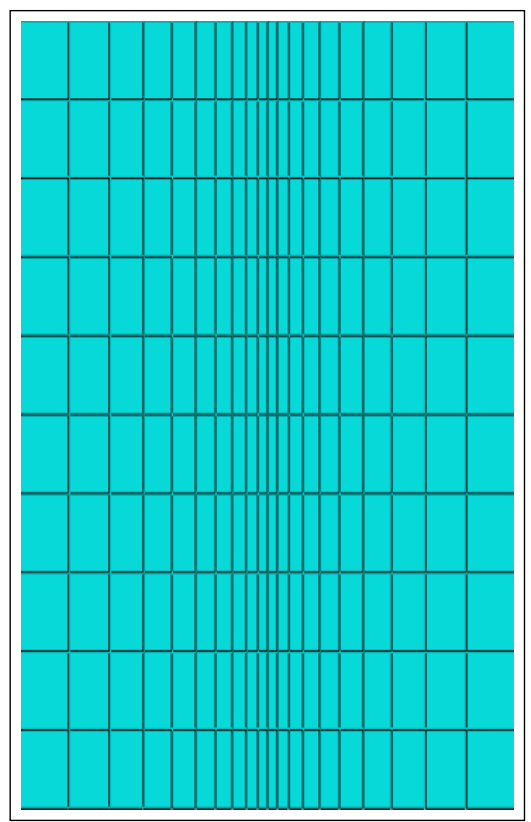

(b) Gradiente duplo

Figura 89 - Representação da direção do gradiente da malha.

Para este modelo selecionar as seguintes opções:

a) Topologia: controle livre;

b) Elementos: quadráticos e integração não reduzida;

c) Malha: distribua a malha de forma global escolhendo um tamanho aproximado de $0.2 \mathrm{~cm}$.

O resultado deve ser o mesmo que o da Figura 90

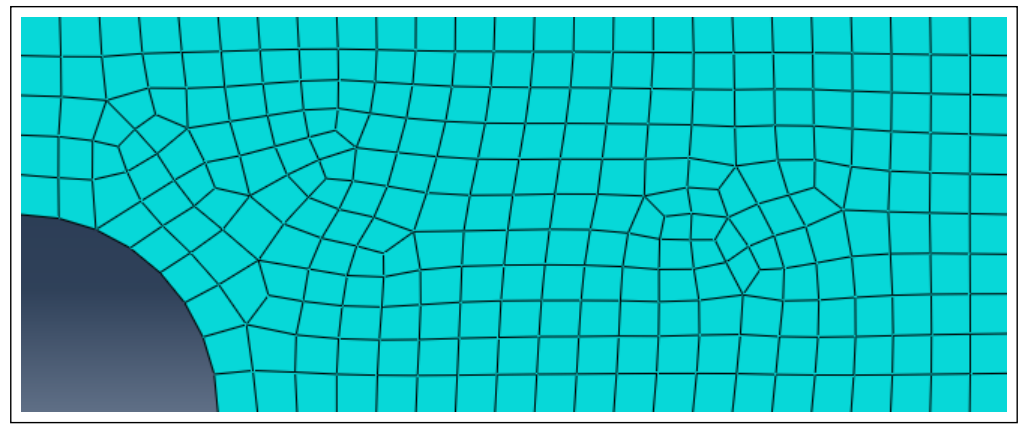

Figura 90 - Malha gerada para o modelo em questão. 


\section{Configurando a análise}

Aqui é a fase em que as etapas do modelo são configuradas, por se tratar de um modelo bem simples ele apresentará apenas duas etapas:

a) Initial Step - responsável por aplicar as condições de contorno do modelo;

b) Step1 - responsável por aplicar o carregamento.

Para inserir as condições de contorno conforme a Figura 79, expandir a seleção de Steps em seguida expandir a seleção Initial e finalmente clicar duas vezes em BCs (Boundary Conditions) como na Figura 91a, a janela da Figura 91b irá aparecer.

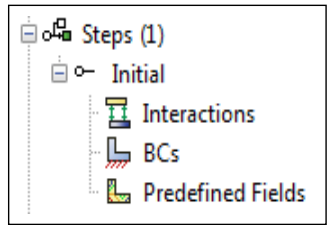

(a) Menu Steps

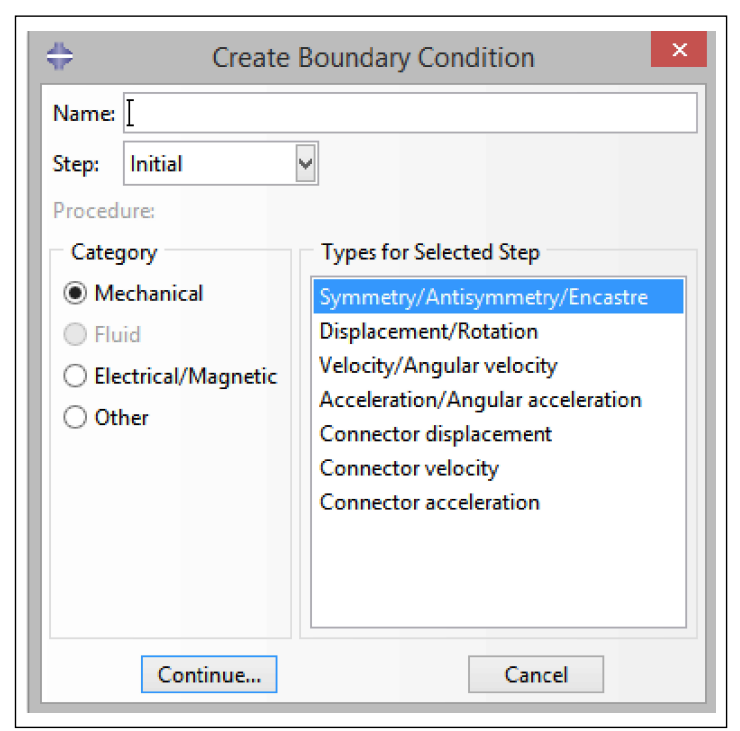

(b) Configuração das condições de contorno

Figura 91 - Etapas para definir as condições de contorno.

Nomear a condição de contorno, selecionar as opções Mechanical e Displacement/Rotation e em seguida clicar em Continue agora selecionar a base do modelo e na janela que irá aparecer marcar a opção $U 2$ fazendo com que qualquer translação em $y$ seja impedida. Repetir o processo e selecionar a borda esquerda do modelo, mas desta vez marcar a opção $U 1$ impedindo translação da placa em $x$.

Para aplicar o carregamento, clicar com o botão direito do mouse na opção Steps e selecionar create..., nas janelas seguintes, clicar em continue e depois em $O K$. Expandir a seleção da etapa recém-criada, clicar duas vezes em Loads, selecionar a opção Pressure e clicar em Continue.

Selecionar a borda direita do modelo e clicar em Done, a janela da Figura 92 irá aparecer, inserir o valor -10000 o que corresponde a $10 \mathrm{kN} / \mathrm{m}^{25}$. Clique em $O K$, o modelo deverá ficar como o mostrado na Figura 92.

5 O Abaqus 6.14 ${ }^{\circledR}$ não tem um sistema definido para as unidades de medida, ficando a cargo do usuário determinar as unidades que o software irá trabalhar, por isso é recomendável sempre trabalhar no Sistema Internacional. 


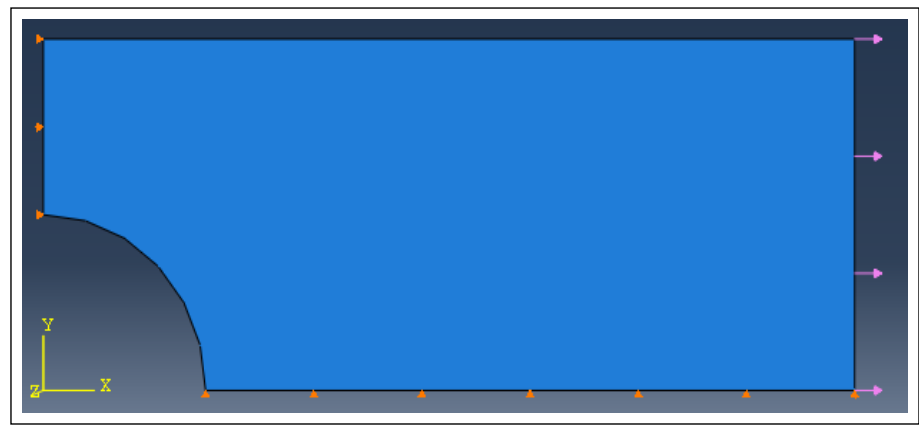

Figura 92 - Condições de contorno e carregamento aplicados no modelo.

O último passo consiste em criar o trabalho na opção Jobs, clicar com o botão direito do mouse e selecionar create, nomear o trabalho. Clicar em Continue... e na próxima janela em $O K$. Expandir a seleção de Jobs e no trabalho criado, clicar com o botão direito do mouse e em seguida em Submite.

O Abaqus 6.14 ${ }^{\circledR}$ irá começar a rodar o modelo. Para acompanhar o andamento do processo, ou seja, verificar em qual etapa de cálculo o programa está, exibir as possíveis mensagens de erro ou ainda verificar quais parâmetros foram utilizados na submissão, clicar novamente com o botão direito do mouse no trabalho criado e depois selecionar a opção monitor.

Se tudo estiver correto a instrução (Completed) irá aparecer ao lado do nome do trabalho indicando que o modelo foi finalizado com sucesso.

Para visualizar os resultados basta clicar com o botão direito do mouse no Job e selecionar a opção results. Neste ambiente é possível visualizar os contornos dos campos de deslocamentos e tensões, bem como obter outras informações de interesse.

\section{A.2.2 MODELO TRIDIMENSIONAL}

Este segundo exemplo tem a intenção de mostrar os conceitos utilizados nos modelos 3D desenvolvidos, tais como:

a) Utilização de planos de simetria;

b) Estabelecer o estado de tensões geostático sem apresentar deslocamentos iniciais;

c) Criar partições no modelo;

d) Usar a opção model change para simular uma escavação;

e) E utilizar a lei constitutiva de Mohr-Coulomb;

Este exemplo busca reproduzir uma etapa de $1 \mathrm{~m}$ de escavação circular com um metro de diâmetro em um cubo com $20 \mathrm{~m}$ de aresta.

A geometria do problema está mostrada na Figura 93 e os parâmetros utilizados na Tabela 13. 


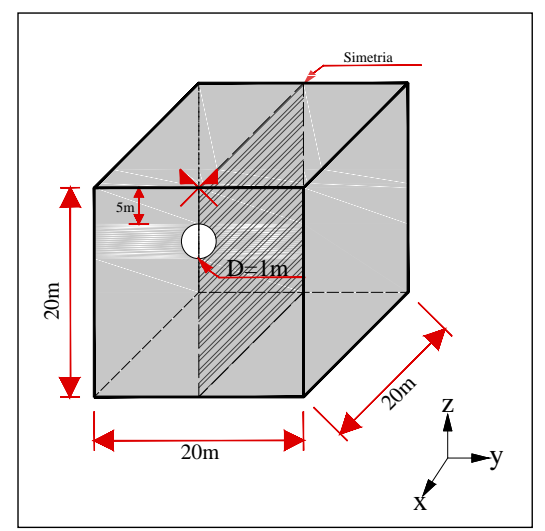

Figura 93 - Geometria do problema.

Tabela 13 - Parâmetros de referência para o solo.

\begin{tabular}{l|ccc}
\hline Parâmetro & Símbolo & Valor & Unidade \\
\hline Peso específico & $\gamma_{s}$ & 18 & $k N / m^{3}$ \\
Módulo de Elasticidade & $E_{s}$ & 10000 & $\mathrm{kPa}$ \\
Coeficiente de Poisson & $\nu_{s}$ & 0,30 & - \\
Ângulo de Atrito & $\phi_{s}$ & 20 & $\mathrm{Graus}$ \\
Dilatância & $\psi_{s}$ & 10 & $\mathrm{Graus}$ \\
Coesão & $c^{\prime}$ & 20 & $\mathrm{kPa}$ \\
Coeficiente de empuxo & $K_{0}$ & 1 & - \\
\hline
\end{tabular}

\section{Geometria}

Clicar duas vezes em Parts, atribuir um nome e selecionar as opções:

3D $\rightarrow$ Deformable $\rightarrow$ Solid $\rightarrow$ Extrusion $\rightarrow$ Approximate Size inserir o valor 40 .

Neste novo ambiente selecionar a opção Create lines: Rectangle (4 lines), o Abaqus $6.14^{\circledR}$ irá pedir as coordenadas de dois vértices opostos, colocar os seguintes valores $(0,0)$ e $(20,10)$. Clicar em Done, a janela mostrada na Figura 94 irá aparecer. 


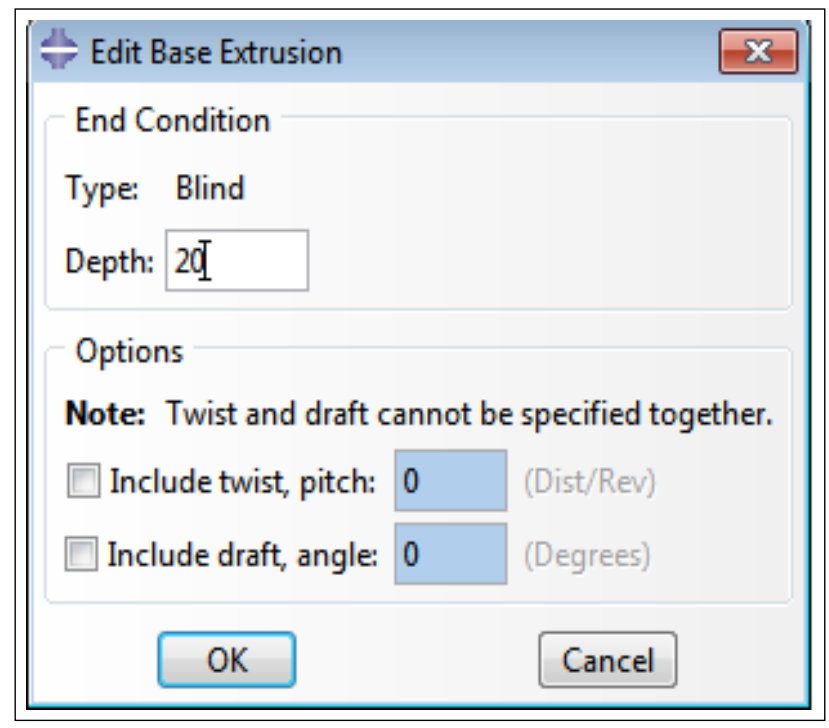

Figura 94 - Profundidade do modelo (extrusion).

Inserir $20 \mathrm{~m}$ para a profundidade e clicar em $O K$. O Abaqus $6.14^{\circledR}$ não identifica de forma automática o eixo $z$ como o eixo em que a gravidade irá atuar, por isso deve-se rotacionar os eixos de forma manual.

Agora é necessário desenhar o contorno da escavação - selecionar a opção Partition Face: Sketch, na sequência clicar na face que se deseja fazer a escavação (plano $y z$ ).

A face selecionada ficará vermelha. Clicar em Done e em seguida o Abaqus $6.14^{\circledR}$ irá solicitar uma borda desta face para que seja de referência, ou seja, a borda selecionada irá ficar posicionada à direita e orientada verticalmente, para isto basta selecionar a borda da direita, assim o Abaqus $6.14^{\circledR}$ somente irá posicionar melhor o maciço e não irá rotacioná-lo.

Agora selecionar a opção: Create Circle: Center and perimeter, indicar as coordenas do centro $(-5,4.5)$ (notar que os eixos agora estão no centro da face selecionada) e finalizar o comando ao clicar com o botão esquerdo do mouse em qualquer ponto fora do retângulo criado anteriormente.

Notar que ao fazer isso o Abaqus $6.14^{\circledR}$ cria um ponto no perímetro do círculo, caso este ponto esteja dentro do retângulo (geometria do modelo) ele será utilizado como referência para gerar a topologia da malha, o que pode criar uma malha com pequenas distorções.

Agora é necessário redimensionar o círculo - selecionar a opção Add dimension e com ela ativada, clicar no perímetro do círculo e inserir o valor de $0.5 \mathrm{~m}$ para o novo raio.

Clicar duas vezes com o botão do meio do mouse.

Com a geometria desenhada é necessário particionar o elemento para que seja possível atribuir comportamentos distintos para escavação e para o maciço, mas antes é necessário definir a profundidade de escavação.

Deve-se repetir o passo anterior só que dessa vez deve-se selecionar o plano $x y$ e desenhar 
uma linha, com o auxílio do comando Create Lines: Connected.

Para desenhar a linha, iniciar o comando em qualquer ponto de uma das bordas (esquerda ou direita) em seguida encerrar o comando na outra extremidade. Selecionar a opção Add dimension e clicar no vértice inferior do maciço e em seguida na extremidade da linha logo acima deste vértice. Inserir a nova dimensão $(1 \mathrm{~m})$ e encerrar o comando.

Após estes procedimentos deve-se ter a situação mostrada na Figura 95:

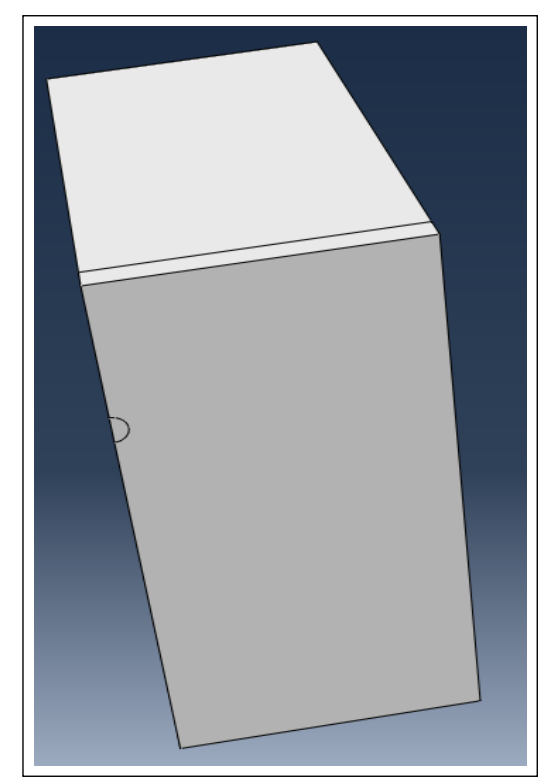

Figura 95 - Etapas de partição do modelo - referências.

Agora, como já dito anteriormente, deve-se particionar o maciço. Para isto selecionar a opção Partition Cell: Extrude/Sweep Edges para habilitar esta opção deve-se posicionar o ponteiro do mouse em Partition Cell: Define Cutting Plane clicar e segurar com o botão esquerdo até que as outras opções sejam habilitadas, como mostra a Figura 96.

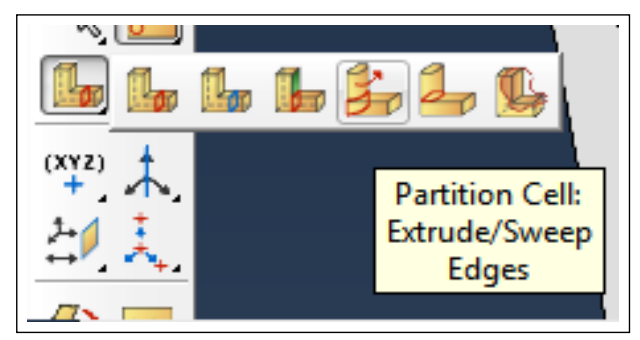

Figura 96 - Etapas de partição do modelo - ferramentas.

Em seguida selecionar a linha foi desenhada anteriormente, duas opções aparecerão no menu inferior do Abaqus 6.14 ${ }^{\circledR}$. Selecionar a opção Extrude Along Direction, em seguida selecionar alguma linha perpendicular a ela, verificar se o sentido da flecha é o desejado se sim clicar em $O K$ e depois em Create partition. Em seguida repetir o mesmo procedimento para o perímetro da escavação. Material 
Criar o material em três etapas:

a) General $\rightarrow$ density $\rightarrow$ atribuir o valor $18 \mathrm{kN} / \mathrm{m}^{3}$

b) Mechanical $\rightarrow$ Elasticity $\rightarrow$ Elastic $\rightarrow$ atribuir o valor de $10.000 \mathrm{kN} / \mathrm{m}^{2}$ para módulo de elasticidade e 0.25 para o coeficiente de Poisson;

c) novamente em Mechanical $\rightarrow$ Elasticity $\rightarrow$ selecionar Plasticity $\rightarrow$ Mohr CoulombPlasticity e atribuir os valores de coesão, ângulo de atrito e dilatância.

As próximas etapas já foram discutidas no exemplo anterior:

a) Criar a seção e atribuir o material a seção criada;

b) Na sequência ir em Assembly e criar o Instance;

c) Gerar a malha.

Neste modelo serão utilizados três Steps:

a) $1^{a}$ etapa ou Initial responsável pelas condições de contorno e também pelo estado inicial de tensões;

b) $2^{a}$ etapa, responsável por atribuir a aceleração da gravidade ao modelo;

c) $3^{a}$ etapa - responsável por simular a escavação.

\section{Estado Inicial de tensões}

No menu principal, expandir a aba de Steps e em seguida expandir a aba Initial, clicar duas vezes em Predefined Fields, a janela da Figura 97 irá abrir. 


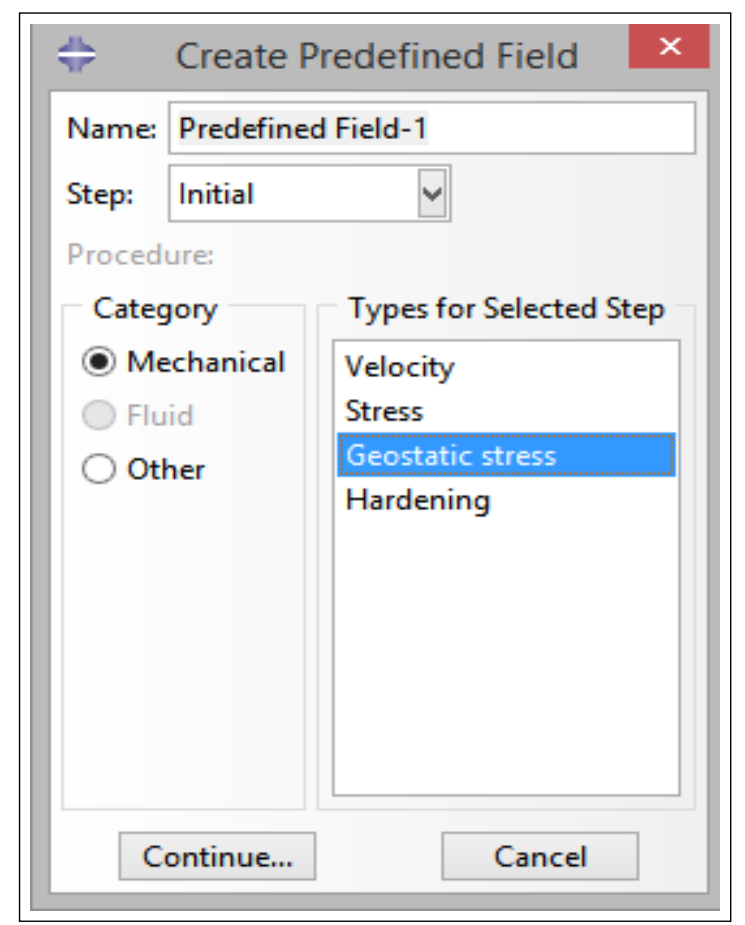

Figura 97 - Criando as tensões geoestáticas.

Selecionar as opções conforme a Figura 97 e clicar em Continue..., selecionar todo o elemento e clicar em Done, na janela que irá se abrir colocar as informações conforme a Figura 98.

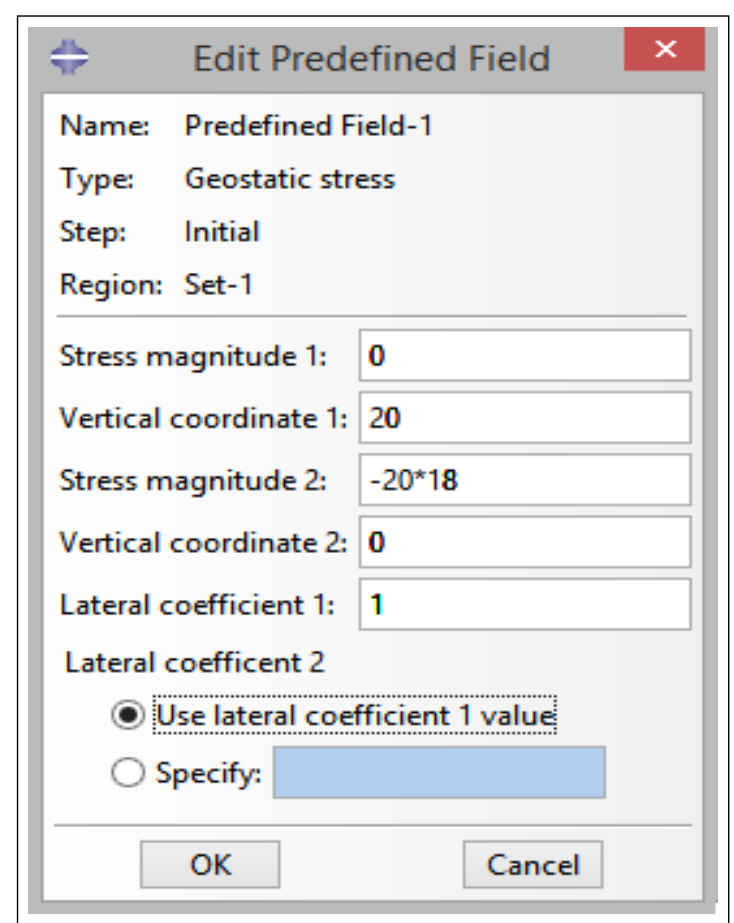

Figura 98 - Configurando as tensões geoestáticas.

No mesmo Step deve-se criar as condições de contorno - clicar duas vezes em BCs. 
Selecionar a opção Displacement/Rotation, selecionar os planos yz e marcar a opção $U 1{ }^{6}$

Repetir o processo para o plano $z x$ da direita deixando a opção $U 2$ marcada. E para o plano $y x$ da base do modelo deixar a opção $U 3$ marcada.

A condição de contorno do plano $z x$ da esquerda é referente ao plano de simetria, por isso deve-se selecionar a opção Symmetry/Antisymmetry/Encastre e em seguida marcar a opção $Y S Y M M(U 2=U R 1=U R 3=0)$.

Criar o próximo Step.

\section{Carregamentos - Gravidade}

Na janela de edição do Step marcar a opção Other $\rightarrow$ Unsymmetric, como na Figura 99.

\footnotetext{
6 Para selecionar mais de uma face ao mesmo tempo deve-se manter pressionada a tecla SHIFT.
} 


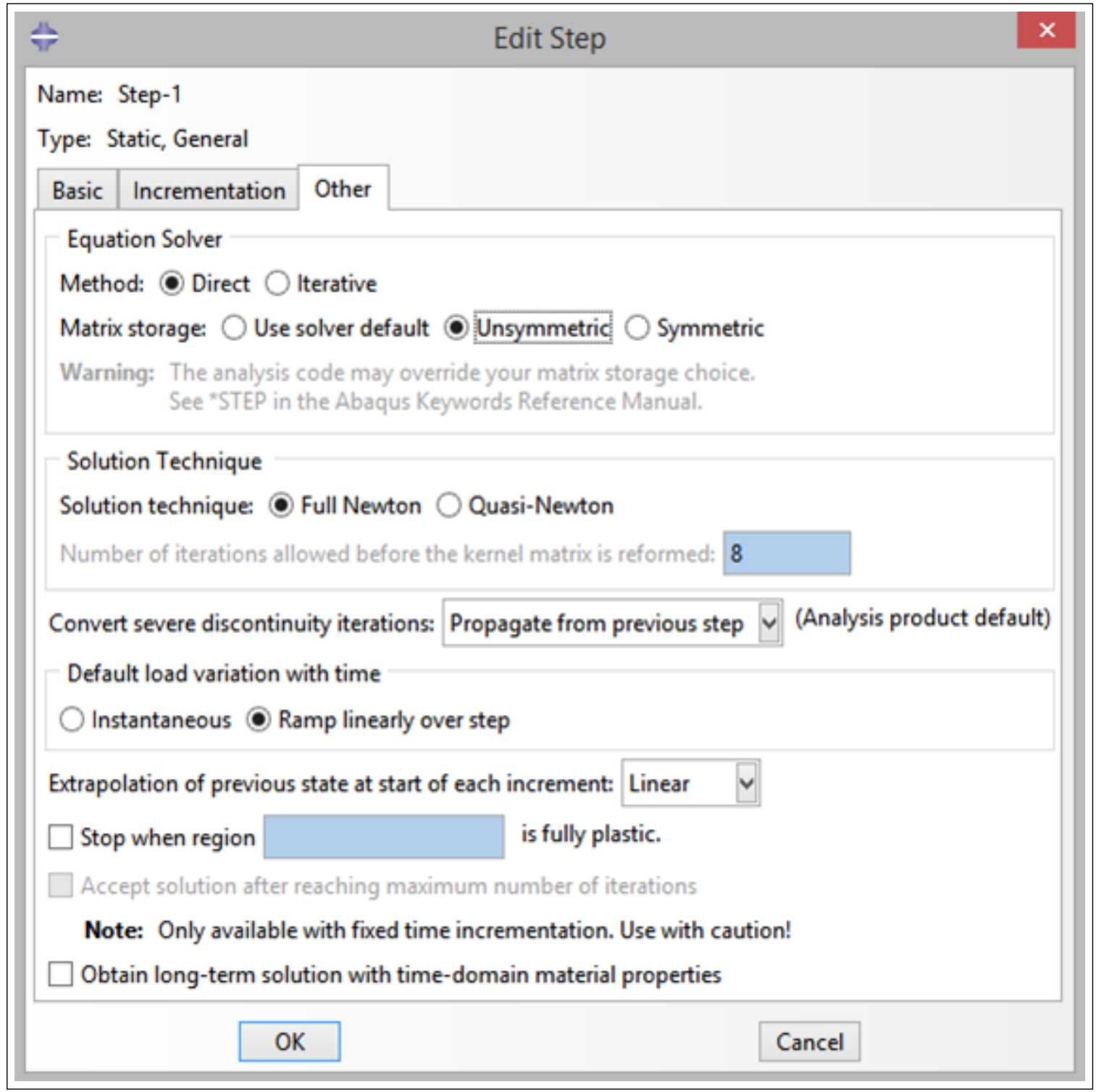

Figura 99 - Configurando o Step.

Como foi escolhida o modelo constitutivo de Mohr-Coulomb esta opção deve ser marcada, caso contrário o modelo não irá apresentar convergência.

No Step criado selecione as seguintes opções:

Loads $\rightarrow$ Gravity $\rightarrow$ em Component 3: inserir o valor -1 que corresponde a aceleração da gravidade ${ }^{7}$.

Criar o Step final

$\overline{7}$ Notar que o valor de -1 deve ser inserido assim, pois ao definir o material foi colocado o peso específico e não a densidade 


\section{Simulando a escavação - Model Change}

No Step criado clicar duas vezes na opção Interactions, selecionar a opção conforme mostra a Figura 100

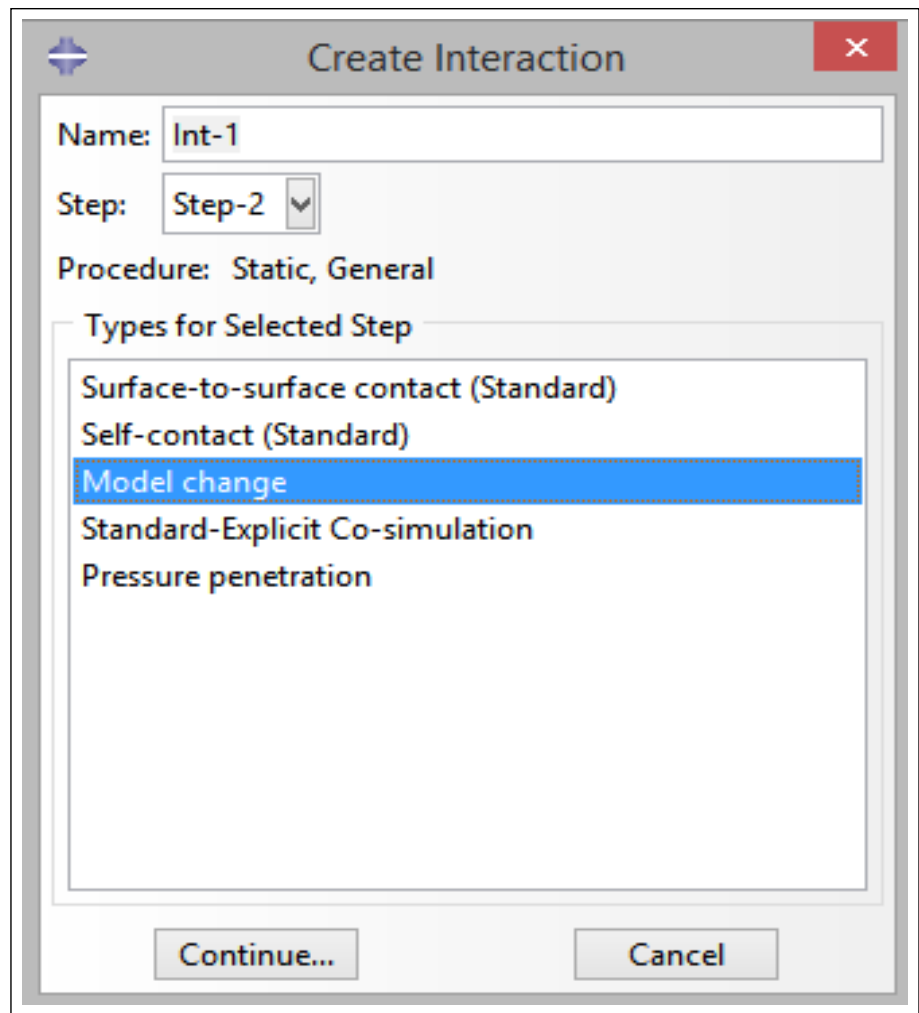

Figura 100 - Criando a interação do modelo - Model Change.

Na janela seguinte - Edit Interaction - clicar no ícone da seta para definir qual região que será modificada, Figura 101. 


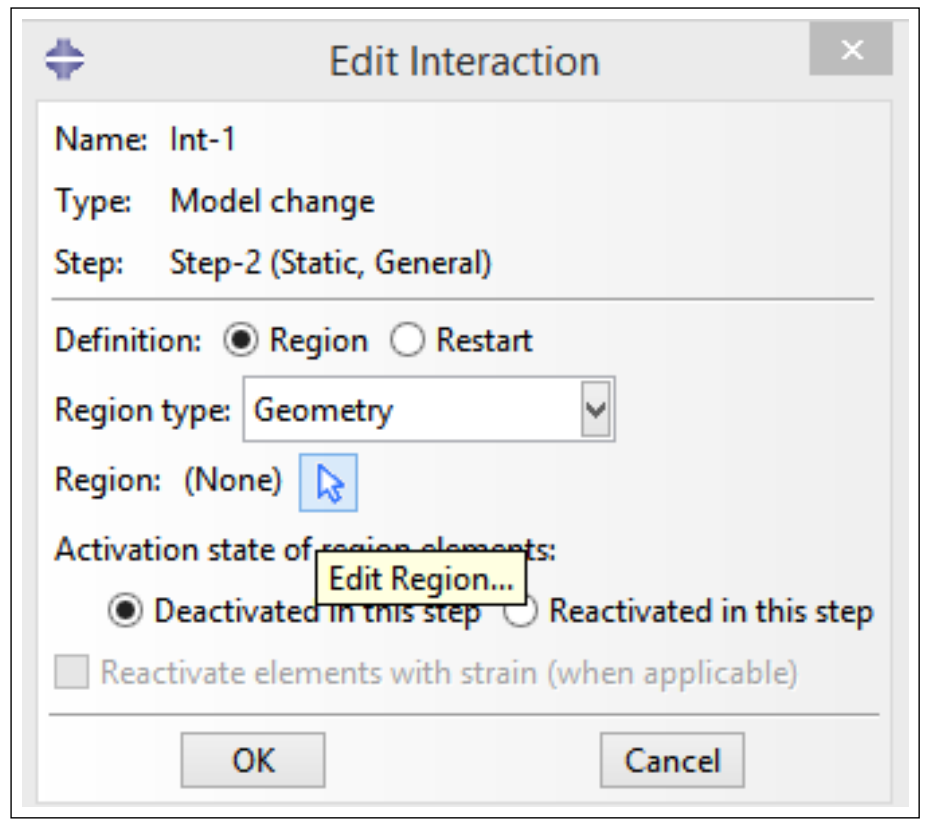

Figura 101 - Selecionando a região da escavação.

Selecionar a escavação. Finalizar o comando.

Finalmente crie um $J o b$ e rode o modelo.

Os seguintes resultados poderão ser visualizados:

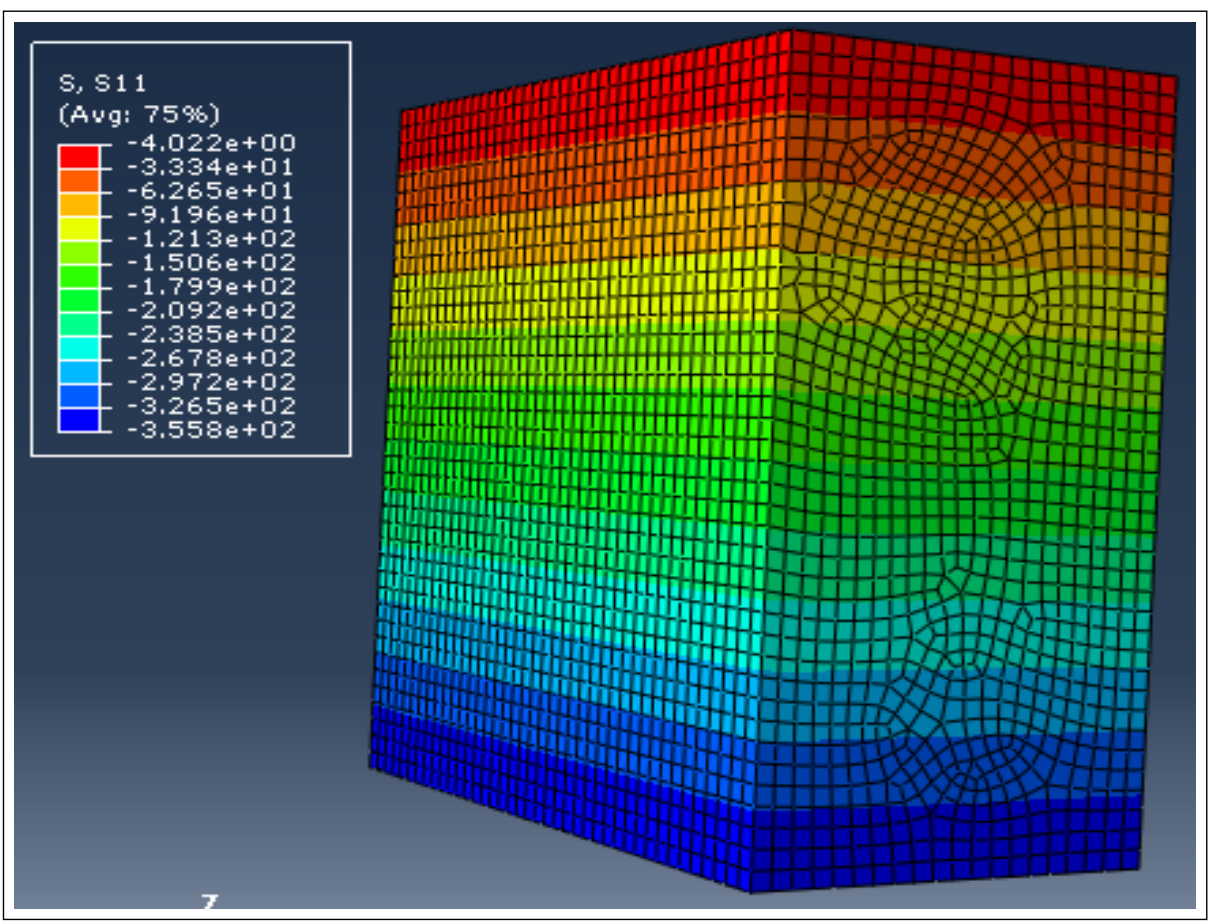

Figura 102 - Tensões geostáticas. 


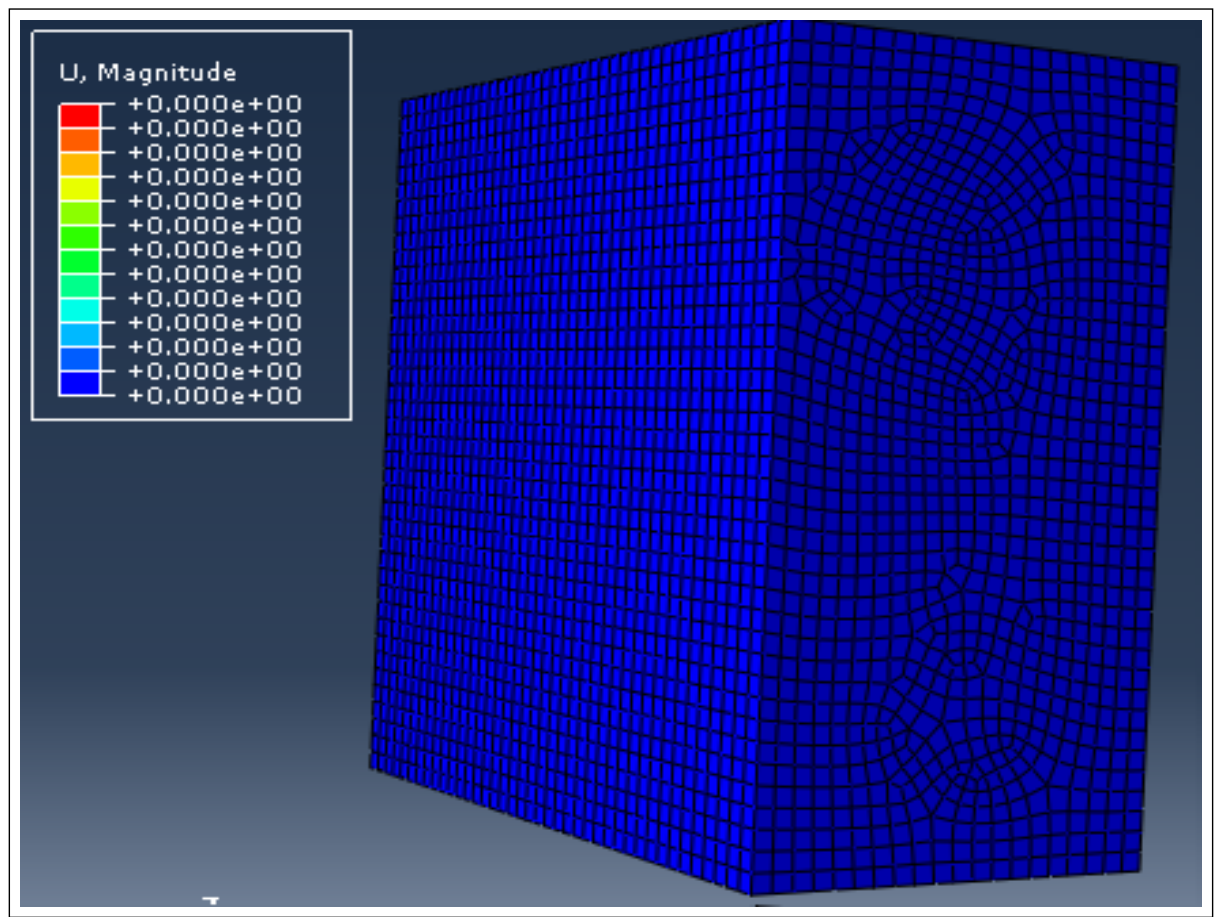

Figura 103 - Deslocamentos na etapa geostática.

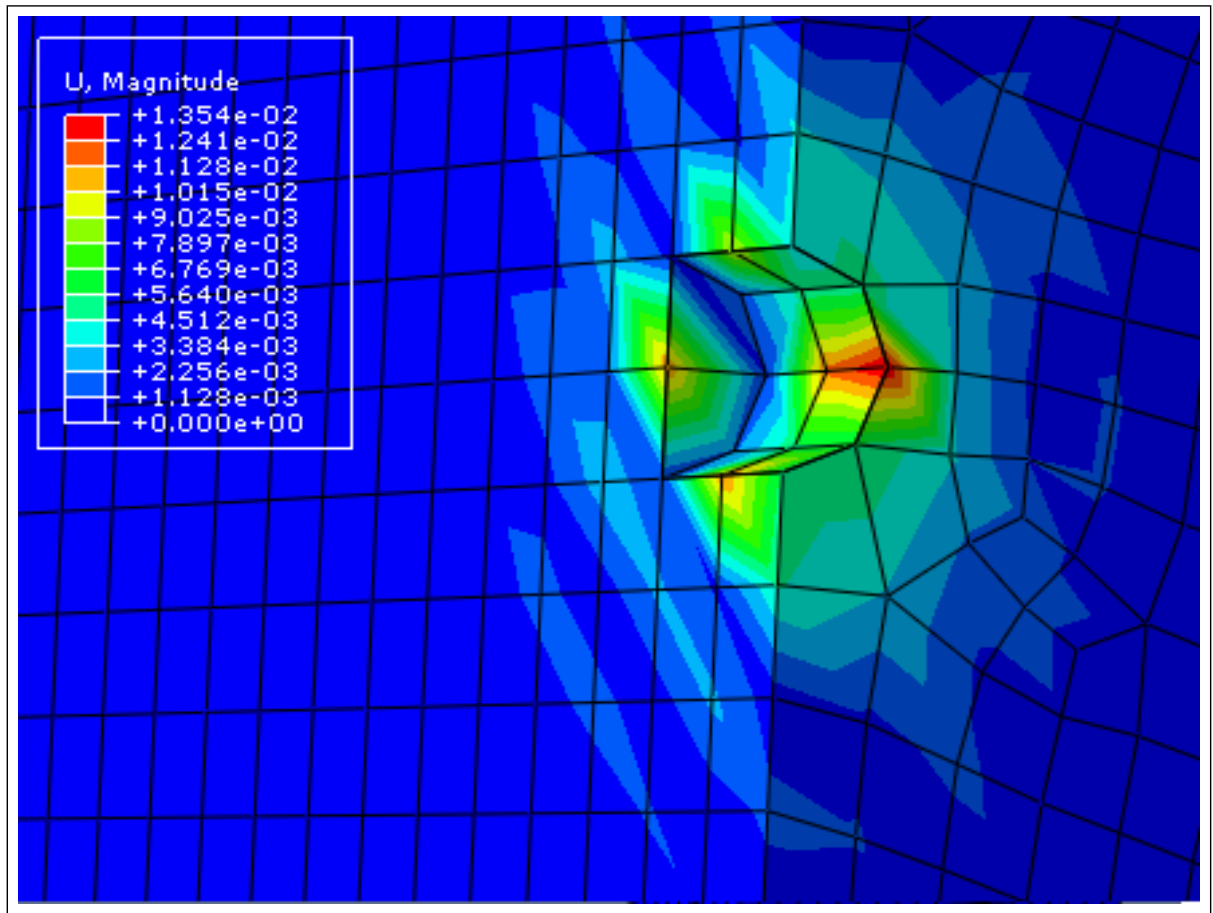

Figura 104 - Deslocamentos após a escavação.

\section{A.3 PROBLEMAS DE CONVERGÊNCIA}

As seguintes orientações foram compiladas a partir de informações levantadas com outros usuários do software Abaqus $6.14^{\circledR}$, da própria experiência ao manipular o software e também através do manual do usuário. São abordados os principais problemas de convergência 
do software bem como a possível causa. A intenção não é esgotar o assunto, mas deixar um material que ajude os futuros usuários do Abaqus $6.14^{\circledR}$.

Causas prováveis que implicam em não convergência do modelo:

a) Unidades incorretas;

b) Não definir adequadamente as restrições do modelo;

c) Não definir totalmente os parâmetros do material empregado;

d) Definir restrições conflitantes com as condições de contorno;

e) Utilizar um elemento inapropriado.

Mensagens mais comuns que indicam não convergência do modelo:

a) ***WARNING: THE SOLUTION APPEARS TO BE DIVERGING;

b) ***WARNING: THE SYSTEM MATRIX HAS 3 NEGATIVE EIGENVALUES;

c) ***WARNING: SOLVER PROBLEM. ZERO PIVOT WHEN PROCESSING NODE 1 D.O.F. 1;

d) $* * *$ WARNING: ELEMENT 381 IS DISTORTING SO MUCH THAT IT TURNS INSIDE OUT;

Procedimentos que podem auxiliar no tratamento dos problemas de convergência:

a) Retire a opção de extrapolação da correção de deslocamento desta forma o Abaqus $6.14^{\circledR}$ não irá apresentar uma mudança de rigidez repentina: *STEP, EXTRAPOLATION=NONE;

b) Para problemas que envolvem deslizamento entre superfícies deformáveis altamente curvas e quando utilizar a lei constitutiva de Mohr-Coulomb utilizar a solução de matriz assimétrica: *STEP, UNSYMM=YES;

c) Para auxiliar em problemas com grandes utilizar extrapolação parabólica: *STEP, EXTRAPOLATION=PARABOLIC;

d) Controlar o passo no incremento das etapas de cálculo evita que o Abaqus $6.14^{\circledR}$ apresente mudanças repentinas da rigidez. Recomenda-se que o passo inicial ${ }^{8}$ do incremento esteja entre 0,01 a 0,1 para que a análise inicie de forma lenta. Diminuir o passo do incremento máximo auxilia o Abaqus $6.14^{\circledR}$ a rodar o modelo de forma mais eficiente;

e) Ao utilizar um modelo constitutivo de um material plástico e o carregamento atinge o fim da curva definida, o Abaqus $6.14^{\circledR}$ irá extrapolar a curva com uma linha horizontal, significa dizer que a deformação plástica pode aumentar, mas a tensão não irá acompanhar este aumento, caracterizando o caso de plasticidade perfeita. Nesse 
caso a rigidez é nula. Quando essa condição ocorrer em poucos elementos é possível que a simulação continue sem muitos problemas, porém se essa situação se propagar para uma parte grande do modelo ele poderá deixar de apresentar convergência. Isso geralmente indica que o carregamento é muito grande para o material empregado.

\section{A.4 RECOMENDAÇÕES PARA A ESCOLHA DOS ELEMENTOS}

O Abaqus $6.14^{\circledR}$ dispõe uma ampla variedade de elementos, por ser tão vasta, sua biblioteca de elementos proporciona uma grande flexibilidade ao modelar, com eficiência, problemas com as mais diversas geometrias e condições de contorno.

Cada elemento é organizado considerando os seguintes critérios:

a) Família - Por ser a categoria mais ampla para se classificar elementos, muitas características básicas entre eles serão idênticas. Existem muitas variações de famílias que podem ser solid elments, shell elements, beam elements, rigid elements, membrane elements, infinite elements, truss elements e special-purpose elements.

b) Número de nós - Usualmente a geometria dos elementos é definida a partir de pontos, denominados nós, de maneira tal que o lado compartilhado por dois elementos seja definido univocamente. Desse modo garante-se a continuidade do domínio em todas as interfaces.

O número de nós do elemento determina a maneira como os graus de liberdade serão interpolados no domínio do elemento, o Abaqus $6.14^{\circledR}$ dispõe as opções de primeira e segunda ordem de interpolação.

c) Graus de liberdade ${ }^{9}$ - essa característica pode ser entendida como a variável primária que está presente nos nós do elemento em questão, exemplos: rotações, deslocamentos, deformações, potencial elétrico.

d) Formulação - esta é uma categoria que se baseia na formulação matemática para classificar os elementos, a formulação matemática utilizada é responsável por descrever o comportamento do elemento. Exemplos: Estado plano de tensões, estado plano de deformações, elementos híbridos.

e) Integração - A massa e a rigidez de um elemento são consideradas a partir de um ponto de amostragem denominado ponto de integração, presente no interior do elemento. $\mathrm{O}$ algoritmo utilizado para integrar tais variáveis influencia diretamente como o elemento se comporta e, portanto, a resposta do modelo numérico considerado. O Abaqus $6.14^{\circledR}$ dispõe de opções de integração completa ou reduzida.

A seguir algumas sugestões de como escolher o melhor elemento dependendo do tipo de problema que precisa ser modelado:

9 É importante salientar que alguns elementos possuem graus de liberdade que não estão associados ao nó propriamente dito, ou seja, são graus de liberdade internos. 
a) Modelos com geometria complexa - quad-hex de primeira ordem ou tet-tri de segunda ordem;

b) Malhas muito distorcidas - quad-hex de primeira ordem com integração reduzida;

c) Problemas que envolvem impacto - elementos de primeira ordem;

d) Contato simples entre dois corpos deformáveis - quad-hex de primeira ordem;

e) Concentração de tensões - elementos de segunda ordem;

f) Materiais incompressíveis $\nu>0.475$ - elementos de primeira ou segunda ordem com integração reduzida;

g) Grandes deformações plásticas $\epsilon_{p l}>10 \%$ - elementos de primeira ou segunda ordem com integração reduzida. 